\title{
SILENCE AFTER SUICIDE: A PHENOMENOLOGICAL STUDY OF YOUNG MEN'S EXPERIENCE OF LOSING A CLOSE MALE FRIEND
}

\section{Christopher James Bowden}

A thesis submitted to the Victoria University of Wellington in fulfilment of the requirements of the degree of

Doctorate of Philosophy

In Health

Victoria University of Wellington 



\begin{abstract}
Losing a close friend to suicide can significantly increase the risk of dysfunction, depression and suicide in young people. Previous studies of suicide bereavement have focused on parents, parentally-bereaved children, young adolescents' experiences of peer suicide and female college-students. A paucity of qualitative research exists that examines young men's experiences of suicide bereavement. This lack of research has meant that their grief may go unnoticed, be minimized, or even misunderstood.
\end{abstract}

The purpose of this research was to explore the experiences of eight young New Zealand men (aged 17-25 years) who lost a close male friend to suicide. Repeated in-depth phenomenological interviews were used to gain new insights into the conceptualisation of this event in the young men's lives through an exploration of their experiences. Interviews were audio recorded and transcribed for analysis. The inductive, descriptive approach of the phenomenological method was used to explore and describe the essence of their lived experience and led to seven themes: Being gutted, stoicism, grieving in silence, being silenced, breaking the silence, being in silence and analytic silence. The overarching essence of their experience and the phenomenon was silence. The silence the men experienced after suicide was ubiquitous.

The findings suggest losing a close male friend to suicide implicates men to suffer, grieve, live through and transform in silence. Participants experienced four types of silence: personal, private, public and analytic silence. The men were gutted and personally unable to talk about their experience. They chose to keep quiet, be stoical, suppress their emotions and keep their grief private. They grieved in silence and were silenced by others. They broke their silence with people they could trust and who provided presence support and care. They sought quiet spaces where they could reconnect, reflect on their experience. Their navigation of silence fostered new values, priorities and identities, acceptance of their loss and helped them move on with their lives. This study has brought new understandings of men's experiences of suicide bereavement and silence. Their experience suggests that health professionals, families/whānau and friends need to learn to see, listen to and interpret the silence of men in order to better understand their experience and needs for care and support. Recommendations are made for intervention, health care practice and future research. 


\section{ACKNOWLEDGEMENTS}

First I would like to acknowledge the men who broke their silence and let me see and hear their lived experience of loss. I will be forever grateful to you and hope that the telling of your stories might go some way to honouring the friends you lost and helping improve understanding of men's experience of suicide bereavement. I would also like to acknowledge the families/whānau of the deceased for helping me find my participants your son's close friends.

To my supervisors, Professor Elizabeth Banister and Dr. Kay de Vries, thank you for all the guidance, resources, feedback, reassurance and time you have given me. Elizabeth, thank you for quiet encouragement, your timely, constructive and detailed feedback and for sharing your wealth of knowledge of qualitative research and young people. Kay, thank you for helping me develop my ideas and analysis, sharing philosophical and existential conversations, and ensuring my research was rigorous and kept 'real'. I am grateful to have had such supportive supervisors who complimented each other's strengths, and knew exactly when to push and when to pull. Without both of you, this would never have started or finished. I would also like to thank Professor Jo Walton from the Graduate School of Nursing, Midwifery and Health for encouraging me to pursue my interest in mental health, suicide and phenomenology and the School of Education for their support to 'get it done'.

Thank you to all my family, friends, and colleagues who supported me in the journey and to all those who were a part of my community of practice. To my dear friend, Delia Baskerville, who experienced the highs and lows of my journey, thank you for reminding me I could do this, having faith in me and for sharing sneaky smokes with me outside. To Mabel and Judy - my fellow phenomenologists, thank you for your comradery, critical feedback and invaluable support. I would like to thank my special friend and dog Hooli for just 'being with me in silence' on our long walks in Waitarere forest during this $\mathrm{PhD}$ and helping me understand more about silent grief. Finally, to my lovely and loving partner, Monique, thank you for your unwavering support, patience and willingness to share your life with me (and my work). Your silent presence, compassion and care reminds me every day why this work and silence are so important. 


\section{TABLE OF CONTENTS}

ABSTRACT

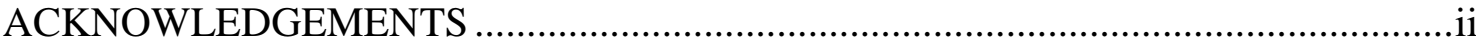

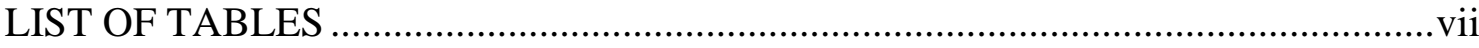

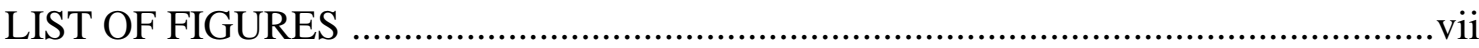

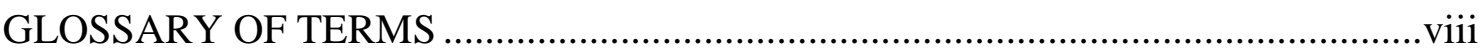

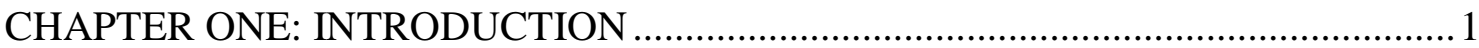

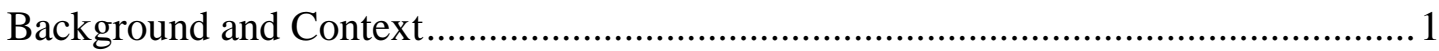

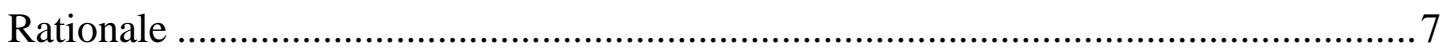

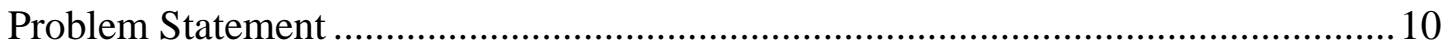

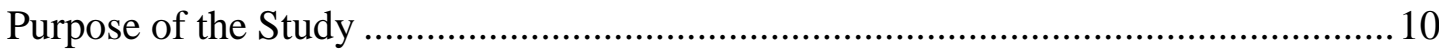

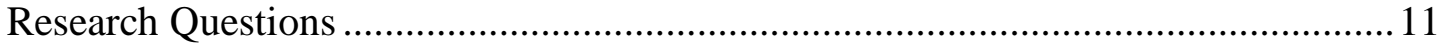

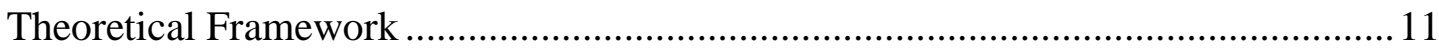

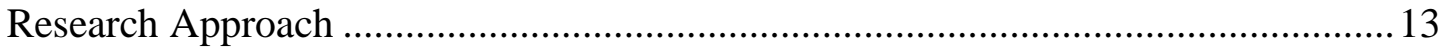

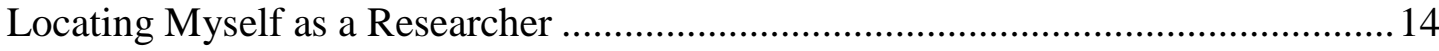

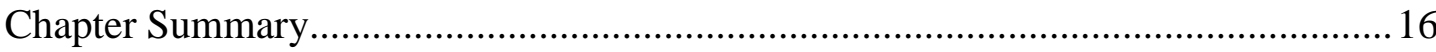

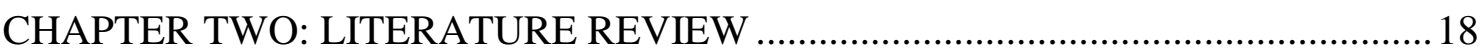

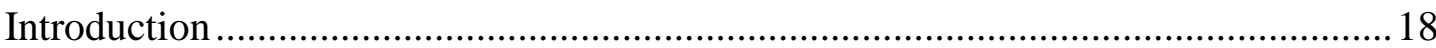

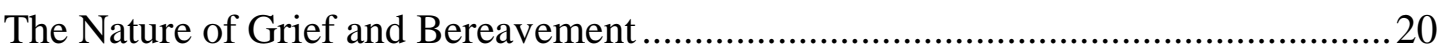

Gender, Masculinity, Health and Grief ..................................................................... 26

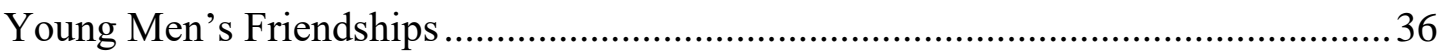

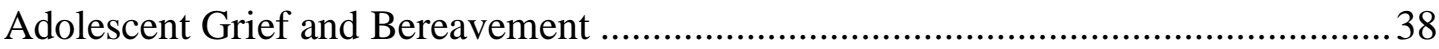

The Effects of Friend or Peer Suicide Bereavement on Young People ......................4 41

Qualitative Studies of the Experience of Grief and Suicide Bereavement .................46

Young Men's Experiences of the Death of a Friend or Peer. ....................................49

Chapter Summary/Synthesis of the Literature ........................................................51 


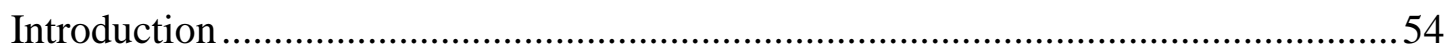

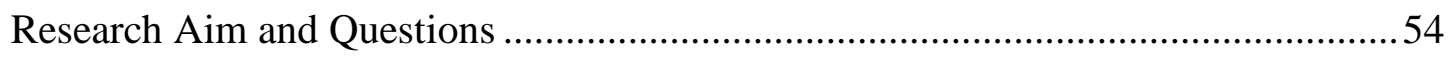

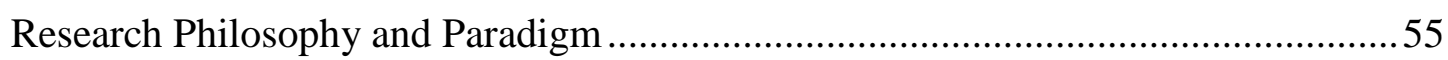

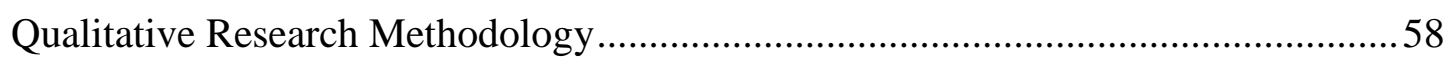

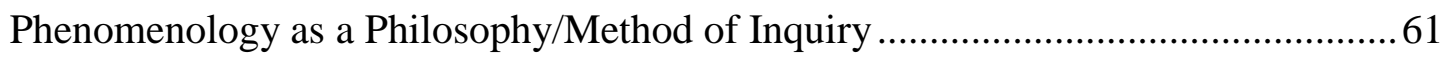

Husserl's Descriptive (transcendental) Phenomenology ............................................6 64

Phenomenology as a Method of Inquiry or Research Methodology..........................66

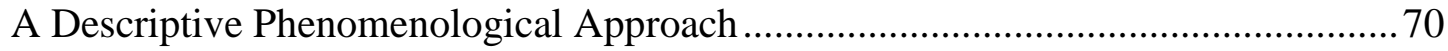

Methodological Considerations: Discussion and Rationale for Choice of Approach.74

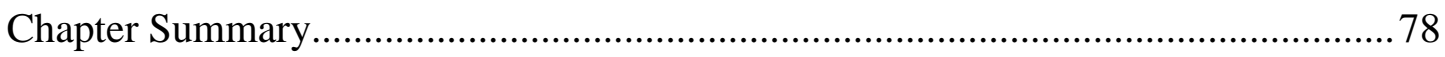

CHAPTER FOUR: RESEARCH METHODS AND PROCEDURE ........................... 80

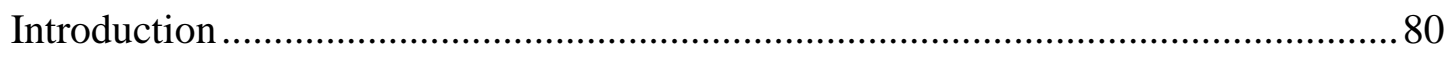

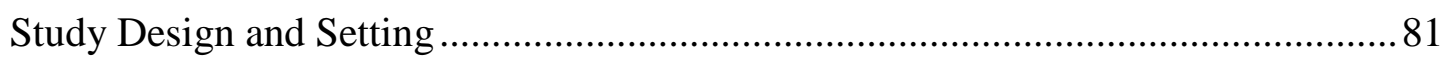

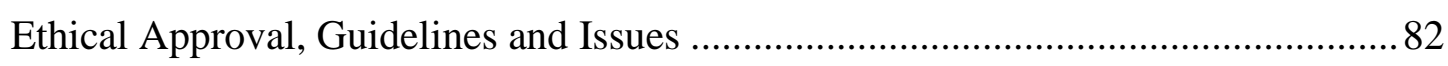

Participant Recruitment, Selection and Sampling............................................... 94

Contextualisation: The Deceased and the Research Participants............................ 102

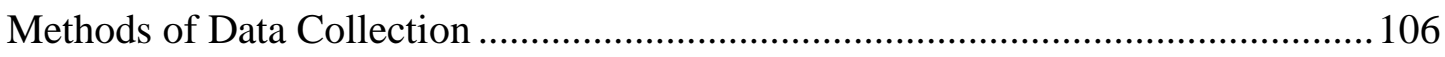

Method of Data Analysis/Interpretation............................................................ 116

Verification Strategies and Trustworthiness ….................................................... 129

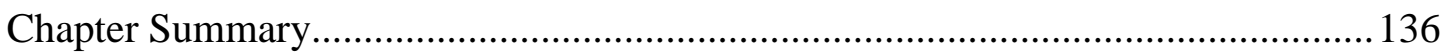

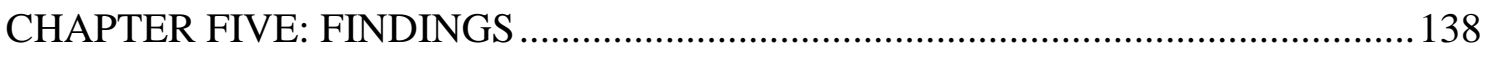

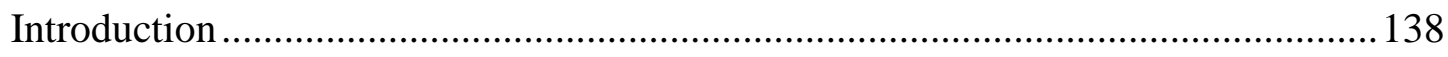

The Essence and Structure of the Men's Experience.............................................. 138

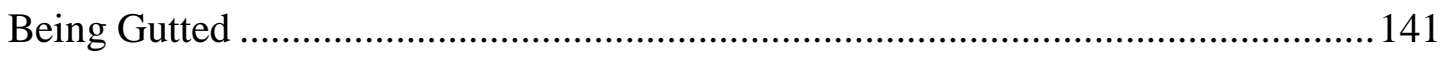

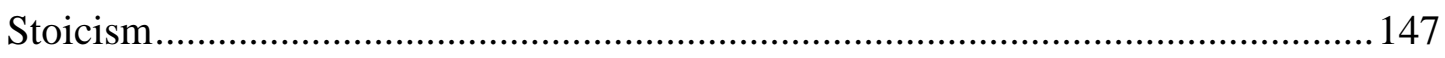

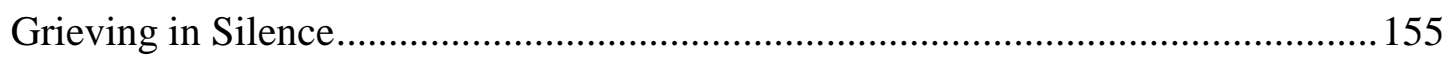

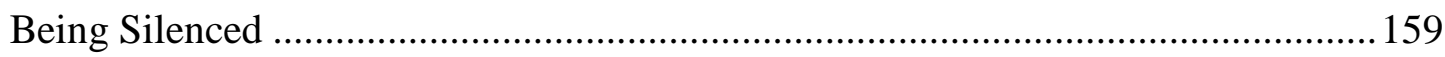




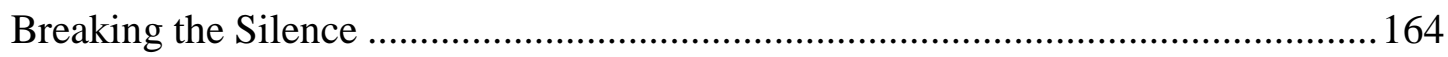

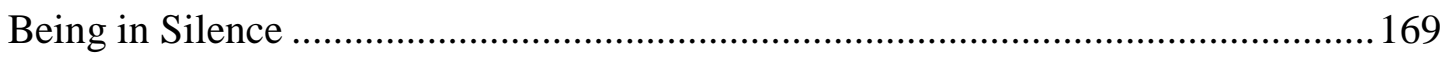

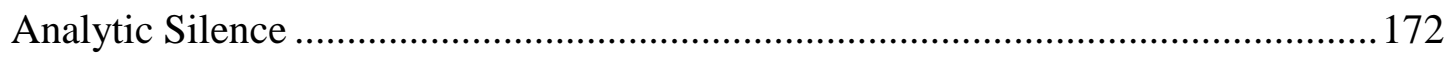

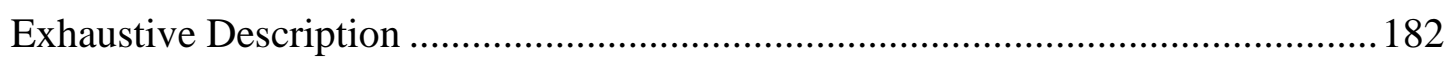

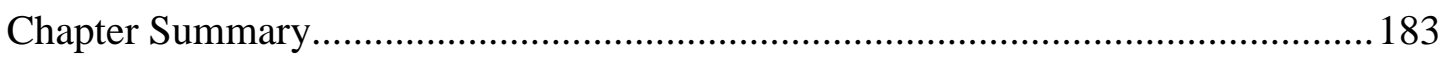

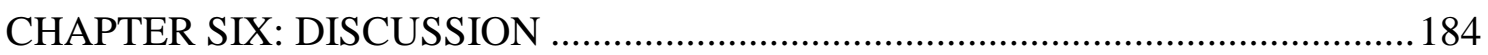

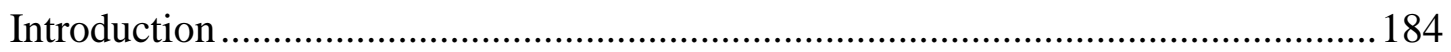

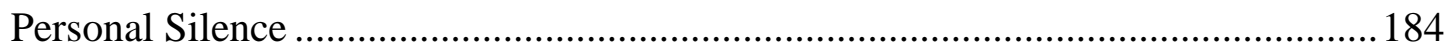

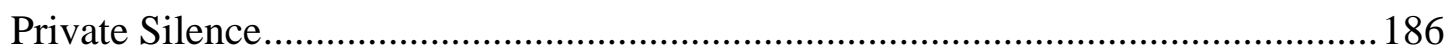

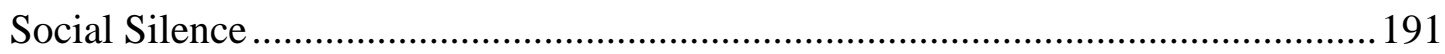

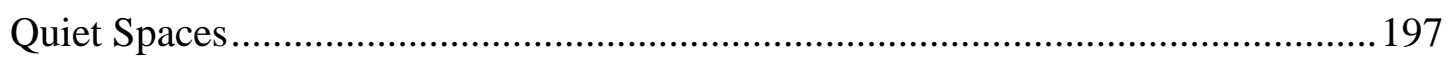

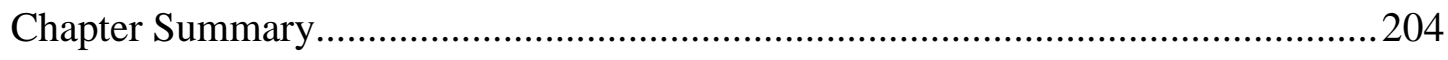

CHAPTER SEVEN: IMPLICATIONS AND CONCLUSION ................................205

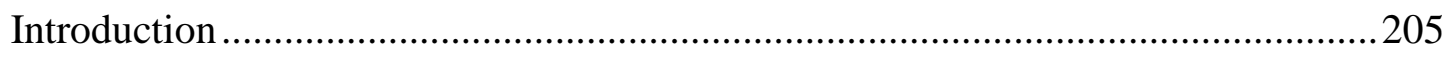

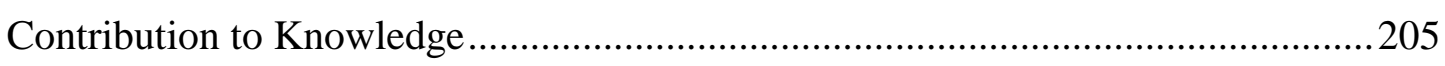

Contribution to Phenomenological Research Methodology ..................................207

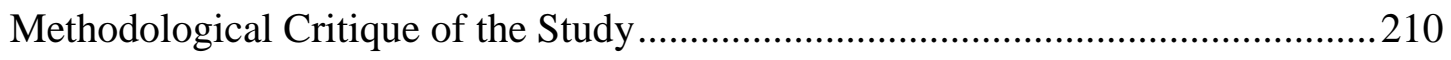

Implications for Healthcare Practice and Support .............................................2 213

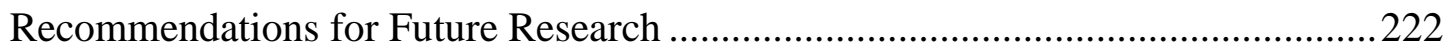

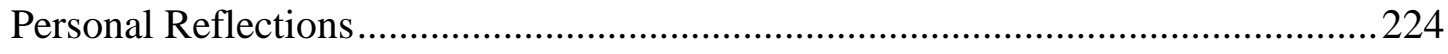

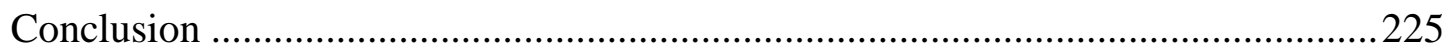

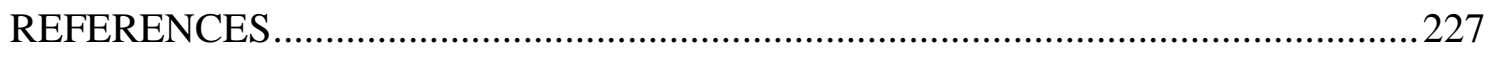

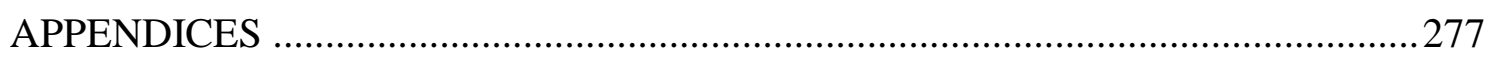

Appendix 1: Human Ethics Committee (VUW) approval letter ..............................2 277

Appendix 2: Participant information sheet ...................................................... 278

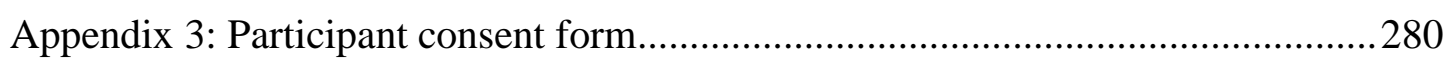

Appendix 4: Semi-Structured interview guide................................................. 281

Appendix 5: Participant demographics ............................................................28 
Appendix 6: Datasets generated from the interviews

Appendix 7: Data analysis: Example of meaning units, coding and categorisation .284 


\section{LIST OF TABLES}

Table 1. Participant demographics and information ................................................... 105

Table 2. Datasets generated from the interviews ......................................................... 111

\section{LIST OF FIGURES}

Figure 1. Relationships of participants to the deceased ........................................... 103

Figure 2. Process of Phenomenological Analysis ...................................................... 121

Figure 3. Thematic Representation of Participant's Experiences................................ 140 


\section{GLOSSARY OF TERMS}

Acute grief

Attempted suicide

Bereaved by suicide

Bereavement

Complicated grief

Grief

Grief reaction

Grieving

Integrated grief

Intervention

Loss

Mourning

Suicidal behaviour/s Encompasses suicide, attempted suicide, deliberate self-harm (with suicidal intent) and suicidal ideation (thinking).

Suicidal ideation Thoughts of suicide.

Suicide

The act of intentionally killing oneself as determined by coronial ruling.

Suicide bereavement Bereavement that occurs after the death of a loved one or peer to suicide.

Suicide-loss survivor A person who had a personal and close relationship with someone who died by suicide (not a person who has survived a suicide attempt, or has been exposed to suicide).

Suicide postvention A wide range of activities undertaken directly after a suicide in a community that aim to prevent further suicides, reduce the risk of contagion and the harmful effects and impact on others.

Suicide prevention A wide range of activities developed by, with or for suicide-loss survivors, in order to facilitate recovery, alleviate the impact of suicide, reduce risk of suicide, and improve life outcomes and quality of life for suicide-loss survivors.

Suicidology
The scientific study of suicidal behaviour (including ideation, attempts and suicides) and suicide prevention. 


\section{CHAPTER ONE: INTRODUCTION}

“What we can't speak, we say in silence.” (Jordan, 2008, p. 316).

\section{Background and Context}

Each year, over 800,000 people die due to suicide, suicide is a major global public health issue (WHO, 2015). According to the World Health Organisation (2011) suicide rates have increased by $60 \%$ worldwide over the past 45 years and suicide is now among the three leading causes of death among people aged 15-44 years of age (male and female). Specifically, the Centre for Disease Control (2010a) reports that suicide among 15- to 24year olds, accounts for $12.2 \%$ of all deaths annually (Centre for Disease Control, 2010b). Suicide is the second leading cause of death among young people (15-29 year olds) globally in 2012 (WHO, 2015) and rates of suicide (per 100,000 population) are estimated as being 2-3 times higher for men than women (WHO, 2015). Consequently, many young people will experience the death of a close friend or peer during adolescence and young adulthood and become a suicide-loss survivor (from now on referred to as a 'survivor').

Suicide also continues to be a serious public health issue in New Zealand (NZ) (Ministry of Health, 2016). According to the latest provisional data available in NZ, a total of 606 people died by suicide in the 2016/17 year. Of those suicides, 457 of them were men (75\%), that is three male suicides for every female suicide (Coronial Services of New Zealand, 2017). There were 38 suicides in the 15-19 year old age group; 28 male and 10 female suicides; 17.2 and 6.5 suicides per 100,000 males and females respectively. The highest number of suicides of any age group were recorded in the 20-24 year-old age group; with 79 suicides (61 male and 18 female suicides). This age group also had the highest rate of suicide of 32 and 11.7 per 100,000 male and females respectively. In this age group there are 3 male suicides for every female suicide. Māori continue to have the highest suicide rate of all ethnic groups at 21.7 per 100,000 population (Coronial Services of New Zealand, 2017). While caution needs to be taken when comparing international suicide statistics because many factors influence the recording and classification of suicide in different countries (Andriessen, 2006) the latest data shows that NZ has the highest youth suicide rates (for both males and females) out of all the OECD countries (Ministry of Health, 2015). For this reason, there is a need for New Zealand research to 
focus on improving suicide prevention but also the experience of and impact of suicide bereavement on young people to inform suicide postvention efforts.

Suicide mortality and morbidity is a major cost to the health sector but also to society in general. The economic and non-economic costs of suicide is significant in terms of direct health care costs (for suicide attempts, counselling and support for survivors/bereaved), loss of economic productivity and resource utilization (police and forensic expenses, funeral expenses, victim support). In 2013, there were 508 suicides in New Zealand. The Ministry of Health (2017), using O'Dea and Tucker's (2005) formula, calculated that these 508 suicides cost the country $\$ 6,635,496$ in service provision (e.g., police, funeral costs, victim support and coronial services) and $\$ 244,250,972$ in lost production, a total of $\$ 250,886,468$ (or $\$ 493,871$ per suicide). Added to this are the difficult to calculate noneconomic costs based on years of disability-free life lost and psychological distress, impaired mental and physical health, pain and suffering caused to survivors, loss of employment and quality of life. The MOH calculated the non-economic costs of the 508 suicides to be $\$ 1,638,000,000$ or $\$ 3,224,409$ per suicide. In response to the burden of suicide, New Zealand and many other countries have developed suicide prevention and postvention strategies to reduce the cost and impact of suicide.

Every youth suicide leaves behind many survivors including parents, siblings, relatives, friends, co-workers, who are left to grieving, coping with their loss, trying to make sense of the tragedy and dealing with anger and stigma. The term suicide survivor refers to a person who has lost a loved one to suicide not someone who has survived a suicide attempt (Cerel, Padgett, Conwell \& Reed., 2009; Gaffney \& Hannigan, 2010; Jordan, 2008). Survivors have been variously defined, ranging from family members to a far wider set of individuals (co-workers, teachers, neighbours and others) affected by the suicide (Jordan \& McIntosh, 2011b). Survivor groups have often been differentiated by age (children, adolescents, adults), kin relationship (widows, widowers, spouses, siblings, parents of adolescents, aunts, uncles, grandparents and other relatives), degree of involvement/intimacy (friends, acquaintances), or special functions (therapists, counsellors) (Jordan \& McIntosh, 2011b).

Recently, an important distinction has been made between "suicide survivorship" and “exposure to suicide” (Andriessen, 2009; Berman, 2011; Crosby \& Sacks, 1994; Jordan 
\& McIntosh, 2011b). Survivors are defined as those who had a personal and close relationship with the deceased (a friend or family member), whereas, the latter refers to a situation where a person who did not know the deceased personally, knows about the death through media reports or through personally witnessing the death of a stranger (for example, train drivers or police). Survivors have been defined by relationship and intimate affect (Andriessen, 2009) and by self-identification as a survivor (Berman, 2011).

Survivors significantly outnumber those who die by suicide (Andriessen \& Krysinska, 2012). Every suicide has a direct, far-reaching and long-term impact on family/whanau, friends and communities. McGlothlin (2006) has reported that 4.5 million people worldwide are impacted by the suicide of a loved one each year. Some researchers have estimated that, on average, for every suicide a further six to ten people will be severely affected by intense grief (Beautrais, 2004; Clark, 2001; Clark \& Goldney, 2000; Crosby \& Sacks, 2002; Pompili et al., 2008) while others estimate that between five and one hundred people may be adversely affected (Cerel \& Campbell, 2008).

The estimates for how many young people have been bereaved by suicide vary and are similar to the estimates for how many people have been bereaved through suicide in the total population (Berman, 2011; Cerel, Maple, Aldrich \& van de Venne, 2013). Pfeffer, Jiang, Kakuma, Hwang and Metsch (2002) found that in the USA, children are bereaved by the suicide of a relative in one third of all suicides. Adolescents and young people are far more likely to be exposed to suicidal behaviour and suicide in people outside their family (vs. inside their families) (Cerel \& Aldrich, 2011). Despite growing concerns about survivors, research on suicide bereavement and survivors has not received the same attention or priority in comparison to research on risk factors for suicide and suicide prevention (Jordan \& McIntosh, 2011a).

Survivors are at increased risk of developing adverse physical and mental health reactions, including prolonged grief disorders and complications to pre-existing health problems, increased risk of suicidal ideation, behaviours and attempts (Suicide Prevention Australia 2009). Survivors have been shown to experience: disruption to family routines and relationships, functional impairments in daily activities, as well as spiritual crises and struggles, financial and issues with the law (Grad, 2005; Grad, Clark, Dyregrov \& 
Andriessen., 2004; McMenamy, Jordan \& Mitchell, 2008; Provini, Everett \& Pfeffer, 2000).

Isolation, guilt, shame, anger, stigmatisation and social rejection are experiences frequently associated with people who suffered a loss by suicide (Jordan, 2001; Sveen \& Walby, 2008; Hunt \& Hertlein, 2015). Some of these difficulties are similar to those experienced after other types of traumatic deaths (accident, homicide) (Cerel, Jordan \& Duberstein, 2008). Survivors also experience some unique features of grief (Jordan, 2001), for example, shame, stigma, guilt, blame, and confusion about the responsibility for the death (Jordan \& McIntosh, 2011b).

Survivors are at greater risk of developing psychological and psychiatric complications including: depression and Post Traumatic Stress Disorder (PTSD) (Jordan, 2008), complicated grief reactions (Prigerson \& Jacobs, 2001), suicide ideation (Mitchell, Kim, Prigerson \& Mortimer-Stephens, 2004; Hunt \& Hertlein, 2015) and suicidal behaviour (Pompili et al., 2008; Hunt \& Hertlein, 2015), particularly in the absence of adequate postvention support (Brent, Melhem, Donohoe \& Walker, 2009; De Groot \& Kollen, 2013). It has been estimated that survivors may be between 2 and 10 times as much at risk as those in the general population (Runeson \& Åsberg, 2003). The impact suicide can have can range from mild to devastating depending on many factors (Jordan \& McIntosh, 2011c) and the sudden and unnatural death of a significant other is one of life's most stressful events (Mitchell \& Everly, 1996; Mitchell, Sakaraida, Kim, Bullian \& Chiapetta, 2009).

Studies of suicide bereavement have tended to focus on three of the major developmental groups: children, adolescents (high school and college age students) and adults. Much of the research has focused on the experiences and views of adult survivors, mostly women and those recruited from support groups (Maple, Cerel, Jordan \& McKay, 2014). Studies on adult survivors have focused on whether suicide bereavement differs from bereavement by other causes, and on pathology and negative effects on survivors (Gaffney \& Hannigan, 2010). Some qualitative studies have tried to capture and describe the grief experience of adults bereaved by suicide (Fielden, 2003; Begley \& Quayle, 2007, Mitchell et al., 2009). 
Only a relatively small number of international studies have explored suicide bereavement in young people (McIntosh \& Jordan, 2011; Servaty-Seib, 2009), the effects of suicide on young survivors (Cerel \& Aldrich, 2011), or the lived experience of suicide bereavement from the perspective of young survivors (Bartik, Maple, Dewards \& Kiernan, 2013). Recent reviews (Andriessen, 2014, Andriessen, Draper, Dudley \& Mitchell, 2015) have found relatively few articles that focus specifically on describing the characteristics of suicide bereavement or support for adolescents, students and young people. Studies of young survivors have focused on adolescents who have lost parents (Brent et al., 2009), siblings (Brent et al., 1993b; Brent, Moritz, Bridge, Perper \& Canobbio, 1996; Pfeffer et al., 1997) and peers but not close friends (Balk, 1991). The experiences of young survivor friends have been neglected, marginalised and made invisible and this has been identified as a priority area for research (Maple et al., 2014; Robinson, et al., 2008).

The majority of studies on young survivors have been quantitative, based on adolescents and high-school populations and shown that adolescents exposed to suicide may experience the same effects as adults exposed to suicide. Adolescent survivors are more likely to experience higher rates of depression, anxiety, post-traumatic and complicated grief reactions (Dyregrov \& Dyregrov, 2005) and suicidal ideation and attempts (Andriessen et al., 2015; Cerel, Roberts \& Nilson, 2005). Exposure to suicide (in a friend or acquaintance) in adolescents has been linked to traumatic grief, depression and PTSD (Melhem et al., 2004) and depression and suicidal behaviour in those who were closer to the deceased (Hazell \& Lewin, 1993). Cerel et al. (2005) found adolescent survivors are more likely to engage in a range of health compromising and risk taking behaviour including smoking cigarettes and marijuana, binge drink, be involved in serious fights and have inflicted injuries on others that required medical attention compared to those not exposed to suicide. Much of the concern about adolescent survivors involves the transmission of suicide, and the psycho-social morbidity among suicide bereaved adolescents and young adults (Cerel \& Aldrich, 2011).

A series of quantitative studies on the impact of peer-suicide on young people were conducted in the United States in the 1990s following growing concern about rates of adolescent suicide. Brent et al. (1993a; 1993b; 1993c; 1995) found that adolescents exposed to peer-suicide had elevated rates of major depression, PTSD, and suicidal 
ideation. They also found adolescent peer-suicide survivors were more likely to make suicide attempts and experience PTSD; and these negative effects were more common in adolescents who had a closer relationship to the decedent, more exposure to the suicide itself and those who had a history of relationship problems (Brent et al., 1995). Much of this research on young high-school survivors has failed to distinguish between peers and friends, or involved mixed-relationship groups (friends and acquaintances).

Studies of young survivors have failed to acknowledge the importance and status of young people's friends and this has contributed to the invisibility or marginalisation of their grief. For example, Mitchell et al. (2009) in their study of survivors (all ages) distinguished between closely related (parent, child, spouse, sibling) and distantly related survivors (in-law, aunt/uncle, niece/nephew, friend or co-worker), and grouped friends with other distal survivors. Research on adolescent grief suggests that the nature of relationship with the deceased is a key factor that influences the grief process and subsequent adjustment (Bonanno, 1999; Meshot \& Leitner, 1993; Rubin, 1992). Closeness, or the nature of the attachment (strength, security, dependence and conflict) has been identified as an important mediator of mourning that influence an individual's reaction to loss (Worden, 2008).

There are important differences between 'peers' and 'friends' and these differences may influence both the experience of grief and the meaning of the loss. Peers are simply people who have certain aspects of their status in common, such as age (Arnett, 2014). For young people, peers consist of a large network of their same-age classmates, community members or co-workers. Friends (tend to be peers) but not all peers are friends. Friends are people whom individuals have developed a valued, mutual relationship with (Arnett, 2014).

Friends play a significant role in the development of young adults and provide young people with many forms of support (informational, instrumental, companionship and esteem) during the transition to adulthood and beyond (Arnett, 2014). Intimate attachments to friends and their strong reliance on them for emotional support can leave young people vulnerable when those friendships end through loss and bereavement. The death of a close friend could disrupt development and test young people's ability to cope and adjust and place strain on normal developmental processes (Williams \& Merten, 
2009). Despite this, few grief studies have explored the loss of close friends or how young people cope with death-related issues (Balk \& Corr, 2009) and so understanding and knowledge of how young people experience this type of interpersonal loss and grief is limited.

\section{Rationale}

There are several reasons for focusing on young adult men's experiences of losing a close friend to suicide. First, previous studies have tended to focus on adolescents rather than young or emerging adults. McNess (2008) highlights that few studies have examined young adults' experiences of bereavement: "Bereavement literature on young adults tends to disappear between the more comprehensively researched bereavement experiences of adolescents and parents" (p. 26). Previous studies have focused on high school based populations and explore the effects of peer suicides (for example, Brent et al., 1989, 1992, 1993a, 1993b, 1993c, 1994, 1995, 1996a, 1996b, Brent, Melhem, Donohoe \& Walker, 2009). Emerging or young adulthood is a lifespan age group that has received little attention despite high numbers of suicides occurring in this age group.

Scholars have begun to recognise that emerging adulthood is a unique and developmentally different stage of life that follows adolescence and that young people in this stage face different challenges and deserve to be studied in their own right (Arnett, 2014). Arnett (2000) proposed a new term "emerging adulthood" (EA). He defined EA as the period of development between adolescence and adulthood, encompassing 18-25 years of age. It is a distinct and long period that lies between the attainment of biological maturity and the entrance into stable adult roles. Emerging adulthood is also fast developing into a new field of scientific inquiry (Arnett, 2014). Another reason for exploring suicide bereavement in emerging adults is that research has established that there are important developmental differences that distinguish children, adolescents and adults in terms of their conception of death and the ways they experience and cope with grief and loss after death (Huritz, Duncan \& Wolfe, 2004; Kail \& Cavanaugh, 2007; Harms, 2010).

Developmental differences may play an important role in how people respond to losing a loved one to suicide. Children may not understand the permanency of death, and may see death as separation (Feldman, 2014). Children may feel guilty or responsible for 
someone's death, become anxious and clingy, regress in terms of behaviour, develop somatic complaints (for example headaches, stomach pains, difficulty sleeping) in response to loss and grief and need a lot of reassurance (Kail \& Cavanaugh, 2007). In comparison, adolescents tend to have romantic conceptions of death but understand its permanency and experience existential issues (for example "What is the point of life?" "Is there life after death?") (Feldman, 2014). Like children, they can experience somatic symptoms when grieving, but tend to use problem-focused coping and grieve in ways similar to adults (Kail \& Cavanaugh, 2007; Harms, 2010). Adolescents also tend to be fearful of expressing their grief and standing out from their peers; they can experience peer-pressure to 'move on' from their loss or; and feel their grief is marginalised by adults (Harms, 2010).

In contrast, adults understand the permanency of death, see it as irreversible and can be less anxious and more accepting of it (Feldman, 2014). Adults experience and express their grief in similar ways to adolescents, but they use increased substance abuse or distraction through work commitments to cope (Kail \& Cavanaugh, 2007). Adults may also delay their grief in order to support children and older family members and grieve in private in order to minimise the impact of the loss on other family members (Kail \& Cavanaugh, 2007). While previous research has explored grief, loss and bereavement in children, adolescents and adults, there is a paucity of research that has explored these experiences in young adults.

A second reason for focusing on young adult men's experiences is that researchers and academics have also noted the lack of visibility and voice that men have within suicide research (Maple et al., 2014), policy and practice concerning men's health and suicide prevention (Bilsker \& White, 2011). Bilsker and White (2011) argue that a lack of focus on gender has led to a silence around men and suicide:

Suicide in men has been described as a "silent epidemic" (Bell, 2008) because of its high incidence and substantial contribution to men's mortality, and silent because of a lack of public awareness, a paucity of explanatory research, and the reluctance of men to seek help for suicide-related concerns. (Bilsker \& White, 2011, p. 529)

Bilsker and White (2011) go on to state that: "Only by breaking the silence-building public awareness, refining explanatory frameworks, implementing preventive strategies, and undertaking research—will we overcome this epidemic" (p. 529). They recommend 
future research focus on gender differences to generate information that can guide clinical practice and the development of effective prevention strategies. Descriptive research on young men's experiences of suicide bereavement is needed to inform the development of effective interventions and support and to increase understanding of the phenomenon from men's (survivors) perspectives.

A third reason for focusing on the suicide bereavement experiences of young adult men is that there has been a call for suicide postvention strategies and initiatives to be informed by research that explores and describes the experiences of survivors. The World Health Organisation has identified support for people bereaved by suicide (survivors) as an important strategy in suicide prevention (WHO, 2014). Suicide postvention has been defined as "activities developed by, with or for suicide survivors, in order to facilitate recovery after suicide and to prevent adverse outcomes including suicidal behaviour" (Andriessen, 2009, p. 43). These activities aim to alleviate the impact of suicide, reduce risk of suicide, and improve life outcomes and quality of life for survivors (Shneidman, 1993). These efforts are not limited to helping the bereaved cope and manage the initial stages of grief, but need to extend over the months of the first critical year and beyond (Shneidman, 1993).

Recently, there has been criticism of clinical and public health postvention interventions because they have been created "top-down" by researchers, clinicians and other experts. It has been suggested that those who design clinical postvention activities could benefit from listening to and working with survivors, exploring their experiences and incorporating their experience and wisdom (Jordan, Feigelman, McMenamy \& Mitchell, 2011). Survivors are now being seen not just as targets of intervention and consumers of service. There is a need to engage survivors as active partners in research in order to develop, implement and evaluate more effective support services, programmes and postvention policies (Peters, 2009). Survivors' perspectives are important for informing more flexible and responsive services (SPA, 2009).

One of the research priorities recommended by leading researchers in the suicidology field (Andriessen, 2009; Jordan \& McIntosh, 2011c) is conducting methodologically sound studies in order to identify the specific experiences and needs of various groups of survivors based upon age, gender, closeness and the type of the relationship with the 
deceased. There has been a recommendation for more personal accounts of survivor experience, the use of qualitative methods to elicit further detail on the bereavement experience (Begley \& Quayle, 2007) and studies to focus on how young survivors' experiences influence their coping and adaptation to life following suicide (Cerel et al., 2008). A lack of research on young men's experiences and a presumption that all survivors are the same in relation to both experience and needs, has led to a "one-sizefits-all" approach to suicide prevention and postvention and a lack of gender-tailored and responsive initiatives. Current prevention and postvention activities and initiatives may be failing to both engage young men and reduce the risk of suicide in this vulnerable population.

\section{Problem Statement}

Young men have the highest rates of suicide in the world, and that means that many young people will experience the loss of close friends to suicide and become young survivors of suicide. Young survivors are at greater risk of negative health outcomes, pathology and suicide. There is a paucity of research on their bereavement experiences that explores how they cope and adjust after suicide, their experiences of care and support and what it means to be bereaved by suicide (Gaffney \& Hannigan, 2010). The few studies that have tried to capture the experiences of survivors have focused on the experiences of bereaved children, adolescents and adult parents and examined loss in relation to limited kinship relationships such as family and school-peers (acquaintances and friends). The experience of young people who have lost a close friend to suicide has not been described and is relatively unknown. Furthermore, the experiences of men are often missing from the research and discourse on suicide, despite being the most at-risk group. Therefore, research into how young men experience suicide bereavement following the loss of a close male friend is warranted.

\section{Purpose of the Study}

The purpose of this qualitative study was to explore the experiences of young men (1725 years of age) who have lost a close male friend to suicide in a New Zealand context. I hope that exploring young men's experience will advance our understanding of suicide bereavement and that the findings can be used to inform suicide postvention (Gaffney \& Hannigan, 2010), education for family and friends supporting young men, and the development of more gender-responsive/appropriate support and health care practice. I 
also hope this study will raise awareness of the need for more research on men's health issues and encourage more researchers to pursue research with vulnerable, and hard to reach populations.

\section{Research Questions}

The key research question underpinning this research project is what are the experiences of young men who have lost a close male friend to suicide? The sub questions are:

a) What is it like to lose a close male friend to suicide? and

b) What are the essential/core components that make up their experience of suicide bereavement? (What is the essence of their experience?)

\section{Theoretical Framework}

My careful examination of available knowledge and theory, and a thorough literature search on suicide bereavement, grief, youth, masculinities and men's health helped me identify a gap in the research so that my study would make a contribution to knowledge. It revealed a paucity of research on young men's experience of suicide bereavement, particularly around the loss of close friends (rather than peers). The literature review was crucial to formulating the research problem, which is guided by the questions: What do we know about the phenomenon? Why is it important to know more? (Elliot \& Timulak, 2005).

During this phase I explored relevant literature on grief and suicide bereavement theory in order to develop what Strauss and Corbin (1998) refer to as 'theoretical sensitivity', that is, to become as aware as possible of the nature of my pre-understanding of the phenomenon. These pre-understandings shape the refinement of research questions, the choice of methodology and methods: data collection, analysis and interpretation and influence the whole research process. The following section outlines my theoretical position on an important issue related to the phenomenon of suicide bereavement.

There is ongoing debate as to whether the grief or bereavement experienced after suicide is more difficult or distinct from bereavement after other types of death. There are conflicting findings in the literature as to whether the type of death effects of the experience of grief and subsequent resolution, adjustment or pathology. Some studies have suggested that survivor reactions do not differ significantly from other types of 
bereavement (Barett \& Scott, 1990; Cleiren \& Diekstra, 1995; Muller \& Thompson, 2003).

Scholars and researchers have criticised early studies that showed there were differences between suicide bereavement and other forms of bereavement as suffering from a lack of methodological rigor. These early studies tended to be based on interviews with small, convenience, selected samples, with no control or comparison groups, and included individuals with extreme pathological reactions which were interpreted as 'typical' reactions to bereavement by suicide (Beautrais, 2004). A more recent systematic review of controlled studies of grief reactions found that there were no significant differences between people bereaved by suicide and other bereaved groups regarding mental health, depression, post-traumatic stress symptoms, anxiety, and suicidal behavior (Sveen \& Walby, 2008). Sveen and Walby (2008) did, however, find that people bereaved by suicide have reported higher levels of rejection, shame, stigma, need for concealing the cause of death, and blaming than all other modes of bereavement.

Many suicide prevention and postvention organisations (SPA, 2009) take an alternative position and argue that suicide bereavement may be unique and survivors may experience different reactions and more severe grief compared to other bereaved populations. Some scholars (Flynn, 2009; Sveen \& Walby, 2008) support this perspective and have argued that suicide bereavement involves qualitative differences as compared to other bereavements. Some studies have found survivors may exhibit higher levels of pathology, problematic grief and heightened risk for physical and/or mental health complications, including suicidal ideation (Mitchell et al., 2004).

Jordan $(2001,2008)$ has suggested that suicide bereavement processes involve different aspects that may lead to delays in survivors healing or integrating their grief, including: (i) the need to understand and make sense of the death, (ii) guilt and feelings of responsibility; (iii) rejection, perceived abandonment and anger; (iv) stigma and accompanying isolation; (v) trauma particularly in those who witness the death or discover the body; (vi) suicide risk including suicidal ideation and behaviour, and (vii) higher risk of complicated grief. Others have argued that suicide bereavement may be more complex (Kniepper, 1999) or that grief following suicide is more difficult to integrate and it takes longer for the bereaved to "move on" (Fielden, 2003). 
In a recent systematic review on the experiences of adolescent survivors, Andriessen et al. (2015, p. 2) summarised the growing consensus about suicide bereavement amongst researchers:

Irrespective of the similarities, the narratives of survivors portray grief themes such as guilt, shame, social stigma, search for meaning, and the suicide risk of survivors, as more characteristic though not unique for suicide bereavement (Dunne \& DunneMaxim, 2009; Jordan, 2001).

The current study is written in the context of the theoretical framework that while suicide bereavement may share some common aspects with other forms of bereavement and grief, there are some unique aspects and it may be different from other forms of bereavement. The research suggests that the complicated grief, guilt, shame, anger, and search for answers are key features of suicide bereavement. Previous literature and research also suggests that little is known about how young people (and in particular young men) experience suicide bereavement.

\section{Research Approach}

A qualitative inductive and phenomenological approach was adopted in order to explore how participants experience the loss of a close male friend to suicide. The qualitative and phenomenological researcher seeks to explore, describe and understand the meaning of a phenomenon or lived experience, in this case, the suicide bereavement experiences of the young men. A qualitative approach to data collection and analysis is appropriate when the research question/s are open-ended and exploratory (Elliot \& Timulak, 2005) and when there is limited knowledge within a research area; existing research is confusing, contradictory, or lacking in progress; or the topic or phenomena of study is highly complex (Barker, Pistrang \& Elliot, 2002).

This study included two of the key features of exploratory research (Elliot \& Timulak, 2005). First it was definitional - exploring the nature of the phenomenon of suicide bereavement and concerned with describing the key features and meaning of the experience. Second, it was descriptive - exploring the common and unique aspects of suicide bereavement. A descriptive phenomenological approach was chosen for this study because of a lack of understanding of the experiences of the phenomenon of suicide bereavement in young men. Phenomenological studies provide insight into phenomena, 
help us understand the nature and meaning of experience, and often highlight the hidden, the unseen. Gaining a rich description of a phenomenon is a necessary step before interpretation can be made of experience.

Descriptive phenomenology is an approach frequently used within health and psychology to explore participant's experiences of phenomena. I hoped to connect with participants to elicit detailed descriptions of their experience and to glean an understanding of their experiences in order to gain a richer analysis of the essential structure of that experience and meaning of losing a close friend to suicide. Because phenomenology is idiographic, it allows the researcher to focus on the particular and relevant. The study sought to describe the essential nature of suicide bereavement for the participants but also explored why the participants experienced suicide bereavement the way they did, and how masculinities influenced that experience.

\section{Locating Myself as a Researcher}

Suicide has always been a part of my personal and professional life. My first encounter with suicide was when my brother's best friend took his own life in the 1980s. I lost three close friends to suicide during high school and while at University. Nobody talked about suicide in those days. At university I studied psychology and education and explored escape-based adolescent suicide in my Master's thesis. I developed an interest in the psychology of suicide, theoretical models and suicide prevention. The theory and models I encountered always seemed divorced from reality. They focused on explaining why young people took their lives, risk factors, variables, and pathways into suicide but failed to capture the essential experience of being suicidal and that of the bereaved.

For most of my professional career I have worked as a university lecturer, teaching students about human development, grief and loss, and issues related to mental health, wellbeing and resiliency. I have taken every opportunity to educate students about suicide and break the silence I encountered. I broke the silence around suicide in my work as a community educator, teaching families/whānau ${ }^{1}$ and professionals about suicide, suicide

\footnotetext{
${ }^{1}$ Whānau is the Māori word for immediate and extended family including senior adult relatives (parents, uncles, aunties) and their spouses and children, as well as others who may be bonded and part of 14
} 
bereavement, prevention and postvention. I wanted to know more about survivors' experiences so I could better support them and educate those in helping professions. My research, interest in supporting survivors and community engagement led me to develop "Waves" a professionally-led psycho-educational programme for adults bereaved by suicide. I have co-facilitated the programme for many years and trained facilitators when the programme was implemented nationally. More recently I have been trying to provide survivors with a voice and way of coming together to understand their experience.

What I have noticed from my clinical work, was that very few male survivors sought help with their grief, and there was a general reluctance for young men to engage in 'grief work'. This observation was supported by colleagues and female survivors who told me male survivors needed to be encouraged to be more like some women - intuitive, emotionally expressive, and talkative. Families and whānau I worked with complained that they did not understand how the men in their lives were grieving or even if they were grieving, because the men tried to be invisible and silent.

Research and professional/clinical experience suggest that gender, developmental differences, the nature of the relationship (and closeness to the deceased), social and cultural contexts, along with many other factors, influence the process of grieving and adjusting to loss. Some men are not only silent grievers (Stadaucher, 1991), but they are also invisible (Addis, 2011) and silent within the discourse on suicide (Bilsker \& White, 2011). Very little is known about how male survivors experience and express their grief, especially after the suicide of a close male friend. Hence, describing the suicide bereavement experiences of young men who have lost a close friend to suicide became the focus of my research. Furthermore, I strongly believe that given the right context, safety and support young men will talk about their experience.

This qualitative study and process allowed men to share their personal experience of suicide bereavement. I compared survivors' narratives and experience and looked for common themes and an underlying essence to their experience. I did this to better

a physical, social, spiritual and economic domestic collective. Whānau may be descendent-based or purpose-based. 
understand their experience of suicide bereavement, so this understanding could be used to develop gender-responsive postvention, support and care, and to encourage future research to focus on young men's experiences. As a result of conducting this research I have realised that there is indeed a silence that comes after suicide and this silence is a key aspect of men's experience of suicide bereavement. As a young man I was not aware of this silence, but it was there, in my own experience, and analysing the experience of the men in this study helped me both see and hear it.

This study contributed to a gap in this field. Young men's voices are missing from the research on suicide bereavement. Without a clear description and understanding of what their experience is like, mental health and counselling professionals will continue to struggle to comprehend their needs, and to provide relevant, effective and male-friendly support and suicide postvention. Therefore, research into how young men experience the loss of a close friend to suicide is warranted. The silence that comes after suicide, does not mean the young bereaved men have nothing to tell us. We need to be aware of and listen carefully to their silence in order to make their invisible experience visible.

\section{Chapter Summary}

This first chapter was designed to introduce the thesis, establish the need for health research on young adult men's experience of suicide bereavement following the loss of a close friend. It included a statement of my interest and reasons for undertaking this research and discussion of the significance of suicide and suicide bereavement or 'survivorship' in contemporary society. The chapter also included an explanation of why qualitative research, specifically descriptive phenomenological, is the preferred method for exploring the lived experiences of survivors, and outlined my theoretical framework surrounding suicide bereavement.

This thesis consists of seven chapters. In Chapter Two I present the current research, evidence and identify the gaps in knowledge of how young people experience suicide bereavement. This chapter provides the background into suicide bereavement, the effects of suicide on young people, and identifies the emerging areas of research into young people bereaved by suicide including a focus on men and masculinities. Chapter Three examines the philosophical and methodological positioning of the study. The chapter 
begins with an explanation of my research philosophy and a discussion of the rationale for using a phenomenological approach.

Chapter Four describes the methods used to collect and analyse my research data. It begins with a description of the data, difficulties with participant recruitment, the relationship building and interview process. It includes a brief description of the participants and the deceased in order to situate their grief and loss experience. The process of immersion within the data, the writing and data analysis process are elaborated upon. The chapter includes a critical and reflexive discussion of how my own lived experience as a survivor and as a professional influenced the research process, and concludes with a discussion of ethical considerations, and boundary issues experienced and resolved.

The following chapters cover the findings, discussion and conclusions. Chapter Five presents the findings of the study and the essence of the men's lived experience - silence. The findings begin with a conceptualisation of silence and presents the major themes in their experience with supporting evidence and interpretation. It concludes with an exhaustive description of the men's experience. Chapter Six is a discussion of the significance of my key findings in relation to the silence experienced by the men, research and current knowledge that have informed a new understanding of how suicide bereavement is experienced by young men. Chapter Seven concludes this thesis and includes a discussion of how this research has contributed to healthcare knowledge by providing new understandings of the experiences of young men, critiques the study and identifies possibilities for further study of the phenomenon. 


\section{CHAPTER TWO: LITERATURE REVIEW}

\section{Introduction}

The care and support of young survivors, is an emerging area within suicide postvention, clinical practice and health research. Understanding the research in suicidology and mental health and a thorough critical review of the literature enables the researcher to gain valuable insights into the field, highlights gaps in the research and methodological challenges (Roberts, 2000). The following chapter shows the progression of thought that led to the current descriptive phenomenological analysis. The purpose of the study was to explore how young men experience suicide bereavement following the suicide of a close friend and the role gender and masculinities play in shaping young men's experience of suicide bereavement.

This chapter has been presented as a structured narrative overview (Green, Johnson \& Adams, 2006) where the available research evidence has been synthesised to convey key messages, provide an overview but not necessarily a critique of individual studies, and to express the need for the present study. Narrative overviews usually present a broad perspective on a topic and describe the history or development of a problem and its management. These types of reviews are rather unsystematic and the selection of articles is subjective; authors tend to discuss theory and context and the purpose of the review is to provoke thought and controversy. Narrative overviews are not suited to drawing conclusions about practice or for informing clinical decisions but are useful for challenging people's thinking and keeping people updated as to key issues in the field (Green et al., 2006).

\section{Locating the literature.}

This research inquiry began with a search of literature within databases that covered the fields of health, nursing, counselling, psychology, psychiatry as well as allied disciplines. Research on suicide and suicide bereavement spans multiple disciplines and fields including: health, psychiatry, psychology, sociology, counselling, and focuses mainly on the effects of suicide on young survivors (research on variables) and personal lived experience (research on individual's experience of suicide loss, bereavement or survivorship). Reading and reviewing relevant literature is part of researching, writing and refining/revising a thesis (Kwan, 2008). My review of the literature continued 
throughout the thesis and began when I first started to explore the topic and wrote the research proposal. The review became more focused when developing the literature review but continued through to the revision of the final drafts. I read additional material throughout the $\mathrm{PhD}$ when I needed to strengthen my understanding of theoretical concepts, explain methodology and methods, when validating findings, and when I needed to discuss the implications of the findings (Kwan, 2008).

Locating literature on young men who have experienced suicide bereavement is challenging. There is great variation in terms used to describe this age group: 'adolescent/s', 'older adolescent/s', 'teen/s', youth/s' and 'young or emerging adults'. There is also variation in how young people are defined by their relationships to others (peers, friends, siblings, sons/daughters) and their participation in education (college/university/high school students). A further complicating factor is there is no standardised or widely adopted nomenclature for referring to people bereaved by suicide (suicide-loss survivors, survivors, the bereaved, suicide bereaved) and there is great variation in how the phenomenon is referred to (suicide bereavement, suicide exposure, grief following suicide, suicide loss). There is also inconsistency in how terms are applied to various populations, and a lack of description of sample populations (gender, age, socioeconomic status and other demographic characteristics). These issues make it difficult to find relevant research and compare findings across studies.

Databases were searched to locate research articles, literature reviews and discussions of suicide bereavement; the search revealed a paucity of research on young people's experiences of suicide bereavement and in particular the experiences of young men. Books, published and unpublished theses, dissertations and government websites were also used to locate relevant literature, the latest suicide statistics, and seminal work published before 1990. A number of specialist journals were examined and the reference lists of relevant publications were used to identify related literature on grief, loss, and suicide bereavement.

Due to the paucity of research on young men's experiences of suicide bereavement, in this literature review I first begin to describe the development in thinking about grief and bereavement, gender differences in patterns of grieving and adaptation to grief. I then discuss how masculinity and gender norms influence men's health, wellbeing and grief 
and the importance of close friendships for young people. I present an outline of what is known about adolescent grief and bereavement, the effects of peer-suicide on young people and the variables which influence their experience. Finally, I provide an overview and discussion of the emerging qualitative research on young people's experiences of suicide bereavement and peer-bereavement. This review and discussion demonstrates that a study exploring the experiences of young men who have lost a close friend to suicide is warranted to advance understanding of men's health and grief.

\section{The Nature of Grief and Bereavement}

As mentioned in the introduction, a debate in the literature exists as to whether suicide bereavement is different from other forms of bereavement. Despite the conflicting evidence and lack of clarity around this issue, it is relevant to consider suicide bereavement within the greater context of theory, research and knowledge about grief, loss and bereavement. Much of the thinking about grief and key definitions have been summarised and discussed elsewhere (Hall, 2014). A recent review summarised much our current knowledge on suicide bereavement and identified issues relating to concerns about research samples and research design, women being overrepresented in studies, limitations imposed by ethical review boards, definitional problems around survivors and the need for further research on men's experiences of suicide bereavement (Maple et al., 2014). Therefore, in the following section I provide a brief overview of important topics and changes within the field that are relevant to the present study including: variables that influence grief, grief theory, continuing bonds, and the importance of meaning making and growth.

\section{Pre- and post-loss factors that influence grief and bereavement.}

There are many factors that influence grief and the bereavement experience and process including: the relationship with the deceased (parent, sibling, relative, friend) (Bonanno, 1999), the type of death (whether sudden or unexpected, accident vs. illness) (Ginzburg, Geron \& Solomon, 2002), historical approaches to bereavement (how one has coped with past experience) and societal influences (Leming \& Dickinson, 1994), cultural norms (Klapper, Moss, Moss \& Rubenstein, 1994), the quality of the relationship with the deceased (Meshot \& Leitner, 1993) and the age of the deceased (Klapper et al., 1994). 
There are also social, psychological and developmental circumstances of individuals that affect the mourning process (Worden, 2008) including: (i) who the person was (the relationship between the deceased and the survivor), (ii) the nature of the attachment (strength, security, dependence and conflict), (iii) mode of death (natural, accidental, sudden, suicidal); (iv) personality variables (coping style, cognitive style, assumptive world, age, gender); (v) social variables (availability of support, social roles, religious and cultural expectations); and (vi) concurrent stresses (change, crises that arise following a death) (Worden, 2003).

Personal factors also influence individual's reactions to loss, including personal vulnerability (Van Baarsen, Van Duijn, Smit, Snijders, \& Knipscheer, 2002), personality traits (Goodman, Black, \& Rubinstein, 1996), age of the individual (Levy, Martinkowski, \& Derby, 1994), social behaviour (Van Baarsen et al., 2002), and familial patterns of adjusting to grief (Book, 1996). Some researchers have suggested that particular factors may have differential influences depending on the stage of bereavement (Richardson \& Balaswamy, 2001) for example, loss-oriented variables such as the type of death may be more important during early stages of bereavement, whereas restoration variables such as engagement in social activities may be more relevant at later stages.

\section{Theoretical perspectives of grief.}

Grief is often defined as a reaction to a perceived loss that may involve physical responses (aches and pains, somatic distress), affective (feelings of anger, relief, hopelessness, or sadness), cognitive (difficulties concentrating, dreaming about the person) and spiritual responses (cause them to re-evaluate their beliefs or struggle to make meaning). Both the experience and expression of grief are highly varied, unique and idiosyncratic and the grieving process may also involve adaptation to the loss of a significant other, mourning the loss and both internal and external processes (Doka \& Martin, 1998).

A proliferation of theories have been developed over time that have emphasised the importance of different aspects of grief phenomena including: how people adapt to grief; attachment and bonds; meaning-making and personal growth that results from the grief experience. Over the past 50 years there have been significant changes in the way grief has been described and theorised in disciplines such as thanatology and suicidology (Hall, 2014). For example, there has been a move away from early stage-based approaches to 
grief (Kubler-Ross, 1975; Parkes, 1996) and task-based approaches (Attig, 1996; Corr, 1992; Rando, 1993; Worden, 2008). These theories have been criticised because of a lack of empirical evidence for the existence of the universal stages and for moving through them as necessary for recovery (Corr, 1993).

Early theories and models of grief have been criticised for their rigidity and failure to capture the complexity, diversity and idiosyncratic quality of the grieving experience and qualitatively distinct paths through bereavement (Hall, 2014). In the last two decades there has been a move towards recognising the diversity within how grief is experienced and expressed and how patterns of adaptation are influenced by age, gender and ethnicity (Martin \& Doka, 2000). These idiographic perspectives recognise the complexity of how the same phenomenon (grief) is experienced and expressed differently. There has also been a greater focus on the social, cultural and spiritual aspects of grief. Contemporary perspectives no longer see the bereaved in a passive role as 'victims' or 'survivors' but emphasise they are active participants who have an important role in re-learning how to live in the world (Attig, 1996, 2004), meaning making, adjustment and coping.

This view of the bereaved as active participants has informed the development of two of the most influential theoretical models of grief - Stroebe and Shut's (1999, 2010) DualProcess Model of Coping and Worden's (2008) Task-Based Model. Despite the criticisms of the task-based models, they may be particularly relevant for understanding men's patterns of grieving which tend to be more cognitive, active and instrumental (Doka \& Martin, 2011). These two models show how the bereaved actively cope with loss and bereavement and have been used by counsellors to guide interventions.

The dual-process model shows that at certain times people adopt a loss orientation that involves engaging with emotion-focused strategies (exploring memories and expressing a range of emotional responses, confronting their pain and sadness, making positive and negative appraisals). At other times they adopt a restoration orientation and use problemfocused coping to make adjustments (for example, coping with a new identity, mastering new skills, taking up new roles, re-evaluating life, developing new assumptions) that eventually lead to restoration (Schut \& Stroebe, 2005). 
Worden's (2008) task-based model also positions the bereaved in an active role; individuals 'work through' their grief by completing four tasks: (i) accepting the reality of the loss, (ii) processing their pain, (iii) adjusting to a world without the deceased, and (iv) developing an enduring bond or connection with the deceased while continuing on with a new life. Worden's (2008) work also identified a number of factors that influence the experience of grief including: who the person who died was (nature of relationship, level of dependency), that nature of the attachment to the deceased (strength of bond, degree of conflict and ambivalence), how the person died (whether it was expected, unexpected, traumatic), historical antecedents (for example, past experiences with grief), personality variables, social mediators and concurrent stressors.

Worden's model is based on the assumption that men and women complete the same tasks to work through their grief and that these are universal and not gender-specific. Staudacher's (1991) model, however, shows how men and women differ in how they work through grief. According to Staudacher's model men and women both experience stage one 'retreating' - management of pain and stage three 'resolving' - reorganising and restructuring their life in similar ways. However, according to her model, men complete stage two 'working through' grief differently to women because men tend to remain silent, engage in 'secret grief', take physical action and become immersed in activities as they work through grief.

\section{Continuing bonds, narratives and meaning making.}

Perspectives that suggest that the bereaved need to sever bonds or attachment with the deceased or 'let go' in order to adjust have also been criticised and rejected (Hall, 2014). Contemporary approaches emphasise the importance of continuing bonds while acknowledging the reality of the death and loss and that a physical relationship is no longer possible (Klass, Silverman \& Nickman, 1996).

A new constructivist and narrative approach to grief has also begun to emerge and is particularly well suited for exploring individual processes of bereavement adaptation (Neimeyer, 2001). Narrative researchers tend to construe grieving as a social process that involves the bereaved "telling their story" of loss (Harvey, 1996) and seeking an audience for a new self-narrative (White \& Epston, 1990). The story about the loss is part of the individual's own self-narrative and events such as suicide can represent a breakdown or 
disruption of a life narrative. This breakdown requires the individual to reorganise and reconstruct their world of meaning that is challenged (Neimeyer, 1998, 2001). This paradigm emphasises that meaning reconstruction is not just a simple cognitive coping strategy or process, but rather a process that involves an individual trying to reorient their self in both existential and practical terms within the world (Neimeyer, 2001). This approach to grief suggests that young men who have lost close friends to suicide may struggle to both tell their story, find an audience to listen and repair their self-narrative.

The narrative approach also recognises social and cultural contexts (including gender) shape the meaning making process, narratives and activities of the bereaved (Neimeyer, Klass \& Dennis, 2014). Narrative and constructivist researchers have shown that the bereaved adapt by engaging with the nature of suicide, reconstructing the death story and repositioning themselves (Sands, 2009) within specific contexts and communities. According to the constructivist narrative perspective, young suicide-loss survivors will construct a story or biography about their close friends/the deceased through discussion with friends, peers and others who knew them:

Bereavement is part of the never-ending and reflexive conversation with self and others through which the late-modern person makes sense of their (sic) existence. In other words, bereavement is part of the process of (auto) biography, and the biographical imperative the need to makes sense of self and others in a continuing narrative - is the motor that drives bereavement behaviour. (Walter, 1996, p. 20)

The constructivist narrative paradigm is supported by a growing body of literature that has demonstrated the importance of meaning making in the grief process (Neimeyer \& Sands, 2011) with a variety of losses and populations (Neimeyer, 2009). Researchers have found that an inability to make sense of loss is the single best predictor of intensified grieving, outweighing other objective factors such as the relationship that was lost (for example, parent, child, sibling), the cause of death (natural vs. unnatural and violent causes), or passage of time (Currier, Holland, Coleman \& Neimeyer, 2007; Keesee, Currier \& Neimeyer, 2008).

\section{Stress-related or post-traumatic growth and transformation.}

In the last twenty years there has also been a move away from a sole focus on grief and psychopathological symptomatology (for example, PTSD, depression, anxiety) (Neimeyer, 2001). The latest development in grief theory is exploration of the qualitative 
and quantitative transformations in the bereaved (Bonanno, 2004; Holland, Currier \& Neimeyer, 2006; Sands \& Tenant, 2010). Grief can act as a catalyst not only for posttraumatic stress but also post-traumatic growth (Tedeschi, Park \& Calhoun, 1998).

Studies have shown that a significant proportion of bereaved people report some perceived benefit from their experience including growth of character (for example, increased empathy and understanding of others, compassion), gain in perspective (for example, greater awareness of the fragility and shortness of life which led to a greater focus on the here-and-now) and strengthening of relationships (for example, richer, stronger relationships with family and friends, more open expression of love, greater forgiveness of old conflicts, making more time for others) (Nolen-Hoeksema \& Davis, 2002). Other studies have found similar trends, with the bereaved reporting personal changes including: appreciation of the brevity of life and reality of death (19\%), greater sensitivity and openness to others (15\%), feeling stronger and more mature (12\%), more emphasis on taking better physical care of self (10\%) (Neimeyer, 2001).

Suicide bereavement research demonstrates that the bereaved can experience important transformation of perspectives, self and relationships with others (Sands \& Tennant, 2010). Researchers working in the field of human resilience also believe that the capacity of people to bounce back from grief has been underestimated (Bonanno, 2004). These studies indicate that an exploration of young men's experiences of suicide bereavement should consider the possibility that they may experience suicide as a transformative event.

The major developments in grief theory and research over the past two decades can be summarised as including: (i) a shift toward idiographic approaches and away from universal stage-based models of grief, and towards non-pathologising models (ii) use of qualitative research approaches (for example, phenomenological and narrative), (iii) a focus on meaning- or sense-making, (iv) how grief contributes to identity change and reconstruction, (v) transformative growth and benefit-finding (Neimeyer, 2001). This study will inform theory development by examining the phenomenon of suicide bereavement in an understudied population (young adult men). A descriptive phenomenological approach will provide a focus on the essential nature of their experience. 


\section{Gender, Masculinity, Health and Grief}

In order to understand how young men experience grief and bereavement after the suicide of a close friend one must understand how gender, masculinity, men's health and grief intersect and influence men's experiences of grief and bereavement and grief practices.

\section{Gender and masculinity.}

Gender is a socially constructed multidimensional construct that refers to the different roles, responsibilities, limitations and experiences assigned to individuals based on their presenting sex/gender (Johnson \& Repta, 2012). Gender is produced, re-produced and shaped by institutions such as the media, education, medical and social and political systems institutions. Gender roles are the social norms, rules or standards that dictate the responsibilities, opportunities, limitations and behaviours for men and women (Johnson \& Repta, 2012).

Masculinity is often thought of as some deep inner essence that makes a man a man, or a set of physical, psychological or social characteristics that make men behave the way they do (Levant, 1995). However, social scientists, such as Kimmel (1997) argue that masculinity is a socially constructed and historically shifting component of gender and is typically associated with men and male characteristics. Others argue that we need to see men's gendered behaviour as performative and contextual practices, see the diversity in the ways boys and men 'do boy and man' (Frosh, Phoenix \& Pattman, 2003; Creighton $\&$ Oliffe, 2010). While men may endorse similar masculine ideals they may enact these differently, leading to diversity in masculinities amongst men (Messerschmidt, 1993). For example, how men demonstrate how tough they are may be influenced by age, ethnicity, social class and sexuality (Courtenay, 2000a).

Addis (2011) views masculinity as a set of beliefs and behaviours that men use to demonstrate their adherence to whatever the dominant gender norms are for the time. For example, in most Western societies the traditional norms of masculinity emphasise that men should: demonstrate emotional restraint, handle problems on their own and be independent, avoid anything considered feminine or "gay", be physically and psychologically strong, have an action-orientation, take control of situations, be a risk taker, competitive and a financial success (Addis, 2011, Coleman, 2015; Levant, 1995). 
Addis (2011) also notes that men face a great deal of pressure to define and defend themselves as masculine. Men constantly have to prove they are a man through risktaking, being competitive, showing no fear, being aggressive and taking action (Addis, 2011).

Contemporary perspectives on masculinity argue that masculinity is a social construction and this has led to the notion that there are multiple masculinities that men can construct and perform (Johnston \& Morrison, 2007) including hegemonic, subordinate or marginalised, oppositional/protest, compulsive, compensatory, inclusive masculinities (Courtenay, 2000a; Randell, Jerdén, Öhman, Starrin \& Flacking, 2015). This has led to the rejection of a single view of masculinity (typically white, heterosexual and middle class). A gender-in-context model posits that men's behaviour is enacted to meet the demands of certain situations and expectations and this has led to more flexible and pluralistic notions of what it means to be or do man (Courtenay, 2000a). What is considered to be masculine in terms of practice, differs across social, historical and cultural contexts (Vogel, Heimerdinger-Edwards, Hammer \& Hubbard, 2011; Liu, 2005). Ethnicity, socioeconomic status, educational level, sexual orientation and social context influence the type of masculinity men construct (Courtenay, 2000a).

Masculinity is not just something men are or do, but it is also something they position themselves in relation to (Johnston \& Morrison, 2007) and influences the way they position themselves towards others, including women (Connell \& Messerschmidt, 2005). Men interpret notions of masculinity, they can accept or reject notions of masculinity and these ideas shape their understanding and presentation of themselves in everyday life (Johnston \& Morrison, 2007). Masculinity also influences health beliefs and behaviours (Courtenay, 2000a, 2000b; De Visser, Smith \& McDonnell, 2009, Evans, Frank, Oliffe \& Gregory, 2011; Marcell, Eftim, Sonenstein \& Pleck, 2011).

For the purposes of this study, gender and masculinity are seen as both expressed and performed in everyday practices (Johnson \& Repta, 2012) and they are likely to be reflected in men's experiences of suicide bereavement and how they grieve. Masculinity is a key factor to consider when researching the experiences of suicide bereavement in young men. Masculinity influences how men experience the suicide of a close friend, their loss, grief practices and how they do grief. 


\section{Gender, masculinity and health.}

Gender, masculinity and health are closely related (Evans et al., 2011, O’Neil, 2013) and any discussion of men's experiences of and the impact of suicide bereavement needs to consider these contexts. Gender and masculinity not only shape men's health behaviours, and therefore, the ways they respond to suicide, but also the outcomes of events like suicide that have negative health impacts.

Scholars have drawn attention to gender differences in health outcomes. They argue that men's adherence to traditional, hegemonic norms and toxic masculinity are a possible reason for men's experiences of negative health outcomes (Beaglaoich, Sarma \& Morrison, 2013, Coleman, 2015, Courtenay, 2000b). For example, men are more likely than women to experience chronic health conditions, die younger, and adopt beliefs that compromise their health (Courtenay, 2000b). They are also more likely to engage in health-compromising behaviours (alcohol and drug misuse, violence, dangerous driving, unsafe sex) that can lead to illness, injury and death (Tyler \& Williams, 2014). Men are also less likely to seek help for a wide range of health issues including depression, substance abuse and physical disability (Addis \& Mahalik, 2003; Tyler \& Williams, 2014) and less likely to engage in efforts to prevent illness and comply with medical practice (Courtenay, McCreary \& Merighi, 2002).

Similar trends and disparities in health and well-being are seen in young men. Randell et al. (2015) report that a large body of research also shows that there are clear gender differences in health between adolescent boys and girls, with boys more likely to drop out of school, be involved in accidents, be the perpetrators and victims of violence, and have a higher rate of suicide. These health compromising behaviours are more commonly found amongst those who hold beliefs about masculinity that are considered traditional, hegemonic and toxic (Garfield, Issaco \& Rogers, 2008).

\section{Hegemonic masculinity and traditional masculine norms.}

Researchers have noted that there are both positive and toxic aspects of masculinity (Kupers, 2005). Nontoxic aspects of masculinity include caring and protective behaviours of fathers, the dedication of men to their families, and men who care for their friends, family and environment. Toxic practices include behaviours such as: hypercompetitive 
behaviour, physical violence and aggression (Connell \& Messerschmidt, 2005), selfcentredness, homophobia, the domination and subjugation of women and weaker men (Creighton \& Oliffe, 2010), not depending on others, not displaying weakness or emotions other than anger, not cooperating with authorities, demanding respect at all times, and suffering pain in silence (Kupers, 2005). These practices are connected to hegemonic masculinity and maintain gender dominance in a particular setting, are socially destructive and make it difficult for men to seek or accept help, treatment and support (Kupers, 2005).

Hegemonic masculinity has been defined as the dominant notion of masculinity within a particular historical context (Connell, 2005; Randell et al., 2015). Hegemonic masculinity subordinates femininities as well as other forms of masculinity, and reflects and shapes men's social relationships with other men and women (Courtenay, 2000a). Hegemonic masculinity is characterised by ruthless competition; an inability to express emotions other than anger; an unwillingness to admit vulnerability; weakness or dependency; the devaluation of women and feminine attributes in men; homophobia and worry that others will view them as less than the hegemonic ideal of a real man (Kupers, 2005).

Over the past 30 years there has been growing concern about men's enactment of hegemonic and traditional masculinity on their health, wellbeing and that of others around them (Connell \& Messerschmidt, 2005; Courtenay, 2000a, 2000b; Kupers, 2005; Creighton \& Oliffe, 2010). Research has shown a link between adherence to hegemonic and traditional norms of masculinity and a range of health compromising behaviours including a reluctance to seek social or psychological help (Chandra, et al., 2009; Levant, 1995; Smith, Tran \& Thompson, 2008; Vogel et al., 2011), more negative attitudes towards help-seeking (Berger, Levant, McMillan, Kelleher \& Sellers, 2005) social withdrawal and increasing use of alcohol and drugs as a coping strategy for dealing with stress and grief (Coleman, 2015, McNess, 2008).

Hegemonic masculinity may discourage men from seeking support when they experience, illness, disability or events such as loss and bereavement because it threatens their status as men (Moss-Racusin, Phelan \& Rudman, 2010). Seeking counselling, reaching out to mental health services or others, and social or emotional disclosure may be seen as a threat to men's sense of masculinity (Schaub \& Williams, 2007). It may constitute an 
admission that they cannot solve their own problems and is thus, perceived as a personal failure (Addis \& Mahalik, 2003). Adherence to traditional masculine norms has also been associated with men keeping quiet about their inner lives, including their health problems (Addis, 2011).

Similar concerns and findings about the negative impact of hegemonic and traditional masculine norms have been found in studies of help-seeking in young men (Richardson \& Raibee, 2001; Tyler \& Williams, 2014). Australian and New Zealand studies further support the idea that adherence to traditional masculinity encourages young men to keep silent about symptoms when there is no immediate danger to life, particularly when there are no physical symptoms such as in the case of mental health issues, emotional, or sexual problems (Judd, Komiti \& Jackson, 2008; Shoveller, Knight, Johnson, Oliffe \& Goldenberg, 2010; Smith, Braunack-Mayer, Wittert \& Warin, 2008). This has led researchers to suggest that more needs to be done to acknowledge and normalise helpseeking in men and reframe help-seeking behaviours as a sign of strength (Garfield, et al., 2008; Tyler \& Williams, 2014).

Studies of young men's bereavement have demonstrated that adherence to hegemonic and traditional norms of masculinity influence men's experience of grief and grief practice. For example, McNess (2008) found young men refrained from emotional disclosure. They did this because they feared the possibility of the costs of social displays of emotion and burdening those around them. The majority of male participants felt that talking openly about grief-related feelings might initiate "humiliating" emotional displays (for example, crying, physical shaking, difficulty speaking) that would have a negative impact on their self- and social-esteem. The young men spoke about the need to control emotional displays of grief within social situations and socially isolating themselves from others was one strategy used by men to help them control emotional displays of grief. This desire to control emotions and fear of the social consequences of emotional expression seem to fit with adherence to traditional masculine norms. Emotional containment was a way of preserving male social status and the fear of the social consequences of emotional display caused bereaved men a great deal of anxiety and stress (McNess, 2008).

Addis (2011) argues men's beliefs about self-reliance, controlling emotions and women's adherence to traditional views of masculinity and discomfort around emotionally 
expressive men can reinforce men's silence. According to Addis, these beliefs and views also make it difficult for men to break or resist traditional masculine norms and restrictions on behaviour and openly express themselves. Fear also reinforces men's silence and adherence to traditional masculine norms. Kimmel (1997) argues that men's greatest fear is being seen as 'unmanly', a failure or being humiliated. This is why men are ashamed to be afraid and vulnerable and remain silent. He proposes that this fear of shame leads to silence and to exclusion (of women and men) and escape (for example, alcohol and violence) as dominant methods by which men keep their humiliation and fears at bay.

\section{Resistance to hegemonic masculinity and traditional masculine norms.}

It is difficult for young men to not-adhere or actively resist hegemonic and traditional forms of masculinity and to express traditional feminine traits, such as emotional expression, dependence on others or interdependence, without experiencing a loss in selfesteem or status (McNess, 2008; White, 2002). Resistance is particularly difficult as young men transition out of late adolescence into adulthood and "manhood" (Way, 2011; Way et al., 2014). Studies have shown that pressures to conform to traditional norms of masculinity increase dramatically from childhood (Crouter, Manke \& McHale, 1995) to adolescence. Boys of all ethnicities and social classes are pressured to "man up" and follow the guy code (Kimmel, 2008).

According to Connell (2002) men who choose to reject traditional masculine (hegemonic masculinity) and take up alternate masculinities experience a number of social and health related costs (verbal abuse, discrimination, violence). They also experience social and economic penalties; are judged more negatively by women; are ostracised by other men for not behaving like "one of the boys", and experience other forms of 'backlash' (Connell, 2002). Research shows that boys and men who violate gender stereotypes and traditional masculine norms of behaviour are penalised for their passiveness, emotional disclosure, and for achieving success in feminine domains (Moss-Racusin et al., 2010). Failure to achieve an "ideal" masculine status may become a major source of stress, anxiety and confusion for some men (White, 2002).

Given the difficulty in resisting or not adhering to hegemonic and traditional masculinity, it should be no surprise that these forms of masculinity would also have a significant 
influence on men's experience of grief and ways of doing grief. Given the dominance of hegemonic and traditional masculinity, alternate forms of social behaviour and grieving, that went against the guy code would not be viewed as socially acceptable or legitimate. The following section, discusses in more detail how gender and masculinity shapes grief and how men do grief.

\section{Gender, masculinity and grief.}

Doka and Martins' seminal work on gender and grieving styles (Doka, 1989; 2002; Doka \& Martin, 1998, 2010, 2011; Martin, 2000; Martin \& Doka, 2000) continues to shape contemporary perspectives on men's grief as well as research and practice. Their research and research by Parkes and Prigerson (2010) shows that culture, masculinity and gender norms influence the way men and women both experience and express their grief and adapt to loss. For example, research (Doka \& Martin, 2011; McNess, 2008) shows in western culture men are often expected to remain stoic, show emotional reserve, suppress the expression of emotions, maintain autonomy and take an action-oriented approach in line with traditional notions of masculinity. The same research shows men are also supposed to avoid feminine traits such as open emotional expression and communication that can nurture interpersonal relationships.

One of the most prevalent perspectives in the grief literature is that the way men grieve is deficient, impaired or ineffective and that men need help with their grieving because they are unable to express their feelings or seek help and social support because of their style of grieving (Corr, Nabe \& Corr, 2009; Doka \& Martin, 2011). This perspective (sometimes called the feminisation of grief) is based on a narrow view that there is only one way to grieve and that the expressing emotion and seeking social support and help from others is critical to effectively coping with loss and grief (Doka \& Martin, 2011).

Empirical research on gender differences and outcomes of adaption to grief is sparse, presents a mixed picture but does not fully support this perspective or the notion that the way men grieve is defective. Some studies have shown that men may be at greater risk of health complications during the course of bereavement, while other studies have shown that widows experience higher mean levels of traumatic grief, depression and anxiety compared to widowers (Parkes \& Prigerson, 2010). Just two studies have focused on gender differences in grief reactions and intensity following the death of friends or peers 
(Melhem et al., 2004; Servaty-Seib \& Pistole, 2006). Melhem et al (2004) found young women were more likely to exhibit complicated grief following the suicide of a peer. Servaty-Seib and Pistole (2006) did not find gender to be a predictor of grief intensity following the death of a high school peer. Few studies have examined how gender may influence the experience of suicide bereavement and grief, particularly in young men.

Studies on gender and grief have produced mixed findings and studies have used different measures to assess psychological distress and psychosocial adjustment when comparing men and women. This has led researchers to conclude that many of the gender differences in health and adjustment outcomes after bereavement may be mitigated by factors other than gender. Factors that may influence bereavement include: personal vulnerability, the type of loss/mode of death, nature of relationship with the deceased, social class and cultural influences (Martin \& Doka, 2000; Parkes \& Prigerson, 2010).

\section{Masculine grief.}

Another perspective in the research and scholarship on grief proposes that men have their own distinct pattern of grief - masculine grief. This perspective is based on a review of the research on gender and grief and was developed by Doka and Martin (1998). According to this perspective men adopt a distinct pattern of grieving. The masculine pattern of adapting to grief is one where feelings are moderated and emotions restrained. Masculine grievers experience conventional aspects of grief (for example, sadness, anxiety, loneliness) but in a less intense way and may express their grief through humour and/or activity. Masculine grief is processed cognitively, introspectively, and managed with cognitive strategies such as diversion and reflection and through the use of alcohol and drugs which can be used to escape and avoid negative affect.

Those with a masculine style of grieving manage their grief behaviourally and through an active problem-solving approach. Men tend to immerse themselves in some form of activity (often related to the funeral arrangements), work or tasks brought about by the loss. These behavioural responses can bring solace but also help people "get through" their grief (Doka \& Martin, 1998). Masculine grievers are also often reluctant to share their grief and tend to grieve in private and in solitude, and avoid situations where people focus on expressing feelings which make them uncomfortable. They also prefer to maintain self-reliance (Doka \& Martin, 1998; 2011). In contrast, the feminine style 
proposed to be adopted by women is one where grief tends to be expressed more affectively, intensely and shared with others (Doka \& Martin, 1998).

The masculine style of grieving is reflective of traditional and hegemonic notions of masculinity and there has been some recent research which supports this historical view. McNess (2008) conducted one of the few studies to focus explicitly on ten young adult men's experiences of bereavement (of a sibling). He found that traditional notions of masculine identity (hegemonic masculinity) influenced their ability to practise emotional disclosure and procure satisfying social support. The young men struggled to emotionally disclose or cry in front of others, felt they needed to be stoical and used a number of masculine grieving strategies including focused or distraction activities (for example, playing sport or seeing a film) to manage their grief.

McNess (2008) also found that it was the perceptions of the young men that constrained them rather than actual lived experience of social rejection for stepping outside an emotionally constrained masculine social identity. The men assumed that people did not want to know about their grief or see them express it openly. He found that the majority of men rarely practised emotional disclosure on a social level (for example, with a parent or peer) even though they believed this was an important part of the grieving process.

The grief counsellors McNess (2008) interviewed, also supported the men's view on social and emotional disclosure, stating that they observed the repression of grief in young men and believed that this naturally slotted into the expected norms and stoical nature of "male culture". The counsellors also suggested that one of the consequences of an emphasis on autonomous action in young adult culture (for example, becoming financially independent, establishing a career) was that there is a cultural impatience with too much reflection at the expense of "doing", which applied to both young men and women.

The masculine grief perspective stresses that men who adopt a masculine pattern of coping and grieving are different but not less effective or deficient compared to those who adopt a more "conventional" or feminine way of grieving loss. This perspective has been criticised for not validating the experience of some women who identify with masculine styles of grieving and men who identify with the feminine style (Doka \& Martin, 2011). 
Doka and Martin, who were using the term masculine grief and gender-based terminology to describe how individuals grieved, rejected this perspective because the distinction between "masculine" and "male" was difficult for readers to comprehend. The term "masculine grief" was often used to perpetuate stereotypical notions of male and female responses.

\section{Intuitive, instrumental and blended grieving styles.}

The rejection of the masculine grief perspective and gender-related terminology led to the proposal of a new perspective on grief - grieving styles (Martin \& Doka, 2000; Doka \& Martin, 2010) which has now become embedded in grief research and practice. According to the new model grieving styles range on a continuum from intuitive to instrumental and are gender-related but not gender-specific. These styles or patterns of grieving appear to be influenced by gender norms and traditional notions of masculinity and femininity and fall into three types: instrumental, intuitive, and blended. These three styles are reflective of the way individuals adapt and cope with stress, which tends to be cognitive or affective (Martin \& Doka, 2000) and it is more likely that the young men in this study may fall into the instrumental grieving style as this is more common among men.

Doka and Martin (2011) describe intuitive grievers as tending to experience and express their grief more affectively (as painful feelings); their grief is expressed through crying, depressed mood, confusion, anxiety and irritability; and they often have the need to share their grief with others. Intuitive grievers tend to adapt by 'going with the experience' and investing energy into experiencing emotions and talking about their feelings. In contrast, instrumental grievers tend to experience grief cognitively and have less intense feelings. They express their grief cognitively (for example, by moderating their emotions) and are generally reluctant to talk about feelings.

According to Doka and Martin (2011) instrumental grievers tend to adapt by 'problemsolving', and value staying in control of their emotions and environment by planning, organising, and taking action (for example, organising the funeral, fundraising for charity) or discussing problems rather than feelings. Instrumental grievers can experience periods of cognitive dysfunction (become confused, struggle to concentrate) while maintaining their energy levels, and affective issues may often go unnoticed by others (Doka \& Martin, 2011). Men are more likely to be instrumental grievers because of cultural and 
gender norms (Doka \& Martin, 2011). Traditional and hegemonic masculine ideals discourage the open expression of emotion, help-seeking and discourage men from grieving in ways that would challenge their masculine identities and status.

Doka and Martin (2011) propose that personality, cultural norms (expectations about the ways people should grieve and mourn) and gender norms (expectations about how men and women should feel and behave) influence grief and the styles that individuals adapt. While they recognise that some individuals may have a blended style of grieving that may involve instrumental and intuitive elements, research shows that men are more likely to exhibit towards the instrumental or 'activity-focused' end of the continuum of grieving patterns, whereas women are more likely to exhibit an intuitive style (Doka \& Martin, 2010, 2011).

According to Doka and Martin's (2011) perspective, the bereaved may experience an alternative style of grief - dissonant grief. Dissonant grievers experience a dissonance or disharmony between how they experience grief and how it is expressed. Men who choose or are forced by others (and social, cultural and gender expectations) to adopt strategies that do not fit or complement their style of grief, can experience dissonant grief (Doka \& Martin, 2011). For example, a male intuitive griever may experience intense emotions, but because he adheres to masculine norms and societal gender stereotypes, the expression of these emotions becomes a threat to his self, identity and status as a man. Intuitive grievers may hide their feelings from others by censoring their expressions of grief, while instrumental grievers may condemn themselves for not having feelings to express or hide (Doka \& Martin, 2011). Dissonant responses to grief (denial, repression, avoidance) may have negative consequences and may lead to feelings of anxiety, guilt and complicated grief mourning syndrome (Martin \& Doka, 2000).

\section{Young Men's Friendships}

The loss of a close friend and friendship represents a significant loss (Balk \& Corr, 2009). Previous studies of suicide bereavement have focused on exploring the impact of suicide on peers rather than close friends. They have also failed to take into account how the nature of the relationship that is lost may impact on the experience of suicide bereavement. 
Peers are a large social reference group whom young people share certain aspects of status with (age, education, employment). Friends on the other hand, are people with whom individuals have a valued mutual relationship with that is emotionally and socially important (Arnett, 2014). Research has shown that young people spend considerable amounts of time with friends and develop strong friendship bonds and emotional attachments. These close and intimate friendships are extremely important for contributing to healthy adolescent development (Worthen, 2012).

Friends provide young people with an important source of intimacy - they are people with whom they share personal knowledge, thoughts and feelings. They promote development by promoting perspective taking, and provide individuals with honest evaluations of their merits and faults; thus influencing self-concept, identity, selfevaluation and self-esteem as well as social understanding. They also help young people establish greater independence and autonomy as they move away from family influence (Arnett, 2014). Friends are an important influence and source of informational, instrumental, companionship, and esteem support (Barry \& Madsen, 2010). The loss of a close friend during adolescence or emerging adulthood deprives young people not only of an important source of companionship, and support but also an intimate/close relationship that influences their development and wellbeing.

Friendships differ for men and women and come with different rules, social norms including expectations regarding intimacy, exchange, involvement with third parties, and coordination of behaviour (Felmlee, Sweet \& Sinclair, 2012). According to Felmlee et al. (2012) people "do gender" in friendships, for example, women place a higher value on their relationships and their connectedness to others than men. Women's friendships are characterised by more intimacy, self-disclosure, and emotional support while men's friendships tend to be more agentic and instrumental, focused around shared activities and interests (Felmlee et al., 2012). Traditional and hegemonic norms of masculinity dictate that men need to show emotional restraint, refrain from demonstrations of physical affection, compete, and conceal all indications of weakness. Adherence to these traditional norms means many men cannot share personal problems, doubts, fears with their close male friends (Felmlee et al., 2012; Tognoli, 1980). 
Scholarship in the area of youth development and research suggests that friendships are particularly important for young people, are different from peer relationships, and are influenced by masculinity and gender norms (Arnett, 2014). Research on gender, masculinity and grief also stresses that young men are likely to be influenced by cultural and gender norms that shape their experience and expression of grief (Doka \& Martin, 2010, 2011). Age is also an important variable and the following section unpacks some of the key findings from the research on adolescent and young peoples' experiences of grief, bereavement and in particular suicide bereavement following the death of friends and peers.

\section{Adolescent Grief and Bereavement}

Since the 1980's scholars in thanatology and suicidology have been drawing attention to a lack of research and understanding of adolescent bereavement (Balk \& Corr, 2009). Scholars have called for further research on how specific types of death such as suicide affect adolescents (Range, 2009), how traumatic peer deaths affect young people (Walker, 2009) and how the deaths of friends impact young people (Servaty-Seib, 2009).

There has been growing concern with how death and bereavement may affect young people's development, health and wellbeing. For example, exposure to death may stimulate young people to think about their own and others' mortality (Walker, 2009). Fear of their own deaths and those of loved ones may lead some young people to engage in increased risk-taking behaviour as a way of challenging their own mortality (Noppe \& Noppe, 2004).

One of the reasons for the present study's focus on young adults is that research shows young people may experience and cope with death and bereavement differently to children and adults. According to Walker (2009) grieving in older adolescents can take on a more complex trajectory than in younger and middle adolescents. Like younger adolescents they may use avoidant emotional coping (rather than engagement-ruminative coping) and this has also been found to be related to greater complicated grief in college students (Schnider, Elhai \& Gray, 2007).

Furthermore, bereavement (by suicide and other means) has been considered to be a life crisis that threatens the completion of developmental tasks during adolescence (Balk, 
2000). Young people may also have a special vulnerability to peer loss because of: (i) major social and biological changes that occur during the developmental transition to adulthood, (ii) their identification with peers rather than with family, (iii) the fact that peer loss is likely to be the result of a sudden and violent death, (iv) and additional stress of their bereavement not being acknowledged or recognised by those around them (Ringler \& Hayden, 2000). The following section discusses in more depth the research on peer and friend bereavement in order to demonstrate why focusing on the loss of close friends, warrants further study.

\section{Peer or friend bereavement.}

Peer and friend bereavement is common amongst young people. Studies have shown that approximately $20 \%$ of high school students have experienced the death of a friend in the past 12 months (Rheingold et al., 2004), and 87\% of 13-19 year olds have reported the death of a friend at some point in their lives (Schachter, 1991). Such rates increase in college populations. Ringler and Hayden (2000) found $43.5 \%$ of their sample had experienced the death of a peer while in high school. Servaty-Seib (2009) estimates that between 10-20\% of adolescents are likely to experience the death of a friend within the previous year, and that between $40-60 \%$ of young people are likely to have experienced the death of a friend by the time they reach the age of 18 .

Despite these alarming statistics no prevalence studies have been carried out in New Zealand and it would be difficult to generalise from these estimates to New Zealand given the differences between countries. The demographic data in both the USA and New Zealand suggests that adolescents and young people are more likely to grieve the death of a male peer and perhaps most likely a minority male (because they have higher rates of mortality) (Servaty-Seib, 2009). Adolescent females (perhaps most likely minority adolescent females) are also more likely to identify themselves as bereaved following the death of male minority peer (Servaty-Seib, 2009).

Given the prevalence of peer and friend deaths it is surprising that there is little research on the experiences of young people who have been friend or peer-bereaved. Servaty-Seib (2009) claims that adolescents who experience the death of a friend or peer are generally a population that have gained little attention in terms of both research and support. Others suggest young people who have experienced peer or friend bereavement are a hidden 
population (Sklar \& Hartley, 1990) and their grief generally goes unnoticed, is minimised or misunderstood (Hooyman \& Kramer, 2006; Podell, 1989; Sklar \& Hartley, 1990). This trend is puzzling and worrying (Balk, 1991) because friendships and peer-relations are critically important during adolescence and young adulthood, when young people are attempting to separate from their families and establish independence and autonomy. Furthermore, some studies have shown that friend deaths may be traumatic and as distressing as losing a family member (Dyregrov, Gjestad, Wiklander \& Vigerust, 1999; Sklar \& Hartley, 1990).

\section{Grief reactions and coping following friend or peer bereavement.}

Results of bereavement and grief research indicates that while there is some variability in how young people experience and express their grief after losing a close friend or peer, there are some common grief reactions (across genders) that young people experience including: (i) a sense of shock or disbelief, (ii) anger, (iii) sadness and crying, (iv) concerns about personal mortality, (v) negative effects on concentration and academic functioning, (vi) anniversaries and other events triggering grief, and (vii) a greater appreciation of life (Servaty-Seib, 2009).

The circumstances and nature of the friend/peer bereavement has a significant influence on bereavement and effects such experiences. Traumatic deaths (sudden, unexpected and often violent deaths caused by accident, murder/homicide or suicide) (Kaltman \& Bonanno, 2003) may particularly challenge young people's capacity to cope and make sense of their loss (Walker, 2009). Traumatic deaths are quite common amongst young people; Balk, Walker and Baker (2010) found that between $22 \%$ and $30 \%$ of young people (18-23 years old) had experienced the traumatic death of a family member or friend in the past 12 months.

Young people exposed to traumatic deaths may experience both bereavement and symptoms of posttraumatic stress disorder (Pfefferbaum et al., 2000). They are also at greater risk of anxiety disorders (Brent et al., 1993c), substance abuse/dependence (Rheingold et al., 2004), impaired daytime functioning and symptoms associated with complicated grief (Hardison, Neimeyer \& Lichstein, 2005) and symptoms of acute stress disorder (Green et al., 2001). 
Reviews of evidence on coping and grief shows young people who are grieving the death of a peer tend to use expressive or instrumental approaches to grieving characterised by: (i) a focus on cognition/moderated affect (they are more comfortable dealing intellectually with their losses), (ii) a desire to master feelings and a general reluctance to talk about feelings, and (iii) problem-solving activity (coping by doing) (Martin \& Doka, 2000). Studies also show young people also tend to use intrapersonal approaches to coping with grief (Bragdon, 2006; Dyregrov, Kristofferson, Mattiesen \& Mitchell, 1994, Ringler \& Hayden, 2000) and prefer to talk about their experience, particularly with friends rather than with parents or other adults (Balk, 1997). Young people also appreciate the chance to think alone and process their loss, and identify that spirituality, religion and prayer are important for coping (Swihart, Silliman \& McNeil, 1992; Johnson, 2006).

Young people may be able to manage grief following the loss of a friend or peer when they have access to appropriate support. Research, however, shows that young people often struggle to access social and emotional peer support following the death of a friend or peer. The main reasons are friends/peers lack understanding of how to support someone who is grieving, and/or avoid interactions with grieving peers, and/or the bereaved feel they cannot burden friends who are also grieving (Dyregrov et al., 1999).

Ringler and Hayden (2000) conducted a study of 85 university students aged 17 to 20 years who experienced loss (43.5\% experienced the loss of a peer) as adolescents. They found parents and peers were rated the most helpful support people and provided: a listening ear, understanding feelings and physical affection (for example being hugged) but support was limited to a few days or weeks and needed to be ongoing. Many of the young people reported receiving no support from family or peers and being 'forgotten grievers'. Ringler and Hayden's study is one of the few to separate and report different experiences and needs of young people based on different types of loss (general, grandparent and peer) but it did not explore gender differences.

\section{The Effects of Friend or Peer Suicide Bereavement on Young People}

Most of the research that has been done on bereavement including suicide bereavement has used quantitative methods (Hogan, Morse, \& Tason, 1996). During the 1990s there was an increase in research on adolescent suicide as teen suicide rates increased around the world and a focus on adolescent suicide prevention grew. These quantitative studies 
(mostly of American high-school students) tended to focus on the effects of suicide on young people and led to the identification of a number of negative mental health outcomes for peer-bereaved adolescents (Brent et al., 1994; 1996a; Bridge, Day, Richardson Birmaher \& Brent, 2003).

Studies of traumatic deaths (including suicides) have shown that young people who lose a friend are most likely to experience Post-Traumatic Stress Syndrome (PTSS) (Poland, 1989) and a higher degree of Post-Traumatic Stress Disorder (PTSD) symptoms (Pfefferbaum et al., 1999). Stigma-related deaths, such as suicide, also increase the amount of trauma experienced (Cerel, Fristad, Weller \& Weller, 1999). Brent et al., (1993b) found high-school adolescents exposed to a peer-suicide had elevated rates of major depression, PTSD, and suicidal ideation, and were more likely to engage in their own suicide attempts. PTSD was more likely to occur in adolescents who had a closer relationship to the decedent, more exposure to the suicide itself and those who had a history of relationship problems (Brent et al., 1995). Brent et al., (1994) found highschool adolescents exposed to suicide in friends and peers had increased risk of recurrent depression.

Qualitative research has also supported the finding that peer or friend suicide bereavement impacts negatively on the mental health of young survivors. For example, Bartik et al. (2013), in a small study of the psychological impact of losing a friend to suicide, found that the ten young survivors (ages 16-24 years; eight females, two males) reported experiencing increased levels of stress, depression, and prolonged grief symptoms.

Melhem et al. (2004) found traumatic grief in $25 \%$ of the young people who had been exposed to the suicide of a friend or acquaintance. Traumatic grief was characterised by yearning, crying, numbness, preoccupation with the deceased, functional impairment and poor adjustment to loss. Having traumatic grief at 6 months after exposure to peer suicide also predicted the onset of depression and PTSD. This was one of the few studies to distinguish between 'friends' and 'acquaintances' in a sample of adolescent survivors. Unfortunately, they did not examine or report on differences experienced between 'friends' and 'acquaintances' in their analysis. Studies that focus on describing the phenomenon of suicide bereavement within important sub-groups (such as friends) may 
help shed further light on the findings from quantitative studies on the effects of suicide as well as pose new questions and areas for future research.

A major concern is that adolescent survivors are at greater risk of suicidality (considering suicide, making a plan, or engaging in non-fatal suicidal behaviour) following exposure to peer suicides (Cerel et al., 2005). Feigelman and Gorman (2008) found that a friend's suicide was associated with heightened suicide thoughts and attempts and greater depression during the first year after loss but not at 6 years. Hazell and Lewin (1993) in an Australian study of young people who were exposed to suicide and suicidal behaviour in friends found those who had close relationships were at greater risk of depression and suicidal behaviour compared to those who were not friends and not exposed (Hazell \& Lewin, 1993). A more recent review by Andriessen et al. (2015) concluded that studies that have examined suicidal behaviour in peer-suicide exposed adolescents have presented mixed findings. Some cross-sectional studies have reported increased risks of suicidal behaviour, but other mostly controlled and longitudinal studies have reported no increased risk of suicidal behaviour. Qualitative studies support this finding from longitudinal studies and have shown that some young peer survivors have described experiencing an increase in self-harm and feeling suicidal but not suicidal behaviour (Bartik et al., 2013).

\section{Pre- and post-loss factors that influence adolescent suicide bereavement.}

As with bereavement and grief, research has identified variables and factors that influence the suicide bereavement experience and process. Andriessen et al. (2015) recently completed a systematic literature review of 58 empirical articles on adolescent (12-18 year olds) suicide bereavement (including all decedent-survivor relationships). They found that the impact of suicide is affected by pre-loss features related to personal/family history of mental health, family life, suicidal behaviour, and type of emotional closeness of the relationship; and post-loss issues such as the quality of remaining peer relationships and social support.

The unexpectedness of the death (Walker, 2009), the suddenness, violence and preventability of some peer deaths (Servaty-Seib, 2009), and viewing the scene of death or witnessing the death (Brent et al., 1993c; Walker, 2009) can impact the grief reactions. For example, Brent et al. (1993c) found that viewing the scene of death or witnessing the 
suicide, discovering the victim at the scene of the death, knowing the suicidal plans of the victim, believing one could have prevented the suicide, and having spoken with the victim the day of the suicide, led to the new onset of depression and increased the chances of PTSD and psychopathology (Brent et al., 1993c).

Andriessen et al. (2015) found evidence of a cumulative or dose-response effect with exposure to pre- and post-loss factors. Studies they reviewed showed that adolescents who have experienced the deaths of both parents are at greater risk of attempted suicide, and suicide risk increases with the number of exposed risk factors (for example, family psychopathology, family suicide attempt, familial suicide, and the individual's own psychopathology). They did not report any studies that focused on cumulative risk that came from being exposed to multiple suicides in adolescent peers and this is an area future studies need to focus on.

Pre-existing vulnerability (for example, prior or current psychiatric issues, affective disorder and prior suicidality) in friends of the deceased may also contribute to risk of suicide following exposure to suicide (Brent et al., 1989). Adolescents who have a personal history of psychopathology have been found to be at higher risk of new psychiatric problems after loss by suicide (Andriessen et al., 2015). A history of interpersonal conflict, a previous history of depression, and a family history of anxiety disorders have been linked to a greater risk of complicated grief in adolescents exposed to a peer suicide (Melhem et al., 2004).

A number of other variables have been associated with different survivor outcomes and experiences of peer suicides including: stigma associated with the death (Walker, 2009), being female, and having feelings of personal responsibility (Melhem et al., 2004). Another variable is being able to make sense of loss, those who can make sense experience fewer symptoms of complicated grief (Currier, Holland \& Neimeyer, 2006; Neimeyer, 2006) and are able to adjust and cope (Holland et al., 2006). Time since the death of a peer does not appear to influence the grief intensity and grief reactions of adolescents and young people (McNeil, Silliman and Swihart, 1991; Servaty-Seib \& Pistole, 2006). 
Wider social and cultural factors also shape how young people experience and express their grief, including their previous life experience, communication skills, developmental tasks and personal situations (Corr, 2000). Culture may also have a significant influence on how people experience and express their grief (Doka \& Martin, 2010). Doka (1989) claims that young people may find that their grief is disenfranchised or not socially recognised, supported or validated.

The nature and quality of social support is an important post-loss factor that influences the impact of suicide loss on young people. Peers appear to have both a positive or negative influence on young people. Peer social support can have either have a protective function helping shape attitudes and beliefs about suicide (for example, belief that suicide is preventable) or reinforce negative and stigmatising attitudes (for example, the belief that suicide is normal or selfish) and prolong grief through co-rumination and encouraging discussion on problems, emotions at the exclusion of activities or discourse (Andriessen et al., 2015).

Jakoby's (2014) online survey showed that there are still a number of barriers preventing survivors from being able to talk and share their grief with others in their social network. She found survivors did not want to talk to others because they did not want to burden people (42.9\%), while others were fearful of sharing their feelings with others $(21.0 \%)$, or did not think sharing feelings was appropriate (18.5\%). A lack of availability of others (28.4\%) and others not asking about their grief (32.8\%) also deterred the bereaved from talking. Jakoby found that a lack of empathy (for example, insensitive comments, awkward silences), a tendency of people to avoid the topic of grief (change topics of conversation or not ask about their grief), and expectations on the bereaved to 'function as normal' contributed to silence in the bereaved. She recommended that further research needs to investigate how gender, age and educational differences influence interpersonal variations in the ability to talk about grief - which is why this study focused on young men's experiences of suicide bereavement.

Emotional closeness to the deceased is another pre-loss variable that influences suicide bereavement (Andriessen et al., 2015; Walker, 2009). Those people who are closer to the deceased have been found to experience more intense grief (Servaty-Seib \& Pistole, 2006), prolonged grief (Levy et al., 1994), complicated grief (Brent at al., 1992) and 
studies have found that grief is higher in peers closest to peers who have died by suicide (Abbot \& Zakriski, 2014). Closeness of relationship has been associated with increased risk of suicidal communication and suicidal plans in adolescents exposed to peer suicides (Ho, Leung, Hung, Lee \& Tang, 2000) as well as the new onset of depression and increased severity of PTSD symptomatology (Brent et al., 1993b).

These studies on pre- and post-loss factors indicate that it is important to explore how attachment, closeness and quality of relationship may affect suicide bereavement experiences and outcomes. Hence the current study's focus on the loss of close friends to suicide. A large body of quantitative research on adolescent suicide survivors has helped identify important variables that influence grief, suicide bereavement process and outcomes, however, there is a paucity of qualitative research on survivors' experience.

\section{Qualitative Studies of the Experience of Grief and Suicide Bereavement}

Coinciding with the paradigmatic shifts in grief theory and growing interest in idiographic approaches to grief, there has been a growing body of qualitative research that explores the experience and meaning of losing a loved one to suicide. This research supplements the traditional quantitative research on assessment of grief symptomatology (Neimeyer \& Hogan, 2001) and the effects of peer or friend suicide bereavement on adolescents. A number of authors have proffered that qualitative studies advance understanding of the experience of suicide bereavement in particular sub-groups (Maple et al., 2014; Maple, Edwards, Plummer \& Minichiello, 2010; Bartik et al., 2013) and provide survivors with a voice to communicate their perspective without the imposition of a researcher's framework or agenda (Edmonds \& Hooker, 1992).

A number of qualitative and phenomenological studies have examined suicide bereavement in adults (Begley \& Quayle, 2007), focused mostly on the experiences of bereaved parents (Walsh \& McGoldrick, 1991) and the meanings parents attach to their loss and adaptation (Braun \& Berg, 1994; Milo, 1997). Phenomenological studies have focused on the experience of grief after bereavement in adults and what it means to lose a loved one (Douglas, 2004; Muller \& Thompson, 2003). These studies of non-suicidal bereavement in adults have provided important insights into the experiences of the bereaved including: what they felt (sadness, feelings of responsibility, shock, anger, missing the deceased, pain, relief and guilt); the effects of their grief (their experience of 
a loss of control, identity crisis, suicidality); coping (things that helped or hindered such as cognitive and behavioural strategies, spiritual beliefs, and social support); their needs (to make meaning, connect with others and to find benefit); and changes they experienced (in perspective, new values and priorities in life, greater appreciation of life and people, personal growth and changes in grief over time). It is unclear, however, whether the findings of these studies can be generalised or transferred to young people and in particular young men, given the samples were middle aged (32-77 years) and included the deaths of family members.

Fielden (2003) conducted the only published New Zealand phenomenological study of suicide bereavement. She explored what it meant to lose a family member to suicide by interviewing six adults (five parents - four mothers and one father, and one sister) who had lost sons or a brother to suicide had been bereaved between 2-9 years. Using a hermeneutical approach she developed a model of grief that showed suicide bereavement to be a transformative process with the bereaved moving through four modes of 'being': Thrown-ness, (experiencing the chaos, shock, disbelief, numbness and paralysis); survival mode (experiencing fear of not being able to come through the experience, living with shame, blame and stigma); searching mode (managing the 'whys', looking for clues and explanations, reflecting and remembering, living with guilt and anger) and moving on mode (creating a new life, focusing attention on the outer world again). Fielden (2003) suggested that the bereaved find new ways of understanding and relating to or 'being' in the world. She recommended that future research explore bereavement in more diverse survivors including those of different cultural backgrounds, those who had different relationships with the deceased, as well as the inclusion of male perspectives.

Compared to research on the effects of suicide on young people, relatively few studies have explored grief and suicide bereavement experiences in late adolescents or young adults. Bartik et al. (2013) state: "The bereavement experience of young people affected through the suicide death of a friend remains under-conceptualised and not well understood" (p. 211). Only a handful of studies have been conducted that explore the suicide bereavement experiences of young people (Bartik et al., 2013; Hoffman, 2004). These studies have focused mostly on the experiences of young women (Hoffman, 2007; Hoffman, Myburgh \& Poggenpoel, 2010) or have included participants who have lost 
close friends and relatives (mixed decedents) assuming that these 'significant relationships' are of similar quality and nature.

For example, Bartik et al. (2013) conducted a narrative study using in-depth interviews with ten young adults (16-24 years) ( 8 females and 2 males) who had collectively lost 22 friends and two family members to suicide. Their analysis revealed four key themes: meaning making, feeling guilt, risky coping behaviours, and relating to friends. Young survivors struggled to make sense of their friend's suicide, felt guilty about not having done more to prevent their friend' suicide, and experienced an increase in the use of alcohol and other drugs and risky sexual behaviour as a temporary escape and relief from their distress. Participants described experiencing difficulties relating to friends and others who did not understand or know how to respond; this had an impact on social relations. Others reported developing a deeper appreciation for their close friends and supportive peers (Bartik et al., 2013).

Hoffman's (2004) South African psychological phenomenological study explored five female late adolescents (17-22 years) suicide survivor's emotional experiences, meaningmaking and coping behaviour. These young college-based women all lost a significant other (close friend or family member) to suicide within the 6 months of the interview. Hoffman (2004) collected data using collage-facilitated face-to-face phenomenological interviews and Giorgi's $(1985,1989,1997)$ phenomenological method to analyse the data. Hoffman (2004) highlighted three experience clusters: (1) lived experiences that seem to worsen over time, (2) 'disorganisation' of lived experience that involved a struggle to cope and adjust to a changed life, and (3) 'healing' lived experiences that involved effective integration and adaptation to a changed life.

Hoffman et al. (2010) conducted a further analysis of the data from Hoffman's (2004) study and identified some key elements of the young women's experience of suicide bereavement (loss of significant other). They reported that the young women experienced guilt (remorse, negative self-evaluations); self-blame (if only's, and feelings of responsibility); blaming others or God (to displace anger and guilt, disillusionment and loss of faith); anger (towards the deceased for their perceived abandonment/rejection and for an unfinished relationship) and loss (of a part or sense of self, of emotions and a future). The young women also experienced depression (crying, sadness, decreased 
motivation, hopelessness, failure); suboptimal coping patterns (increased smoking, social withdrawal, alcohol misuse); changed relationship dynamics (superficial relationships with others, increased interpersonal conflict, social distancing, social stigma) and suicidality (suicidal thoughts, wanting to be reunited with the deceased) that worsened over time. While Hoffman et al (2010) only focused on female survivor's experiences and took a snap-shot of their experience, it nonetheless provides a deeper understanding of what it is like for late adolescents to lose a loved one to suicide. Hoffman et al. (2010) highly recommended exploring the experiences of adolescent male survivors and longitudinal studies regarding the course of suicide survivor bereavement.

\section{Young Men's Experiences of the Death of a Friend or Peer.}

A significant gap in the literature exists around young men's experiences of grief, the death of a close friend or peer, suicide bereavement and peer or friend suicide bereavement. Studies of young men's experiences of grief have tended to focus on young men's experiences of accidental, sudden or unexpected deaths (including suicide, homicide, drug overdose) of friends/peers and have not explored suicide bereavement.

Bragdon (2006) conducted a phenomenological study of the experiences of 12 university/college males (ages 18-22 years) which included an ethnically diverse sample of men who experienced the sudden and unexpected death of a male friends. The study revealed a range of themes including: increased risk-taking behaviour, avoidant coping strategies, projection of anger, developing a story about the deceased, new learning and growth from the experience, the importance of rituals and continuing bonds, and a lack of good guidance and support from others.

Creighton, Oliffe, Butterwick and Saewyc (2013) explored 25 young men's (19-25 years of age) experiences of grief following the tragic accidental deaths of friends (by motor vehicle accident, adventure sports, drug overdoses and fights). They found the predominant grief responses in men were emptiness, anger, stoicism and sentimentality: the young men struggled to reconcile feelings of vulnerability and masculine ideals of strength and stoicism and developed a post-loss masculine identity. The men described the sudden loss of their friends as switching off the manly virtues of strength, decisiveness and self-regulation. They were concerned with being publically seen as less of a man for showing their vulnerability and this meant they withdrew socially until they regained their 
composure and "manned up". Their loss also created an opportunity for them to reinvent themselves and to rethink how they engaged with their dominant discourses of masculinity. Creighton et al. (2013) suggested the need for future studies to further explore gender differences as well as similarities in grief among young people.

More recent qualitative studies have highlighted that young men's risk taking behaviour and health practices may be influenced (increased or decreased) by grief and the loss of a friend (Creighton, Oliffe, McMillan \& Saewyc, 2015; Creighton, Oliffe, Matthews \& Saewyc, 2016). Creighton et al. (2015) found men who were grieving the loss of male friends (to accidental deaths) adopted two different responses. Some young men engaged in hyper-masculine performances of risk, accepted death and emphasised that they remained unchanged, undamaged and committed to living life in the moment. Others decreased their risk practices and had a renewed or new appreciation for their surroundings and the people around them. They drew on masculine ideals of rationality and responsibility for others (Creighton et al., 2015).

In a later study of a larger sample of 35 men (19-25 years old) and 22 men (26-35 years old) who lost close male friends to accidental deaths, Creighton et al. (2016) explored how young men used alcohol in their grief process. They found men used alcohol to dull their pain (drink their feelings away) and purge sadness (alcohol facilitated the expression of grief and connect with their sadness). Over time their alcohol use became problematic (increased frequency and binge drinking, increased dependency and disruptive of work and social relationships). Findings showed "alcohol use constitutes a masculine practice in the context of grief for young men, both to suppress and to express feelings of sadness, vulnerability, and loss" (Creighton et al., 2016, p. 59). The researchers recommended that health interventions for grieving men (who have lost a male peer) need to be sensitive to gender norms that influence grief practices and need to promote recovery and wellbeing (Creighton et al., 2016).

While these studies have contributed to our understanding of the ways young men grieve and respond to the death of friends, and masculine practices, they have focused on accidental deaths (drug overdose, motor vehicle accidents) and/or included deaths from illness and homicide. These deaths, which can be sudden and traumatic, are different from suicide in the effects they have and the experience of bereavement. In these studies the 
phenomenon explored was bereavement following a "sudden death". In other studies, such as Bragdon's (2006), not all of the deceased were "close friends"; some were described as being part of the participant's social and peer networks and that their connections were through social connections and activities (sports, clubs). These studies have made a valuable contribution to understanding young men's responses to bereavement; their findings, however, cannot be generalised to young men's experience of suicide bereavement given the unique aspects of suicide bereavement (Jordan, 2001; Jordan \& McIntosh, 2011b).

\section{Young men's experiences of friend or peer suicide bereavement.}

At the time of this research I could find only one study that specifically focused on young adult's experiences of a friend or peer suicide bereavement that included a sample of young men. Mallom and Stanley (2015) conducted a study of suicide bereavement in 12 British young adults (20-37 years old) (seven men and five women) using a universitybased population. They found that young people either immediately accepted or understood that their friend's death was a suicide (because they had seen the body) or engaged in a personal inquest (struggle to understand why, to decide whether it was intended or accidental) to determine whether the death was a suicide.

While Mallom and Stanley's (2015) study highlighted the ways some young people engage with the suicidality of another and their struggle to make sense of the event, it did not provide a full and rich description of the phenomenon of suicide bereavement in young men who had lost a close friend. To my knowledge, no studies have been conducted that focus on describing what it is like for young men to lose a close friend to suicide. Before we can begin to interpret men's experience we first need to access lived experience descriptions (LEDs) and hence, a descriptive phenomenological study of young men's experience of losing a close friend to suicide is warranted.

\section{Chapter Summary/Synthesis of the Literature}

The research and literature on grief and bereavement demonstrates that there are some unique aspects of suicide bereavement that make it different from other forms of bereavement (Jordan, 2001; Jordan \& McIntosh, 2011b). There are also many pre- and post-loss variables that influence the nature of bereavement and grief including the type of death, closeness and quality of relationship with the deceased (Andriessen et al., 2015). 
Modern perspectives on grief suggest that while there are some idiographic aspects to grief and adaptation to loss, there are also some important patterns in how people express, cope and manage grief. These patterns may be gender-influenced but not gender-specific (Doka \& Martin, 2011).

Scholarship in the field of gender, masculinity and health informs us that gender is socially and culturally constructed, masculinity is something men do or practice, and traditional or hegemonic masculine norms influence men's health, help-seeking, and how men experience, express and adjust to grief (Connell \& Messerschmidt, 2005; Courtenay, 2000a, 2000b; Creighton \& Oliffe, 2010). Developmental literature shows how important friends are in the lives of young people (Arnett, 2014).

Quantitative research indicates that deaths and suicides of friends or peers is common amongst young people (Balk et al., 2010; Rheingold et al., 2004; Servaty-Seib, 2009) and that young people may struggle to cope with bereavement (Balk \& Corr, 2009). Furthermore, friend or peer suicides increase the likelihood of young people experiencing negative health outcomes including: traumatic and/or complicated grief, depression, PTSD and suicidal thinking (Brent et al., 1993b, 1994, 1995). Bereavement research shows how young people's grief (especially that for friends) is often marginalised, invisible and understudied.

A small amount of qualitative research has highlighted a number of key themes in young survivor's experience of suicide bereavement including: guilt, anger and blaming; the struggle to make sense of their loss, risky behaviour and coping problems, stigma and problems with social relationships, and positive and negative personal transformation (Bartik et al., 2013; Bragdon, 2006; Hoffman, 2004, 2007; Hoffman et al., 2010; Mallom \& Stanley, 2015; Maple et al., 2010, 2014). A few studies on young men's experiences of friend or peer bereavement show that masculinity influences how men experience, express and manage grief (Creighton et al., 2013, 2015, 2016). Coleman (2015) states: "Given these marked differences by gender, surprisingly little suicide research makes the dynamics of gender and suicide a central analytic focus" (p. 368). Other scholars have also identified an invisibility of men in suicide related research and policy (Bilsker \& White, 2011; White, 2002). 
This chapter has highlighted the need for research to focus on exploring the experiences of young men who have lost close friends to suicide. In particular, it has shown the perspectives and experiences of young men are missing from the research. This chapter has demonstrated a need for further qualitative and descriptive research that will advance understanding of what it is like for young men to lose a close friend to suicide and how masculinity may influence their bereavement experience. The following chapter, outlines the research methodology chosen for this present study - descriptive phenomenology and methodological considerations. 


\section{CHAPTER THREE: RESEARCH PHILOSOPHY AND METHODOLOGY}

\section{Introduction}

In chapter two, a review of the literature demonstrated there is a paucity of research on young people's experience of suicide bereavement, and in particular a lack of studies that explore men's experiences of losing a close friend. There is a need to better understand the phenomenon of suicide bereavement in young men as it has been lived and experienced by them. The current study explored the experiences of young men who lost a close friend to suicide within the New Zealand context.

This chapter describes the aim of my research and the research questions; the research framework, the origins, evolution and key principles of my research philosophy (phenomenology). It also describes the methodology or approach (primarily descriptive phenomenology) that underpins my study. Methodology often includes the underlying assumptions and a justification guiding the choice of research methods (Alvesson \& Deetz, 2002). Justifications for the use a phenomenological approach for this study are presented. In the following chapter, chapter four, I describe the pragmatic aspects of the research methods used including: sampling, the challenges of recruiting a hard to reach and vulnerable population, challenges encountered and the procedures, instruments and methods used to collect and analyse empirical material (Alvesson \& Deetz, 2002).

\section{Research Aim and Questions}

The aim of the research was to learn more about the nature and experience of losing a close friend to suicide. I used a qualitative, descriptive, explorative and contextual research strategy with a phenomenological psychological approach to inquiry (Creswell, 2007 ) to explore the lived experience of losing a 'close friend' ' to suicide in young men aged 17-25 years.

${ }^{2}$ A 'close friend' was generally defined as a friend (rather than an acquaintance or peer), whom the men had personal and regular contact with, and shared an attachment, or bond with. Close friends were self-identified and/or identified by family of the deceased. 
The research questions guiding my study were: "What are the experiences of young men who have lost a close friend to suicide?" and from the perspective of young men, "What is the essential structure of the lived experience of losing a close male friend to suicide?" and "What does it mean to lose a close friend to suicide?" A phenomenological psychological approach was chosen because of its focus on the psychological meanings of research participants' lived experiences in their particular life worlds (Giorgi, 1997, Kruger, 1988). A qualitative methodology was best suited to this study because the aim of the study was to explore and describe how young men experience suicide bereavement related to the loss of a close friend; young men's accounts and descriptions of their experience are missing from the discourse on suicide bereavement.

\section{Research Philosophy and Paradigm}

Research philosophies provide researchers with the lens through which researchers think about, study and understand and phenomena. There need to be a synergy between all aspects of research; thus, it is important for researchers to articulate and justify their research philosophy, methodology and methods (Koch, 1999). A researcher's philosophy is based on ontological, epistemological, and methodological assumptions and it shapes the aims of research as well as research methodology and methods (Gray, 2014).

Research paradigms are a sort of world view that guides an inquiry but they need to be seen as constructions, fallible and persuasive (Guba \& Lincoln, 1994). It is possible for researchers to work across paradigms to a certain degree and need not be fixed hard and fast to the beliefs and practices of any single paradigm (for example, positivist/postpositivist, critical theory, constructivism/interpretivism). In the Western tradition of science, there are four major research philosophies or paradigms. The Post-positivistic paradigm is characterised by determinism, reductionism, empirical observation and measurement and theory verification. The Constructivist paradigm is characterised by a focus on understanding; beliefs that there are multiple participants' meanings and that truth and reality are social and historical constructions, and that research should focus on theory generation. The Transformative paradigm is characterised by a focus on power and 
justice, research as political, collaborative and change-oriented. The Pragmatist paradigm is characterised by a focus on problems and the consequences of actions, a pluralistic approach, and the application of real-world practice) (Creswell, 2014).

The aim of the present study was to understand the men's lived experience, the way their reality appeared to them. I wanted to describe the essence of the experience of eight men, and the core components or structures that make up that essence to deepen our understanding of what the phenomenon is like from their point of view. For this reason, a constructivist and descriptive phenomenological approach was adopted.

\section{My research philosophy and paradigm: Constructivism.}

In order to understand, locate and develop my own research philosophy and philosophical stance I read the philosophical works of German philosophers, Husserl (1970, 1976; Kohak, 1978), Heidegger (1962) and Gadamer (1976, 1989); this was a useful starting point for exploring my ontology (beliefs about the nature of reality) and choice of constructivist framework for guiding analysis of my data. I used Guba and Lincoln's (1989) description of ontology, epistemology and methodology and Creswell's (2014) discussion of world views and research perspectives to locate my position and guide the development of my primarily descriptive research process. As Sandelowski (2010) argues qualitative descriptive research is never only descriptive, it also involves a level of interpretation and is important for the knowledge it can produce. I also read the works of other phenomenological researchers such as Colaizzi (1973), Giorgi $(1985,1989,1997)$, Giorgi and Giorgi, (2003), Moustakis (1990, 1994), Finlay (2011), van Manen (1990, 2014) and Smith (2003, 2007) before deciding on which phenomenological methodological approach to take for collecting and analysing the data.

The main epistemological beliefs underpinning my research are based on constructivism (Creswell, 2014) because of its fit with my beliefs about the world and how it can be known. Constructivists believe individuals construct their own understanding (meaning) of the world reality through their interactions with the world and with others (Merriam, 2009). I accept the ontological assumptions associated with constructivism and the idea that because people interpret reality in different ways then multiple realities exist that are time and context specific (Gray, 2014). I believe that understanding of reality is subjective, relative and constantly changing. 
A researcher adopting a constructivist epistemology would argue that there is no single, timeless truth existing 'out there', independent of an observer or his/her particular theoretical or philosophical method, waiting to be discovered using scientific procedures. As a constructivist researcher I assume that reality is socially constructed, and that there is no single observable reality that can be objectively known. I do not believe that I can "find" or discover knowledge, but rather that knowledge is constructed. Constructivists contend that reality can only be understood by accessing the subjective interpretations of that reality. Therefore, according to my constructivist position there is no single meaning of 'suicide bereavement', 'grief' or 'loss of close friend' out there to be discovered or uncovered. I can only access men's description or accounts of their lived experience and the meanings they ascribed to these experiences.

The focus of this study is on individuals and their conscious experience of their life-world. According to Merriam (2009), descriptive phenomenologists are concerned with understanding experiences as they are lived, that is, their pre-reflective experience. Other hermeneutic phenomenologists are interested in understanding how those experiences are transformed into consciousness, how they are interpreted and their meanings (Merriam, 2009). I wanted to explore and describe the men's pre-reflective experience, their experience as it is given to them, and the invariant structure or essence of that experience.

When describing the phenomenon of suicide bereavement and trying to understand the phenomenon, the central question is to ask 'what is happening here?' A constructivist approach suggested that I needed to encourage participants to describe their experience and ask them to tell me about their lived experience. For this reason I chose to carry out this study using a qualitative methodology and methods so that I would be able to describe and gain an understanding of those experiences.

A constructivist position meant that the inquirer (myself/the researcher) and the subject of inquiry (phenomenon) are interlocked in such a way that the findings of an investigation are the creation of a process of their coming together (Koch, 1994). When I enter the participant's world, we co-construct knowledge, sharing our understandings of the world (Smith \& Osborn, 2008). Together, with participants, I planned to create a construction (a research product, narrative or story) and perhaps we would reach 
consensus about the construction of reality that makes the most sense. This may be a construction of their experience that gives the reader a new understanding of the world.

Taking a constructivist position meant engaging my whole self in the research, including my understanding of what is real and what is important in life, making my assumptions about the phenomenon clear. Both participants and researchers take with them into the interpretive act, self-awareness, this sense of what is real, and what it means to be a human being in the world (Koch, 1999). Constructivism is based on the idea that there is no single objective 'Truth'; truth is whatever the participant says it is or the best of competing interpretations (Koch, 1999). Constructivists admit that there may be many different interpretations of reality and that these interpretations help build scientific knowledge (Levin, 1988). In adopting a constructivist philosophy it was important to remember that my own account of the men's experience should also be considered a construction and that researchers present a specific version of social reality rather than one which is definitive and non-contestable (Bryman, 2008).

There is a good fit between the constructivist philosophy and my own world view; but there were two additional reasons for choosing this research philosophy/paradigm. First, a constructivist paradigm has made a significant contribution to the philosophy of phenomenology and to its development as a research method in the social sciences. For example, constructivism draws attention to the unique experience of the individual (suggesting that each person's way of making sense of the world is valid, to be respected) (Crotty, 1996). Second, nursing, health-related, and suicide research has been dominated by positivist research. However, in the last two decades the numerous benefits of constructivist approaches and qualitative research have been acknowledged and demonstrated in healthcare research (Everest, 2014).

\section{Qualitative Research Methodology}

Research methodologies, or the general approach or way to research a topic is often distinguished from research methods, the specific techniques employed (to collect and analyse data, report findings, and so on) (Langdridge, 2007). Methodologies (like research philosophies) guide and structure research and shape all aspects of the research inquiry process: the choice of problem, paradigm to guide the problem, theoretical framework; the types of research questions asked; choice of major data-gathering and 
data-analytic methods; choice of context, treatment of values already present within the context, and choice of format for presenting the findings (Given, 2008; Gray, 2014). It is important for researchers to ensure there is synergy between the research methodology, philosophy/paradigm and methods and that researchers make their work transparent, open to critique, replication, adaptation (Given, 2008). Choice of research methodology and methods is also influenced by the nature of the research questions and practical reasons (Kasinath, 2013).

There are two main types of research methodologies, qualitative and quantitative. Qualitative methodologies are different from quantitative methodologies in terms of philosophy, research aims and questions, designs and data gathering criteria and techniques (Ayres, 2007). Qualitative methodologies differ from the objective quantitative methodologies that require rigidity and objectivity and focus on explanation, hypothesis or theory testing. Qualitative research is often based on constructivism (Bryman, 2008), is flexible, subjective (Gray, 2014; Streubert \& Carpenter, 2007), inductive (Patton, 2002) and has an emphasis on discovery/exploration, description and meaning of complex human phenomena and the world (from the perspective of those experiencing it), rather than prediction, control and measurement (Gray, 2014; Laverty, 2003). Researchers who adopt a qualitative approach see reality as socially constructed, complex and dynamic and believe there are multiple realities (Streubert \& Carpenter, 2007). Qualitative researchers tend to acknowledge and embrace subjectivity through reflexive practice (Elliot, Fischer \& Rennie, 1999); they know they affect the participants, the research process and the findings (Parker, 1994).

The focus of qualitative research is often human experience, the lived experience of individuals and groups, but in particular, the personal and social meanings of those experiences (Ashworth, 2003a; Hesse-Biber \& Leavy, 2006). Qualitative descriptive studies aim to offer a comprehensive and accurate summary or account of an event or phenomenon in the everyday terms of those events but also the meanings attributed to those events or experiences (Gray, 2014; Sandelowksi, 2000). In-depth explorations of experience leads to the development of a narrative that is rich in data, detail and description (White, 2011). Some qualitative methodologies, such as phenomenology or grounded theory, require researchers to move farther into or beyond the data, to read into, between and over the words of participants, transforming the participant's description of 
an event or experience into a researcher's phenomenological or grounded theory description of that event/experience (Sandelowski, 2000).

There is no single qualitative methodology or approach to doing research, rather there is a family of approaches that have been developed under the qualitative umbrella. These approaches often used in health, nursing and psychological research include: ethnographic research, case study, phenomenological research, grounded theory, clinical research, participative inquiry, action research, narrative analysis and others (Denzin \& Lincoln, 1994, 2008). All of these approaches tend to rely on linguistic rather than numeric data and use meaning-based rather than statistical forms of data analysis (Elliot \& Timulak, 2005).

Different qualitative approaches/methodologies utilise a range of methods to collect and analyse data. These methods provide the researcher with a gateway to the experiences of the people studied (Boss, Dahl \& Kaplan, 1996). Data may include interview transcripts, documents, video recordings, photographs, reflective diaries and other artefacts as well as field notes that record both the participants' and researchers experiences and personal reflections (Saldana, 2011). The following section outlines my rationale for choosing a qualitative methodology; this chapter then goes on to explain my choice of phenomenology as an appropriate qualitative methodology and method.

\section{My research methodology.}

A qualitative research methodology was appropriate for the purposes of this study and exploring young men's lived experience of losing a close friend to suicide. Very little is known about the suicide bereavement experiences of young men. Thus, I decided to conduct an exploratory and descriptive study (Gray, 2014) of the experience. Exploratory studies and research questions are suitable for baseline qualitative studies: when there is little known about an area (Gray, 2014); when existing research is confusing, contradictory or failing to make progress; and when the topic is highly complex (Barker et al., 2002). This study also fits with two of the five types of qualitative research described by Elliot and Timulak (2005): (i) definitional research: that seeks to define the nature or key features of a phenomenon; and (ii) descriptive research that seeks to describe the key aspects of the phenomenon. 
I also chose to take a primarily descriptive phenomenological approach to study the experiences of suicide bereavement in young men because of its fit with the research problem and questions, my personal philosophy and skills as a researcher and for its potential to advance knowledge of the experience of suicide bereavement in young men. Phenomenology has also been recognised as a methodology and method of research that can illuminate the less tangible meanings and intricacies of the social world and is of particular benefit in the field of health and therapeutic practice (Finlay, 2011). The next section describes the tradition of phenomenology, its origins, evolution and how it is a philosophy and a method of research inquiry.

\section{Phenomenology as a Philosophy/Method of Inquiry}

Phenomenology is one of five approaches to research based on a constructivism/interpretivism epistemology, the other approaches are: symbolic interactionism, realism, hermeneutics and naturalistic inquiry (Gray, 2014). Phenomenology is a theoretical perspective and a method of inquiry for advancing understanding of conscious experience, within the first-person context. It has been used by philosophers and researchers focused on the lived experience of human existence from the perspective of the person experiencing the phenomenon (known as "lived experience").

\section{The aim and focus of phenomenology.}

The aim of phenomenology is understanding (rather than explaining or predicting) human experiences as they are lived through in the everydayness of a person living in the real world (van Manen, 2014). Phenomenology is considered central to the constructivist/interpretive research paradigm (Denzin \& Lincoln, 1994; Koch, 1995) and is both a philosophical movement/tradition and a qualitative research methodology (Merriam, 2009). As a philosophy it suggests to us how we should see the world, but as a methodology it suggests ways in which we can conduct qualitative research (Dowling, 2007). As a methodology: "It is rigorous, critical and systematic study of the 'essences' of life experience" (Cutcliffe, Joyce \& Cummins, 2004, p. 308).

Phenomenology as a philosophy and research methodology does not seek to categorise, predict or explain human behaviour (like quantitative and positivistic approaches), nor does it seek to generate theory (like Grounded Theory approaches). It seeks to solely 
advance or deepen understanding of what it means to be human, and to capture that in all its richness, as it is 'given' to the people who experience it, and in all its layers of meaning' (Finlay, 2011). Phenomenology is the study of perceptions or the 'things in their appearing' (Langridge, 2007, p. 11), the presence of phenomenon as it is given or experienced by the individual (Giorgi, 1997) and how human experience comes into consciousness (van Manen, 1990). Phenomenologists study the everyday and lived experiences of individuals, and their perceptions of their life world (or the meanings they ascribe to their experiences) (Streubert \& Carpenter, 2007). Phenomenologists focus on producing 'thick descriptions' of individual's experiences and perspectives within their natural setting (Gray, 2014) and through careful examination of the qualities of those experiences, they identify the essence of that experience (Balls, 2009).

\section{The history and evolution of phenomenology.}

Phenomenology began as a philosophical approach to inquiry in Europe in the $19^{\text {th }}$ Century and its founder is widely acknowledged as being Edmund Husserl (1859-1938), a German transcendental philosopher who wanted to forge a new science that moved away from positivism (Finlay, 2011). Husserl (1976) saw phenomenology as a way of finding true meaning through penetrating deeper into reality. Husserl believed that scientific inquiry could provide an accurate description of phenomenon 'things themselves' or 'the world of experience as lived' (prior to their interpretation) and this could advance understanding of human consciousness and experience (Husserl, 1976; Dowling, 2007). These rich descriptions of phenomenon allowed people to get closer to the essence of it, the essential, unvarying nature of a phenomenon, and thus, understand it. The overall aim of lifeworld research is "to describe and elucidate the lived world in a way that expands our understanding of human being and human experience" (Dahlberg, Dahlberg \& Nystrom, 2008, p. 37).

The phenomenological movement split between early phenomenologists who believe that experience is transcendental (for example, Husserl) and later phenomenologists such as Heidegger who believed it is interpretive and by subsequent philosophers such as van Manen and Merleau-Ponty (Connelly, 2015). Over time they modified, critiqued and developed Husserl's approach to philosophy and research methodology (Wojnar \& Swanson, 2007). There are important differences between the branches and different schools of phenomenology. For example, interpretive (hermeneutic) phenomenologists 
such as Heidegger, argued that the importance of phenomenology lies in interpretation and understanding, rather than description of consciousness and experience (Finlay, 2011).

While all phenomenology includes an element of description of human experience of the phenomenon in question, hermeneutic phenomenology goes beyond seeking to understand the core concepts or essences of a phenomenon. Interpretive phenomenologists believe it is impossible to transcend or completely "bracket" personal knowledge, bias and preconceptions about a phenomenon and be able to approach a study in a completely blank and neutral way (Balls, 2009). While interpretive and descriptive phenomenology both involve the researcher and the participant talking about and exploring the essence pf the experience of phenomena, interpretive phenomenologists enter into a dialogical relationship to better understand the meaning of that experience (Benner, 1994). This is in stark contrast to descriptive phenomenology which proposes that the researcher must remain (as much as possible) objective and detached in order to transcend biases, presuppositions and reflections/interpretations so s/he can see the core structures and essence of a phenomenon (Koch, 1995). The key differences between the two main phenomenological traditions (descriptive and interpretive/hermeneutic phenomenology) that are widely used in health and social science research have been described elsewhere (Koch, 1995).

In the last two decades a new hybrid or non-pure form of phenomenology as a research method has developed in the USA. Crotty (1996) has called this 'new phenomenology', while others have called it 'scientific phenomenology' (Giorgi, 2000) and 'American phenomenology' (Silverman, 1987). This form of phenomenological methodology emerged from nursing research and Crotty (1996) argued that it is not pure phenomenology in the European sense of the tradition. He argues it cannot be classified as phenomenology because it does not adopt the philosophical situation (phenomenological reduction) regarded by Husserl to be critical to any form of phenomenology (Dowling, 2007). Crotty criticised the new forms of phenomenology as being descriptive, subjective and lacking critique and was critical of their combination of symbolic interactionism, humanistic psychology and descriptive phenomenology. 
Van Manen (1990, 2014) has also developed an approach to phenomenology that emphasises phenomenology as practice, and is more concerned about it as a research methodology (than philosophy). Van Manen draws attention to the importance of phenomenological writing and proposes that the way to get to the essence of a lived experience if through writing and rewriting about the phenomenon, dwelling with the data, and paying close attention to the words and language used to describe the phenomenon (Van Manen, 2014). Phenomenology also developed in the North American tradition to examine the experience of others, which is reported in third person and was shaped by researchers with a pragmatist philosophy, symbolic interactionism perspective and those working in humanistic psychology (Barkway, 2001).

Today there are many different philosophical schools of thought within phenomenology including: descriptive (transcendental constitutive), naturalistic constitutive, existential, generative historicist, genetic, hermeneutic (interpretive) phenomenology, and realistic phenomenology (Wojnar \& Swanson, 2007). All of these different types of phenomenology are located in different research paradigms including the positivist (Husserl), post-positivist (Merleau-Ponty), interpretivist (Heidegger) and constructivist (Gadamer) paradigms and have led to different phenomenological approaches to research and ideas about how best to understand lived experience (Dowling, 2007). The following section outlines the key ideas and principles in Husserl's descriptive phenomenology which was the philosophy and methodology that principally informed the present study.

\section{Husserl's Descriptive (transcendental) Phenomenology}

Descriptive phenomenology was developed by the German philosopher Edmund Husserl (1859-1938) who is considered to be the founder of phenomenology as a philosophy and the descriptive (eidetic) approach to phenomenological inquiry (Dowling, 2007). Husserl's definition of phenomenology was the study of how people describe things and how they experience them through their senses. Husserl contended that we can only know what we experience and that researchers need to focus on perceptions of experience and the meanings associated to experiences. According to Husserl (1976), the objective of phenomenology is to provide a clear undistorted description of the way phenomena or the things themselves, appear to people in consciousness, or how they are genuinely perceived prior to interpretation and the giving of the meaning of that experience. Husserl (1976) defined phenomenology as "the science of essence of consciousness" and 
proposed that it should focus on intentionality, or the meaning of lived experience, from the first-person point of view.

A key idea in phenomenology is that body and world are intimately intertwined (Finlay, 2011). It is not possible for researchers to study either of these objectively or without considering the influence of the other. As van Manen (1990) has noted:

A lived experience does not confront me as something perceived or represented; it is not given to me, but the reality of lived experience is there-for-me because I have a reflexive awareness of it, because I possess it immediately as belonging to me in some sense. Only in thought does it become objective. (p. 35)

Descriptive phenomenologists are concerned with 'objective meaning' - that is the meaning of experiences as presented, or given to the consciousness of the individuals who experience them. The following example from Giorgi (1997) helps illustrate this concept: Person A may view a painting and calls it ugly; person B views the same painting and calls it beautiful. For person A, the painting has the phenomenal properties of ugliness, and for person $\mathrm{B}$, it will have the phenomenal properties of beauty. However, from a phenomenological perspective (and the researcher's perspective), no claim is made that the painting is in itself ugly or beautiful; only its presence for the experiencer counts, and an accurate description of the presence is the phenomenon, and it usually contains many phenomenal meanings (Giorgi, 1997).

\section{Human experience of lifeworlds.}

A key concept in Husserl's descriptive phenomenology was Lebenswelt or the lifeworld (Husserl, 1976). The lifeworld is made up of objects around us as we perceive them, or the world as it is lived and experienced, not a world that is objectively out there, but a world that appears meaningfully in consciousness (Finlay, 2011). "Phenomenology invites us to slow down, focus on, and dwell with the 'phenomenon'- the specific qualities of the lived world being investigated." (Finlay, 2011, p. 3). For example, in order to understand what a particular phenomenon is like, (for example, dying of cancer, being pregnant) phenomenologists do not inquire about some inner, subjective realm but rather seek to access experience of the lived world.

The aspects of a lifeworld that phenomenologists are interested in studying that lead to a better understanding of what it means to be human, include: a person's sense of 
selfhood/identity, embodiment, sociality, spatiality, temporality, project, discourse and mood-as-atmosphere (Ashworth, 2003b). These interlinked fractions of a lifeworld make up a lens through which to view a phenomenon, and it is the role of the researcher to look at these in terms of the parts and whole, and how they are experienced individually and shared socially by people who experience the same lifeworld or share the same lived experience (Finlay, 2011).

Husserl (1976) argued that phenomenology should focus on understanding pre-reflective lived experience and the lifeworld of individuals rather than interpretation of that experience or lifeworld, or the cultural context that shapes interpretation. In the context of the present study that would mean focusing on the young men's descriptions of their experiences of losing a close friend to suicide rather than their interpretations, thoughts, ideas about that experience. Transcendental phenomenologists argue that it is possible to transcend individual interpretations of an experience or phenomenon and get a birds-eye or gods-eye view of that experience/phenomenon. Later, the followers of Husserl's philosophy emphasised that researchers should refrain from judgment (using the process of bracketing) and examine phenomena through a scientific description of the experiences (Dowling, 2007).

\section{Phenomenology as a Method of Inquiry or Research Methodology}

Phenomenology is not just a philosophy it is also a research methodology that has been used to study phenomenon in health care, nursing, psychology and education (Connelly, 2010). Phenomenologists tend to agree that the lived experiences of the world are not open to an empirical or positivist approach to research, and therefore, a phenomenological methodology is used to capture and reveal how people experience the world they live in (Rapport \& Wainright, 2006).

Phenomenology does not provide researchers with a correct method to follow but rather a methodology (Polkinghorne, 1989) that allows researchers to be creative and responsive to particular questions and subject matter (Laverty, 2003). This flexibility has led to many different research methods and techniques used under the banner of phenomenological research (not all of which would fit under a purist approach) (Finlay, 2009) and to debate and criticism. For example, some researchers state that they utilise a phenomenological research design without specifying a specific phenomenological philosophy or tradition. 
This lack of connection to philosophy and epistemology has led to the recommendation that all phenomenological researchers be clear about what philosophical or research traditions they are following (Finlay, 2009).

For example, Bragdon (2006), in one of the only studies to focus on young males (18-22 years old), examined their experience of grief and bereavement after the sudden death of a peer (through suicide, drug overdose, car/vehicle accidents, illness and homicide). Bragdon presented four major themes from the twelve young men's lived experience (release, friends, rituals and ceremonies, and grief) which were reported to make up the essence of their experience. She used phenomenological methods such as bracketing, alongside other qualitative strategies such as member checking and triangulation. However, she did not articulate the philosophical foundations of her phenomenological approach to the study or data analysis, and did not present an exhaustive description of the essence of their experience. Therefore, it remains unclear what her philosophical perspective was and how this may have shaped her methodology and findings.

It is possible for researchers to conduct qualitative research using just the tools of phenomenology (for example, bracketing of prior beliefs, analysing experiences looking for essences of lived experience) to get to the basic structure and meaning of experiences (Merriam, 2009). This has led to criticism of researchers who are unable to demonstrate how their research methodology (for example, use of bracketing) is linked to and has been developed out of phenomenology as a philosophy (for example, the ideas of Husserl) (Giorgi, 2000). Finlay (2009) clearly argues that for a phenomenological method to be sound it needs to link appropriately to some phenomenological philosophy or theory and the researcher's claims about method need to be justified and consistent.

To complicate matters, the different schools of phenomenological philosophy have also led to the development of different approaches to research. For example, Giorgi (1985) was a proponent of descriptive Husserlian method and his work led to the development of the Duquesne approach or tradition. Others have embraced and developed hermeneutic, existential approaches that led to the development of the Dallas School (van Manen, 1990, 2014); the open lifeworld approach (Ashworth, 2003a, 2003b; Dahlberg et al., 2008) and Interpretive Phenomenological Analysis (IPA) (Smith, 2007; Smith \& Osborn, 2008). 
Scholars and researchers in these different schools have developed their own rigorous methods for analysing data. For example, there are specific methods of phenomenological analysis based on descriptive phenomenology (Colaizzi, 1978, Giorgi, 1997, Spiegelberg, 1975). Some of these methods of data analysis involve processes such as: (a) intuiting, (b) analysing, and (c) describing. Some researchers adhere closely to Giorgi's phenomenological psychological $(1989,1997)$ framework, while others have adapted methods to suit their own studies.

Phenomenological studies may also vary in terms of their focus on description and interpretation. Studies that include both description and interpretation can be seen as problematic by purists who argue that researchers need to stick to one philosophy and methodology. However, Finlay (2009) sees description and interpretation as existing along a continuum where specific research may be more or less interpretive. Van Manen (1990) suggests that interpretation is more strongly involved in description that includes expression through action, artwork or text. However, he draws on Gadamer's hermeneutic ideas, when he distinguishes between interpretation as 'pointing to something' (interpretation suited to phenomenological description) and interpretation as 'pointing out the meaning of something' by imposing an external framework (such as when offering a psychological interpretation). The current study is more focused on 'pointing to something' the essence of the experience - rather than pointing out the meaning.

The diversity of phenomenological approaches to data collection and analysis has led to much debate about what distinguishes phenomenological approaches from other forms of qualitative inquiry that focus on subjective experience and meanings. For example, Giorgi (1989), argues that the following are necessary for a study to be considered phenomenological: being descriptive, exploring intentional relationship between the person and his/her lived experience/world, the use of phenomenological reductions, and providing knowledge of psychological essence of structure or meaning in human experience through the use of imaginative variation (Giorgi, 1989). For Giorgi (1997) the phenomenological method involves three important interlocking steps: phenomenological reduction, description and the search for essences. 
Others have described what they consider 'key' but not 'core' characteristics of phenomenological inquiries (Finlay, 2011; Swanson-Kauffman \& Schonwald, 1988) recognising the great deal of variation in how methodology is applied. Finlay (2009) summarises some of the key aspects of phenomenological research:

Phenomenological research is phenomenological when it involves both rich description of the lifeworld or lived experience, and where the researcher has adopted a special, open phenomenological attitude which, at least initially, refrains from importing external frameworks and sets aside judgements about the realness of the phenomenon. (Finlay, 2009, p. 8)

Some of the most commonly described key features of phenomenological research are:

(i) a focus on lived experience (Valle \& King, 1978, Creswell, 2007);

(ii) a phenomenological attitude (openness) (van Manen, 1990), epoché or reduction (van Manen, 2011, Wojnar \& Swanson, 2007);

(iii) collection of data in the form of rich narratives and concrete descriptions of lived experience (Wertz, 2005) through observation, participant diaries, reflective journals and art work (Creswell, 2007) that may explore the meaning and existential dimensions of the phenomenon (how the person felt in space, time, and within their social world) (Finlay, 2011);

(iv) data analysis that may involve the use of bracketing (Caelli, 2000; Gearing, 2004, Starks \& Trinidad, 2007; Tufford \& Newman, 2010; Wall, Mitchinson $\&$ Poole, 2004), analysing, intuiting (Bruyn, 1966, Wojnar \& Swanson, 2007), horizontalization; imaginative variation (Finlay, 2011, Valle \& King, 1978) or a combination of those steps (Finlay, 2011; Swanson-Kauffman \& Schonwald, 1988);

(v) the production of a description of the essence or meaning of the phenomenon (Colaizzi, 1978; Merriam, 2009, van Manen, 1990).

The following section discusses what I believe are the most important features of a descriptive phenomenological approach to conducting research: a focus on lived experience, adopting a phenomenological attitude, using epoché or bracketing, phenomenological reduction, the search for essences and producing a rich in-depth description of lived experience and its meaning. 


\section{A Descriptive Phenomenological Approach}

The approach I adopted for this study is primarily based in the philosophy of Husserlian descriptive phenomenology was informed by the research methods of data collection and analysis developed by Giorgi (1997), Kvale (1996) and van Manen (2014). These will be explained more in the following chapter on research methods. The discussion that follows focuses more on the philosophical ideas and key concepts that underlie my research methodology.

\section{Collecting rich in-depth narratives of lived experience.}

Descriptive phenomenological researchers ask, "What is this kind of experience like?" "How does the world present itself to people?" (Finlay, 2011). They tend to use social science and qualitative research methods such as observation, conversation and participation rather than setting up an experimental study where variables are controlled for, and manipulated and where experience of reality is examined divorced of its meaningful social context. Husserl believed that the meaning of lived experience could only be unravelled and understood through one-to-one interactions between the researcher and the objects of research (Wojnar \& Swanson, 2007). Descriptive phenomenological researchers need to listen attentively, interact, and observe to create a description of reality more sophisticated than previous understandings (Husserl, 1976).

Descriptive phenomenological researchers attempt to help participants express their lived experience as directly as possible and then explain the essential structure, essence, dimensions or meaning of that lived experience/world (Finlay, 2008). Studying lived experience involves:

\footnotetext{
"A philosophical "method/practice" of observing, recording, and interpreting "lived experience" through vivid and detailed descriptions. The practice of phenomenology seeks to expose, uncover, or reveal "universal" (transcendental) elements of human existence that are instantiated within practical, "particular" empirical situations" (Magrini, 2012, p. 1).
}

Capturing and recording lived experience is not sufficient for a descriptive phenomenological study, researchers also need to bring a particular attitude to their research that enables them to see and understand phenomenon in new ways. 


\section{Phenomenological attitude and reduction.}

Descriptive and other phenomenologists come to their research with a philosophical perspective (phenomenology) rather than a social science theory or perspective that shapes their inquiry (what is studied and how it will be studied) and the description or explanation of what they find in the real world (Creswell, 1998). They also come to their research with a phenomenological attitude of openness and wonder (Finlay, 2011). In order to study lifeworlds and consciousness, Husserl (1976) suggested that phenomenologists bring a special attitude to bear on their study of phenomena, involving reduction(s). Reduction is the process of continually returning to the essence of the experience to derive the inner structure or meaning in and of itself (Merriam, 2009). The phenomenological method is used to "reduce individual experiences with a phenomenon to a description of the universal essence" (Creswell, 2007, p. 58).

Husserl (1976) identified several different types of reduction or steps whereby the philosopher puts aside the natural world and world of interpretation in order to see the phenomenon in its essence. This process was developed to give rigour to the search for essences and involved:

(i) epoché of the natural sciences (bracketing of scientific theory and knowledge, preconceptions);

(ii) the epoché of the natural attitude (bracketing of taken-for granted psychological presuppositions, beliefs, emotions);

(iii) the transcendental reduction (bracketing of one's own consciousness, ego and subjective experience of the phenomenon, to rise above and see the phenomenon as god would); and

(iv) eidetic reduction/intuition of essences (seeing and describing the invariant core characteristics and meanings of the phenomenon (essences or essential meaning) and distinguishing them from particular, incidental or accidental ones, or those shared with other phenomena) (Finlay, 2011, pp. 47-48).

Husserl did not see the process of reduction as a narrowing or abstracting process by which meanings are uncovered, but rather a movement towards seeing, perceiving and 
reflecting on phenomenon in more complex, layered, expansive ways which transforms understanding of phenomenon in quite radical ways (Finlay, 2011).

\section{Epoché or bracketing.}

In order to study acts of consciousness (noesis) and objects of consciousness/awareness (noema), and see the phenomenon as it appears to people who have lived experience, the descriptive phenomenologist needs to rigorously bracket their preconceptions (Husserl, 1976). This requires becoming aware of and setting aside prior experiential knowledge, personal bias, ideas about how things are supposed to be (Finlay, 2011; Wojnar \& Swanson, 2007). In doing so, the researcher can grasp the meaning of that world from the perspective of the individual who has the lived experience (Bryman, 2008) and describe the essence as it is experienced. Husserl believed that consciousness was a part of all human experience and he sought to find a way of transcending personal biases so that people could attain a state of pure consciousness (Wojnar \& Swanson, 2007) and therefore, see and understand the experiences of others.

Bracketing allows a phenomenologist to achieve a state of transcendental subjectivity - a state of consciousness where they can abandon his/her own lived reality in order to see and describe the phenomenon of study in its pure, universal sense. This bracketing and reductive reflection is regarded as a thoughtful process, free from theoretical, prejudicial, and suppositional interference (van Manen, 2007) and encourages the phenomenologist to be vigilant to the way their previous understanding may distort their description of the phenomenon (Finlay, 2011).

\section{The search for essences or the 'what' of a phenomenon.}

Phenomenologists are interested in examining, exploring and describing the nature or structure "essence" of a phenomenon as it appears or is experienced (Kleiman, 2004) but also the meanings they ascribe to such experience (van Manen, 2014). Phenomenology is derived from the Greek word phainomen (an appearance) and logos ("reason, hence a reasoned inquiry") (Gearing, 2004). Phenomenology is, therefore, a reasoned inquiry which seeks to discover the inherent or underlying essence of appearances. An appearance is anything of which one is conscious (Balls, 2009) and phenomenologists are concerned with embodied, experiential meanings (Finlay, 2009). 
Descriptive phenomenologists ask "What are the essential features of the lived experience/phenomenon?" (Finlay, 2011). The essence of the lived experience of suicide bereavement could be revealed through asking questions such as "What was your experience of losing a close friend to suicide?' Phenomenologists want to know what it is like to live it, not just the person's psychological reaction to the experience (for example, fear, anxiety, and anger) (Munhall, 2007).

It was through the process of reduction and bracketing that Husserl believed that one could gain insight into the common features of any lived experience (Husserl, 1976). He referred to these characteristics as 'universal essences' or 'eidectic structures' and considered them to represent the true nature of the phenomenon (Lopez \& Willis, 2004). Husserl argued that in order for a description of the lived experiences to be considered scientific and generalizable, researchers had to strictly adhere to the principles of descriptive phenomenology, and commonalities among research participants had to be identified (regardless of differences in context, or their environments) (Wojnar \& Swanson, 2007).

\section{Rich descriptions of lived experience.}

Descriptive phenomenological researchers aim to provide a rigorous and rich textured indepth description or account of lived experience (the way things appear to people in their consciousness) and the context (lifeworld) in which that experience takes place (Giorgi \& Giorgi, 2003). This description provides "what they have experienced" and "how they experienced it" (Creswell, 2007, p. 58). These descriptions should illuminate and help people see the phenomenon in a new light. Finlay (2009) states that: "Phenomenological researchers generally agree that our concern is to return to embodied, experiential meanings aiming for a fresh, complex, rich description of a phenomenon as it is concretely lived" (Finlay, 2009, p. 6).

The descriptions produced should advance understanding and make things clearer. Phenomenologists study lived experience in order to advance understanding of human experience (Caelli, 2000) and gain a deeper understanding of participants' everyday experiences (Broussard, 2006) and the human condition, but from the perspective of those being studied. Husserl and other descriptive phenomenologists wanted to bring to light 
the ultimate structures of the consciousness (essences) and evaluate how these influence how people make sense of experience (Koch, 1999).

As a researcher using a descriptive approach to phenomenology I would ask participants independently about a specific experience (suicide bereavement) and would generate a large volume of data as participants tell their stories about loss, grief and bereavement. I would then summon my own experiences of suicide bereavement or bereavement, record, analyse and describe and leave aside these (bracket prior assumptions and preconceptions) so not to contaminate the data of participants. I would then dwell with those stories until I could describe the essence of bereavement, extracted from participants' stories as lived experience. As a result, both myself (researcher) and participants become subjectively aware of the essence (Koch, 1999) of suicide bereavement as an experience that may have been taken for granted previously.

\section{Methodological Considerations: Discussion and Rationale for Choice of Approach}

This study drew upon the theoretical perspective and methodology of the descriptive psychological approach to phenomenology that focuses on the meaning of experiences found in individual rather than group experiences (Creswell, 1998). This approach is based in the thinking of Husserl and the principles of Duquesne Studies in Phenomenology that aim to determine what an experience means for the persons who have had the experience and are able to provide a comprehensive description of it.

While several other qualitative methodologies were considered when planning this study, including grounded theory and case study, they were not suited to the research question, the expertise of the researcher and would not have led to the development of a description of the essence of the young men's experience. I did not want to explain their experience nor present them as individual cases, rather I wanted to explore, describe and find the essential aspects of their individual and common experience so I could better understand what that experience is like. There were several other reasons why I chose a qualitative and primarily descriptive phenomenological methodology.

First, phenomenology is an appropriate and credible approach to the study of human phenomena, lived experience and has made an important contribution to advancing understanding in the discipline of nursing and health (Dowling, 2007). I wanted to signal 
to other researchers in the field of suicide postvention and health that phenomenology is a challenging, rigorous methodology that has the potential to be enriching and transformative in terms of shaping practice. Good research is not all about numbers, hypotheses and measuring change. A deeper understanding of the nature and meaning of suicide bereavement, grief and loss can offer insights that will assist in understanding the lifeworlds of young men who have lost a close friend to suicide and inform suicide postvention.

Descriptive phenomenology was also chosen because it has been used effectively by a number of researchers to study and advance understanding of health related issues, especially where there is a significant research gap and few studies (Swanson-Kauffman, 1986; Wojnar, 2005) and when researchers want to inform healthcare and practice (Beck, 1992; Riemen, 1983, 1998). Phenomenology has also shown to be a rigorous methodology to study suicide phenomena (Fielden, 2003) and bereavement (Douglas, 2004).

A second reason for choosing descriptive phenomenology, is that researchers need to choose the phenomenological approach that suits their world views, professional knowledge of the phenomenon, and the long-term research objective (Wojnar \& Swanson, 2007). A descriptive phenomenological approach fits with my constructivist position, my professional knowledge in the area of suicide postvention and prevention, and with my research objective and goals to advance understanding of young men's experiences of suicide bereavement. It also fits the research question: "how do young men experience the loss of a close friend to suicide" and "what does it mean to lose a close friend to suicide."

Third, a descriptive phenomenological approach is best suited for research that seeks to discover universal (or local specific) aspects of a phenomenon (Wojnar \& Swanson, 2007). It is best suited to situations where there is limited understanding of "what an experience is like' from the point of view of those with lived experience (Beck, 1992; Lopez and Willis, 2004; Wojnar \& Swanson, 2007). There is a need for a detailed closeup view because prior studies have not investigated the experiences of young men. A descriptive phenomenological study is also appropriate when the end goal is to develop 
caring interventions that promote wellbeing, healing, or recovery in clinical practice (Wojnar \& Swanson, 2007).

Little is known about how young men experience the loss of a close friend to suicide. Previous studies have identified some aspects of suicide bereavement in other populations (adults, adolescents, and children) and attempted to distinguish it from other forms of bereavement but these studies have failed to describe the essence of the phenomenon. Other researchers following in the footsteps of Husserl have supported the importance of phenomenological description: "Without thereby first disclosing the foundations of a phenomenon, no progress whatsoever can be made concerning it, not even a first faltering step can be taken towards it, by science or by any other kind of cognition" (Colaizzi, 1973, p. 28).

The end goal of this research was to advance understanding of men's experiences of suicide bereavement and inform health care and the development of support. Furthermore, there has been a growing interest and call for more qualitative research in the area of men's health and suicidology. I wanted to conduct research that could be published and add to the knowledge base of a number of disciplines including health, counselling and youth development. I also wanted the findings of this study to inform the development of education and practise in suicide postvention.

Fourth, a qualitative design should be chosen when researchers have an interest in writing in a literary style and in bringing themselves into the study (Creswell, 1998). I wanted to tell the stories or narratives of the young men but also present their stories and experience in a way that would enable the reader and health professionals to gain a better understanding of what it was like from the young person's point of view, enabling people to better see and imagine their experience. A descriptive phenomenological approach enabled me to privilege the voice of the participants, provide opportunities for reflexivity, and also draw on my strengths as a suicide researcher and practitioner who has worked with those affected by suicide.

Fifth, phenomenology was chosen because it has the potential to be transformative for both the researcher and the participants (con-constructors or co-researchers). Phenomenology “...offers individuals the opportunity to be witnessed in their experience 
and allows them to 'give voice' to what they are going through. It also opens up new possibilities for both researcher and researched to make sense of the experience in focus." (Finlay, 2011, p. 10) (emphasis in original). I wanted participants to have a positive experience that validated their experience, encouraged them to break their silence and provided them with an opportunity to turn their loss onto something meaningful and constructive. On several occasions we (myself and the men) recognised a 'therapeutic' element to the research - an unexpected outcome. For my part, I experienced a comradery with other young men who experienced suicide loss, had aspects of my own experience validated by the participants, and developed a new perception of what it means to be a young man and to grieve. This is supported by researchers who have noted Kavanaugh and Ayres (1998) who described the benefits of participating in qualitative interviews, including catharsis, self-acknowledgement, empowerment, and healing (Hutchinson, Wilson \& Wilson, 1994; Kavanaugh \& Ayres, 1998).

I also wanted to use a methodology that would not only help answer the research questions but which would challenge myself as a researcher to develop a different and more humanistic understanding of suicide bereavement. Phenomenology played a special role in teaching me something new, and moving me in a new way, to slow down and appreciate the experience, to carefully consider lived experience, to let go of psychological labels and be with and imagine the experience. This experience has helped me become more aware of myself, more 'present' with others and my capacity to be-with another has also grown. It has helped me develop an approach that is open, non-directive, non-instrumental and relationally-oriented and to helped me learn to dwell with the bereaved as they seek to describe their grief and journey in all its richness, complexity and suffering. Using phenomenology will have an ongoing influence on my own practice as suicide bereavement educator and facilitator of suicide bereavement support groups. Phenomenology has taught me about listening, the importance of eliciting detailed narratives and about ambiguity and contradictions in meaning.

Finally, a qualitative and descriptive phenomenological design was chosen because I had sufficient time and resources to spend on extensive data collection in the field and time to conduct a detailed analysis of text information (Creswell, 1998). When designing this study I knew that it would take time to find the participants, build trust and rapport and to develop an understanding of their context and lifeworld. I also knew that data collection 
and verification would take time, involve multiple interviews, checking themes and descriptions of the experience with participants, and developing a rigorous discussion of the findings. I also chose this design because I wanted to emphasise my role as an active learner who can tell the story from the participants' view rather than the expert role who judges and evaluates the participants' view (Creswell, 1998).

The aim of the current study was to try and gain a 'better' understanding of what it is like for young men to lose a close friend to suicide. Thus, it seemed imperative for this to be done by allowing participants to tell, in their own words, their own stories of suicide bereavement in order to uncover the meaning or unvarying essence of their experience. Therefore, it was necessary, in order to meet these aims, for the research to employ a qualitative descriptive phenomenological approach.

\section{Chapter Summary}

To summarise, this chapter has outlined the research aim and questions, my research philosophy and how these connect with a choice of qualitative descriptive phenomenological approach and methodology. Research on suicide bereavement has utilised both positivist and interpretivist paradigms, however, as the literature review presented in the previous chapter has shown, there is a paucity of research that has focused on describing the lived experiences of suicide bereavement in young men, in particular the loss of close friends. A qualitative and phenomenological study would provide a deeper understanding of those experiences from the perspective of those involved and affected.

A phenomenological approach was also chosen to study the phenomenon of suicide bereavement because it enables the researcher to focus on describing and understanding lived experience of the phenomenon (Husserl, 1976). A lived experience is how a person immediately experiences the world before reflecting on it (Husserl, 1970). Phenomenological philosophy and methodology acknowledges that the study of lived experience and lifeworlds involves examining the accounts, narratives, and perceptions that people have of their world and the meanings they ascribe to those experiences. A descriptive phenomenological philosophy was chosen to explore, discover and gain a deeper understanding of how young men experience suicide bereavement and to develop an exhaustive description of a phenomenon and an understanding of what the 
phenomenon is like. The following chapter describes the methods used in the collection and analysis of the data and an explanation of the phenomenological approach taken. 


\section{CHAPTER FOUR: RESEARCH METHODS AND PROCEDURE}

\section{Introduction}

Whilst there are numerous studies on people bereaved by suicide (mostly adults and parents) and the effects of suicide bereavement on adolescents, little is known about the experiences of young men who have lost a close friend to suicide. Therefore, the purpose of this study was to explore young men's experience of the phenomenon as they live it, so called lifeworld experiences and to discover the meaning of that experience. Since I wanted to understand the complexity but also the core essence of their experience, descriptive phenomenology was selected as a theoretical approach and methodology.

The method used in this study is grounded in Husserl's $(1970,1976)$ phenomenological philosophy. Phenomenology considers that an understanding of the person's experience of a phenomenon cannot occur in isolation from the person's lifeworld. Each person experiences a phenomenon such as suicide bereavement from an individual, social, perceptual and practical perspective, in a way that is both similar and different to others (Connelly, 2015). Each individual also experiences the phenomenon within a situated context - a specific time in history, their cultural, political and social context (Connelly, 2015). According to the phenomenological perspective, each person has a unique view of the world and each person's experience of being in that world is as valid and as true as any other; it is their social reality.

Young male survivors of suicide-loss experience and interpret their own world and make it meaningful for them. This is their social reality; so as a researcher I needed to understand that reality by examining their individual perceptions and accounts of experience (Smith, 1996). The goal was to search for a general, but not universal, essence or meaning structure of the studied phenomenon (Karlsson, 1995). The methods used arose from the research questions: "What are the experiences of young men who have lost a close friend to suicide?" and "What does it mean to lose a close friend to suicide?" The purpose of this chapter is to discuss the research methods used to collect and analyse data. 


\section{Study Design and Setting}

In a phenomenological study it is important to access the lived experience of participants in order to develop an understanding of the phenomenon (as it is lived or appears to them) through description or interpretation (Johnson \& Christensen, 2008). The data consisted of spoken accounts contained within the perspectives of eight young men who all had personal first-hand experience of losing a close friend to suicide. The data were primarily collected through semi-structured conversations with participants. Data also included field notes, recorded before and after interviews in a reflective diary (Smith \& Osborn, 2008).

The purpose of the descriptive phenomenological method is to obtain a description of the phenomenon only (no interpretation or as little interpretation as possible). The descriptive method allows data to come from the participants without the need to transform, analyse or interpret them - allowing myself and others to see the phenomenon as the participants did. According to Partis (2003): "Phenomenology, is an attempt to give a systematic, descriptive account of the most fundamental aspect of the experience as reported by the subjects" (p. 11). The purpose of this study was to analyse participants' experiences of the phenomenon and uncover underlying perceptual and conceptual themes that structure or characterise the experience. It was anticipated that exploring the experience, would lead to a new understanding and description of the phenomenon that would help primary health care providers, counsellors and others better understand and respond to young men. The findings would also aid the development of postvention support which could in turn reduce risk and save more young men's lives.

The study was conducted in a medium-sized city in New Zealand. The city was chosen because it is home to many diverse cultures and around $25 \%$ of its population are born overseas and has a high youth population. Another reason for choosing this particular city was because I had established relationships and credibility with youth mental health services, the District Health Board's, counselling services and with the bereaved/survivor community. Recruiting participants regarding the topic of suicide is potentially difficult because of the stigma associated with suicide. Previous research has not included adequate male samples and this suggests they are a hard to reach population. Young men may also be unable to talk about their feelings (Levant, Allen \& Lien, 2014) reluctant to 
talk about their experiences (talking is seen as a feminine trait), especially sensitive (emotional) topics that could threaten their sense of control or lead to emotional expression (Doka \& Martin, 2011). Successful recruitment demanded drawing on my contacts and relationships with gate keepers and the local community in order to locate and gain entry to the groups of young men. For this reason the decision was made to recruit from within this city rather than nationally and to expand recruitment if I had no success.

\section{Ethical Approval, Guidelines and Issues}

Prior to beginning the research and starting recruitment, research ethics approval was gained from the Victoria University of Wellington Human Ethics Committee. The research project, flier, participant information sheet (Appendix 2), interview guide (Appendix 4), consent form (Appendix 3), disclosure process and other documents were approved prior to data collection (Appendix 1).

One of the reasons there is less research conducted on suicide bereavement and survivors is because it may be difficult for researchers to navigate the ethical issues associated with researching vulnerable populations (Dickson-Swift et al., 2007, 2009). Despite the ethical challenges, research on survivors is important. McIntosh and Jordan (2011) state: "Although ethical issues are raised about conducting research during this sensitive time for the suicide bereaved, carefully conducted, ethical research can be done to study this important time period..." (p. 512).

This study was guided by both ethical guidelines (Christians, 2005) and research guidelines for conducting research with the suicide bereaved (Stroebe, Hansson, Stroebe \& Schut, 2001; Stroebe, Hansson, Schut \& Stroebe, 2008). The study was carefully planned, monitored and supervised. Four main ethical principles for conducting qualitative research guided my project: informed consent, confidentiality, avoidance of deception, and accurate collection and reporting of data (Christians, 2005).

\section{Informed and ongoing consent.}

An information sheet that outlined the study's aim, duration, potential benefits and potential emotional discomfort, and how the findings would be utilised was provided to each potential research participant (Appendix 2). Participation in the study was voluntary. 
No monetary incentives were offered to research participants. All of the participants gave informed consent (or assent, positive agreement) (Gillies, 2012) and were provided with opportunities to withdraw from the study at any time (or withdrawn by myself if they were assessed as being at risk). Ongoing consent was requested and given freely by all participants prior to all data collection activities (meetings, conversations, ride-alongs/goalongs, and individual or group interviews).

Family representatives of the deceased also provided their verbal consent for background information about their loved ones to be used to inform the research. Gaining their consent was important for me to show respect, build trust, and to protect the field for future research. Gaining their consent was also important because it helped secure the involvement of participants who were friends of the families. The families of the deceased helped disseminate the information sheets and facilitated initial meetings with potential participants. The families were promised that their identities and that of the deceased would be protected.

Previous research suggests that participants in qualitative studies often experience a validation of experience in sharing their accounts; the interview process can have a therapeutic effect by giving meaning to participants' loss and leaving them feeling empowered (Dyregrov et al., 2011; Rossetto, 2014). Stroebe, Stroebe and Schut (2003) have noted that some bereaved may take part in research as a way of sharing and coming to terms with their loss experience, while others may hope that their contribution will further understanding of bereaved persons as a group. This is supported by other studies that have found that research that is conducted sensitively (Lee, 1993) can provide the bereaved with beneficial opportunities to discuss and reflect on their experiences within the context of interviews (Payne \& Field, 2004).

These benefits have been linked especially to the use of phenomenological methodologies in bereavement research. This method facilitates meaning reconstruction of experience, stresses the inherent worth and credibility of participants' narratives of experience, provides opportunities for participants to explore and gain new insights into themes within their experience, and utilises in-depth interviews that permit a lengthy, coherent focus on the bereaved' experience (Dyregrov, 2004a). Lindqvist, Johansson and Karlsson (2008) found that $100 \%$ of participants in their study of parents and sibling survivors of 
teenage suicide reported their experience of participation as positive or very positive experience because they were able to express their story and because they hoped in doing so it would benefit others.

In the present study, the families of the deceased and participants expressed an appreciation for being able to talk about the lives of their sons/brothers and close friends during the recruitment and data collection process. The participants wanted to help others (families, mental health professionals, and other bereaved young men) understand their experience. They also wanted to help other young men understand the impact suicide has on friends left behind. These were similar reasons to those found in previous bereavement research: (i) helping researchers and professionals better understand the grieving process; (ii) helping other bereaved individuals better understand their grief, and (iii) providing hope to other bereaved individuals (Beck \& Konnert, 2007).

In many ways, participants cannot know whether participation in the research will be a positive or negative experience until they experience it. I provided participants with opportunities to review their decisions throughout the research process. Researchers need to be aware of verbal and non-verbal signs of dissent and check with participants if they are willing to proceed or wish to halt their participation (Wendler, 2006). I was also sensitive to the development of risk throughout the whole research process. Prior to taking part in the research I developed clear research protocols that included the following areas: (i) disclosure, (ii) establishing and maintaining rapport, (iii) providing clarity around therapy versus research nature of the interactions, (iv) strategies for leaving the research relationship, and (v) the management of professional boundaries, including friendships with participants (Dickson-Swift, James, Kippen \& Liamputtong, 2006).

Initial meetings with potential participants occurred at their places of work, the university and in the homes of the deceased. These meetings provided an opportunity for them to evaluate my trustworthiness and to ask any questions they had about the research, and how privacy and confidentiality were to be protected. We discussed my background, experience of suicide bereavement and work in suicide prevention and postvention. We talked about the potential risks and benefits outlined in the information sheet. I made it clear that this was a research study, so they did not confuse research procedures with clinical care and evaluation. This prevented them from falling prey to the so-called 
therapeutic misconception that many survivors or trauma and vulnerable populations have of research (Collogan, Tuma, Dolan-Sewell, Borja \& Fleischman, 2004).

These meetings and contacts helped build trust and rapport and establish boundaries and enabled participants to make an informed choice as to whether they wished to take part in the research. Once participants demonstrated a willingness to participate and had the opportunity to discuss any issues they had with the research and/or protocols, they were provided with a consent form to sign (Appendix 3). Participants were assured that they could withdraw from the study at any time without penalty or disadvantage and that any data they may have contributed would not be used as part of the study and would be destroyed. They were encouraged to discuss their participation with close friends and family and to seek advice if they felt uncomfortable volunteering.

\section{Confidentiality and privacy.}

Managing confidentiality and privacy was of utmost importance during the study. During recruitment it was important that potential participants' privacy be protected. Participants were invited to personally contact the researcher (by email, text or phone) for further information about the study and I did not discuss who volunteered with the families of the deceased. However, due to the nature of the recruitment, anonymity was only protected for the one participant who was recruited through a youth mental health service. Anonymity was not possible for the other seven participants, because they knew each other, had disclosed to one another (and to the family of the deceased) that they were taking part; and three even requested a group interview so they could share their individual as well as collective experiences.

Participants were assured that all information gathered through the interviews, conversations and meetings would be kept confidential and the processes for this. Confidentiality was protected and maintained by using pseudonyms in the thesis (for both participants and the deceased) and other publications and presentations and through the removal of any identifying personal details. Pseudonyms were also used to guard against socially desirable answers.

Given the nature of the methodology used in this study and the depth, detail and richness of quotes, there was a potential risk for identifiability. Therefore, in addition to the use of 
pseudonyms, steps were taken to ensure the identities of participants, others, locations and events were modified or deleted from quotes. Even with these precautions, there was a small possibility of identifiability; the information sheet acknowledged that the use of quotations in the study may carry with some level of risk to the maintenance of confidentiality.

\section{Management of risk of distress and relationships.}

Research publications based on the studies of vulnerable populations are not often accompanied by a discussion of relevant ethical issues, but simply state that guidelines were followed (Zion, Gillam \& Loff, 2000). One of the biggest issues in conducting this study was the management of potential risk of distress to participants and the researcher. Participating in bereavement research has been recognised as being distressing for some research participants (Dyregrov, 2004a). However, participation in qualitative research has also been shown to help people express themselves and share experience, have their experienced validated and used to benefit others; promote self-awareness, empowerment and providing a voice for those who are disenfranchised (Hutchinson et al., 1994; Kavanaugh \& Ayres, 1998). I was aware that participants would be recalling experiences, thoughts, feelings and responses during the study, and these could be upsetting, distressing or the beginning of renewed personal trauma. However, I was also aware of the potential benefits of participation. As such, I followed the principle that the therapeutic imperative would take precedence over the research imperative (Munhall 1998) but this would be negotiated with participants.

I also took a number of steps to minimise the potential of distress to participants. First, participants were carefully selected to help minimise the risk of recruiting participants who were experiencing complicated grief or had current mental health issues that may make them more vulnerable. Second, I sought continued consent throughout the research, so that participants were aware they could stop the interview at any time and make a decision to proceed, postpone or cancel the interview altogether or withdraw from the study. None of the participants withdrew from the study. I also stated at the beginning of interviews that it is quite normal for some people to get upset when discussing issues such as grief, bereavement and loss (Cook, 1995). 
While none of the participants asked for the interview to be stopped one did express his fear of 'breaking down' and looking feminine:

I had no idea if I was going to break down or not... The reason guys wouldn't want to do this is because they don't want to break down in front of other guys. People want to be in a comfortable space to talk about their grief. (Max1, 20; 6-17)

Despite this fear none became distressed or broke down. In actual fact, participants found the experience of being listened to therapeutic and helpful:

I actually found our last talk was quite helpful because I'd sort of had time to mull it over, think on things a lot and try and work stuff out... When you're talking about something right after the event, shit's going up and down everywhere and you don't have a good take on things. (Max2, 14; 2-9)

I developed a disclosure protocol and discussed it with participants prior to the interviews. This ensured that participants knew what would occur if they indicated that they or others were at risk of harm. I also reminded participants that may be withdrawn from the study should concerns arise that they could be harmed by continued participation in the study. Three participants disclosed during interviews that they struggled with thoughts of suicide following their friends' suicides and had engaged in self-harm but these were historical and they had sought help. None of the participants were withdrawn from the study. I provided all participants with information about local support services, 24/7 anonymous telephone counselling services and provided them with the contact of a counsellor. The counsellor was aware of the nature of the study and had experience in supporting survivors (in particular young people). She offered to provide participants with support free of charge should they wish to discuss their feelings or seek professional support. None of the participants took up the offer but appreciated the gesture.

Risk to participants was also managed by encouraging them to make use of their informal social support networks (family, friends) as well as mental health professionals and counsellors they had a relationship with. At the end of each interview, we discussed practical strategies for coping and maintaining their wellbeing (for example, physical exercise, working on their car, talking to partners and friends about the process). All the interviews were concluded with a general chat and refreshments and participants had the opportunity to discuss any concerns. For example, after interviews with one participant, we would go outside and have a cigarette. This helped him relax a little after and the chance to change the topic of conversation helped create a transition for him. Follow-up 
contact 1-2 weeks after each interview also provided me with an opportunity to check on participants' wellbeing.

A final strategy to manage risk and ensure the wellbeing of participants was the use of a clinical supervisor (counsellor) during the duration of the field world, data collection and analysis. The primary purpose of supervision was to reflect on interactions with participants, help assess and manage risk, identify and address any issues that may have arisen for participants and issues that may arise for me. Debriefing after interviews with my academic supervisors (one a Registered Psychologist) also helped ensure my wellbeing and provided an opportunity to discuss any issues of practice and ethics that required further attention to protect participants.

\section{Managing risks to the researcher.}

Conducting bereavement research is potentially distressful for researchers and members of the research team (Sque, 2000). Qualitative researchers can experience distress from intensive research practices during data collection, transcription and analysis because they relive difficult events (Wray, Markovic \& Manderson, 2007). For example, Cowles (1988) stated: "observing frequent intense emotional responses of others, [and] very personal activities or violent behaviors can be psychologically and emotionally wrenching for investigators regardless of how experienced they are in conducting research" (p. 173).

There is a growing awareness and concern about how researchers may be emotionally affected by their work. Dickson-Swift, James, Kippen and Liamputtong (2009) have called for researchers to not only reflect upon and write about the impact on them but to actively engage in more "emotion work" - the management of emotions, exhaustion, vicarious traumatisation, and to put into place strategies for debriefing, self-care and supervision. Qualitative researchers often report having to grapple with many issues related to undertaking sensitive health research including: self-disclosure, feelings of guilt and vulnerability, listening to untold stories, leaving the research relationship and mental exhaustion (Dickson-Swift, James, Kippen \& Liamputtong, 2007).

I used a number of strategies (Dickson-Swift, James, Kippen \& Liamputtong, 2008) to minimise both physical and emotional risk to myself and to prevent issues from 
compromising the research process and data validity. These strategies included (i) having a good understanding of and previous experience of conducting sensitive research and training in managing distress and self-care, (ii) maintaining professional boundaries; (iii) the use of informal supervision (with colleagues in suicide postvention) and debriefing sessions with supervisors after particularly difficult interviews; (iv) seeking clinical supervision outside of the university setting (with a counsellor); and (v) the use of cell phones and reporting back to supervisors at the conclusion of interviews. I developed clear guidelines for handling disclosures, ending research relationships with participants, and implemented a number of self-care strategies to prevent burn-out (for example, maintaining a regular physical exercise routine, making time to write and reflect in my journal, using music, poetry and other forms of expression). These strategies and a combination of reflexive practice, sufficient time between individual interviews, supervision and debriefing helped minimise any potential risks to myself during interview, data analysis and write-up of the research.

James and Platzer (1999) propose that peer support and informal networks can be helpful for both participants and researchers who are part of the research process, but they argue this is not ideal and they should have access to clinical supervision. Dickson-Swift et al. (2008) also argue that it is important for researchers who feel helpless or hopeless following interviews to have access to therapeutic or clinical supervision, and counselling and formal support be offered to participants that become distressed.

Clinical and academic supervision proved to be very useful following a week where I conducted three intense interviews. It was during the time I was reading and analysing the transcripts, remaining open to their experiences (exercising the phenomenological attitude), and 'dwelling with the data' that I became aware that I was beginning to reexperience my own grief. I identified with the participants' experience and was overcome with sadness. I realised the hurt they had experienced and how they had been silenced by themselves and those around them. It was at this time I first realised that this too was my experience when I lost my friends as a teenager. I made some notes about the experience in my reflective diary (see below) and discussed the issue with both my clinical and academic supervisors and talked to my partner. 
I interviewed Adam, Luke and Max this week. This was their second interviews. They were more intense than the first. I was emotionally shattered at the end of each of these interviews. I was not prepared for my response when I listened to the recording and checked the transcripts. Alone in my office at the farmhouse, I became overwhelmed with sadness. Why did he do it? Why did he use a gun? How alone and desperate he must have been in those final moments. The guys would have imagined the scene, I can picture it vividly, how he sat, back to the door, where the gun was placed and what happened afterwards. Just like the cases I have dealt with. I'm staring at the poster of Ian Curtis on the wall, listening to Joy Division. Suicide is violent, it violates. It silences the pain suicidal people feel but it also silences those left behind. These guys have lived with this silence every day. They have lived with that loss, emptiness, and they were left behind. Just like me (C. Bowden, personal communication, December 11, 2013).

As a result of this experience I changed my focus and moved away from looking at the details/parts to focusing in the whole (the meaning and essence of the experience). I made some further notes on how the experience affected me and was managed because I was considering writing a future research article on emotion work (Dickson-Swift et al., 2009).

Wray et al. (2007) conducted a study of the effects of saturation, data triangulation and intensive-research practises on the researcher. They found that researchers who are involved in all aspects of data collection (recruiting, observing, expanding field notes, and interviewing), transcription, and data analysis, repeatedly relive events. Reliving events may potentially compromise the researcher's well-being, and, in turn, the research process and data validity. They recommended that researchers be trained in research praxis, access supervision, use reference groups, debrief with others, and consider accessing professional counselling in order to manage unanticipated emotional responses to the research. I discussed the issue of re-reading interviews with colleagues who were also conducting phenomenological research on sensitive topics - we formed a collective community of practice to support one another and I continued to write about these in my reflective journal.

Wilkes, Cummings and Haigh (2014) have also highlighted the need to protect transcribers from negative emotional and physical effects of transcribing sensitive material. They found that transcribers had been offered debriefing and support for handling sensitive material but many had developed their own strategies. The transcriber 
I chose to use was very experienced with transcribing research on medical, social, criminal and health topics. We discussed the nature of the research and the interviews and I provided her with a copy of the interview guide. She signed a confidentiality agreement to protect the participants, accuracy and confidentiality were discussed. Data was transferred online through a password protected file-sharing system with non-identifying information. We discussed her strategies for dealing with such material (including, relaxing and debriefing with friends, family and colleagues) and I provided her with warnings when some of the interviews contained offensive (swearing) or distressing material (participants going into detail about methods of suicide) so that she could prepare for listening to that.

\section{Ethical issues.}

Sanders, Munford, Liebenberg and Henaghan (2014) note that in certain types of research (including field work) researchers face the challenge of managing participant disclosures, catharsis, hopelessness and their own motivation as well as the emotional impact the research can have on them. They argue that sometimes young people tell researchers about their experience because they want help, sometimes just because they want someone to listen. Occasionally researchers have to grapple with leaving the participants in situations that are less than ideal and grapple with motivation to do something (Sanders et al., 2014). Sanders et al. (2014) recommend that researchers need to accept these challenges as part of doing emotionally sensitive research and that there is analytical value in reflecting on these experiences.

During data collection I encountered a number of occasions where participants raised issues which prompted me to ask them whether they wanted me to assist them to take action or resolve the issue. For example, one of the participants, Max talked about how suicide had destroyed his friendships and how he wished he could repair or mend those relationships. We talked about possible solutions outside of the interview space and I listened to his ideas. During the course of the study he did repair his relationships with two of the other participants (Adam and Luke). The three friends grew curious about the others involvement in the research and this spurred them to reconnect. I wondered whether working through their own experiences in the interviews helped them understand their own and others possible reactions. 
During the group interview with Jace, Fin and Rod it became clear that the men were very angry about how the police and court had treated their friend (Devon) and how they believed this led to his suicide. They felt harassed and disrespected by the police who attended the funeral and had a presence at the burial. I asked them if they had told me these things because they wanted help or because they were important to their story. They said they felt powerless to address the issue and I decided to raise the issue about better training for police, the importance of 'youth friendly' approaches and addressing the use of 'scare tactics' at the next Regional Youth Mortality Review Group meeting. I did this on behalf of the young men who did not have a voice and who tried to discuss their concerns with the police directly but were unsuccessful. At this point I knew I was no longer acting as a researcher but as youth advocate, but was comfortable doing so because it was not something that was beyond my usual role as a praca-demic (academic who applies knowledge to practice).

Dickson-Swift et al. (2006) found that researchers often have difficulties managing boundaries in sensitive research. They note that rapport building process and maintain relationships in long-term research can require a merging of boundaries between researcher and participants. In the current study I shared meals with some of the participants, attended gatherings, looked at photos and kept in touch over the period of a year during data collection and in the year during analysis and write-up.

Dickson-Swift et al. (2016) also note that many researchers use self-examination, sharing and self-disclosure to develop rapport and trust and that it is important for researchers to communicate feelings of empathy, respect and validation in order to encourage participants to 'open up' and participant disclosure. When I first met the participants they wanted to know why I was studying this topic, what I did at the university and how I came to be working in the field of suicide. I disclosed to them a little about my own experience of suicide bereavement. However, I made it clear to them that this was a long time ago, in a different context and I would not be comparing their experience to my experience. I told them I was interested in understanding what their experience was like from their point of view. I said that they were experts on their lifeworld, and that young men today might experience suicide bereavement very differently to 20 years ago. 
Researchers also disclose what they think and how they feel to participants when they want to validate their experience (Dickson-Swift et al., 2006). At times I disclosed to participants during interviews because I wanted them to know that I really did understand what they were going through. This was a conscious decision because I was aware that some of them had not experienced any validation and it was the first time they had talked about some aspects of their experience.

I also experienced the challenge of remaining "emotionally distant" and maintaining the "professional researcher boundary" (Dickson-Swift et al., 2006) because it was difficult not to show emotion during interviews and data gathering events. I expressed emotion when it was appropriate, to show participants that I was with them, was listening and moved by their accounts. I laughed as they recounted positive memories of their friends and I shed tears when they described certain events (finding out about their friend's suicide, the funerals). I also stood in silence with them at the unveiling of their friend's headstone and shared a drink with them afterwards. As Sanders et al. (2014) note research occurs within relational spaces, and I knew I had to be genuine and honest with these men in order to gain and maintain their trust.

Some researchers have difficulties managing blurred boundaries between friendship and research and exiting the field or saying goodbye to participants at the conclusion of research (Dickson-Swift et al., 2006). In some cases researchers do not leave the field entirely, keeping in touch with participants for a number of years after the completion of a project. This practice can be one way of managing the difficulty of severing relationships that develop through the research (Dickson-Swift et al., 2006).

During this study I discussed exiting the field with participants. The participants suggested we get together for a beer after the examination and acceptance of the thesis and this would signal the end of our relationships as researcher and participants. However, we also discussed the possible dissemination of the findings. They suggested sharing the findings at a seminar or open-lecture after the $\mathrm{PhD}$ was accepted and this would be an appropriate way for their input to be acknowledged. It would also achieve their goal of helping others understand their experience. The participants wanted the option to attend the seminar/lecture but remain anonymous. They wanted to see their words, and hear their experiences acknowledged in a wider public space and hoped this would help break the 
silence around suicide. Until that time, we agreed to stay in touch via FaceBook (social networking) and messaging.

\section{Participant Recruitment, Selection and Sampling}

Seven of the eight participants were recruited through families of young men who had died by suicide and one participant was recruited through a youth health service. Accessing "vulnerable" (suicide survivors) and "hard to reach" populations (young men) is complex and challenging (Anderson \& Hatton, 2000). Normal sampling strategies cannot be used when researching "hidden populations" - those that are difficult to locate because of their social status, at-risk behaviour, stigma (Salganik \& Heckathorn, 2004). Recruitment of vulnerable and hard to reach groups also requires multiple strategies (Caserta, Utz, Lund \& de Vries, 2010). Research with hidden populations often requires the researcher to negotiate entry, work with organisations who provide services for vulnerable populations and is often time-consuming (Salganik \& Heckathorn, 2004).

I chose to use targeted (non-random) sampling (Salganik \& Heckathorn, 2004) and a variety of outreach techniques to attract or access a sample of young men in the hidden population. I used two strategies to ensure a representative sample of participants: (i) focused out-reach efforts, initiating contacts with key members of the bereaved community, gatekeepers (education providers, youth health service providers) and cultural groups, and (ii) use of print and electronic media to advertise the study in the chosen city and surrounding region. The city had a diverse population and offered a good possibility of providing access to a diverse sample of suicide bereaved young men. Steps were taken to enhance participation of persons from diverse ethnic and cultural backgrounds, because this is critical to the generalisability of the findings but also because they are often hard-to-reach populations (Caserta et al., 2010). Of the eight participants, one was Māori and another was Samoan (see Appendix 5).

Information flyers, were sent to community and tertiary, youth health and counselling services, the regional suicide postvention coordinator; GPs; counsellors, including grief counsellors; funeral directors; youth workers, youth one-stop-shop services; and men's groups. I hoped potential participants would respond to fliers and information sheets displayed in offices and waiting rooms and would contact me directly, protecting their anonymity. I planned to take an incidental and opportunistic approach to recruitment 
(Minichiello, Aroni, Timewell \& Alexander, 1990) and then possibly use respondentdriven or snowball sampling (Salganik \& Heckathorn, 2004).

Suicide bereavement researchers have noted the difficulties recruiting young men for bereavement-related research (Bragdon, 2006). Rigorous 'gatekeeping' (often by wellmeaning individuals and bereavement services) has limited the access of researchers to potential participants and has the potential to create issues for research (Payne \& Field, 2004; Sutton, Erlen, Glad \& Siminoff, 2003). Researchers need to build time into their study to collaborate with gatekeepers, lay the groundwork, and to communicate with them about the purpose, protocols and how participants will be protected (Sutton et al., 2003). By building and maintaining relationships I built trust, mutual respect, and ensured that gatekeepers understood the potential risks and benefits of the study, the protocols and ways participants would be protected, this maximised access to potential participants.

Despite taking time to collaborate with gatekeepers, offering to visit gatekeepers and talk to staff about the project and having pre-existing relationships with youth service providers, recruitment through youth mental health and community service providers was largely unsuccessful. I either got no response from service managers, or they replied to emails saying they were too busy or were 'over researched' on youth health issues. Only one youth mental health service took up my offer to talk to staff about the project and this led to one participant (Harley) being recruited who heard about the study from a mental health nurse.

The other seven participants were recruited through out-reach efforts focusing on survivors and families of young men who had died by suicide. I contacted individuals and families I had met facilitating the Waves psychoeducational suicide bereavement programme. These family members (mothers, fathers, sisters) acted as gatekeepers and introduced me to the other seven participants. I met with Devon's mum and step dad and discussed the study and they offered to arrange a time for me to meet with a large group of young men who were friends with their son. About twelve young men attended the BBQ and four of them approached me after to volunteer. We talked while cooking and eating connecting over 'guys stuff' cars and youth culture. Coby requested to be interviewed alone while Jace, Fin and Rod were interviewed as a group and individually. They all knew each other and Jace, Fin and Rod had lost two close male friends (Dave 
and Devon) to suicide within a 6 month period. Follow-up was done by text and Facebook (they don't answer their phones and often have no phone credit left). The participants gave me permission to 'friend' them and to look at past posts and photos of them and Dave and Devon.

Likewise, I met Phil's sister through the Waves programme. She suggested that some of Phil's friends might be interested in taking part in the study and passed on information and fliers to them. Three of Phil's friends, Luke, Adam and Max contacted me by email asking for more detail about me and the study and were interviewed separately. We connected over a love of computer and console games, discussing our favourites and strategies, star wars and aspects of "geek" culture. The three participants also loved having heated and deep philosophical discussions about life (and I had taken several philosophy papers as an undergraduate student).

Harley heard about the study through talking to a mental health nurse at his workplace. When we first met he told me he was a bit shocked as he wasn't expecting a lecturer from the university to be wearing jeans, a hoodie and sunglasses. He shook my hand and grinned. He had a warm, caring and jovial presence to him. Straight away (in the preinterview meeting) he started to tell me how he had met his friend (Kane), how it had affected him and how he had been an angry young man who was often in trouble with the law. We talked a lot about life on the streets and getting into trouble with the law and gang life - something I knew about through my teaching in youth studies and adolescent issues.

Initially, I expected to interview 5-10 individuals, unconnected participants with diverse and different experiences of the phenomenon who had lost a close male and/or female friend to suicide. I ended up with a unique opportunity to explore the experience of eight participants who had all lost close male friends and the experiences of two groups of friends who had lost three friends to suicide. I was excited about what I might learn from these participants and how each of them experienced the loss of the same close friend within the context of a 'friendship group'.

I interviewed the eight young men who volunteered for the study who met the following inclusion criteria: (i) males, (ii) aged between 17-25 years (emerging adults, Arnett, 
2010), (iii) have personally experienced the suicide of a 'close' male or female friend to suicide described as someone they had a close attachment or bond to (this ruled out parental, sibling or extended family bereavement). Participants were encouraged to describe their relationship with the deceased and define this for themselves in their own words; (iv) 'recently bereaved' between 6 months to 3 years (this rules out childhood bereavement and allows participants sufficient time to be able to reflect on their experience and to process their grief and minimises limitations of recall); (v) able to discuss and articulate their experience of suicide bereavement (this rules out participants who have cognitive or other impairments who are unable to discuss or express their experiences verbally) and (vi) able to provide informed consent.

\section{Sampling and saturation.}

There has been much debate about sampling methods (theoretical, convenience, respondent driven), sample size and data saturation in qualitative research (Trotter, 2012). Sampling methods need to be consistent with the aims and assumptions of the method, maximising efficiency and validity (Morse \& Niehaus, 2009). Sampling in qualitative research needs to be flexible and reflect the research problem. Some researchers try to ensure their sample has maximum variation to identify common patterns that cut across variations, while others select homogenous cases for reducing variation, simplifying analysis and facilitating finding commonality (Palinkas et al., 2015). Opportunistic or emergent sampling are designed to achieve both goals (Palinkas et al., 2015).

I chose an opportunistic/convenience but purposeful sampling strategy because the research required "the identification and selection of information-rich cases related to the phenomenon of interest" (Palinkas et al., 2015, p.1). I also used criterion-based sampling to ensure the participants had direct lived experience of the phenomenon (Elliot \& Timulak, 2005), experienced the loss of their friend during their youth or emerging adulthood, had sufficient time to process and manage their grief, and were able to articulate their experience. The purpose of this study was to find the common (but not universal) essence of the phenomenon and so I decided to focus on a homogenous sample. While there was some variation between the men in terms of age, demographic background (education, employment, and socio-economic status), they did represent a fairly homogenous subgroup of survivors. All the participants shared experience of the 
same phenomenon, they had all lost male friends to suicide during a time when they were transitioning into adulthood and silence was a common aspect of their lived experience.

\section{Sample size.}

There has been an ongoing debate in qualitative research about ideal sample size (Mason, 2010). Qualitative research does not tend to concern itself with large sample sizes to ensure reliability, rather it relies on the concept of saturation or "data adequacy" (Morse, 1995). Qualitative researchers try to sample broadly enough and interview people deeply enough to capture all the important aspects and variations of a phenomenon - whether the sample be small or large (Elliot \& Timulak, 2005). The richness of data is derived from detailed description, not the number of times something is stated (Morse, 1995).

Samples tend to be smaller because the frequency of data is relatively unimportant, the meaning and understanding of data is more important than making generalizable statements, and qualitative research tends to be labour intensive and so a large sample can be impractical and time consuming (Mason, 2010). Sample sizes in phenomenological studies have varied from five to thirty (Smith \& Osborn, 2008) with an average of 15 participants (range 8-31) in education-based studies and 25 participants (range 8-52) in health science studies (Guetterman, 2015). Sample size can refer to both numbers of participants but also numbers of interviews or events sampled, and may include observations (Sandelowski, 1995).

The sample for this study consisted of eight participants which is within the recommended range for phenomenological studies (Creswell, 1998; Morse, 1994; Smith \& Osborn, 2008) and for homogenous samples (Kuzel, 1992). The eight men represented a relatively small, homogenous and special population (age, experience of the phenomenon). This sample size is appropriate for descriptive studies which tend to have relatively small and representative samples of either a whole culture, subculture, or special populations in order to explore specific beliefs, behaviour or experiences (Weller \& Romney, 1988). A smaller sample allowed participants sufficient time to describe their experiences in detail and depth (Huws \& Jones, 2008; Smith \& Osborn, 2008). Having a smaller sample also allowed me to analyse data in more depth and to develop an understanding of participant's experiences over time (Larkin, Watts \& Clifton, 2008). 
A total of 13 interviews, 12 individual in-depth interviews (which included follow-up interviews) and one group interview (with three participants) were conducted. Guest, Bunce and Johnson (2006) suggest twelve interviews may suffice if data quality is high and the group is relatively homogenous and the aim is to understand common perceptions. Numerous conversations, emails and other exchanges also provided additional data and were separate data collection events, offering triangulation of data source (Denzin, 2009). There were a total of $19 \mathrm{hrs}$ of interviews and 1,126 pages of interview transcripts containing detailed statements and descriptions of the experiences of participants. This suggested that the study had both rich data (many-layered, intricate, detailed, and nuanced) and thick data (a lot of data) and that saturation was able to be achieved because of the depth of the data (Fusch \& Ness, 2015).

\section{Data saturation.}

The issue of finding an optimal sample size has led to the concept of data saturation. Data saturation or theoretical saturation is a key part of naturalistic inquiry and often involves bringing new participants into a study until the data set is complete as indicated by data replication or redundancy (Guest et al., 2006). In other words, saturation is reached when a researcher finds nothing new about a phenomenon (Guest et al., 2006) and where replication verifies and ensures comprehension and completeness (Bowen, 2008). Saturation means that "sufficient data to account for all aspects of the phenomenon have been obtained" (Morse, Barrett, Mayan, Olson \& Spiers, 2002, p. 12).

Despite some agreement about the importance of data saturation and it being held up as a key ingredient for justifying adequate sample size (Guest et al., 2006), it has been a difficult concept to operationalise (Morse, 1995) and has been inconsistently assessed and reported (Fusch \& Ness, 2015). Bowen (2008) points out that researchers need to explain how saturation was achieved and substantiate it with clear evidence. Part of the problem is that there is no clear way to assess saturation because there is no set ideal number of participants from which saturation might be achieved (Trotter, 2012).

An additional issue is that saturation may never be reached as Wray et al. (2007) state:

"...no data are ever truly saturated: there are always new things to explore...qualitative research cannot be fitted into a paradigm or judged against norms of quantitative research, and specifying numbers can be misleading and inappropriate." (p. 1400) 
Essentially theoretical saturation is achieved when collection of new data does not reveal anything new about a phenomenon/issue (Mason, 2010). In theoretical sampling, the researcher is not so concerned about size, generalisability or the representativeness of the sample. Researchers who use theoretical sampling are more concerned about the adequacy of the sample and whether it is composed of participants who best represent or have knowledge of the phenomenon. They are also concerned with whether the sample will lead to efficient and effective saturation of themes, categories or codes, with optimal quality data and minimum surplus (Bowen, 2008).

Morse (1995) defines data saturation as "data adequacy" or collecting enough data until no more new information is found or when a researcher feels they have "heard it all" (p. 147). She claimed that saturation is not just about the frequency of which data occurs but is also about eliciting all forms or types of occurrences and valuing variation over quantity. According to Morse, richness is more important than quantity or frequency and it is more important for the researcher to "know it all" than to hear things over and over (Morse, 1995, p. 148). Saturation should be based on depth as well as breadth of information and sampling adequacy evidenced by saturation and replication (Bowen, 2008). Researchers may return to participants for a second and third time to elicit data to expand the depth or address gaps in the emerging analysis, or interview additional participants to increase the scope, adequacy and appropriateness of the data (Morse et al., 2002).

Data collection and analysis were ongoing throughout my study but recruitment stopped when data saturation was evident. Data saturation was achieved when I felt that I had data of sufficient richness, depth and quality and had a complete picture of the experience. I interviewed seven participants twice in order to achieve depth, elicit more information and description, and clarify understanding of my emerging understanding of suicide bereavement. When I interviewed an eighth participant towards the end of the study I believed that I had reached saturation. Analysis of the final interview with Harley (the outlier and only individual case) suggested that his experience was not significantly different to that of the two groups of participants. I also realised saturation had been achieved when analysis of the last few follow-up interviews led to no new concepts, categories or themes and descriptions added only additional detail but nothing new to 
initial themes. At this point all of the research questions had also been explored in detail (Trotter, 2012).

Data saturation was achieved quite quickly because this study had a number of features which influence saturation: my sample was relatively small (Fusch \& Ness, 2015), cohesive, homogenous (the participants shared similar characteristics in terms of age, social and cultural backgrounds, and relationships to the deceased) (Morse, 1995); the sample was purposive based on careful sampling and certain selection criteria (Morse, 1995; Ritchie, Lewis \& Elam, 2003); and the data was rich, full and complete (Morse, 1995). The use of phenomenological methodology which has been shown to lead to saturation, the use of phenomenological interviewing, probing questions and creating a state of epoché may have also helped achieve data saturation (Fusch \& Ness, 2015).

Data triangulation and crystallisation (Fusch \& Ness, 2015) was also used to achieve saturation. Initial descriptive and contextual interviews (Bevan, 2014) with individuals and one group of three participants led to the development of a number of tentative concepts and themes (naïve analysis). Follow-up interviews were conducted to help participants apprehend and clarify the phenomenon (Bevan, 2014), and deepen my understanding of the phenomenon and the different ways it appeared to participants. During data collection I constructed a saturation grid in excel, listing major topics and themes vertical and interviews conducted on the horizontal (Brod, Tesler \& Christianssen, 2009). This helped me monitor saturation and development of themes across interviews and participants, decide when to stop recruitment, and helped me determine core characteristics of the phenomenon.

I used interview accounts, informal conversations, and field notes based on observations to check the validity of my interpretation. I presented my interpretations to the participants during follow-up interviews and in subsequent communications. Participants generally agreed with my description of their experience and the core themes. I also presented initial findings to a range of mental health professionals (general practitioners, nurses, counsellors, therapists, psychologists, trauma specialists) who also confirmed that the data and description 'fitted' with their experience of other young men they had supported. 
I drew on Denzin's (2012) idea of crystal refraction (many points of light) to extrapolate the meaning inherent in the data. I crystallised the meaning through recognising that there are many sides from which to approach the concept (Richardson \& Adams-St. Pierre, 2008), that a phenomenon may present itself in different ways to different individuals, and it may "appear" to them differently (Bevan, 2014). Despite this, participants may be talking about the same concept (for example, silence/d) but use a different label or word (for example, quiet, left out, unheard) to describe their lived experience of the phenomenon (Denzin, 2012).

\section{Contextualisation: The Deceased and the Research Participants}

Descriptive phenomenology focuses on finding the essence and invariant structure of the phenomenon under study. As such, it is less concerned with context and assumes that context has a minimal influence on phenomena (Wojnar \& Swanson, 2007). However, it is important in qualitative research to provide contextual information about the participants in order to understand their lived experience, the nature of their loss and life world. Qualitative researchers aim to provide thorough descriptions of their sample, so that others can make judgements about the transferability of findings to other similar samples (Elliot \& Timulak, 2005).

The following section provides some contextual information in order to help with the transferability of the findings and understanding of the participants' experience of suicide bereavement (who and what they lost). The eight participants (who were given pseudonyms) had lost four close male friends (also given pseudonyms) but had also experienced the suicides of other peers and adult members of their community. The deceased each had their own circumstances and unique backgrounds (see Appendix 5).

Each of the participants had a unique relationship with their close friends all of whom died by suicide (hanging, complications following hanging, gunshot, jumping from a cliff). Only Phil's and Dave's suicides seemed to be connected with long-standing prior mental health issues and all of the suicides were precipitated by specific but typical events linked to increased risk of suicide in this age group (bullying, recent break ups, being arrested, being a victim of an assault). 


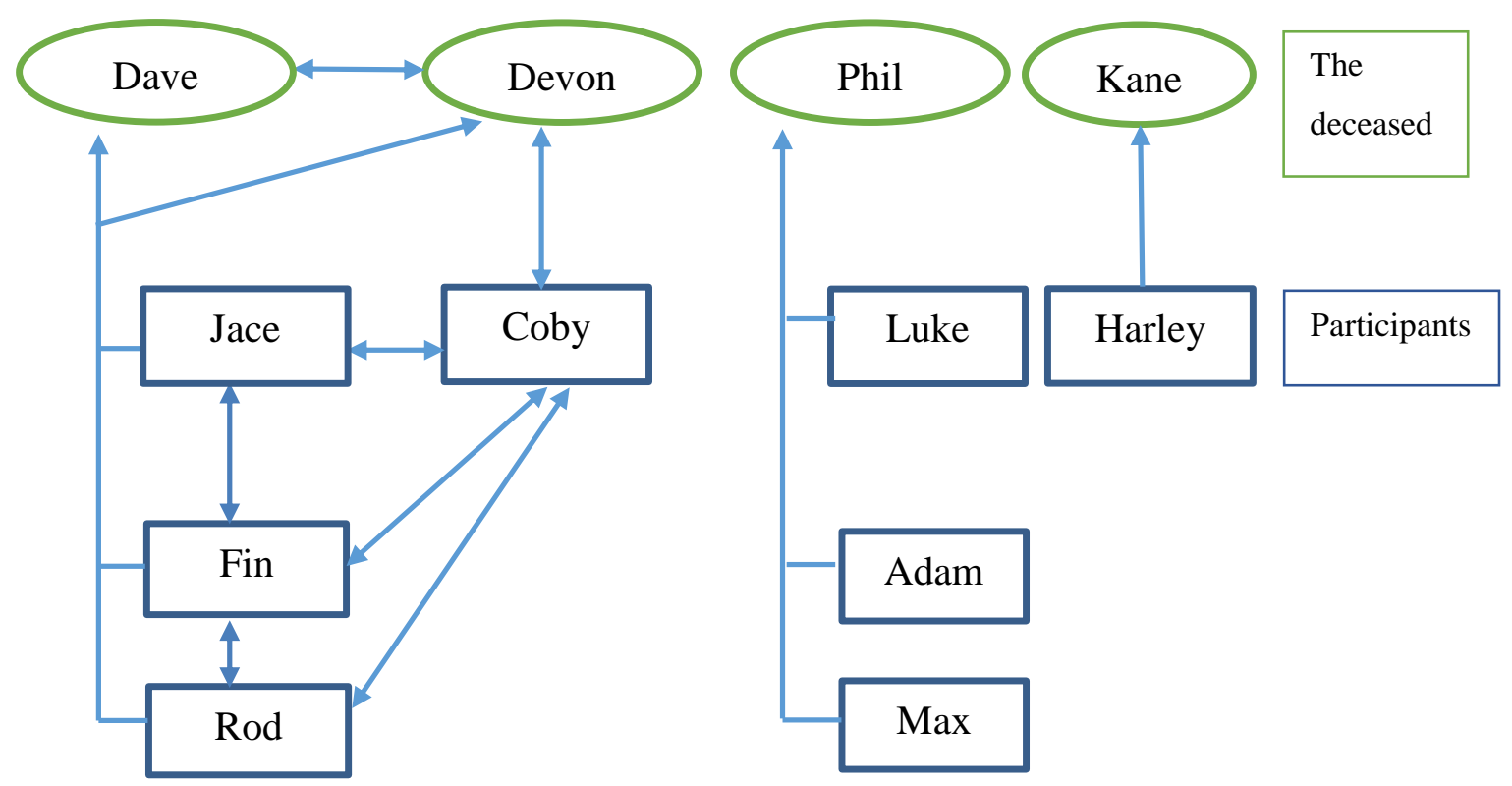

Figure 1. Relationships of participants to the deceased

\section{The participants.}

The participants were eight young men (6 European/New Zealanders, 1 Māori, and 1 Samoan) aged 17-25 years who lived in both urban and rural parts of the city region. Four of the men were 17-19 years of age, one was 22 years and three were 25 years old at the time of the interviews. They had all been bereaved between 1-3 years and had known the deceased for between 3-17 years). They had a mix of backgrounds, educational experiences and qualifications and varied in terms of the life situations (see Table 1. below for more demographic information and Appendix 5 for more background on the participants).

Half of the participants (Coby, Jace, Fin, Rod and Harley) were from a working class background. They grew up in working class (lower socioeconomic status) areas, many of them dropping out of school early and working in trades and manual labouring jobs or undertaking training and apprenticeships in the suburbs. Harley was an ex-gang member and Rod had also been in frequent trouble with the law. Many of these men still lived at home, or with their girl-friend's family and they had limited income. In contrast, Adam, Luke and Max, were all from white-collar backgrounds, they were university graduates and working full-time in IT, administration and other jobs in the city. These men rented and lived in their own flats and none of them had been in trouble with the law. 
The participants differed in their experiences and use of support following the suicides. Coby, Jace, Fin and Rod relied more on informal support (family and friends) to get them through, whereas, Adam, Max and Harley utilised a range of counselling and professional support. The younger participants had been offered professional support but were suspicious of authority figures and counsellors, who they found unreliable and unfamiliar with their lifeworld. Adam, Max and Harley had also found working with health professionals challenging. They persisted with 'the system' and eventually were able to engage with some professionals and find some realistic and useful support.

The suicides also had different effects on the men's social networks. For Dave and Devon's friends the experience brought them together, for Phil and Kane's friends it seemed to tear their social network apart. Jace, Fin and Rod (with the exception of Coby) stayed very close, closing ranks, supporting one another and looking out for each other and they maintained their relationships with one another. They experienced a shrinking of their social circle with some friends dropping away. This was in stark contrast to Adam, Luke and Max who separated and maintained distance from one another up until to the end of the interviews.

Despite their lack of use of professional support Dave and Devon's friends showed remarkable resilience having lost two close friends within one month. They were very involved and included in the funerals of their friends and their relationships with the deceased had been respected and acknowledged. Adam, Luke and Max had lost their friend Phil three years ago, and Harley had lost his friend two years earlier; none of them were deeply involved or included in the funerals of their friends. Despite some of these differences there were common themes in the men's experience. 
Table 1. Participant demographics and information

\begin{tabular}{|c|c|c|c|c|c|c|c|c|c|c|c|c|}
\hline Pseudonym & Age & Ethnicity & Occupation & $\begin{array}{l}\text { Education } \\
\text { Level }\end{array}$ & $\begin{array}{l}\text { Relationship } \\
\text { Status }\end{array}$ & $\begin{array}{l}\text { Religious } \\
\text { Affiliation }\end{array}$ & $\begin{array}{l}\text { Time Since } \\
\text { Bereavement }\end{array}$ & $\begin{array}{l}\text { Time } \\
\text { Known }\end{array}$ & $\begin{array}{l}\text { Deceased } \\
\text { Pseudonym }\end{array}$ & $\begin{array}{l}\text { Age of } \\
\text { deceased }\end{array}$ & $\begin{array}{l}\text { Method } \\
\text { of suicide }\end{array}$ & $\begin{array}{l}\text { Support } \\
\text { Offered or } \\
\text { Accessed }\end{array}$ \\
\hline Coby & 19 & $\begin{array}{l}\text { NZ/ } \\
\text { European }\end{array}$ & Manager & $\begin{array}{l}\text { NZQA } \\
\text { Level2, } \\
\text { Nat Cert } \\
\text { Level2 }\end{array}$ & Separated & None & 1 year & $7 \mathrm{yrs}$ & Devon & $17 \mathrm{yrs}$ & Hanging & Family \\
\hline Jace & 17 & $\begin{array}{l}\mathrm{NZ/} \\
\text { European }\end{array}$ & Student & $\begin{array}{l}\text { NCEA } \\
\text { Level2 }\end{array}$ & Defacto & None & $\begin{array}{l}1 \text { year } \\
1 \text { year }\end{array}$ & $17 \mathrm{yrs}$ & $\begin{array}{l}\text { Devon } \\
\text { Dave }\end{array}$ & $\begin{array}{l}17 \mathrm{yrs} \\
16 \mathrm{yrs}\end{array}$ & $\begin{array}{l}\text { Hanging } \\
\text { Hanging }\end{array}$ & $\begin{array}{l}\text { Family } \quad \& \\
\text { Friends }\end{array}$ \\
\hline Fin & 17 & $\begin{array}{l}\text { NZ/ } \\
\text { European }\end{array}$ & Automotive & $\begin{array}{l}\text { NCEA } \\
\text { Level2 }\end{array}$ & Single & None & $\begin{array}{l}1 \text { year } \\
1 \text { year }\end{array}$ & 12 yrs & $\begin{array}{l}\text { Devon } \\
\text { Dave }\end{array}$ & $\begin{array}{l}17 \mathrm{yrs} \\
16 \mathrm{yrs} \\
\end{array}$ & $\begin{array}{l}\text { Hanging } \\
\text { Hanging }\end{array}$ & $\begin{array}{ll}\text { Family } \quad \& \\
\text { Friends }\end{array}$ \\
\hline Rod & 19 & Māori & Automotive & $\begin{array}{l}\text { NCEA } \\
\text { Level2 }\end{array}$ & Defacto & None & $\begin{array}{l}1 \text { year } \\
1 \text { year }\end{array}$ & $5 \mathrm{yrs}$ & $\begin{array}{l}\text { Devon } \\
\text { Dave }\end{array}$ & $\begin{array}{l}17 \mathrm{yrs} \\
16 \mathrm{yrs}\end{array}$ & $\begin{array}{l}\text { Hanging } \\
\text { Hanging }\end{array}$ & $\begin{array}{l}\text { Family } \quad \& \\
\text { Friends }\end{array}$ \\
\hline Luke & 25 & $\begin{array}{l}\text { NZ/ } \\
\text { European }\end{array}$ & $\begin{array}{l}\text { Web } \\
\text { Developer }\end{array}$ & $\begin{array}{l}\text { BSC Comp } \\
\text { Sci }\end{array}$ & Single & Agnostic & 3 years & $10 \mathrm{yrs}$ & Phil & $21 \mathrm{yrs}$ & Gunshot & None \\
\hline Adam & 25 & $\begin{array}{l}\text { NZ/ } \\
\text { European }\end{array}$ & $\begin{array}{l}\text { Admin } \\
\text { Officer }\end{array}$ & $\begin{array}{l}\text { NCEA } \\
\text { Level2 }\end{array}$ & Defacto & None & 3 years & $8 \mathrm{yrs}$ & Phil & $21 \mathrm{yrs}$ & Gunshot & $\begin{array}{l}\text { EAP, Family } \\
\text { \& Friends }\end{array}$ \\
\hline Max & 25 & $\begin{array}{l}\mathrm{NZ/} \\
\text { European }\end{array}$ & IT & UE & Defacto & None & 3 years & $\begin{array}{l}3 \text { yrs } 4 \\
\text { mths }\end{array}$ & Phil & $21 \mathrm{yrs}$ & Gunshot & $\begin{array}{l}\text { GP \& } \\
\text { Counselling }\end{array}$ \\
\hline Harley & 22 & $\begin{array}{l}\text { Samoan/ } \\
\text { European }\end{array}$ & Receptionist & $\begin{array}{l}\text { NZCEA } \\
\text { Level1 }\end{array}$ & Single & Mormon & $\begin{array}{l}2 \text { years } 10 \\
\text { mths }\end{array}$ & 4 years & Kiti & $17 \mathrm{yrs}$ & Jumping & Counselling \\
\hline
\end{tabular}




\section{Methods of Data Collection}

The data used to study the phenomenon consisted of verbal (subjective) descriptions of their lived experience following the suicide of a close friend. All of the men in this study had lost a close male friend (of similar age to them) to suicide in the past 1-3 years. Other forms of data included conversations that took place outside of interviews, (online through Facebook, email and texts and during ride-alongs), non-verbal cues during interviews, field notes and reflections recorded in my diary. Demographic data for the participants was also collected including occupation/employment status, age, time since bereavement, marital or relationship status, level of education, cultural and religious affiliations. This background data was important to provide some contextualisation and to enhance transferability.

\section{Data collection methods.}

In phenomenological studies, data is usually collected through phenomenological indepth interviews with participants who have experienced the phenomenon. Phenomenological interviews seek to elicit rich descriptions of experience and follow-up interviews were conducted to gain further descriptions and examples of experience (Creswell, 2007). Phenomenological studies may also utilise other forms of data collection, collected through observation, participant diaries or reflective journals, and art work (Creswell, 2007). The main source of data was interviews but I also kept a reflective diary recording memos and notes about my preconceptions, and experiences of conducting the research to aid with reflexivity. Memos were used on transcripts of interviews to record thoughts and help with development of description and analysis of themes.

A total of twelve semi-structured/phenomenological interviews were conducted. Phenomenological interviews are usually conducted on an individual basis. However, three of the participants (who had lost two close friends) requested to be interviewed as a group. A group interview provided an opportunity for participants to support one another in recounting both individual and collective experience and co-construct and make sense of their experience. While I encouraged each of the participants to tell their own account and share their own individual experience it became clear during one of the group interviews that the participants were censoring and policing each other. I recorded the 106 
process in my field notes and reflected on this. In a later follow-up group interview with Jace and Fin there was less censoring and correcting of each other's statements. Rod (who was interviewed separately the second time) disclosed that he felt he could talk more freely and openly about his experience in private. It was in this follow-up interview that Rod shared aspects of his experience that he had not shared with his friends but felt safe sharing with me.

For this study, adopting a 'right time' approach to data collection (Urry, Sanders \& Munford, 2014) meant keeping the door open and engaging with participants in different types of data collection, receiving information by text, email, unscheduled conversations and being prepared to interview on the go. I was aware that the participants were young people and that engagement, data collection and retention for follow-up interviews would be challenging because many young people face adversity, live in fluctuating circumstances and are highly mobile (Urry et al., 2014).

For this reason I decided to collect data and conduct interviews when and where it was convenient for participants. For example, some participants wanted to be interviewed on campus away from their flat mates and family members, others wanted to be interviewed at home (where they had supportive partners), while others wanted to be interviewed at times that fitted in with their work hour or shifts. On one occasion a participant rang me early on a Sunday morning to tell me he couldn't make the interview that day as he was still in a holding cell at the police station. I offered to pick him up and we conducted the interview in the car after he got a feed and continued when I dropped him at his girlfriend's flat.

\section{Interviews.}

The primary data collection method used was face-to-face semi-structured phenomenological interviews (Laverty, 2003, p. 18) which were used to explore and gather experiential narratives and lived experience descriptions (van Manen, 2014, p. 314). Open-ended and semi-structured interviews can permit the researcher to use questions as prompts and provide flexibility for the researchers to adapt their line of questioning to fit with the participant's account (Smith, Joseph \& Das Nair, 2011). These types of interviews often provide rich and unexpected findings, can allow participants to define, describe and focus on the aspects of phenomenon that are important to them. They 
allow the participant to freely talk, and to talk in conversation with the interviewer (Rapley, 2001). The interviews were carried out as an informal conversational interview (Moustakas, 1990) until the phenomenon was thoroughly discussed.

Brinkmann and Kvale (2015) state: "An interview is literally an inter-view, an interchange of views between two persons conversing about a theme of mutual interest" (p. 4) where the researcher "attempts to understand the world from the subject's point of view, to unfold the meaning of their experiences, to uncover their lived world prior to scientific explanations" (p. 3). The interviews were about entering into an intimate dialogue in order to make the hidden meanings visible, to develop a deeper understanding and to check understanding. Through this process and intersubjectivity, both the participant and my understanding of the phenomena was changed. In line with descriptive phenomenology and reflexivity, I was careful to remain open to new findings and not to let themes and ideas from the first interviews shape successive interviews with participants.

The location of interviews was negotiated and conducted at a place where both the participant and researcher were comfortable. Van Manen (2014) suggests that phenomenological interviews are best conducted in surroundings that are conducive to thinking about the experience or phenomenon of study and thus, may need to occur in settings that 'feel right' to participants. The interviews were conducted at the participant's houses/flats, two at the university (which was close to one of the participant's work), one at a participant's work, and the two group interviews were conducted at Devon's parent's house at the participant's request and with their permission.

I followed the guidance of Kvale and Brinkmann (2009), by adopting deliberate naiveté (phenomenological reduction) setting aside personal knowledge, theory and beliefs, and what I already knew about the phenomenon prior to interviews. This allowed me to become a perpetual beginner and immerse myself in the participant's lifeworld. At the beginning of each interview I stated to participants that they were the experts in their own experience (Spradley, 1979) and that I was interested in understanding their experience as it appears to them. I told them I wanted to understand their world through their eyes and their experiences so far as possible, and that together we could explore their experiences fully and understand them. I followed Giorgi's (1989, 1997) two-tiered 
method of interviewing and Bevan's (2014) three phase method of phenomenological interviewing (combining the last two phases).

The first interviews focused on obtaining descriptions of the phenomenon, context (lifeworld), and biography from which the experience gains meaning (Bevan, 2014). These interviews helped participants reconstruct and describe their experience, and describe accounts of places, events, actions and activities. The aim of the interviews was to capture pre-reflective experiential accounts (not opinions, perceptions or interpretations). I asked participants to describe specific situations and actions rather than offer their perceptions and opinions. This allowed me to examine the phenomenon as it appeared to participants and as it stands out against context, and this informed its meaning.

I designed an interview guide to encourage participant's descriptions of context, apprehension and clarification of the phenomenon (Bevan, 2014). Questions were focused on participant's experiences, feelings and thoughts about the phenomenon, for example "what goes on within". The interviews started with descriptive and broad less specific questions and moved towards more specific, sensitive topics. Questions covered three main areas: (i) aspects of the relationship with the deceased; (ii) the event (finding out about the suicide, first reactions) and experience of bereavement in the time after (funerals, grieving, unveilings); and (iii) adjusting to life without the deceased and the meaning of their experience (See Appendix 4).

I used prompts to gain further description ("Tell me more about what happened, when that occurred, how you reacted, what that experience was like"), structural probes to encourage introspection and reflection on meaning ("What was that experience like? Can you describe how life would be different if the deceased had not taken his life?"). I used loops ("Can you give me another example of what that experience was like? What else happened?) when participants avoided or misinterpreted questions. I rephrased questions to make it clear that I was trying to understand, and that the participants were the experts teaching me about their experience. I did not want them to feel like they were being doubted or made to seem incompetent (Oliffe \& Mróz, 2005). 
The follow-up interviews were conducted approximately 2-6 months after initial interviews and analysis. Seven follow-up interviews were conducted with participants. One did not want a follow-up interview; he provided a sufficient and detailed account of his experience. The second interviews on seven participants were used to elicit greater detail and more lived experience descriptors (LEDs) (van Manen, 2014), to explore the phenomenon in more detail, so that I could apprehend it and the many ways in which it appears to different participants. These interviews focused on clarifying the key structures of the phenomenon. This involved using imaginative variation (Finlay, 2011; Giorgi, 1989) to examine, explore and clarify aspects of the phenomenon by asking participants to describe what life was like in the presence and absence of the phenomenon, or before and after an experience. During data analysis I then compared individual structures with other participants, in order to develop an intersubjective experience structure or general essence (Bevan, 2014) and construct an exhaustive description. The follow-up interviews also enabled me to check my understanding and interpretation with the participants and further explore the meaning of the experience.

Interviews were between 1-2 hrs long; this allowed sufficient time for participants to talk freely about their lived experience. All the interviews were digitally recorded with participants' permission and transcribed verbatim to ensure reliability of the data. The interviews were transcribed by a transcriber and then I listened to and checked them for accuracy, additions of pauses, tone, and so on, and added comments to reflect context of what was said and meaning/intentionality. All participants were provided with copies of transcripts of their interviews, with only two making minor amendments to the names of people and places (which were later removed to protect the identity of participants).

During the analysis when selecting significant statements, the source of quotes were indicated by the name of the participant followed by the number of the interview, page and line number. For example, (Max2, 8; 3-14) would indicate the quote is from the second interview with Max, page 8, lines 3-14. Data collection and analysis occurred simultaneously, was ongoing and occurred over a period of seven months; this led to a wealth of rich data (see Table 2 below). 
Table 2. Datasets generated from the interviews

\begin{tabular}{|c|c|c|c|c|c|}
\hline Interview & Participant/s & Date & $\begin{array}{l}\text { Interview } \\
\text { length } \\
\text { (mins) }\end{array}$ & $\begin{array}{l}\text { Pages of } \\
\text { transcript }\end{array}$ & Field Notes \\
\hline 1 & Coby & $5-4-2013$ & 95 & 55 & $\begin{array}{l}13 \text { mins } \\
5 \text { pages }\end{array}$ \\
\hline 2 & $\begin{array}{l}\text { Rod, Fin \& } \\
\text { Jace }\end{array}$ & $27-4-2013$ & 60 & 61 & $\begin{array}{l}20 \text { mins } \\
6 \text { pages }\end{array}$ \\
\hline 3 & Adam & $17-9-2013$ & 60 & 30 & $\begin{array}{l}12 \text { mins } \\
3 \text { pages }\end{array}$ \\
\hline 4 & Luke & $19-9-2013$ & 68 & 26 & $\begin{array}{l}11 \text { mins } \\
3 \text { pages }\end{array}$ \\
\hline 5 & Max & $21-9-2013$ & 131 & 29 & $\begin{array}{l}10 \text { mins } \\
3 \text { pages }\end{array}$ \\
\hline 6 & Coby & 21-10-2013 & 120 & 46 & $\begin{array}{l}11 \text { mins } \\
3 \text { pages }\end{array}$ \\
\hline 7 & Fin \& Jace & $27-10-2013$ & 120 & 58 & $\begin{array}{l}5 \text { mins } \\
1 \text { page }\end{array}$ \\
\hline 8 & Luke & 21-11-2013 & 148 & 36 & $\begin{array}{l}10 \text { mins } \\
3 \text { pages }\end{array}$ \\
\hline 9 & Adam & $26-11-2013$ & 121 & 38 & $\begin{array}{l}10 \text { mins } \\
3 \text { pages }\end{array}$ \\
\hline 10 & Max & $30-11-2013$ & 131 & 36 & $\begin{array}{l}11 \text { mins } \\
3 \text { pages }\end{array}$ \\
\hline 11 & Harley & $2-12-2013$ & 65 & 33 & $\begin{array}{l}10 \text { mins } \\
3 \text { pages }\end{array}$ \\
\hline \multirow[t]{2}{*}{12} & Rod & $15-12-2013$ & 80 & 35 & $\begin{array}{l}12 \text { mins } \\
3 \text { pages }\end{array}$ \\
\hline & & & $\begin{array}{l}1,199 \\
\text { mins } \\
19.2 \mathrm{hrs}\end{array}$ & 483 pages & $\begin{array}{l}135 \text { mins } \\
39 \text { pages }\end{array}$ \\
\hline
\end{tabular}

Field notes.

During the interviews and conversations with participants, I observed and listened attentively in a manner that broke down the distance between them and myself; that is I entered and participated in their lifeworld as this is considered to be a valuable method of collecting experiential material from others (van Manen, 2014). "Close observation" requires researchers to assume a relationship as close as possible to the participant but still retain alertness to situations that allow them to step back and reflect on the meaning of those situations (van Manen, 2014, p. 318). 
I recorded field notes after interviews and these provided information on behaviours, interpersonal relationships and dynamics and the meaning of the persons and relationships lost. These were later reflected on when developing themes, writing about themes and conducting the data analysis. The following is an example of a field note following the first interview with Coby:

During the interview Coby became quiet, he looked down and away from me when it came to discussing his last words to Devon. He tried to hide his emotions and struggled to find the words to talk about Devon dying in hospital. I sat quietly and just waited. I gave him space. The silence persisted. He seemed to pull back, put a wall up. We decided to stop the interview and have a smoke on the porch. We talked about his car, and music. He told me about how his car was a safe space for grief and for reconnecting with Devon through music and memories. He also told me about the void in his life that would never be filled by another friend. The void was another form of silence, empty quiet, a space that reminded him of who he lost (C. Bowden, personal communication, April 5, 2013).

During the times between interviews and when I was building rapport and getting to know participants I also kept field notes. I drew on the go-along method described by Kusenbach (2003, pp. 463-467) used in ethnographic and sociological research. This method helps researchers understand and expose complex and subtle meanings of structures in the lifeworld of participants, experiences, as well as places (actual and remembered ones) as they move through and interact with their world. Natural go-alongs or ride-alongs (on wheels) involve researchers accompanying participants on routine outings and by asking questions, listening and observing they explore experience and interpretations in situ. The go-along method is more systematic than "hanging out" with participants in ethnographic research (Kusenbach, 2003).

As Kusenbach notes, sit down interviews often keep participants from engaging in natural activities; making it difficult to grasp what participants are talking about. In street phenomenology, go-alongs can help unearth personal, biographic experiences, give clues to how participants integrate memories, how places and spaces represent others and how participant's feel towards their interactional past (Kusenbach, 2003). Becoming and being a "privileged insider" can help researchers further their phenomenological understanding and are best used in combination with interviews (Kusenbach, 2003, p. 461). 
Some participants invited me to go to places that had meaning to them (for example, skate parks, cemeteries, and events where young people did controlled skids and burnouts). They did this to help me better understand their experience. They took me to the places they talked about in interviews and that had meaning for them because they bore connections to the deceased. On some occasions I travelled with them in the same car, and we talked about their experience and memories on the way, an example is described in the following field note:

The guys took me for a ride over the hill tonight. I was flung around in the back seat, hanging on for dear life. They were taking corners at close to $100 \mathrm{kms}$ per hr, recounting near-misses and reckless driving. One of them pointed out a section of the road where their friend had engaged in some drifting and showed me where they had nearly left the road: "That's where we nearly lost it. It was fuck'n sick as". We got to the other side of the hill and parked up in picnic area and lit a smoke. We sat in silence. The ride back was quieter, the guys didn't talk about their friend on the way back. The rap music and throttle of the engine filled the gap and emptied the silence in the car (C. Bowden, personal communication, May 5, 2013).

Engaging with participants "on the move" and conducting walking interviews can generate rich data because participants are prompted by meanings and connections to the surrounding environment and can help researchers explore connections between people, experience and the environment (Evans \& Jones, 2011). There are numerous advantages of using go-alongs and it has been used successfully to study topics related to health and wellbeing from a post-positivist standpoint and develop theories grounded in the lived experience of people (Carpiano, 2009).

I found the go-alongs, walk-alongs and drive-alongs helped both with rapport-building and gaining entry to the group. They helped me show that I was genuinely interested in their experiences and was prepared to invest time into developing a relationship and understanding. They also helped avoid the perception of being a "drive-by researcher", or one who is only interested in his own study and who enters and exits the field in a superficial way (Carpiano, 2009). I recorded the data from these events by hand in my note book and digitally as field notes rather than record conversations on the move. I then transcribed them and reflected on them making entries in my reflective diary. 


\section{Reflexivity and reflective diary.}

I kept a reflective diary for recording memos and notes about my preconceptions, and experiences of conducting the research to aid with reflexivity. Reflexivity involves reflecting on the ways in which research is conducted and the influences on interpretations (Banister, 1999; Finlay, 2008). Reflecting on the research made me aware that being a man and a survivor had its advantages in relation to recruitment and data collection but also in terms of analysis. As a man I connected with participants and understood some of the norms, language and practices of traditional masculinity. I adopted a side-by-side approach when interviewing, disclosed something about my own experience so that they felt safe talking and disclosing and conducted interviews in spaces they were comfortable in. I ensured that participants felt they had power and were in control at all times, letting them decide when and where interviews took place, letting them ask the first questions, set the pace, and "take charge" as both expert and teacher, and emphasising their strength, courage and contribution (Schwalbe \& Wolkomir, 2002).

As I examined the interview transcripts and field notes I also began to pay more careful attention to my own language and that of participants, using terms they were familiar with (mate, wounded, crushing it, sorted, pigs [police]), humour and self-depreciation as interviews progressed. I was conscious not to directly ask participants about feelings during interviews because feelings and talking about feelings are often associated with femininity (Martin \& Doka, 2000; Addis, 2011). Instead I asked them to describe what they thought, how they responded, and to simply describe their experiences. I also used many of the strategies for conducting research with men around health issues outlined by Oliffe and Mróz (2005) which helped me understand the nature of conducting research with men and my role as a male researcher.

I was conscious during the literature review and data analysis phase that previous studies on young people's experience of grief, loss and suicide bereavement had been conducted predominantly by female researchers. These studies involved few male participants and as a result men's experiences were not captured, described, re-presented or interpreted with masculinity in mind. Furthermore, these studies overlooked the role that the gender of the researcher may have had on seeing the phenomenon from the horizon (Geniusas, 2012; Luft, 2002) or perspective of male participants. 
My reflective research diary became a valuable tool for prompting insights and informing methodological decisions (Nadin \& Cassell, 2006): "reflection is aided by the use of a diary as it enables the researcher to continuously think about their own research practices and assumptions, by recording those thoughts in a systematic way" (p. 210). Research diaries can increase the trustworthiness of data and integrity of the research process (Finlay, 2003). A reflexive approach can help researchers think deeply about topics, spot excluded voices and inform their learning so they become better/more expert researchers (Nadin \& Cassell, 2006). The use of a reflective diary also fits with my positon as a constructivist researcher who believes it is important to examine the role the researcher plays.

My research diary was a lined A4 book that I recorded my thoughts in, usually before and after an interview. Each entry was started on a new page, staying the date, location, and included comments on my assumptions/preconceptions about how I thought the interview would go, how I experienced the interview, what I thought dominant themes were. I also noted any issues that arose with the interview process and ideas about methodological and theoretical implications. The following is an example of one of my early reflective diary entries following initial interviews with three participants who were friends:

I was surprised how much detail the men were willing to share during the interviews but how much they struggled to explain and put into words their experience. I steered clear from asking them about feelings. I picked up from them that feelings was a no-go word. Instead I asked them to describe what happened, how they reacted, what they thought - this made it much easier for them to discuss their experience. They still talked about emotions such as anger, sadness, hopelessness even though they did not use those words. Some of the participants maintained an objective distance focusing on the logical sequence of events. They had analysed their experience and made sense of it. Others found it hard at times, they "choked up" and needed time to gather their thoughts and words especially when talking about the funerals (C. Bowden, personal communication, September 21, 2013).

In reflecting on this entry I became aware I had assumed I had removed all the barriers to participant's being able to describe their experience. I had not thought about how traditional masculine gender norms might influence how the participants would talk about their experience. I started to look more closely at how my gender and that of the participants, might influence the research process (types of questions asked, stance, and 
recruitment) and data collected. I started to read more about ways to help men feel safe in research, the importance of self-disclosure and how methods such as photo-elicitation (Oliffe \& Bottorf, 2007) might help men talk safely about emotions and their inner experience by providing them with a safe distance framework. Practical comments allowed me to explore methodological issues (such as wording of certain questions) as well as how participants' responded, non-verbal cues and behaviour allowed me to adjust my technique. Comments on my experience enabled me to reflect on how I responded to revelations (my emotional state) and the experience of doing research. The diary also helped me keep track of the research process as a whole.

\section{Data management and audit trail.}

I used a number of strategies for managing and organising the data during data collection and analysis. First, I kept a spreadsheet/table that contained interview data (significant statements, memos, themes) for each participant and for all the interviews. This enabled me to monitor and track the development of key themes, changes in descriptions, names of themes, see how themes could be organised, collapsed or expanded. It also helped me to see data and themes that were not about participants' lived experiences and remove themes that were perceptions, or accounts of the reactions and responses of others. This tool allowed me to keep data organised in a systematic way and provided a means for careful checking and auditing of all steps of the analysis (Elliot \& Timulak, 2005). Second, I used diagrams with key ideas and theme trees to help map and track the relationships between themes.

\section{Method of Data Analysis/Interpretation}

In this study data collection and analysis happened simultaneously and was ongoing and was theoretically informed. Hycner (1985) argues that no method can be arbitrarily imposed on a phenomenon and must be responsive or "be true" to the phenomenon. A number of phenomenological scholars have developed rigorous methods for analysing data based on descriptive phenomenology (Colaizzi, 1978, Giorgi, 1997, Spiegelberg, 1975), many of which involve processes such as: (i) bracketing/epoché, (ii) intuiting, (iii) horizontalisation, (iv) analysing, and (v) describing the phenomenon (Finlay, 2011; Swanson-Kauffman \& Schonwald, 1988). I kept in mind the phenomenological principles outlined by Ihde (1986): the need to bracket or bridle preconceptions in order to understand and see the phenomenon in new ways; keeping to phenomenological 116 
description and avoiding causal explanations and interpretations; and the importance of horizontalisation (Finlay, 2011; Swanson-Kauffman \& Schowald, 1988). This is about not making assumptions about the relative importance of aspects of the phenomenon. These and the steps/process outlined below were used to ensure rigor in the study.

\section{Phenomenological attitude, reduction and bracketing.}

Phenomenological research acknowledges the important role that the researcher plays in the interpretations of the research findings (Smith, 2007). Researchers must take steps to remain open to new possibilities and interpretations of the world that come from the participant's experiences (Finlay, 2008). At all stages of the research (including data analysis), I adopted the phenomenological attitude of attentive openness (Kleiman, 2004). This attitude allows researchers to discover something meaningful and insightful and see phenomena in new ways. The essence of a phenomenon may be revealed "in such a fashion that we are now able to grasp the nature and significance of this experience in a hitherto unseen way" (van Manen, 1990, p. 37).

In order to remain open to seeing the phenomenon in a new way I engaged in phenomenological reduction: "the scientific process in which the researcher suspends or holds abeyance his or her presuppositions, biases, assumptions, theories, or previous experiences to see and describe the phenomenon" (Gearing, 2004, p. 1430). Phenomenological reduction involves the process of bracketing, a technique for mitigating the potentially deleterious effects of unacknowledged preconceptions (Tufford \& Newman, 2010).

Bracketing involves being honest and vigilant about one's perspective, pre-existing thoughts and beliefs, and developing hypotheses; it is, a self-reflective process where researchers recognise and set aside (but do not abandon) their a priori knowledge and assumptions, with the aim of attending to participants' accounts of experience with an open mind (Starks \& Trinidad, 2007). Bracketing is based on Husserl's concept of epoché and has been described as being "essential" to the tradition of descriptive phenomenology (Gearing, 2004). Epoché has been defined as: "an original vantage point, a clearing of the mind, space, and time" (Moustakis, 1994, p. 86). Bracketing can help researchers to 'see the world as it really is', rather than 'see it as it is constructed' (Caelli, 2000) and discover the meanings and describe the particularities of the phenomenon (Moustakis, 1994). 
Bracketing can also be used to increase the rigor of a research project. It also gives researchers an opportunity to engage in sustained in-depth reflection (to prevent the skewing of results and interpretations) and can enhance the accuracy of the research and produce a more multifaceted analysis and results (Tufford \& Newman, 2010). It can also be a method to protect the researcher from the cumulative effects of researching an emotionally challenging topic, or one that s/he is close to or has a relationship with. (Tufford \& Newman, 2010).

The process of bracketing has been described in more depth by other phenomenologists such as Giorgi (2000) and is said to involve the following steps: (i) separating the phenomenon from the world and inspecting it; (ii) dissecting the phenomenon to unravel its essential and unvarying structure, the core components that make it unique and defining it and analysing it; and (iii) suspending all preconceptions regarding the phenomenon (including prior theories, ideas, experience), and confronting the subject matter on its own terms. This ensures the researcher can hold at bay any preconceived ideas while s/he is listening to, interacting with, and analysing the narratives and accounts of experience as described by participants (Giorgi, 2000).

I used descriptive (eidetic) bracketing (Gearing, 2004) which has its philosophical foundation within the work of Giorgi (1985), Husserl and researchers such as Ashworth (1999). Descriptive bracketing requires researchers to set aside presuppositions connected with the phenomenon but recognises that it is not always possible to bracket out some larger social and cultural influences (Gearing, 2004). Descriptive bracketing is flexible and allows for some interpretation of the researcher. It is a type of bracketing suited to modern qualitative researchers who seek to understand the essences of experiences without claiming to find universal insights into the phenomenon (Gearing, 2004). Descriptive bracketing can lead to some universal truths about a phenomena or essences, but is more likely to lead to descriptions of the immediate specific phenomenon or 'local truths' and is thus more suited to research projects that examine phenomena within a specific context (for example, a population, age group, or cultural group).

Bracketing was accomplished through the use of my field notes which informed my reflective diary. My diary was used to write down thoughts, emotions (feelings of anger, blame), observations, assumptions, theories and wonderings (preconceptions) (Cutcliffe, 
2003). Recording presuppositions and thinking (about my reasons for undertaking the study, assumptions about gender, ideas about suicide bereavement, conflicts in values, reflections on power) in my research in my field notes and reflective journal (entries before and after each interview) helped me identify and acknowledge the influence on description and interpretation and to sustain a reflective stance (Ahern, 1999; Tufford \& Newman, 2010).

My field notes, reflective diary, and memos (cognitive notes, observational comments, insights) (Glass, 1998) helped me stay aware of how I may have been influencing the recording and analysing the data. These notes helped me describe my presuppositions about suicide bereavement, loss, grief and my theoretical understanding of these phenomena (before data collection) and then set them aside and keep them in check. This enabled me to enter (as much as possible) into the lifeworld of the unique individual who was interviewed while acknowledging the impossibility of complete and absolute phenomenological reduction or "pure objectivity" (Merleau-Ponty, 1962). Bracketing enabled me to listen, read and write about the phenomenon with openness, which is essential to phenomenological reduction and to see and determine the meaning of text (Keen, 1975).

Bracketing can involve seeking insights from fellow investigators or methodological experts who might have personal or professional experience with the topic. These experts can help researchers maintain an openness to new understanding and can provide a caution when personal bias begins to affect interpretation of the data (Wojnar \& Swanson, 2007). My supervisors helped with bracketing by questioning my perceptions, descriptions, interpretations and use of theoretical and psychological language and terms (for example, trauma, complicated or disenfranchised grief). At times, these concepts crept into the psychological descriptions I developed for the participants' experience.

Bracketing is also achieved by allowing interviewees opportunities to review and check analysis of data (Butt, 2006). I shared my descriptions and developing analysis with participants. I allowed them to check that I was not imposing my interpretation on the data, and made sure their descriptions predominated. Participants also checked and traced the path of the constructs (themes or categories of concepts) which helped to ensure credibility (Butt, 2006). 


\section{Five step approach to data analysis.}

While a number of phenomenologists (Colaizzi, 1973) have pioneered step-by-step procedures for analysing interview data to enhance rigour and validity, these methods do not always fit a research study or provide a full-proof recipe for conducting phenomenological research. I agree with van Manen (2014) that the approaches to data analysis such as thematic analysis (used in grounded theory and ethnography), that emphasise codification, conceptual abstraction and generalisation cannot adequately produce a phenomenological understanding. He states: "None of the work of the leading proponents of the phenomenological tradition would be commensurate with abstracting, coding and procedural approaches; developing taxonomies; looking for recurring themes; and so on" (van Manen, 2014, p. 319).

Phenomenology for van Manen is more about practice than philosophy, it is about "seeing" meaning that comes from epoché and reduction. Phenomenological analysis is an active process of identifying themes and meanings embodied in human experience that is represented in text. Van Manen (2014) states: "analyzing thematic meanings of a phenomenon (a lived experience) is a complex and creative process of insightful invention, discovery and disclosure. Grasping and formulating a thematic understanding is not a rule-bound process" (p. 320).

With that in mind, the methods developed by others are a useful guide, can sensitise researchers to issues and enhance the quality of research. For this reason, the data analysis was guided by van Manen's (2014) three step approach to holistic, selective and line-byline analysis of lived experience descriptions and Giorgi’s (1997) and Kvale's (1996) five-step descriptive phenomenological method. The key steps in Giorgi and Kvale's approach are as follows:

1. Assume phenomenological attitude and read naïve description to get sense of whole.

2. Demarcate and extract phrases or sentences "meaning units".

3. Categorise meaning units into themes and create psychological descriptions (for each participant).

4. Interrogate meaning units and condense into essential categories and meaningful themes (across participants).

5. Synthesise into essential themes and formulate exhaustive description of the phenomenon. 
Figure 2. below illustrates the steps I used in the data analysis and the process.

Preparing for Analysis

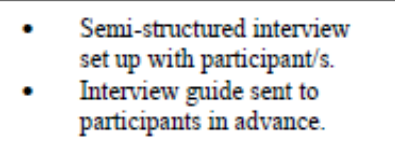

Analysing Individual Experience

Thematic Reduction.

STEP 2: Demarcate and extract significant statements/meaning units.

- Re-read Lived Experience Descriptors, selective and lineby-line approach.

- Look for where meaning changes.

- Identify significant statements/meaning units.

- Focus is on meaning of text "What does this mean?""

- Statements given code/psychological or phenomenological descriptor.

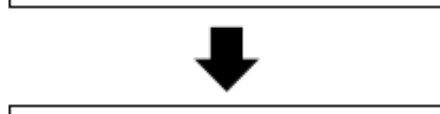

Horizontalisation

- Laid out all statements/meaning units and codes - all have equal value.

- Develop non-repetitive nonoverlapping list of meaning units.

- Second interviews - used to verify and discuss description and themes from first interview.

- Additional LEDs recorded and added to analysis.

- Explored possible meanings of experience with participants.

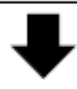

Analysing Collective Experience

STEP 4: Interrogate meaning units,
categories/clusters and themes
across participants.
Horizontalisation - laid out all
individual meaning units,
categories/clusters and themes
for participants.
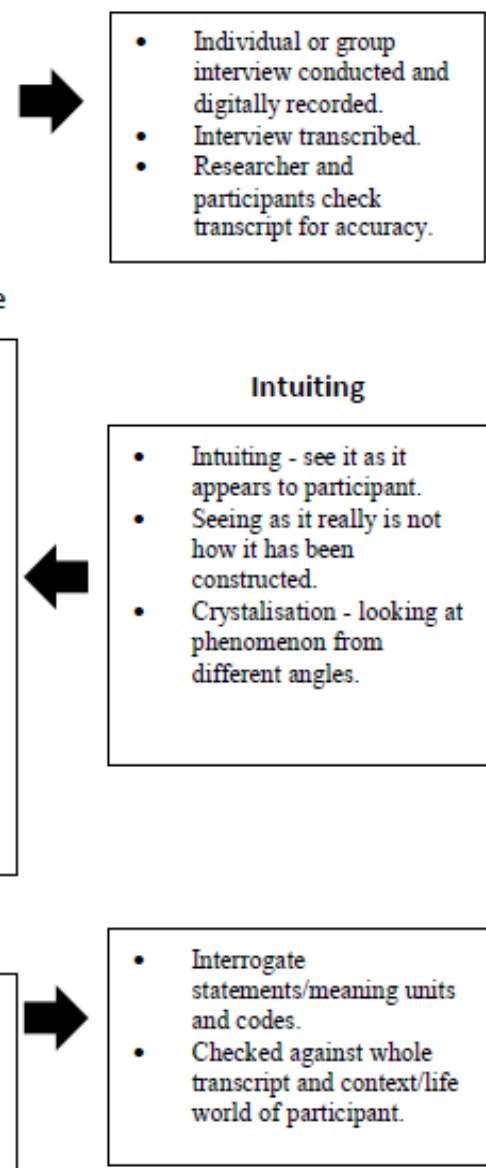

Intuiting - see it as it appears to participant.

- Seeing as it really is not how it has been constructed.

- Crystalisation - looking at phenomenon from different angles.

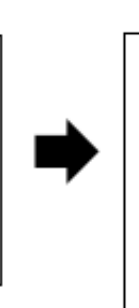

STEP 1: Assume phenomenological attitude of openness/attentiveness. Phenomenal reduction.

- Descriptive (eidetic) bracketing throughout process.

- Reflection on process recorded in reflective diary.

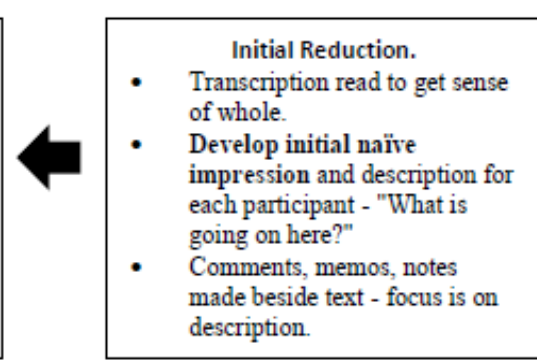

STEP 3: Categorise meaning units into themes.

- Similar statements/meaning units compiled into clusters/categories.

- Clusters/categories collapsed or expanded.

- Reflected on and recorded changes.

- Listed in a table with corresponding LEDs/quotes as evidence
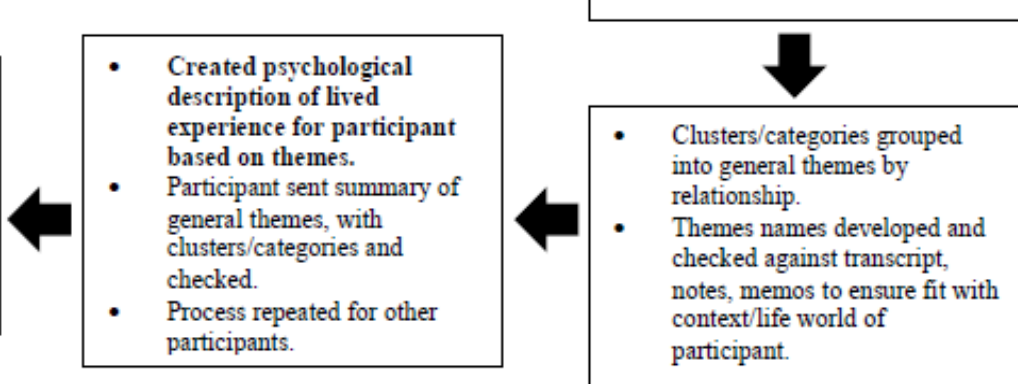

\section{Arriving at the Essence}

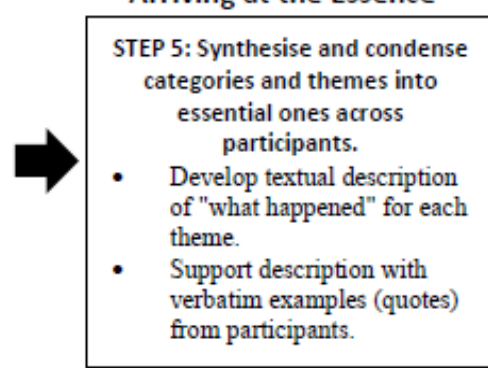

- Check resonance of exhaustive description and theme structure with three participants, other suicide survivors and professionals.

- Develop tentative descriptive model.

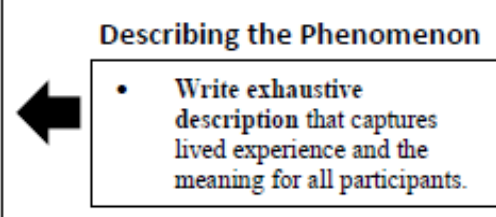

- Use imaginative variation. Determine invariant

- What makes this phenomenon what it is?"

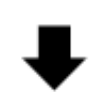

- Reflect on textual descriptions for different possible meanings.

- Use insight cultivators. participants?"

- "What did this mean for participants?" structure of phenomenon.

- "What was this like for

Figure 2. Process of Phenomenological Analysis 
Step 1: Assuming the phenomenological attitude of openness and attentiveness.

When preparing the data for analysis I assumed the phenomenological attitude of openness/attentiveness. This involved the use of eidetic bracketing and then I engaged in the initial reduction. First, I read each transcript and checked them for accuracy (comparing it with the digital recording). I made notes in the right hand margin noting non-verbal communication and para-linguistic cues (sighs, emphases, pauses, intonation) that might provide additional context and meaning to the statements. The focus of my reading was on description and noting what was happening. I deleted nonessential material such as social exchanges, repetitions and discussion of matters not related to the phenomenon to reduce the bulk of the text down to a series of anecdotes or what van Manen (2014) calls lived experience descriptors (LEDs). Words were not changed, nor their order to preserve the meaning but provide an abbreviated narrative. I then read and re-read the whole text (transcript for each participant) and narrative to develop an initial naïve impression or understanding of their experience - this is the initial reduction (Moustakas, 1994, p. 90).

Next I engaged in the process of intuiting (Wojnar \& Swanson, 2007, p. 176). According to Husserl, in order to develop an innate sense of what a phenomenon is like for a participant (what it is like to be them) researchers have to enter into the field of perception of the individuals. This enables them to see life as the participants see it (Bruyn, 1966), enables them to be able to identify and describe the essential structures of that social reality. Intuiting leads the researcher to own a sense that s/he has personally lived the experience of participants. To achieve this state of transcendental consciousness (remain open to the reality of another's experience), I had to listen attentively, critically reflect about the commonalities across participants, and make a concerted effort to understand 'What it might be like" (Wojnar \& Swanson, 2007, p. 176). Intuiting and bracketing work together and must be balanced so the researcher makes a conscious effort to honour insights about emerging evidence (see phenomenon as participants see or experience its presence) while simultaneously refraining from prematurely foreclosing on the meaning of an experience based on hunches about the emerging concepts (Swanson-Kauffman \& Schonwald, 1988). 
My role was to understand and describe the participant's experience not to interpret or explain it. This meant entering the field and the context of the men and the field of perception of the participants; seeing how they experienced, lived and displayed the phenomenon (alone and around others); and looking for the meaning of the men's experiences. Intuiting does not mean being "captured by an individual's construction", but instead subsuming it, recognising it as one of many possible valid formulations (Butt, 2006). Intuiting occurs when there is a merging of horizons (Luft, 2002) (between the individual and interpreter) that enables subjectivity to emerge. In everyday life, the world is primarily pre-reflective and people are unconscious of it. It is through engaging with the participants that I was able to help participants become more aware of how their experience appeared to them (Butt, 2006).

Intuiting was also aided by becoming immersed in the text to identify the implicit or essential (ontic) basis of the participant's experience of suicide bereavement. This is similar to the first step in van Manen's (2014) approach. I asked myself "What is really going on here? What is the meaning of this experience?" to gain an initial impression of the data and phenomenon, a naïve reading/interpretation. It also involved crystal refraction (Denzin, 2012; Richardson \& Adams-St. Pierre, 2008) as discussed earlier. In other words this involved looking at the experience from different angles and perspectives to see the different and varied ways in which is appeared to participants.

\section{Step 2: Demarcating and extracting significant statements/meaning units.}

In order to analyse each individual's experience and carry out a thematic reduction (Giorgi, 1997; Kvale, 1996). Thematic reduction involves demarcating and extracting significant statements/meaning units from the text. This involved re-reading the LEDs to identify significant statements/meaning units or phrases that directly pertained to my research question or revealed something about the phenomenon or experience. Meaning units were identified by looking for where the meaning of a statement changed. The focus of my analysis here was on the meaning of the text and answering (for example, what does this statement mean or say about the phenomenon?). I circled, underlined and highlighted these statements and made further notes/memos, noting where in the text the meaning changed. I then transformed the meaning units into a short psychological or phenomenological description and gave them a code/label. An illustration of this step is presented in Appendix 7. 
Then I laid out all the data (significant statements/meaning units, descriptors and codes) for each transcript for examination/analysis. This process is called horizontalization (Finlay, 2011; Giorgi, 1997) and all parts of the data are assumed to have equal importance (Merriam, 2009). The extraction of significant statements is an interpretation of the text, so careful attention needs to be given to reliability. I generated a composite list of all the statements in excel for each transcript, and for each participant so that these could be checked or interrogated against the whole transcript and the context/lifeworld of the participant (field notes, observations, memos about the participant's experience).

\section{Step 3: Categorising meaning units into themes.}

The third step involved categorising the meaning units into themes. This involved determining which statements were illustrative of themes and central to the structure of suicide bereavement. In order to determine the essential themes I utilised van Manen's (2014) selective and line-by-line reading approach to thematization of text (van Manen, 2014). I looked at the sentences or sentence clusters and asked myself "What does this sentence, or sentence cluster be seen to reveal about the phenomenon or experience being described?"

I transformed the meaning units/significant statements into brief psychological/phenomenological descriptions (Giorgi, 1997) which were reflective descriptive-interpretive paragraphs. Some phrases or statements that were particularly evocative were kept as "gems" to inform the development of the exhaustive description for participants (and across participants). For example, the following statement from Adam revealed how the suicide of a friend could transform a life and encourage positive change but was something that had to be kept secret:

So I felt like in a way he kind of saved me. I feel kind of bad about that. It took his life to save my life. I didn't tell anyone. I kept it to myself for so many years. (Adam1, 20; 2-4)

I then entered all the meaning units/statements and psychological/phenomenological descriptors and codes into a table so that I could develop a list of non-repetitive, nonoverlapping statements about the phenomenon for each individual. I organised or linked the data (meaning units/significant statements) thematically into clusters (Merriam, 2009) 
or "clustering units of relevant meaning" (Hycner, 1985, p. 287) for each interview. I grouped similar meaning units (significant statements) together and their codes (for example, cognitive distraction, emotional distraction, physical distraction, being active) into categories/clusters of meanings expressed in psychological and phenomenological concepts (for example, keeping busy). Categories/clusters were then related together and given a theme name (see Appendix 7 for an example).

I then used and combined the psychological/phenomenological descriptors into an exhaustive description of the phenomenon for each participant. This led to the development of a textual description (Giorgi, 1997; Kvale, 1996) of what happened, including verbatim examples (quotes). Participants were sent a summary of their themes and categories/clusters by email to check as well as the textual description. This process was followed for all participants. Follow-up interviews were used to discuss the theme structure, the psychological/phenomenological description of the overall lived experience for each participant, to explore other possible meanings. Participants provided additional examples of lived experience to support or show alternative aspects to a theme. These additional LEDs were added to the analysis.

\section{Step 4: Interrogating meaning units, categories/clusters and themes across participants.}

Before analysing the lived experience across all the participants to find the common essence I first needed to interrogate the meaning units/significant statements, categories/clusters and themes across participants (Giorgi, 1997; Kvale, 1996). Again, all the data was laid out for horizontalisation. When there were meaning units/significant statements that were similar I clustered them together indicating a general (and perhaps essential) theme. I collapsed or expanded themes as necessary, eliminating redundancies but also keeping open to the fact that it is not just the amount of times a meaning is mentioned but how it is mentioned that is important for determining significance. This process of deciding general themes was continued until I was satisfied that the thematic structure was best representative of all the narratives and LEDs, and no new themes arose.

Interrogating and analysing the data across participants also meant returning to the original transcript, text and memos at times to see the context under which a statement was made. Placing general and unique themes back within the context or horizon from 
which they came (contextualisation of themes) is important for advancing understanding of the essence and meaning of a phenomenon (Dahlberg, 2006). During this stage I critically reflected on the choices I was making in my reflective diary, and the research process. For example, in one instance in discussing and interrogating a theme with my supervisors we came to the conclusion that what the participants described was not a form of silence but rather a form of invisibility. The participants had simply not been seen or heard by others rather than them being deliberately or intentionally silenced by others. This revealed another aspect of the phenomenon and their experience of it.

\section{Step 5: Synthesising and condensing categories and themes into essential ones across participants.}

Once I was satisfied with the synthesised thematic structure across participants I developed short textual descriptions of what happened for each theme, supporting these with verbatim examples from across participants. Phenomenologists aim to describe "what" a particular phenomenon is like, the essential or core features that make it what it is, regardless of particular variations (Finlay, 2011). I then determined which meaning units/significant statements, codes, and categories/clusters and themes were essential and which were non-essential (Giorgi, 1997). In order to see, understand and describe the essential invariant characteristics of the phenomenon it is important that researchers start with a concrete example (textual description) of the phenomenon and then imaginatively vary it in different ways to distinguish essential features (Finlay, 2011).

I reflected on my own textual description and used imaginative variation, looking for all the possible meanings and divergent perspectives, varying my frame of reference about the phenomenon to understand "What makes this phenomenon what it is?" For example, if hopelessness was thought to be an essential feature of suicide bereavement, but it was possible to be bereaved by suicide and hopeful, then hopelessness would not be an essential feature or essence of suicide bereavement. Valle and King (1978) state that the same phenomenon is seen as: "Having the same essential meaning when it is perceived over time in many different situations... Only after seeing different reflections and varied appearances on repeated occasions does the constant unchanging structure become known to us" (p. 15). 
As I reflected on and wrote about the synthesised general themes and the participant's experience I asked myself "What is the meaning without which the phenomenon cannot present itself fully and the meaning structure changes?" to identify the invariant structure of the phenomenon and get closer to the essence. I asked myself: "What is it that makes this young men's experience of losing a close friend to suicide and not some other form of grief, loss or bereavement?" "What is the essence of this experience?"

After re-examining the synthesised themes, individual and collective experience, I had determined that silence was the core aspect of all the participant's experiences. The silence the participants experienced could be seen in seven essential themes (Being gutted, staying stoic, grieving in silence, being silenced by others, breaking the silence, being in silence and analytic silence). Each essential theme was represented by 2-5 categories/clusters and meaning units/statements from more than half the participants. Many of the essential themes were supported by 1-3 extracts/statements from more than four participants. This is in line with recommendations made by Smith (2011) for phenomenological studies with samples of between 4-8 participants. Exemplary quotes were chosen to illustrate the findings but are by no means exhaustive or fully representative of the diversity or number experiences in participant accounts. It is important to note that another researcher might develop a slightly different description and interpretation, given they may have a different perspective, different levels of skills and experience in analysis (Hycner, 1985)

At this stage of writing and analysis I used what van Manen (2014) calls insight cultivators, sources from philosophy and the human sciences that help researchers interpret, make sense of, see new possibilities and limits of a phenomenon, or stimulate creative insights and understandings in regards to the phenomenon under investigation. Finding powerful examples of vicarious lived experiences in texts, that result in an "Oh, now I see" moment provide researchers with helpful ideas, new ways of seeing and understanding a phenomenon. Insight cultivators I drew on included poetry that focused on men's experience of loss and grief, essays and accounts of survivors, and clinical case studies.

I read a number of articles on silence in health, counselling, psychotherapy, to explore this aspect of the phenomenon including the functions of silence (Ephratt, 2008), the 
meaning of silence (Urlić, 2010), silence as a form of communication (Lane, Koetting \& Bishop, 2002), connecting with others in silence (empathy) (Maata, 2006) and witnessing grief in silence (Cohen-Konrad, 2009; Weingarten, 2000). These readings helped me gain some important insights into the phenomenon; understand the nature of silence better and consider the participant's lived experience from different perspectives and different truths (called crystallisation) (Vik \& Bute, 2009). These readings helped me develop a deeper understanding of silence. The silence appeared to participants in different ways and it was different in shape and function to the types of silence discussed in literature on other phenomena (men's health, trauma, abuse, meditation, grief and loss in adults).

\section{Describing the phenomenon.}

The outcome or aim of phenomenological studies is the development of a composite or exhaustive description of the essence (essential structure) of the lived experience of the phenomenon which is an accurate understanding of the phenomenon (Merriam, 2009). This description or model (that is developed through disciplined reflection) (Finlay, 2011) should illustrate or represent the essential unvarying and universal structures or core concepts/components of a phenomenon (Colaizzi, 1978). The exhaustive description should provide a vivid example and include details that give the reader the feeling of having the experience or helps them imagine having it (van Manen, 1990). In this study, it should help readers have a better understanding of what it is like for a young man to lose a close friend to suicide.

Earlier in the analysis I had developed a textual or descriptive summary of how the phenomenon had been experienced for each participant. In the final stage of the analysis I developed a narrative or structural description focused on the meaning of the participants' statements and on how the phenomenon was experienced collectively across participants. This was similar to the process described by Dyregrov (2003-2004) who investigated parents' experiences of the sudden and traumatic death (including suicide) of their children. Dyregrov used meaning interpretation procedures (see Kvale, 1996) to seek the meanings behind or beneath what participants said directly, in order to work out the structures and relations of meaning that were "hidden" and not immediately apparent in the text. 
Consistent with the Husserlian tradition, anyone who has experienced this phenomenon should be able to identify their own experience in the proposed exhaustive description of the phenomenon (Wojnar \& Swanson, 2007). According to Wojnar and Swanson (2007):

The ultimate test of the quality of a descriptive phenomenological investigation of caring, healing, or wholeness would be testimony from the participants themselves that the investigator's universal description of the phenomenon captured their personal experiences. (p. 174)

The final step of the analysis involved sending copies of the exhaustive structural description to participants who verified that it did describe or resonate with what they experienced and what the experience meant to them. I presented my initial findings (the description and essential thematic structure and supporting evidence) to a range of researchers, health professionals (counsellors, GPs, mental health nurses, therapists) and to adult survivors of suicide who also said it resonated with their lived experience and those of young men they had encountered.

\section{Verification Strategies and Trustworthiness}

Qualitative researchers are concerned with issues of methodological rigour (MaggsRapport, 2001) and qualitative research should be assessed for quality using criteria appropriate to the paradigm and methodology (Smith, 2003, Tracy, 2010). Issues of reliability (dependability) and validity (truthfulness) of qualitative research are often addressed through the examination of trustworthiness, rigor, credibility, and authenticity (Denzin \& Lincoln, 2008; Golafshani, 2003). Researchers have different ideas about how to evaluate qualitative research, but many agree that in order to be considered trustworthy, research must be credible, have transferability, dependability and be able to be confirmed (Malteraud, 2001). Tracy (2010) outlines eight criteria for judging the quality of qualitative research which were useful for enhancing and evaluating the quality of this study: a worthy topic, rich rigor, sincerity, credibility, resonance, significant contribution, ethical and meaningful coherence.

First, the topic for this study (suicide bereavement in young men) was worthy because it emerged from disciplinary priorities in both health and suicidology. It also sought to explore the phenomenon in a sample which had not been previously studied, and was not opportunistic or convenient but rather has larger significance and personal meaning. This 
meant I took an in-depth approach to the study and was devoted to being thorough in both its design, data collection and analysis.

Second, steps were taken to ensure the study was conducted in a rigorous way. Qualitative studies need to consider and strive for theoretical, procedural, interpretive and reflexive rigor if they are going to offer accounts of phenomenon that are considered accurate (Tan et al., 2009). In regards to "rich rigor", quality studies are rich in their theoretical constructs, data sources, contexts, samples and data and when researchers show the complexity and multifaceted nature of phenomena (Tracy, 2010). Rigor is also about face validity - whether the study appears to be reasonable and appropriate (Golafshani, 2003). Researchers need to show that they collected sufficient data to support their claims, that sufficient time was spent collecting interesting and significant data, that the sample was appropriate for the study and that they used appropriate research methods and procedures (for example, field notes, interview practices, analysis procedures) (Tracy, 2010).

The rigor of a study can be judged by the care and practice of data collection and analysis procedures (Tracy, 2010, p. 841) which may be evidenced by: the number of pages of field notes, time spent reviewing, reflecting on and learning from field notes, the number and length of interviews, the types of questions asked, level of transcription detail, practices taken to ensure transcription accuracy and transparency regarding the process of analysing and organising raw data. According to Morse et al. (2002) qualitative researchers should use a range of verification strategies in both their design and at end of their research to ensure rigor.

Rigor was enhanced by spending adequate time in the field (12 months) and collecting multiple forms of data (Creswell, 1998) that included interviews, and field notes which led to rich, interesting and significant data. I encouraged participants to provide credible data (Shenton, 2004) by establishing rapport, and encouraging them to see the interviews as an interactional encounter (Kvale, 1996) where they took on the expert role to help me to understand and describe their experience as best as possible. I encouraged them to be frank, honest and tell "their truth" in their own words and language (hence transcripts full of swearing) indicating that there were no right or wrong answers. I listened sensitively and empathically but also reminded them that they could withdraw or stop at any time. This ensured only those who genuinely wanted to share their accounts did so. This was a 
similar approach to that employed by Dyregrov (2003-2004) who conducted sensitive interviews with parents who experience the sudden and traumatic deaths of their children.

Rigor in this study was also supported by a focus on neutrality/openness and the use of bracketing. I looked for themes in the data and tried to reach genuine insights with no prejudgements (Giorgi, 2002). Furthermore, my attitude during the analysis and reduction was one of looking at the reality of the participants as openly as possible without closing of any possibilities in terms of meaning (Kleiman, 2004). Bracketing, and the use of a reflective diary and consistent record keeping helped me track progress, audit decisionmaking and reflect on potential bias which can prematurely close down analysis (Koch, 2006). Frequent debriefing sessions with my supervisors and peer scrutiny (Shenton, 2004) also helped enhance rigor. Discussing methods and findings with colleagues and other academics at conferences and seminars during all stages of the research helped me to develop ideas, see the data in other ways and identify alternative interpretations. This process also helped me recognise my own biases, preferences and assumptions.

The rigor and credibility of the study was also supported by using sound well established methods for collecting data (Brinkmann \& Kvale, 2015; Kvale \& Brinkmann, 2009; Shenton, 2004), observation procedures (Carpiano, 2009; Kusenbach, 2003) and ensuring the data was analysed using a systematic process (Giorgi, 1997; Kvale, 1996; van Manen, 2014). For example, I drew on the work of Oliffe and Mróz, (2005) which provided helpful suggestions for conducting research with men, including how to show respect for ideas/thoughts, handling sensitive topics, using prompts, probes and loops to manage silences, being mindful of participant fatigue and providing plenty of opportunities to meet and develop rapport with men prior to data collection. The work of Dickson-Swift et al. (2007) on doing sensitive research was useful for developing both rigorous and sensitive methods and process, especially because this study encouraged men to talk about personally sensitive experience.

Third, the sincerity or genuineness of a study can be achieved through self-reflexivity, honesty and transparency and data auditing (Tracy, 2010). I showed my commitment to rigor by being transparent about my decision-making and providing a coherent and detailed description of the whole research process (Braun \& Clarke, 2006); this included the research, analysis and write-up (Smith, 2003). Reflexivity involves the researcher 
explaining the ways in which their own subjectivities, the subjectivities of participants, and interactions and relationships between researcher and participants shape the research (Finlay, 2003).

Self-reflexivity (Pezalla, Pettigrew \& Miller-Day, 2012) was developed with the use of my reflective journal and is an important aspect of confirmability (Koch, 2006). I was transparent about mistakes and successes, difficulties and strengths in the research process and explored negative and divergent cases (Morse et al., 2002) often returning to the data to make sure all the constructs accounted for all instances even if it only appeared once (Shenton, 2004). My journal helped me develop an awareness of how my background experience, position as a survivor and professional might influence data collection and interpretation. I used my journal and supervision sessions to explore my motivation for doing the study, my preconceptions about the topic and the sample population. I also used it to record and explore my thoughts about the design of the study, the challenges of recruiting young male survivors, how I would enter the field as a male survivor and researcher, the process of building rapport and trust with participants, how I reacted and responded to participants, and explored my "self-as-instrument" and leaving the field as researcher and postvention professional.

I created an audit trail of analytical processes to generate a transparent and explicit decision-making process (Biggerstaff \& Thompson, 2008). The decision trail was described (including changes in theme structure and names) and is a key indicator of trustworthiness in a phenomenological study (Koch, 1994). Transparency and dependability was supported by providing detailed and clear descriptions of: the research methods and process (Johnson \& Christenson, 2008, Malteraud, 2001); how I gained entry into the lifeworlds of participants; my level of participation in go-alongs and activities, field note practices; unexpected twists and challenges, the way the research focus changed over time; the recording of decisions and changes in way data was organised (audit trail) and the role of supportive colleagues and supervisors.

Fourth, credibility refers to the trustworthiness and plausibility of the research findings, which should be persuasive, seem true, and provide a credible account of the participant's sense of reality (Tracy, 2010). Credibility is achieved through prolonged engagement with the collection and analysis of data (around 12 months in this study) thick description, 
and processes such as triangulation or crystallisation, multivocality and partiality (Tracy, 2010). Thick description is evidenced in research that includes concrete, detailed examples of participant's accounts (Elliot, Fischer \& Rennie., 1999) as well as description of context and tacit knowledge (what was explicitly said and not said). These accounts need to include sufficient detail about participants and their circumstances so readers can judge the accuracy of these accounts (Elliot et al., 1999) and "show" rather than "tell" the reader what to think, allowing them to come to their own conclusion and interpretation. The use of verbatim extracts also enhances credibility by enabling the reader to see connections been the raw data and description and interpretation (Morrow, 2005).

Making use of multiple data sources and crystallisation (Ellingson, 2008) also enabled me to explore the complexity of the men's experience, to see their suicide bereavement from different angles and the different patterns and forms of silence. This enabled me to explore the phenomenon in-depth, and see the different "truths" and realities as they appeared to the participants. Multivocality was demonstrated by providing thick descriptions and quotes that demonstrated that there are a range of voices and experiences within the participants, and noting when participants described similar or different experiences. It also involved being aware of the differences in ethnicity, age and culture between myself and the participants, and allowing participants space and opportunity to shape the voice of the research.

I also used "member reflections" (Tracy, 2010, p. 884) rather than participant confirmation or "member checking" (Shenton, 2004, p. 68) which suggest there is only one form of truth, to enhance credibility. All of the participants checked their transcripts for accuracy, and all but one of the participants (Harley, closed his social media account and left no forwarding contacts) checked the credibility of the analysis of themes and textual description for their data (Kreftling, 1991). Participants were contacted approximately 1-2 weeks after the interviews to discuss any concerns and were invited to take part in a follow-up interview. Follow-up interviews provided them with an opportunity to share their reflections, provide additional insights and critiques of the process and analysis. These reflections (offered in follow-up interviews) not only ensured that I had "got it right", and confirmed that silence (even though it appeared in different forms) was the core aspect of their experience, but also provided new data and threw fresh light on the findings which led to richer analysis (Bloor, 2001). 
The participants explained that they found the findings, themes and description comprehendible and meaningful confirming they may be recognisable to others with similar lived experience. The only aspect of the data analysis that they contested was the use of the word "love" which I used to describe the close bond and relationship they had for the "thing" (friend) they had lost. While they acknowledged they loved their friend, they were uncomfortable with using that word to describe the relationship shared between heterosexual men, and suggested using the word "mate" to refer to the person and object they had lost. Three participants also reviewed the theme structure and exhaustive description for the overall data and vouched for them being true and accurate. This suggested there was correspondence between my findings and the understandings of the participants.

Fifth, qualitative studies need to demonstrate resonance - the ability to meaningfully reverberate and affect an audience or empathic validity (Tracy, 2010). The study demonstrated resonance evoking empathic and identification and reverberation with a range of health professionals (GPs, counsellors, therapists, victim support workers, mental health nurses) who had worked with young male survivors. Those who attended workshops and attended a key note paper I gave at a suicide-focused conference in 2014 said that they had been moved, had their perspective shifted, or had a deeper understanding of "what it was like" for their clients and would be "doing things differently". They were surprised by some of the findings, especially the ones relating to how the men perceived health professionals as "untrustworthy f*cking randoms who were paid to care" who failed to connect with them. It also reverberated with scholars and researchers who attended the two papers I gave at the Qualitative Health Research Conference in Toronto, Canada in 2015 (Bowden, Banister \& de Vries, 2015a, 2015b) showing it had resonance beyond a local context. The resonance of the findings to different audiences also suggested the study had transferability.

Good quality qualitative studies tend to demonstrate transferability - provide a reader with a sense that the story overlaps with their own situation (Tracy, 2010). I enhanced transferability by collecting accounts of direct lived experience, providing rich description of the demographics and backgrounds of participants (Balls, 2009), writing accessibly and inviting readers to imagine, engage with both their hear and their head. The study demonstrated resonation, transferability and naturalistic generalisation (Tracy, 
2010) because the findings were able to be generalised to a larger context or frame. For example, counsellors, social workers and psychologists who attended a presentation I gave at the University of Victoria in Canada (Bowden, 2015), later emailed me and told me the study had prompted them to think differently about their own practice, and some were prompted to explore the concept of silence with both young men and women, and in clients from different cultures - showing the research had resonance across populations and contexts.

Sixth, according to Tracy (2010, p. 846) research needs to make a significant contribution, extend knowledge, improve practice, generate new research, liberate or empower "bring clarity to confusion, make visible what is hidden or inappropriately ignored, and generate a sense of insight and deepened understanding" (Tracy, 1995, p. 209). Phenomenology is not concerned with theory building and tests and this study did not aim to extend, build or critique disciplinary knowledge, so has limited theoretical significance. However, the findings and analysis do offer new and unique understanding of the phenomenon and conceptual understanding of silence that could be used by future researchers; and thus has heuristic significance (Tracy, 2010).

Seventh, quality research adheres to procedural, situational, relational and exiting ethics (Tracy, 2010). I adhered to procedural ethics throughout the study and gained ethical approval for the study from the Human Ethics Committee at Victoria University of Wellington. Participants were not subjected to harm, or deception, they provided informed consent, and we negotiated how privacy and confidentiality were to be protected. In relation to situational ethics ${ }^{3}$, there were times when some participants disclosed their engagement in unlawful or illegal activity, and I had to consider what to do with that information. This was reflected upon in my diary and field notes.

At all times I adhered to relational ethics, showing participants respect, treating them with dignity, and valuing the connections with them and their community, being mindful of how my actions and reactions affected others and showing an ethic of care and

\footnotetext{
${ }^{3}$ Situational ethics are ethical practices that arise from a reasoned consideration of a context's specific circumstances (Tracy, 2010).
} 
compassion. Researchers never have full control over how their research will be read, understood or used and I was careful when writing the findings to report with both accuracy and truth. Personal change was a key theme in the findings and the participants made it clear they did not wish to be seen or positioned as passive, helpless or tainted victims. I reported the findings clearly and accurately to highlight both their struggles and changes and will continue to ensure participants are not subject to stigma, marginalisation but rather challenge stereotypes about how men experience, express and cope with grief.

The final component that adds to the quality of research is meaningful coherence (Tracy, 2010) or methodological coherence (Morse et al., 2002). Studies need to demonstrate congruence between the research question and the methods chosen. They need to achieve their purpose, use methods that are aligned to an appropriate methodology/paradigm and attentively connect appropriate literature to the research focus, methods and findings (Tracy, 2010). The study needs to "hang together" well with the literature situating the focus and research questions and the discussion connecting literature to the findings. Careful consideration was given to the selection of phenomenological methodology and methods so that the research question could be answered. Keeping a focus on describing (rather than interpreting or explaining) the phenomenon, the use of descriptive bracketing, phenomenal reduction and following principles of phenomenological studies helped ensure methodological coherence. The data collection and analysis were in line with the methodology and the analysis was systematic.

\section{Chapter Summary}

This chapter described the study design and demonstrated the connections between the research methodology and methods. The chapter included a description of ethical considerations, the methods used to collect and analyse the data and the research process. I discussed participant recruitment and sampling, provided some background information about the participants and the close friends who died. I explained the interview process and how data on the phenomenon was managed and analysed and the strategies employed to ensure trustworthiness.

The next chapter sets out my findings and the essence of the experience of the participants. The themes and findings follow a process narrative and this represents the ways the participants chose to discuss their experience. Interviews and conversations 136 
flowed from them describing their relationship with the deceased, their experience of finding out about the suicide of their friends, their initial and ongoing reactions and experience of grief and loss. It includes the stories of their friend's funerals, unveilings and the impact the suicides have had on their social circle, relationships with others, their mental health and wellbeing. It also shows how the men described suicide bereavement as a process that involved personal analysis and self-reflection and all of this occurred within a context of ubiquitous silence. 


\section{CHAPTER FIVE: FINDINGS}

\section{Introduction}

I can't look people in the eyes or anything because I'm feeling it. So the best thing to do is just look down (pause) [silence] I'm sorry. (Coby1, 39; 25-27).

Participants described silence as being at the heart of their experience of losing a close friend to suicide. I begin this chapter with a brief overview of how silence was conceptualised. I then present each of the seven major themes that make up the essential structure of their experience of suicide bereavement, along with supporting evidence of participants' lived experience.

\section{The Essence and Structure of the Men's Experience}

All of the participant's experienced silence after suicide. It was all around them, it was ubiquitous. Silence was the context against which the other main themes or essential components of the phenomenon become figural. When the participants found out about the suicide they struggled to find the words to describe how they felt; they were shocked and voiceless. They experienced disbelief, withdrew from others and maintained silence; they had unanswered questions and feelings of powerlessness. In the time after the suicide they tried to remain stoic and silence their grief and feelings. They kept quiet, restrained their emotions because of fear of judgment. They suppressed their grief, depression and suicidal thoughts and tried to keep busy in order to distract themselves. When they grieved they did so in silence (alone and with others) and they realised their loss when they were confronted with the reality of their friend's death and when others broke the silence.

At times they were silenced by others. This happened when they and the suicide were not acknowledged, when they felt unwelcome or when people did or said things that excluded them, shut them down or out. They broke their silence and expressed their grief when they found friends and family who understood, had similar lived experience and/or connections with the deceased, with professionals and others who provided safe spaces for them to vent, learn and receive help. Participants also sought out quiet spaces that helped them reflect/make sense of their experience, remember and reconnect with their friend and experienced the silent therapeutic presence of others who were "just there" for them. Participants were able to reflect on and became aware of changes they experienced. 
They realised and became aware that they had experienced multiple losses, that their relationships with others had changed, and that they had become more sensitive, empathetic, and caring. Their perspective on life had changed; experiencing acceptance of their loss enabled them to move forward with their lives.

The silence the men experienced after the suicide of their close friend was a response to a traumatic loss, a strategy and a space in which the participants experienced grief, integrated their loss and transformed. Participants experienced silence both within themselves (self-censorship, inner quiet, suppression and control of emotional expression, reflection) and in their relations with their life world (between themselves and others). It influenced the way they adapted to life without their close friend and their way of being in the world. Sometimes grief threatened to overwhelm them and took their voice. At other times, in public, the men silenced themselves. They kept quiet and busy to prevent themselves from losing control, appearing vulnerable, weak and feminine. There were unspoken rules about silence and when it could or should be broken. The men were silenced by others in situations where they had no power or authority to speak. They broke their silence when their grief became too much to contain and when others presented them with safe environments. Silence was also a place/space and state of being. Being in silence helped the men remember, reflect, and integrate their loss; it was through silence that the men transformed and took on new ways of being in the world.

The themes in this study are presented within a larger context of the experience of silence. Participants described their experience of life after the suicide of their close male friends in terms of silence; they described their need for silence and their struggles to manage, maintain, and hold onto it; their reactions to the silence and noise of others; and the circumstances and ways in which they broke their silence. Silence, therefore, was an inherent and essential component of their experience of suicide bereavement. The analysis indicates that the essence of this silence is made up of a number of core components and embodied in seven major themes: being gutted, staying stoic, grieving in silence, being silenced, breaking the silence, being in silence, and analytic silence.

Figure 2 below presents an illustration of the thematic structure related to participants' experience of losing a close friend to suicide. The themes and clusters of categories are interrelated, as often the participants described their experience holistically. 


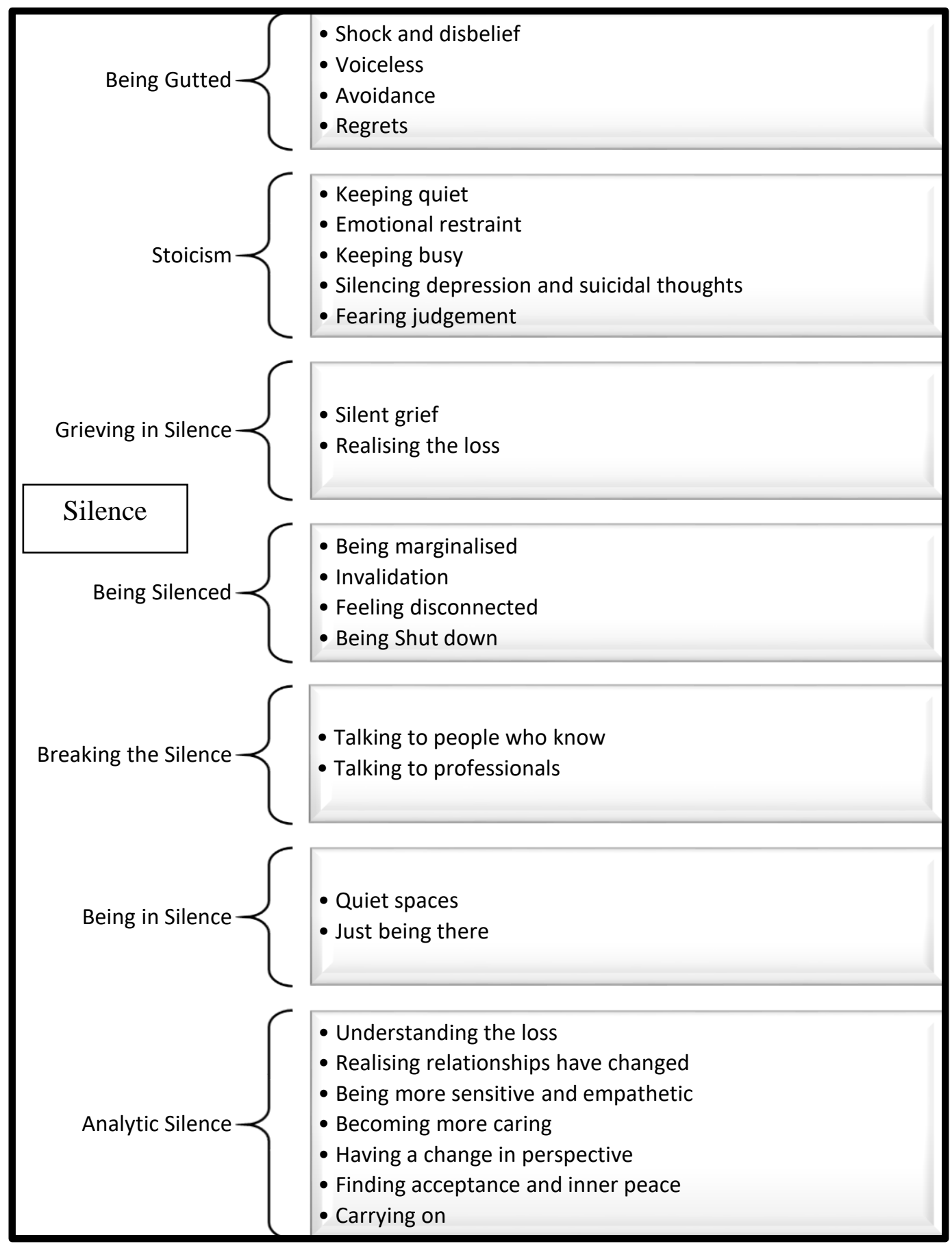

Figure 3. Thematic Representation of Participant's Experiences

The following sections present the major themes and support these themes with relevant descriptions of participants' lived experience. Following the description of each theme is an explanation of how it relates to the essence of silence. 


\section{Being Gutted}

Losing a close friend to suicide left the men feeling "gutted". Their friend's suicide shattered their way of being in the world, cut and hurt them, and left them feeling empty:

You feel whole one day and then that next day it happens and it's just like everything has changed. Like things aren't the same. Like when he left he took something from all of us...Like he took a piece of our heart with him. $(\operatorname{Rod} 2,7 ; 33-37)$

Participants expressed that they were shocked, wounded, angry and emotionally "wrecked". They withdrew from others, struggled to make sense of what happened and suffered alone and in silence. In the first theme, being gutted, the data was organised into four separate but related categories: shock and disbelief, voiceless, avoidance, and regrets.

\section{Shock and disbelief.}

All of the men were gutted when they found out about their friend's suicide. Hearing the news of their friend's violent death left them in a state of shock and disbelief; some were frozen in silence:

Mum rang me...And then she was like crying and then she told me, and I didn't quite believe it, and then I just sort of sat there, sort of thinking I'm going to get a text from him. (Fin1, 15; 28-32)

A massive shock. Because I actually saw him the day, well, the day he did it. (Coby1, 5; 27-28)

The reality that their friend was gone forever did not fully register:

It's hard to get your head around it. (Jace1, 36'; 21)

Like it didn't feel like he was gone...It kind of felt like it wasn't actually happening. (Fin 1, 26; 7; 24; 20)

As they began to realise what had happened and the finality of death they understood that suicide had severed their connection and silenced their friend:

Like you have moments when you think, oh you just forget that he's gone, and then you realise that he's actually gone forever, you're

${ }^{4}$ Gutted is a term often used in New Zealand to refer to huge or bitter disappointment or being extremely upset. It is also used to refer to a feeling of being broken, torn down, completely destroyed or emptied as in a building that has been gutted. 
never going to hear his voice or see him again. It's sad. (Fin2, 13; 12-15)

It was difficult for them believe their friend was dead when they still had an online presence:

I woke up in the morning, checked my text, 'Phil shot himself'. So I got up, got onto my computer you know Phil's still online everywhere...It was still not registering...then you're realizing that you're not going to see them again. (Max 1,$7 ; 13-15 ; 1 ; 1-3$ )

Some had to postpone their response, endure the silence alone, and wait for the story to be verified by others:

I went on Facebook in the morning to see if he was all goods. I went on his page and I just seen 'rest in peace', shit! I thought what the fuck? And then I just waited till I seen one of his cousins post up eh, I was like oh fuck! and then my mate rung me it's like 'Bro. fuck, T's killed himself. Jumped off a cliff', eh?' I was like 'What the fuck! Are you serious?' (Harley, 7; 1-5)

The men's initial reactions to their friend's suicide were ones of shock and disbelief. They did not want to believe their friend was dead or the information that they were given. They struggled to make sense of their experience and to articulate how they felt; they were voiceless.

\section{Voiceless.}

The suicides left participants experiencing personal silence; they struggled to understand their experience and to find the words to describe their depth of hurt:

I can't even describe the feeling; it was just a real sore feeling that he was gone. (Coby 1,$14 ; 1)$

They were mute, confused, and bereft of language to help others understand what they were experiencing:

I couldn't talk about it. ... I just know the feeling and it's like you don't really know what to say. $(\operatorname{Rod} 2,161 ; 8-10)$

They had no way to explain to others - to help them understand what it was like or what they needed - so they remained disconnected and alone in their experience. Some expressed their immediate grief nonverbally:

Everyone was tired and just crying all the time. It was shit. (Jace1, $16 ; 41)$ 
Others withdrew into silence and tried to muffle their grief and keep it private:

I felt it crazily but I wouldn't show it. And if I did show it, it was with myself. (Coby1, 39; 19-20)

They did not want others to see their helplessness and vulnerability:

I turned my phone off. Kept crying. I couldn't even talk. I was like doing the sniffle ones you know, I just couldn't walk or anything. I just felt like I was paralysed, eh? I was like fuck! I was pretty cut up, eh. (Harley, 7; 6-8)

The participants were left stunned and voiceless when they heard of their friend's suicide. There were no simple words to describe a whole range of emotions they experienced, and they struggled to articulate what was going on for them. Their grief left them feeling drained of energy, paralysed, and unable to act and speak. The men reacted to their loss by withdrawing, isolating themselves and keeping quiet.

\section{Avoidance.}

Withdrawing from others and shutting people out was an immediate response to the traumatic loss. Participants tried to escape awareness and ignore the reality of their loss:

I guess I was trying to just forget. Because this was the first time it ever happened I didn't know how I'd take it and I just, fuck! I just shut down, pretend like it didn't really happen. (Harley1, 8; 16-18).

They avoided situations and people that reminded them of their loss to protect themselves and retreated to preserve their energy:

I think there was a bit of distance and separation probably for selfpreservation. (Max2, 8; 27)

People put a bit of space between themselves and put up a wall, sort of moved their own way a bit as well. (Max1, 8; 12-16)

I close up for a little while... Sometimes I will say only things that need to be said, otherwise, I withdraw from any conversation. (Luke2, 17; 13-18)

Withdrawing from others meant the men could keep their grief private and minimise interference, concern and the noise from others:

You really don't want to make them worry about stuff...There's a fear that they may overreact as well. (Max2, 24; 32-34)

They might not know what to say and it's just easier for me to just do it on my own... I don't want people worrying and thinking something's wrong. I just like to do things on my own. Most of the time I choose not to show it at all. (Coby2, 31, 2-9) 
Participants avoided people who they perceived as ignorant about suicide bereavement because they often made insensitive and judgemental comments:

Some people don't know. You can't let it get to you, like try not to let it get to me when I hear people talking about it because they don't really know what we've been through"' (Jace2, 25; 5-7).

Avoiding others was also a way to avoid talking about what happened and their feelings. The participants were concerned about how others (including family) might judge them if they broke down, cried, or looked weak:

I didn't even talk to my Mum for like a couple of days, eh. I just stayed in my room, keep to myself. I was pretty angry...For the first two days I didn't tell nobody, eh. I was just like fuck! You know I was just cut up. My Mum always wondered what was wrong with me. I couldn't tell her because I knew that I would cry again and I didn't want to, I hate crying... I just didn't want to tell anyone because every time I'd just think about it you know, the nose would start itching and the waterworks would pop up. Yeah I just shut down, went into hibernation, eh. I just stayed in my room for two days straight. (Harley1, 7; 11-29)

Avoidance was also a way of protecting others. Participants desperately wanted to talk about their friend (but not their grief). They wanted to talk to friends and family who knew their friend. They often had good relationships with the deceased's parents but decided to keep their distance because they had witnessed the parents' suffering at the funeral. They avoided that parents in order to protect them and themselves from further pain:

I'd love to talk about him. I feel [Devon's mother's] pain from it and it's too hard for me to bring it up with her. ...I saw her when it happened. I've never seen anything like that before. I couldn't talk to them, well I could have but I chose not to. (Coby1, 22, 18-21)

As time passed participants became aware that they needed to avoid triggering others' grief and that even close friends wanted to maintain their silence:

A lot of people have still got it buried. It's kind of sad because now it's very hard to even mention him in passing without out bringing up old feelings. I think people are very careful around one another when and how they bring him up as well because I don't think people really want to open that door to be honest. (Max2, 33; 1620) 
Avoiding others meant the men spent a lot of time alone and this contributed to their experience of isolation:

I stayed to myself, I hung around a couple of my mates, like pretty much most of the time...I pretty much cut myself off. (Harley1, 11; 3-5)

I just became a recluse really for a year and a half or two years or something. Yeah, that's pretty much all I did, I just became a recluse, you know saw people a bit, got really depressed and again I was having my own problems as well. (Max1, 10; 29-31)

The participants did not want to be alone and preferred being with their friends who helped distract them with activities like drinking, playing Xbox or PS3/4 or driving around:

Yeah I hate to be alone, oh like afterwards I didn't like to go home and just sit there. I always want to be around mates. (Fin1, 41; 2224).

The friends they reached out to and spent time with, knew their friend, shared the lived experience with them, and so they shared an inherent understanding and comradery.

By maintaining their distance and silence, the participants were able to minimise chances of being overwhelmed by their own grief or by the grief of others. Withdrawal was a strategy the men used to protect themselves and others from further suffering, conserve energy, avoid showing their vulnerability, and avoid conflict and stress/distress. However, it also contributed to them being alone and feeling isolated. Sometimes they chose to maintain distance and silence; at other times the distance and silence was created by ignorance and lack of sensitivity in others and lack of appropriate support. It was when the participants were alone with the noise of their thoughts that they began to try and make sense of what had happened, who was responsible and deal with regrets.

\section{Regrets.}

One of the consequences of avoiding others was that the men were often left alone, in silence, to think about what happened and who might have been responsible:

Being by yourself is just not fun. You just get worse, you just get your thoughts. (Adam2, 23; 32-33) 
They needed to get "the facts" so they could understand what had happened and why to silence the questions they had about responsibility and blame:

People wanted to know how it happened and also if there was a person to blame. Some people like to blame; it helps them. Other people like me just want to know. (Luke2, 7; 7-10)

They were gutted when they realised that they would never get the answers to some of their questions. They were also gutted when they realised that they couldn't change what happened, and became aware of their personal powerlessness. When they were alone and it was quiet they often mulled over whether there was more that they or their friend could have done:

He had so many opportunities to talk to friends. We just wished he'd called us. We wish we'd called him.... And we were just thinking 'maybe if we did this, maybe if we did that, we could have helped'. We could have stopped it. (Adam1, 5; 19-23)

They regretted some of their actions or inaction and wondered if they had let their friend down or betrayed them:

Then I started like thinking, fuck, maybe if I talked to him that time on Facebook longer or you know just a couple of minutes more or rung him or text him after, you know. It makes you question how much of a good friend you are. (Harley, 8; 27-34)

Adam explained:

It's horrible. You feel like you get that bit of doubt where maybe I could have done something. But I didn't know, it was a shock to me, I didn't see it coming. I knew he was depressed, I didn't think he was that depressed! [raised voice]. (Adam2, 27; 5-8)

One of the biggest regrets expressed by the men was that they had not told their friend how much they meant to them, how much they cared for and loved them while they were alive. Coby regretted wasting two opportunities to break his silence and say goodbye to his friend, both in the hospital and, symbolically, at his funeral:

I mean I'd just wish, I kind of (pause) accepted the fact that he was going to pass and having say goodbye but (pause) too stubborn. In a way like I didn't say goodbye I said 'You're coming right, you'll get better. (Coby1, 8; 27-28)

I regret not getting up [at the funeral] and saying anything but (pause) I didn't know what to say. (Coby1, 10; 27-28) 
Losing a close friend to suicide meant the men had to deal with questions about the suicide, responsibility and their own sense of powerlessness. They tried to silence these inner thoughts:

Just not being able to change it. Just heaps of thoughts going through your head, trying to get rid of the painful feeling. You don't know what to do. (Coby2, 29; 37-38).

\section{Relationship of the theme to silence.}

The men's initial response to hearing of their friend's suicide was that they were gutted. All eight men reported being gutted and this involved feelings of shock, confusion, disbelief, and being stunned or paralysed. They were overwhelmed with unassimilated unprocessed thoughts and emotions, words were inadequate for describing their experience to others. They were rendered personally silent, speechless as they organised their thoughts and absorbed the shock of losing their friend. They found it difficult to connect and talk to others. Avoiding others and talking about their grief meant they could minimise conflict, stress, and maintain peace and quiet. However, isolating themselves meant they were often alone with the many questions, doubts, regrets and feelings of powerlessness. Another key theme in the men's experience of suicide bereavement was staying stoical and silencing the expression of emotions.

\section{Stoicism}

The second theme within the men's experience of suicide bereavement was - stoicism. The data that made up this theme was organised into five separate, but related categories: keeping quiet, emotional restraint, keeping busy, silencing depression and suicidal thoughts, and fear of judgement.

\section{Keeping quiet.}

Participants worked hard not to let others see that they were hurting, upset and grieving the loss of their friend. Being stoic meant being careful about when and where they expressed their grief and who they showed it to. The men chose to keep quiet about what they were experiencing inside. They withheld their grief from others and kept it private:

I would not volunteer anything...I was never the one to bring it up...They won't get access to what's going through my head ... I would never ever talk about that sort of thing. I don't like talking about what I actually think or feel. (Luke1, 17; 6-15) 
I prefer not to talk about things that make me feel sad. I tend to be very private with that sort of thing. (Luke1, 16; 28-31)

There were a number of reasons why participants chose to remain quiet and stoical. They wanted to be strong for others and be the one who kept things together. Keeping quiet and remaining in control of their emotions meant they could continue to perform their perceived roles of providers and protectors. Their stoicism also protected them and minimised the possibility of female partners from worrying or pressing them to talk about their feelings and go into their grief in more detail:

You can tell them some things but you don't want too much of a fuss made of you. Otherwise they won't let you out of the house because they'll be afraid you're going to jump off a bridge or something. If I told her everything then she'd probably worry a lot more. So it's just on a need to know basis really. (Max2, 10; 26-30)

You just get over it sometimes, you just think that's enough talking. Enough! [raises voice] (Coby2, 9; 16-17)

When others pressured them to break their silence they sometimes reacted strongly, expressing their anger while others remained quiet and pretended to be OK and gave minimal responses to "shut people up":

Well one night my sister she kept asking me questions and shit. That's when I snapped at her. And said "Shut the fuck up!" It just gets annoying. (Fin2, 23; 4-5)

I didn't like to be at home because that's when Mum asked me "Are you alright", "yeah I'm alright". "You sure?" "Yes Mum". Just play some X-boxes. (Fin2, 18; 12-14)

The participants remained stoical and chose to keep quiet about their feelings and experience around professionals. They were cautious about what and how much they disclosed and shut down conversations when they did not feel safe, felt pressured or that professionals lacked the skills to genuinely engage with young people (particularly men):

I know full well that I can control definitely how much I say and how much I give up. (Luke1, 28; 38-40)

You can't just open it up and it runs out, no it's not that easy, eh...Y You don't want to tell someone when you're uncomfortable telling them. (Rod2, 9; 21-34)

When professionals such as counsellors, general practitioners and psychologists used direct questioning about feelings (usually as part of their assessment), rushed and took a non-conversational approach the men remained stoic and shut down the dialogue: 
They always ask you "How do you feel?" "Are you sure you don't want to talk? Why don't you want to talk?" (Fin2, 56; 18-21)

Yeah try and be tough. Those fucking school counsellors eh, they piss me off. Oh well they ask 101 questions and I'm like "yep, yep", oh "Do you want to talk", "No". "Why not?" "Fuck! I said no I don't want to talk". (Fin2, 17; 14-23)

The men needed time to figure out what they were experiencing before they could talk about it and they were worried that they could be overwhelmed if they started to express their grief:

I was still figuring everything out myself and they keep prodding you, saying "You've got to talk if you want to feel better about this. You've got to talk it out and get it out there and everything" (Max2, $25 ; 37-39)$.

You are putting yourself in quite a vulnerable space... It is fear of losing control. That's one of my fears that god I hope I don't cry, it looks so bad you know. It's just being put in an uncomfortable space to be honest. (Max 1, 21; 35-40)

Participants also stayed quiet and stoical because they dealt with their grief cognitively and believed that talking or expressing how they felt would not change what happened:

I felt maybe if I did talk about it and let it out I might feel better but I just couldn't. I just blocked it off. I'm more a silent thinker. (Coby1, 16; 19-21)

I just kept quiet really. I wanted to talk but I just didn't. I was just speechless really over the fact that he's gone. Talking about it's not going to bring him back. I have to go through it myself, like mentally. Been thinking about it a lot. I haven't stopped thinking about it for ages (Rod2, 8; 37-40)

Choosing to keep quiet helped the men retain an appearance of stoicism, calmness and control. By remaining silent they continued to appear "OK", protecting others from worrying, preventing others from pushing them to explore or express their grief, and this helped them remain in control. Participants struggled to find people who understood their experience, who respected their need for privacy and to take share things at their own pace. They continued to keep quiet and suppress emotions while they tried to make sense of their experience and grieve their loss. 


\section{Emotional restraint.}

Suppressing emotions helped participants appear as though they were OK, in control and managing. It was important for them to adhere to traditional masculine norms such as individualism, bravery/courage, perseverance, and toughness:

I kind of tried to bury it... I'll just try and suppress my emotions. You know men don't like to talk about it. (Adam1, 10; 6-8)

Just keeping it bottled up, eh. Like trying to be composed around other people and seem like nothing's wrong. I think that's important, eh. (Harley1, 16; 27-28)

The men avoided crying, talking or showing they were upset and described these as feminine ways of being. The men needed to be action-oriented and were concerned about being brave, showing perseverance, and carrying on:

I think girls love talking about stuff...I think we have a stronger hold on keeping our emotions in...girls have closer relationships with their friends and can easily express, and talk about how they feel... They all talk you know. (Coby2, 34; 4-21)

Girls like to just to be sad together eh, ... be sad with each other and stay the night... us guys would want to go and do stuff like he used to do. (Fin 2,$33 ; 31-32$ )

We all hang out and shit like they do, but then we won't just sit at home and cry. (Jace2, 33; 35-36)

You don't want to just sit there being a sook all day, you want to just like harden up and go do what you gotta do. (Jace2, 34; 14-15)

They took their cues to suppress emotions from other men around them and were uncomfortable and embarrassed when they saw men expressing their grief and revealing their vulnerability:

When they were carrying the coffin out, looking over at [Phil's brother], and I saw him just breaking down...[Phil's other brother] didn't like to show much emotion, he was just quiet the whole time. He didn't want to get up and speak...he just kept quiet. (Adam1, $11 ; 37-40)$

They were loading the coffin into the hearse outside. That's when I saw [Phil's Dad], completely break down. He's not someone that shows his emotions. Normally he doesn't reveal a lot. I saw him just break down onto the hearse driver. Yeah it wasn't good. (Max 1, 7; 36-40) 
Their stoicism and emotional suppression was driven by fear of judgement and being different from their friends and peers:

You don't want other people to really see that you're in a worse state than they are. I know I felt like shit on the inside and then I looked around and all my friends are holding it together. So that's the sort of path I followed because I don't want to be the one friend in the group that breaks down. (Max2, 18; 22-26)

They sometimes gave each other permission to break the code of silence and to express their grief publicly and even though they contained their emotions they could tell that others were sad and quietly connected with them:

I looked at [Devon] and I don't want to cry in front of him because I know he's tough. But then he just like patted me on the shoulder and said "It's all good" and then kind of had a little tear and so did he. (Fin2, 16; 17-22)

We knew everyone was sad. (Fin1, 49; 16)

You could tell when they're sad. We all knew it anyway... Like we were just looking at our mates but we all know what we're feeling $(\operatorname{Rod} 1,49 ; 18-24)$.

Participants restrained and suppressed their emotions and in doing so maintained their stoical and masculine appearance. The men also suppressed their emotions and managed their grief by staying busy and using distractions.

\section{Keeping busy.}

Keeping busy, working hard, sticking to routines and focusing on their jobs provided the participants with a valuable emotional and cognitive distraction from their grief and enabled them to continue their appearance of coping, "being OK" and stoicism:

It's fine when I'm working, I've got my mind on something else. When I'm doing something it's helpful because my brain's not rushing around or anything I'm just focused (Coby1, 20; 1720)....just a break from hurt feelings. (Coby1, 25; 15)

Part of keeping busy, is that you're not allowing yourself time or space to have those feelings and even if you do feel like having those feelings you're too busy managing everything else (Max2, 16; 33-36).

Engaging in physical activity, taking on projects in and out of work (working on cars), and spending time socialising with friends (drinking, playing Xbox or PS4) provided them with a distraction from their pain and loss. These activities were often carried out 
alone or with others in silence, they helped them feel better and tended to provide them with respite from the "noise" of others:

Sometimes I like to go to the gym when I'm angry or upset. Take it out on my body instead, it makes you feel so much better. You just do what makes you feel the best at the end of the day, go for a run or just do something that's outdoors. (Adam2, 15; 19-21)

Despite their attempts to suppress their emotions, keep busy, distract themselves from thinking and feeling, and hide their grief from people at work it their grief they acknowledged that this did not always work. Their grief was buried, not gone, and it began to interfere with their work and lives:

It would be like burying a bomb to be honest. You bury it. I did sort of try to ignore it for a while and it did come back in a negative way. (Max2, 13; 37-38)

No the grief doesn't go away. You can hide it, you can bury it, but it's not gone... I don't talk about it I just want to get rid of it. I just don't want to go down that road really. Like yeah it's a hard time. Like dig a hole, cover it up, concrete over the top. (Rod2, 5; 2-9)

Keeping busy was a way participants could suppress their thoughts, emotions and grief. Work, normal routines, and activities helped distract them and provided them with quiet space. Being active, doing rather than talking, and delaying dealing with their grief was their way of coping. However, they soon became aware of the negative consequences of bottling up, burying, and silencing their grief.

\section{Silencing depression and suicidal thoughts.}

Constantly trying to be stoical, suppressing emotions, and keeping busy took its toll on the men. Four of them struggled with depression and suicidal thinking following the suicides of their friends. The loss of their friend and emotional numbing left them feeling empty, devoid of hope and depressed. When they were alone with their thoughts they would often think about their friend, how they died (gun shot, hanging and jumping from a cliff) and identify with their pain and situation; this added to their distress:

When you've taken a gun to your head that's a whole different situation. You get the feeling of how bad it was and what was going through Phil's head at the time that he had to go and resort to that. (Adam2, 2; 27-31)

I just didn't want to be around anymore. Like I was thinking, fuck if he took his life in this shit world ... he had everything, he played good solid footy, and if he didn't want to be around ...I didn't have 
none of the stuff he had going for him or anything, I was like, fuck, am I ever going to do anything with my life? (Harley1, 7; 36-39; 8, $18-23)$

It was difficult for the men to maintain a state of numbness and suppress their emotions and when they could no longer restrain or silence them they engaged in self-harm and risk-taking behaviour (for example, not taking medication, fighting, playing with knives). This was often precipitated by a build-up of emotions, too much time reflecting on what happened, and a desire to feel anything other than inner psychological pain. Hurting themselves and engaging in acts of violence towards others (fighting with others when drunk) helped externalise their inner pain. It also enabled them to feel something other than the numbness they had built up over time and validated their grief. Rod described an incident at work when he had not been able to block out his thoughts and emotions, he was angry with what Devon had done to him and with himself, and he turned a powerful electric sander on his arm:

You end up hurting yourself, eh... I don't know why it just fucking happens. But after I do it, I feel better. Like I thought about it more than I should... I just had had enough. I wanted to feel something other than this shit...I was just sanding and it was like fuck it! [in an angry tone] It wasn't the answer you know. I was just mad and then like the moment just took me. At the time it was just taking me away from there. (Rod2, 21; 15-37)

Four participants also struggled with suicidal thoughts and engaged in an internal, private, silent battle between wanting to give up on life and not wanting to die:

You're trying to find a way out of your own dark tunnel...If other people have this way of coping with it, do I have any other options? (Max2, 11; 14-18)

I can't deal with this anymore!'...I felt like I had this voice that was telling me just get it over and done with, forget about everything that is making you upset, just go to eternal happiness. (Adam1, 22; 33-36)

The voice in my head...was like "Just do it" and then when you start arguing with yourself...So then I said "I can't do this!" and I threw the knife in the wall. (Adam1, 22; 13-31)

Participants tried to silence their self-destructive and suicidal thinking and used alcohol to gain some internal quiet although this often made things worse:

Suicidal thoughts. I went through all of it eh. So I just fucking drink. (Rod1, 41; 12-13) 
I sort of felt like I might have been at the start of the same path that he was going down. I was basically seven days drinking, total emotional wreck. (Max1, 11; 20-24)

Drinking provided a temporary escape from their hopelessness and sadness and a fear of judgement stopped the men for asking for help and motivated them to remain silent and stoic.

\section{Fearing judgment.}

Participants described a fear of judgment and being seen as weak or feminine as a main reason for not showing others their vulnerability and remaining stoic. Max spoke about how years of male conditioning and holding emotions in check meant his grief, sadness, and anger were trapped inside him making their expression difficult:

I wanted to cry or whatever, but you just can't escape it and you can't just turn it on like that. It's like it's trapped in there and you're sort of trying to let it out. I'm quite jealous of girls...I don't think guys have that switch they can activate and they can't tap into that to get rid of all of that feeling. (Max2, 9; 12-17)

Others kept their grief private at work because they were worried about being judged, being seen as vulnerable, and of how others might react. Their comments show that they feared looking feminine, weak, being judged negatively by friends, or friends ruining their reputations as "hard men":

You want to keep all the bad emotions in; you want everyone to see the good side. No one wants to see the bad side so you keep the bad side suppressed all the time. (Adam2, 10;1-3)

Well like it's a weakness for me. Showing a weakness or showing feelings. I don't like getting sympathy from people. I hate people feeling sorry for me and stuff so I choose to act like everything's alright. And I don't like to cause trouble. Just like to keep it myself and cope on my own. (Coby2, 30; 34-37)

They also indicated that they restrained their emotions to escape having their masculinity questioned and being taunted with homosexual insults. Suppressing their expression of emotions was seen as good, while talking, crying, or looking vulnerable, like a girl, was bad:

You wouldn't see a guy hugging it out, no way! If you did they'd think you're gay.... They would probably be on Facebook saying you're gay or something. ...People would give you shit. (Coby2, 34 ; 14-39) 
If you show a sensitive side, you don't want to show that off to people. You don't want to bring that out because you're a guy. (Coby2, 6; 7-8)

I just didn't want to talk to anyone eh. I didn't want to cry in front of people. I felt like they'd tell the other guys...I think it's just looking like a female, having those emotions. I think that's the main thing, everyone's just scared to look like a bitch. You've got to look manly. So, yeah, that's what I was scared of. (Harley1, 15; 12-26)

These worries reinforced their silence and they further justified their need to keep quiet, suppress their emotions, and remain brave and composed because they thought that was what their friends would have wanted and how being strong would be an example for others to remain strong.

\section{Relationship of the theme to silence.}

All of the participants tried to remain stoical following their loss. They managed their grief in the time immediately after the suicide according to traditional masculine norms: they did it alone (individualism), showed emotional restraint (stoicism), persevered, and showed their bravery and toughness by not showing others they were in pain or suffering. They endured the pain of their loss without complaint, keeping quiet, showing emotional restraint, and they carried on and kept themselves busy as a way of distracting themselves from the noise of their emotions and thoughts inside. Keeping their loss private and suppressing their thoughts and emotions gave them temporary reprieve from their grief and allowed them to carry on as normal. Four of the participants began to struggle with hopelessness and depression and being emotionally numb using self-harming behaviour and alcohol. Fear of judgement and being seen as weak or feminine reinforced their silence and stoicism.

\section{Grieving in Silence}

The third theme was that the men grieved and mourned the loss of their friends in silence. They struggled to talk about what their friend meant to them, honoured and connected with their friend in silence and with others who were grieving and mourning. When the participants witnessed others openly expressing their grief and breaking the silence they realised the finality of death and their loss. The two categories that made up the theme grieving in silence are: silent grief and realising the loss. 


\section{Silent grief.}

When the men attended the funerals and unveilings they paid their respects, endured their loss in silence and silently shared their grief:

When we were at the cemetery everyone just kind of kept in their own little groups and their head down. And you heard Brenda's tears and we just all went silent. It was horrible. But I think all his close mates were feeling it too. We didn't say much. (Coby1, 39; 610)

In their silence they were able to communicate their love for their friend and show to his family the mana/status he had. Being there and physically present (even when choosing to remain silent) meant they cared and that they were there to support friends and family. Participants took pride in being invited to take part in the ceremonies - even if it was a silent part.

Being included and having space made for them meant their relationship and close friendship with the deceased was recognised and publicly acknowledged (legitimising their grief and loss):

When I got asked it was like the best feeling ever knowing I was going to carry my good mate out. Knowing that I was recognised as a close mate. I don't know how to describe the feeling, it was just the best feeling. (Coby2, 10; 36-40)

It was good to be able to carry Devon out. He would have wanted his mates to send him out. Out of his home. (Fin2, 2; 23-24)

Being able to remain physically close to their deceased mate, to carry them, and to sit near them enabled the men to demonstrate nonverbally what their friend meant to them and helped them honour their commitments to their friend.

All of the participants struggled to speak publically at the funerals. Those that were offered an opportunity to speak talked about the special nature of the relationship they had with their friend:

All the family talked because everyone was too scared to go up because it was like, fuck this, there was so many people there. The school hall was packed, so probably over 1000 or 2000 people maybe, there was a lot of people there. (Harley1, 10; 2-5)

So I kept to myself and my friends went up. They had a few words. I was the last one to speak... I didn't want to say something but I 
felt like I had to say something otherwise I would have regretted it. (Adam 1, 9; 29-33)

The men grieved primarily in silence and struggled to express their grief and loss in words and in public situations. They appreciated being given opportunities to be involved in the funeral rites in ways that allowed them to retain their silence. The next category describes how the men came to realise their loss and the finality of suicide when connecting with others.

\section{Realising the loss.}

For all of the men, the funerals and burials were one of the hardest days of their lives. At that time and in those spaces they realised that their friend was "really" dead. They found it hard to see their friend in a lifeless state:

Just gutted eh to see him that way. How we seen him. (Rod1, 24; 22)

What was worse was coming here [Devon's parents' home] and seeing him in that coffin eh, that was the hard part. Like you thought he'd just wake up. (Fin1, 36; 27-29)

Seeing, hearing, and experiencing the grief of others confirmed their loss and the finality of their friend's death. Participants retreated or stood stunned and silent particularly when they witnessed the enormity and intensity of the emotions of the mothers who had lost their sons:

That was the worst thing for me, seeing his Mum like sad that her younger son died. You know her son died! [raised voice] It ripped me up eh. [sigh] And then like I was thinking fuck! Just freaking out my mate being like in a box in the ground you know. That shit cut me up, eh" (Harley, 9; 35-37). I can't see him get buried that will just kill me. So I just went straight home after I kissed the coffin. (Harley, 10; 10-16)

Yeah when I was sitting there and listening to everyone just talking about Devon it didn't feel real. Then seeing the family and the grief on their faces, I just realised. I think what did it for me at the funeral was [Devon's mothers'] speech. That was the saddest thing to hear. That was when I first realised properly that he was gone. I was stunned. (Coby2, 30; 14-19)

The permanence and reality of their loss was even more keenly felt when the coffin was closed and when it was taken away to be buried. It was in these moments that the men 
realised that would be the last connection they would have with their friend, they could no longer touch, see or hear their friend:

It was just seeing it go and knowing he's in there. You realise that once it's in the ground that's for real, he's gone. ...It was an open coffin - it was just good to see him and then once it was closed and all tied up, then carrying it out - you knew this is the last day we'll ever see him. Putting him in the car was the hardest bit and seeing it go. (Coby2, 10; 18-22)

When you see that coffin in that car disappear that's the last time you see any form or shape of that, of that body and that's just gone. All you have is your memories. (Adam1, 13; 7-9)

Phil's friends were spared from seeing the burial because he was taken away for private cremation, and, similarly, Damien's coffin was driven back to his home town for a tangi ${ }^{5}$ and burial. They had to say their final goodbyes at the funeral and did not witness the outpouring of grief at the burials.

\section{Relationship of the theme to silence.}

Connecting with their friend and other mourners was an important part of the men's bereavement experience. Participants tried to find the words to express their sadness and love for their friend, and struggled to say goodbye. They chose to grieve and mourn the loss of their friend in silence. Participants felt uncomfortable witnessing open expressions of grief in others, it challenged them and helped them with realising their loss and the finality of suicide and death. When it became too much for them, they retreated into silence and avoided others. Participants were not always made to feel welcome, acknowledged or respected during the funeral rituals and in the time following the death.

${ }^{5}$ A tangihana is a traditional Maori funeral rite held on a marae. The body is usually openly displayed on the porch of the meeting house (wharenui) and is rarely left alone. It usually occurs over three days with the burial on the third day. Free expression of grief for men and women is encouraged (Higgins, 2017). 
There were many times and situations when the men felt marginalised, disconnected and silenced.

\section{Being Silenced}

The fourth theme in the men's experience was being silenced. While the men described silence as something they experienced on a personal and intrapsychic level (for example, choosing to keep quiet, showing emotional restraint, trying to silence their thoughts, and grieving and mourning in silence), they also described it as something they encountered in social contexts. In some social situations they were publicly silenced by others and made to felt unimportant, invisible, left out, or excluded. For example, their friendship with the deceased and thus their loss was marginalised by others when they were not directly consulted, involved, or included in funerals and other rites. They also felt their experience was silenced or not validated when people failed to acknowledge their friend had died by suicide, and when family members signalled that they were not comfortable discussing the suicide and their loss, or when others were negative and critical towards the men.

Being silenced created a negative space for the men and the experience further reinforced their personal silence and choice to keep what they were experiencing private. Their social isolation worsened and the emotional chasm between themselves and those around them widened. The categories that made up the themes being silenced were: being marginalised, invalidation, feeling disconnected, and being shut down.

\section{Being marginalised.}

Participants felt upset and disrespected when they found out about their friend's suicide in the same manner as the rest of the public and/or second-hand from their peers. They were hurt that they had not been told verbally, in private and in person. They were made to feel invisible, and unimportant; they became angry that others, who were "not as close", were informed of the death before them:

She was telling everyone that didn't really need to know... on Facebook of all places! There's a time and place... So she was telling everyone, heaps of people that weren't even that close to Phil...she didn't even tell me! ...I would have liked to have known from either the family or [Phil's ex-girlfriend]. (Adam2, 7; 24-37) 
Not being consulted or involved in the funeral arrangements also contributed to participant's pubic silence. Phil's friends were frustrated that his funeral (the music, readings, and ceremony) did not reflect the identity and character of their friend, but instead reflected the family's wishes. They had known their friend for a long time and considered that they knew him best. Some of the participants felt that they, their relationship and grief had been marginalised. They believed they had been given a clear message that others were more important - they were insignificant and not part of the family's "inner circle". They felt marginalised when they were not told where Phil's ashes were scattered or invited to be a part of that ritual. Out of a sense of respect they kept silent and did not complain to the family and kept in the background:

A lot of people who had known Phil for life, but weren't close to him went up. Like a few people I'd never met but apparently were friends with him at college, like, went up to give speeches. I don't think anyone from our main circle did. (Luke1, 9; 31-34)

I didn't really have any say in it because I'm not the family. I was a bit gutted when they decided to burn him and scatter him. They scattered the ashes in some remote location that I couldn't even figure out where it was if I was looking for it. (Max2, 32; 35-37)

Being marginalised contributed to the men's silence. Failure to acknowledge their close friendship and not being consulted, invited or involved in funerals and other ceremonies meant participants felt unimportant, that they had no right to be seen or heard. The men were also silenced when others failed to acknowledge the suicide leading them to feel invalidated in their experience.

\section{Invalidation.}

When the family of the deceased and others failed to acknowledge the death was a suicide the men experienced invalidation and were silenced. They felt that their perceptions of reality were negated and denied. For example, Phil's family and friends failed to acknowledge at the funeral that his death was a suicide. A funeral celebrating the life of their friend which failed or diminished the reality and impact of the suicide felt inappropriate and unbalanced:

I think people try to keep it kind of light hearted, saying positive and funny stories or whatever but it just feels kind of awkward to me. To be honest, it was weird. You'd see his family and everything and afterwards when they're all eating food or whatever in the other room, and people are chasing plates of food. It's like this is bizarre, the last thing I feel like doing right now is eating... it doesn't really 
seem like people were openly acknowledging that he's actually gone. ...He's just dead and everyone sort of just carries on. (Max2, $4 ; 12-21)$

The avoidance and silence of others may have covered up the darkness and sadness of the suicide but it reinforced the silence of the men. It made them feel uncomfortable and signalled that they too needed to keep quiet about the suicide. In some social contexts the men were made to feel marginalised and were left out, but in others they were made to feel unwelcome. Feeling disconnected also contributed to the men's experience of being silenced.

\section{Feeling disconnected.}

Some of the men were made to feel unwelcome and excluded at the funerals and subjected to "silent treatment" from the "others" at the funeral. Despite wanting to be seen and heard the men chose to maintain silence out of respect for the occasion/ceremony and for the family:

I remember standing at the back with my mates and it was real weird, like none of the town people would talk to none of us. You know like "What's up?" like try and be kind, because we're all there for the same person. And you could feel it... none of them wanted to talk to us, and it was sort of like a standoff. It was like fuck we're here for this guy! And everyone's too busy and worried about each other. It was like someone was waiting for someone to start something and then everyone was ready to jump in. (Harley1, 9; 1223)

A year later, at the unveiling, Harley and his friends were subjected to the same silent treatment and were made to feel unwelcome. They suppressed their anger and desire to break the silence with violence. They dealt with their sense of disconnectedness by banding together in a show of solidarity and creating their own private space to talk to their friend and with each other about their loss:

Like everyone was just eyeing us up like "Fuck. What are you doing here?" you know. We didn't talk to no one, we just all stuck in our group and when they all went in together...We're just like fuck these guys ... I was like "Fuck this. I've just as much right as them." I was just cut up, eh. And then I went in had a prayer and we all went out to where he was buried for the unveiling. We were just getting eyed up the whole time so we just waited till everyone left and then sat down next to his grave and was talking you know. Sort of like talking to him eh, we were all just cut up. (Harley1, 12; 2440) 
All of the men, except Phil's friends, had somewhere physical to go that was a memorial to their friend. These spaces were important for maintaining their connection with their friend and with each other. They provided a ritualistic gathering point, a place they could visit in their own time, where they could grieve in their own way and in private. They could visit their friend, contemplate life with and without them, and say the things that were left unsaid. These real and physical spaces were important reminders that their friends existed and were loved. Max, Adam and Luke were not informed or invited to take part in the scattering of Phil's ashes and this meant they had no space to visit or way of staying attached to their friend:

I think the focal point is important not because I would go every week but just because you know where he is. If he's scattered then there's no trace he ever existed. When you've got a physical reminder you know yes he did exist and there he is. (Max2, 32; 3740)

When participants felt unwelcome, excluded they were disconnected. They felt as if they had no right to be present, to mourn, to speak or have access to their friend. They resisted being silenced by banding together but some were left feeling unable to talk or connect to their friend. Participants were also silenced by family, friends and others who shut them down and reinforced their silence.

\section{Being shut down.}

The men were shut down and publicly silenced when their family, partners, and friends said and did things that discouraged them from talking about their experience. For example, when they chose to disclose their loss to their parents, some were met by an overwhelming emotional response, awkward silences from family members or a lack of empathy and support that discouraged them from initiating any further conversations about their grief:

Yeah I told her and she was devastated eh. She didn't know what to say to me, so she pretty much just left me to do my own thing. (Harley1, 10; 23-24)

Oh it came up like once. 'Oh he killed himself?' type thing and then that was never discussed again. So I don't tend to bring those conversations up. (Luke1, 16; 8-9).

Silence within the home also shut down the possibility of the men sharing their experiences and publicly silenced them. They felt that because others no longer brought 
up the topic, and had "moved on" that it was no longer OK for them to talk about their loss:

My parents, they, they don't really like to talk about (pause), they did talk to me when it initially happened but then as time went on they kind of (pause) stopped talking about it. So I didn't. I'm not one to bring it up so I stopped talking to them about it. (Coby1, 22; 10-13)

They kept quiet rather than confront family members who were judgemental, insensitive or pressured them to "man up" or "get over it":

My Mum believes that suicide's a coward's way out. Her own words. But they don't take into account all of the factors that have led to that point. They just think this person hasn't been thinking about anyone else but themselves. (Max1, 21; 10-14)

I know my mother got really frustrated with the whole thing and at one point she said "Maybe you need to find a whole new group of friends" because at the time it seemed like mine were all you know dropping like flies. (Max2, 24; 16-18)

Friends, workmates and colleagues also publically silenced the men and reinforced the silence with their insensitive comments and "awkward silences":

People are like 'We've already talked about this. What's wrong with you?' you know. 'Why are we still talking about this?'... people just think we've already had one big talk about it we don't have to worry about it anymore. (Adam2, 13;1-8)

And not so long ago, when I was working, they were just making jokes about suicide. Like someone who stuffed up at work said "oh I may as well just go hang myself now" and I thought fuck man don't say that! Don't joke about that shit. (Fin2, 23; 5-9)

The men withdrew in silence when family and friends who did not understand their experience or needs shut down the conversation. When they disclosed their loss or tried to talk about their experience with others, the men were met with a range of responses; lack of interest and empathy, and insensitive or judgemental comments. These acted as barriers to the men connecting with others, sharing their experience thus contributing to their experience of being silenced.

\section{Relationship of the theme to silence.}

All of the participants were silenced by others within particular social situations and contexts. When they were not consulted or included in ceremonies they felt marginalised, that their relationship with their friend, their experience, and loss were unimportant. They 
felt they had no right to speak up when funerals did not reflect their friends and people failed to acknowledge the awful truth of how their friend died. This invalidation of their experience silenced them. When others made them feel unwelcome, or excluded them they felt disconnected from other survivors and disorientated, detached from their friend. Being silenced happened when family and friends did not understand their needs or experience, made insensitive, judgmental and critical comments, or could not offer the support they needed. These interactions shut down or closed opportunities for the participants to express and share their grief. Being silenced publicly sent a message to the men that talking about the suicide and their loss was not appropriate and further reinforced the choice to keep quiet. The men struggled to find ways to break the silence.

\section{Breaking the Silence}

The fifth theme was breaking the silence. Participants were reluctant to break their silence and express their grief and show their vulnerability. They wanted to avoid their family and partners overreacting (worry, concern) and a lack of empathy, insensitive comments, criticism and public silencing further shut down opportunities to talk with family and work colleagues. The men chose to connect with and talk to people who they felt understood them, their experience, and knew their friend, those who they trusted and showed they were active listeners. The two categories that made up the theme of breaking the silence were: talking to people who know, and talking to professionals.

\section{Talking to people who know.}

Silence and distance were also created by a lack of access to people who understood men's grief and suicide bereavement. Participants wanted to talk with people (family, partners and professionals) who knew what it was like to lose a close friend to suicide or had relevant lived experience. They desperately wanted to talk about their friend to someone who understood who they had lost:

If I was going to talk to someone it would be someone who knows what it is like and what Devon was like. (Fin2, 56; 23) 
Like when I went to the $\mathrm{EAP}^{6}$ they didn't know who he was. They don't know what kind of person he was. Even when you explain that to them they didn't quite get it. (Adam1, 27; 29-34)

When they invited or allowed others to see their distress and experience it alongside them it was usually with people who knew the deceased; had similar lived experience of grief, loss, or adversity; or they trusted. These were usually their closest friends, chick-mates ${ }^{7}$ or other men who they had had a connection with and who were non-judgemental:

He's understanding, I can tell him anything and he's not going to judge me by it. $(\operatorname{Rod} 2,6 ; 21-22)$

The people that are easiest to relate to are the people that are going through the same kind of kind of stuff. (Max2, 23; 4-5)

Participants sometimes preferred to talk to and share their experience and grief with chick-mates who were non-judgemental, open to sharing their own vulnerability and active listeners over their male friends:

Chick mates are just ones you can say anything to and they don't care. (Coby2, 44; 31)

The first time I ever properly talked about it and what happened with me would have been with [name of chick-mate] and that was when she was telling me her side. She was open about talking about her experience and I was able to reciprocate. (Luke1, 15; 35-38)

The men explained that their male friends often lacked understanding of how to support friends and usually tried to distract men from talking about feelings and their inner worlds:

...fellows, you know, they'll listen and offer you a beer and off you go. I think it is an uncomfortable thing as well with guys. Chicks they will listen and they'll talk, then they talk about it and stuff... But you have got to be pissed. (Coby2, 6; 23-38)

${ }^{6}$ EAP stands for the Employment Assistance Programme, free confidential assistance for employees for personal or work-related issues that affect employee performance. It is usually offered to employees when normal supervision and work place support have been ineffective in resolving issues. It may include counselling and therapy for issues such as stress, grief, trauma, addictions, bullying, mental health and relationship issues.

${ }^{7}$ Chick-mates are female friends who are considered mates, take part in male activities (for example, drinking, gaming, driving, and skating) but with whom there is no sexual relationship. 
They also preferred to talk to people who were supportive, let them go at their own pace, challenged their self-defeating thinking and gave them some constructive advice:

You just want to talk to someone who you know who either knows what you're going through or someone who can help. (Adam1, 18; 29-30)

I think the big one is just letting guys know that you're there to support them and they can talk to you but not trying to force it out of them basically. Let them open up in their own time. (Max2, 27; 6-9)

Participants opened up to friends, family and the family of the deceased, people who shared memories, stories, positive and negative emotions and who reciprocated:

I went round to dinner the other night and we just talked about him for ages. She [Devon's mum] actually seemed happy to talk about the old stories. (Coby2, 36; 7-8)

So I just hang out with a couple of mates and my Mum...we all just talked about him. Like it seemed that's all we'd talk about, just talk about him and stories and then we'd cry together, be as gay as. Like nice kind of stories, try and remember the good things he done. (Harley1, 11; 5-14)

Talking about their friend was important because it helped the men keep the memory of their friend alive. As long as they kept talking about their friend they kept them close and connected:

Every time we talk about him, man [big grin] I still feel him in my heart, like a warm feeling. Like every time his name's brought up... so it's sort of like they're still there. It's more of a good feeling now, eh. (Harley1, 24; 13-15)

Participants connected with people who knew them, their friend, and who understood what they were going through. It meant they could have a reciprocal conversation with people who cared, had relevant lived experience, and who showed them they could be trusted. When they broke their silence with these people they were able to share positive memories, reduce their sense of isolation, maintain their connection with their deceased friend, and gain validation and emotional support from others. Some of the men chose to break their silence by talking to professionals who provided the men with a safe environment which supported them to share and learn from their experience. 


\section{Talking to professionals.}

Talking to professionals was not usually something the men did as a first step. However, when they showed or disclosed that they were depressed, suicidal, and/or struggling to cope, it enabled them to break their silence and gain professional help. Harley was able to reach out to a youth one-stop-shop and get some counselling that helped him change his thinking and behaviour. Max went to see his General Practitioner and Adam received some counselling through Employee Assistance Programme (EAP) at work:

I had to go see a counsellor about it because it was just building up at work. I was taking it out on people at work and even though I had no idea at the time where it was coming from. It was just all these things that you just keep inside you. (Adam2, 9; 14-17)

Participants found it easier to talk to and work with mental health professionals who did not rush them, who tried to understand their experience, were solutions-focused (rather than focused on their feelings, distress), helped them vent their emotions in a safe way. Professionals helped the men express their emotions in a safe environment and space where they did not have to worry about upsetting friends, family or partners. They welcomed the opportunity to let go of some their thoughts and feelings and express them to people who did not try to interpret them or tell them what to do with them:

I went to a counsellor...I spoke to someone who I didn't know, about all the things that I couldn't tell other people and it just made me feel better. (Adam2, 15; 13-15)

For me talking about it has been a better experience than just hiding it and keeping it to myself...They don't have to give you an explanation, or a solution. It's just venting. It's like I said you're bottling it up and then you're just letting that out, opening that bottle, you're just letting it out whether it be a little bit or the whole thing. (Adam1, 25; 29-30; 27; 9-12)

Talking to and working with professionals helped the men learn new skills, take an active approach to managing their grief and helped them maintain their self-reliance. For example, Max found talking within a safe controlled and contained therapeutic environment at a mental health day programme with other young people helpful, and working in silence on projects (like gardening) at mental health services therapeutic. Others also gained relief when the professionals they spoke to challenged their thinking and helped remove some the guilt they had been experiencing:

She said 'Do you blame yourself?' Actually, I said "I did". And when she said 'Don't blame yourself because if you feel like you 
could have stopped it, it was still going to happen'. So she put a lot of things into perspective. (Adam1, 17; 3-6)

Talking to professionals helped them accept what happened and to let go of the responsibility and energy the men were investing into their grief. They responded positively to the systematic problem-solving approach of concentrating on one thing, fixing that, and then moving on:

That just made me accept it much more and it was just like something like an energy in my body that just released... That's one thing you have to at least think about, like somebody had just gone flipped a switch in my brain. Don't have to think about that anymore. Let's get onto something else that's making you depressed. (Adam2, 26; 19-26)

A conversation with a counsellor about his experience led to Harley being encouraged to attend a camp for young men who were transitioning to manhood run by youth workers and counsellors. It was within this trusting and safe group environment that he was given, and gave himself, permission to express his grief in public and in front of other men:

I talked about it with all these guys that I didn't even know, or trust. I trusted them with something that's so big in my life and then they didn't break up [laugh] or anything... It was good because all of them were there to support me. Yeah it was just and being around boys. You can cry, like people were crying, and like you can cry yourself. It just changed me. Like fuck, it's hard to explain man, but I just seeing other males cry, I guess. (Harley1, 21; 16-29)

These sorts of opportunities enabled the men to find support, companionship, and comradery and gave a voice to what was inside:

I learned that it's okay, better than bottling it up. It's the thing I use is like, tears are like the pain dripping down your face and it slowly disappears. You know, so it's better to cry and let it out than bottle it up inside and rage out at someone. That's what I think now. But I feel like, fucking gay when I tell people that same thing. Fucking gay bro! But now I don't care what other people think. I don't give a fuck what people think. Like, I'm me (Harley1, 22; 1-8)

Talking to and working with professionals was easier when the professionals took time to understand them and their loss, were objective, helped them identify and resolve issues, and learn new skills to improve their wellbeing. Breaking the silence with professionals also helped participants find a safe space to vent and express their grief, problem-solve and connect with other young men with similar experiences. 


\section{Relationship of the theme to silence.}

Breaking the silence meant finding friends, family and mental health professionals they could talk to and share their grief with. Participants chose to break their silence with people who had relevant lived experience, people who knew what it was like to lose someone, and people who they trusted and could have a reciprocal conversation with. They also connected with professionals who took time to understand them and their loss, helped them address their concerns and learn new skills and ways of living/being in the world. Breaking their silence helped the men find their voice, connect with others, learn to express their grief, and develop new skills for managing their grief and wellbeing. While participants valued being able to talk to and share their experiences, at times they sought and needed silence and appreciated the quiet supportive presence of others.

\section{Being in Silence}

The sixth theme was being in silence. Participants experienced being in silence when they found space and stillness to fully experience their grief. They sought out silent spaces (for example, work, their cars, and the cemetery) and used silence as a space to reflect, remember, and re-connect with their friend, as well as connect with others. They also encountered it in the silent presence and quiet understanding, and closeness and acceptance from others. This experience communicated safety and containment, and the men experienced this silent connection as liberating or healing. These silent connections also fostered their experience of change and integration of their loss. The two categories that make up the theme of being in silence are: quiet spaces and just being there.

\section{Quiet spaces.}

When the men were in public spaces they often cloaked themselves in silence and enclosed themselves within a quiet space. This space enabled them connect with others and the dead. For example, during the burial and at the unveiling the men often stood back, letting family gather closer to the grave. At Devon's unveiling his friends dressed mainly in black and wanted to show their respect for the family, so they stood, often with their girlfriends, side-by-side at the back. They had their hoodies up, or caps on, and their heads were bowed. This was their way of enclosing themselves in silence and claiming some silent space. 
Being in silence enabled them to focus on their friend and honour their friend. It was their way of saying the unspeakable:

It's like when I look down at the ground or at the grave well I'm just showing gratitude to him, I suppose. And you've got full listening going on. I think when I look down nothing else distracts me. You're kind of focused and can listen. It is just my kind of way of showing respect. (Coby2, 26; 21-24)

They sought out quiet spaces where they could have quiet internal conversations with the deceased. The men often made trips to the cemetery when they missed their friend, needed advice or just wanted to talk to their friend in their head and update him about their activities:

Sometimes when I get angry I just go up and see him. Go pay a visit and that which is cool. Go and sit and have a chat and shit. (Fin2, 3; 10-11).

I just sit down, talk, go see him. I tell him that I miss him, bring up old times, mostly. Most of the time I just sit there in silence too, sitting there thinking, put my music on. I just like to look at all the stuff [on the grave]. (Coby2, 36; 16-19)

Participants would also go to other locations, special or private places, or spend time in their cars where they had good memories and could reflect and grieve in private. These were private spaces where they could be vulnerable in private:

Always when I go to [town] skate-park I think of Devon, eh. We spent a few years there chilling growing up. Get into mischief. (Fin2, 45; 39-40)

It's when I'm driving and having some downtime that I kind of remember. Thoughts start coming through. (Coby1, 20, 18-19)

You get a lot more time to think about things. Like think things through and think of what it will be like without him. But it is hard to cope sometimes when you're on your own. You just have a little cry and you feel a bit better afterwards. (Coby2, 37; 10-13)

The internet was also as a quiet space the men could access anywhere, any time to reflect on their friend and the friendship they had lost and participants also used physical objects to help them remember and hang onto important memories:

Like I found one the other day on his profile which I was reading through with comments. He was just getting cheeky about having a race and that. (Fin2, 13; 24-25)

I just keep the memories close, got photos, got videos, I just keep the memories in my head. You don't need to go to a place to 
talk... and you don't need a venue...it's good to just dwell on your thoughts. (Adam2, 5; 21-25)

Occupying and creating quiet spaces enabled the men to take a break from the intensity of their own and others' emotional responses to the loss and engage in uninterrupted selfreflection. Silence in this context meant a safe, private space where the men could reflect, contemplate and gain greater insight into their own emotions, thoughts, and actions and remember and reconnect with their friend. When the men shared this silent space with others they described their silence and comforting presence as just being there.

\section{Just being there.}

The men responded to the silent therapeutic presence of others. Friends and family who were "there" for the men provided comfort, security, and containment. They often provided the distractions the men needed from their grief, and took care of them, feeding them and providing them with a space where they could relax:

Like, so, we're just at his house just chilling really. Playing games, watch TV, talking, working on our cars, just keeping ourselves busy and doing stuff. I think that that for me, that's enough. (Rod2, 7; 1012).

Just being there. Like being there at the time just has its own feeling. I can't explain it now but like at the time you know exactly what it is. $(\operatorname{Rod} 2,16 ; 34-36)$

They felt at ease with people who were comfortable being in silence, those who respected the boundaries the men had established; they did not pressure them to discuss their feelings:

If you want to talk about it you can talk about it, if you don't want to talk about it, you don't have to talk about it just go out, play some pool, have a drink, go see a movie, you know anything...Just being there for the mate who needs you. (Adam2, 22; 33-38)

They wanted companionship, to spend time with friends who could distract them and give them time out from their grief, and people to sit alongside them in their suffering rather than treatment and guidance or intervention. They would allow those they trusted and felt safe with to see their distress and vulnerability:

You stick with people that aren't going to get concerned or overreact. Friends who offer to help you through it, but not ones that are going to start telling you how you need to be managing things... What I appreciated most was just doing something and not thinking about it. Just gives you a break. (Max2, 25; 17-29) 
I've fallen asleep in alleyways in town. Just been too drunk eh, and these guys will just sit next to me until I wake up because they can't drag me you know... Like these guys are good people, eh. (Harley1, $32 ; 18-21)$

Spending time with other men who took time to just be with them in silence and who shared their own stories of loss, adversity, and resilience helped the men develop hope and showed them that others cared about them. This experience of being cared for by other men and their quiet acceptance helped them deal with the rejection of their friend's suicide and gave them a new perspective:

I met some people over there and they put me in a good mind. ...they helped me out a lot because I ended up opening up to them. I told him about what had been happening with me and then he understood and then he just looked after us, eh...I started seeing life different. I didn't want to die... I came back different. I just started looking at everything different... I realised I'm the only one that can change. I can't change what happened but I can change myself... It made me realise that you only live once. You might as well make the most of it. That, that's a big point eh. Like just keeping going. (Rod2, 31; 30-32; 33; 6; 33; 32-36; 34; 7-11)

Just being there was described by the men as a form of therapeutic presence which was healing and promoted analytic silence and reflection on personal change.

\section{Relationship of the theme to silence.}

Participants created their own opportunities, spaces, and times to talk to, visit, remember, or reconnect with their friends in private or with others. The men also connected with and experienced the silent therapeutic presence and care of others who were comfortable just being there for them in their grief. In these spaces the men began to integrate their loss and make sense of their experience, leading to personal change and silent analysis of how they had changed.

\section{Analytic Silence}

The final theme was analytic silence. All of the participants experienced personal and social change as a result of losing a close friend to suicide. The loss of their friends prompted the men to engage alone or with others in self-reflection. Analytic silence was a creative space, or container, for processes such as thinking, reflecting, and remembering. It was only in silence that the men could interpret and integrate their experience of loss. In these analytic spaces they shut out the noise of others, listened to 
what was inside them and became more aware of how they, their relationships with others, and the world had changed and transformed.

The men experienced a number of personal and social changes as a result of their friend's suicide and silence helped them reflect on these changes. They developed new values, a new perspective on life, greater awareness of their own and others' vulnerability, and more compassion for others' sorrow and suffering, mental health issues, and suicide bereavement. When the men experienced silence as acceptance and found inner peace they were able to carry on, and walk forward in their lives. Ultimately, the loss of their friends to suicide led to new selves and new ways of being in the world. The categories that made up the final theme of analytic silence were: understanding the loss, realising relationships have changed, being more sensitive and empathetic, becoming more caring, having a change in perspective, finding acceptance and inner peace, and carrying on.

\section{Understanding the loss.}

The men used silence to engage in individual reflection. Reflecting in silence helped them understand who and what they had lost. Losing a close friend to suicide meant they had experienced a personal loss. They had lost someone who was part of their past, present, and future, someone unique who was integral to their life:

I'm not going to meet anyone like him again you know. I'll never meet anyone like him. He is irreplaceable. $(\operatorname{Rod} 1,25 ; 17-21)$

It was like your whole childhood was gone with him. (Fin1, 25; 25)

Participants had to reform their ideas about the infinity of relationships and realised that they were vulnerable to future losses and this made them wary of investing in other close relationships:

It could happen anyway, anytime...You're always going to lose someone. They're not really there forever. (Fin2, 51; 24-26)

Just unreal. Then he's just gone one day... It's hard to be mates with other people...It affects you in a way you kind of keep distant from people... I don't want to be as close with someone else like that. (Coby2, 41; 13-39)

When examining their lives the men began to understand that they (and other friends affected by the suicide) had lost a sense of "normalcy", they had to adjust to life without their friend and had adopted new identities as "survivors": 
I was thinking they were hurt, we all were. I just feel the same about everyone; you know, they're all not normal anymore. $(\operatorname{Rod} 2,12 ; 6$ 7)

You still have to survive. You have to survive for other people to survive, so time doesn't just stop because you want to. In the end you'll figure out whatever you need to, to make it work out. Not necessarily quickly or in a long time from now but eventually you will get there. (Luke2, 36; 4-13)

Silence and reflection encouraged the men to think about who and what they had lost - a friend, their security, and a sense of normalcy - and to see themselves in new ways. They also became aware of changes they had experienced in their relationships with others.

\section{Realising relationships have changed.}

The bereaved men realised that suicide had slowly and silently reshaped relationships with friends and family. The suicides brought participants closer to those who shared their experience and helped them figure out who their real and loyal friends were. Their loss triggered them to evaluate their relationships, reduce the number of friends in their "inner circle" that they cared for. They did not have the energy to support those who were struggling with serious mental health issues or who caused dramas and so they cut ties with them:

Definitely changed the way I think about friendship. I'm pickier about who I'm mates with. (Coby2, 42; 9)

I've, like, made the circle smaller so I don't have to worry about more people; like, you know, just the ones I really do care about. (Harley1, 9; 1-2)

The men experienced secondary losses when some of their friends drifted away. They found that their friend was often the person who held the group together and some of their friends wanted distance to grieve or their living circumstances changed:

I had my own group which were also mates with Devon that was [pause] good. But I don't really see that group either. They've all [pause] gone their own ways. (Coby1, 27; 18-20)

I felt like once we went out of that house that it was pretty much all over. Like I haven't seen half of those people in a long time. People just go their separate ways obviously. (Adam1, 12; 36-39)

The men realised that their social circle had shrunk and they were more aware of how they trusted, valued, and were protective of their remaining "close friends". Since the 
suicide they were more wary of investing in new relationships and had made adjustments to friends who went their own way or had less contact. They were also more sensitive to the vulnerability of others and empathetic.

\section{Being more sensitive and empathetic.}

The men became more aware of others' emotional states, more sensitive to the vulnerability of others and how their actions can affect others. Thinking about what their deceased friend may have experienced leading up to the suicide helped them with this empathy:

When I think about all the things that were rushing back with Phil that day, in his last seconds, the amount of pain and sadness he must have been feeling. To have felt there was nothing else that could help him. ... I don't know what was going through his mind but it must have been pretty bad. (Adam2, 27; 22-35)

Well it has changed my view. I'm real against people giving people shit now for their looks and stuff because I think what if you offend them so bad they go home and top themselves? I never thought of that before. (Coby2, 45; 15-18)

Participants described becoming more sensitive, vigilant and responsive to the vulnerability and mental states of others:

You're more responsive to how people are feeling... it does give you a new appreciation of things and, yeah, definitely makes you more responsive. You try and pick things up sooner. (Max2, 30; 812)

If they say one thing that I think's suspicious I'm texting them all night bro. Even if I the don't text back I'm phoning them "Are you all good bro?" ring them like yeah. I'm different, a different person now, eh. (Harley1, 8; 31-34)

Developing sensitivity to others and empathy was an important change experienced by the men. When reflecting on their own feelings and those of their deceased friend, they became more aware of how others might be feeling and more proactive in reaching out to them. This sensitivity and empathy contributed to them becoming more caring.

\section{Becoming more caring.}

Surviving the suicide of a close friend led the men to become more caring toward others. They had become more selfless, responsible and protective of their close mates: 
If I hear of a friend of a friend or whatever [who has been affected by suicide] I'm much more likely to listen and actually start wondering what they're going through. I guess it's made me care much, much more about it. (Luke1, 23; 1-4)

Yeah I guess it makes you a bit more mature. You're just there for your mates more. If they need you you're there. (Fin2, 50;1-2)

They sometimes showed they cared non-verbally, reaching out in unobtrusive ways, so they didn't encroach on men's space and privacy:

Always go "Are you good?" Yep. But not trying to be that pushy person that I would hate you know...It gives them an opportunity to say if they're all good or not... Giving them the nod [gang nod, raising chin] is your chance to say something. And if there's nothing it's dropped. And it still shows them you care because I've given you the nod. (Coby2, 46; 1-9)

The men's experience of being listened to, sharing their own stories and being cared for encouraged them to reduce the barriers men face in talking about their experience and help other men find their voice:

Most people speak up now. Like let us know if something is happening, they will say something. (Rod1, 42; 35-36).

It's become more widely accepted in the overall friends circle... People are more open about stuff since then, like if you're feeling shit or upset about something (Max1, 14; 36-37).

They also learnt to gently persist with asking if their friends were $\mathrm{OK}$ and began to confront and challenge silence in their friends especially when they were aware something was wrong. They felt more confident to reach out to friends who were upset and offer support:

I just said "What's the matter"? He goes "Oh nothing". So I was like okay, left him alone for a couple of days, went back to him and I was like, "You look down, something's bothering you", he's like "No it's not". And I insisted something's bothering you and he told me. (Adam2, 32; 35-40)

After the suicide of their friend the men experienced a shift in how much they cared for others. They reached out to other men, silently acknowledged them, provided support, and encouraged them to break their silence. Not only did the men become more caring towards others, they also developed a different world view and life perspective. 


\section{Having a change in perspective.}

Reflecting on their experience of their friend's suicide led to a change in perspective and world view. Surviving the suicide challenged what were perhaps naïve views, and forced them to acknowledge there was suffering within the world and encouraged them to appreciate their own circumstances and what they had in life:

Now you know that the world is not all a bunch of beautiful colours. There are a lot of horrible things that people go through in their head that gets them to kill themselves. I mean the world is not a pretty place...it just paints a picture for you. (Adam1, 24; 13-18)

It's definitely changed my perception of a lot of different things. It makes you appreciate what you have a bit more as well. I've got things that Phil never had, things I might have taken for granted once. Now I appreciate the value of them all. (Max2, 37; 37-40)

They also reviewed the value they placed on their family and friends and developed a deeper sense of gratitude for the gifts they had in life:

It makes you look at life different, eh. Well when I lost Devon I kind of felt like I wanted to respect Mum more. I wanted my Mum and that more.

I think it's just respect each other more...Carry on doing what we do but just be grateful to be there. Appreciate what we get up to and good mates. Appreciate being happy. (Fin2, 50; 20-21; 54; 6-18)

Participants also changed their focus in life. Some learnt to appreciate the here- and-now, while others learnt to set and work towards short-term goals that helped motivate them and keep them going:

You've just got to enjoy it while you're young and keep doing what you're doing. Just do it for him. Carry his legacy on. Just keep going... live it the way you want to and chase your dreams. (Fin2, $50 ; 25-29)$

You've just got to think how you want to feel like in a month's time and work on that. (Jace2, 34; 9-10)

That's the big thing, meeting goals and having achievements. Like you feel like as soon as you achieve something you're happy...It helps me keep going and it gives me something new to focus on. $(\operatorname{Rod} 2,28 ; 1-12)$

The men described developing a perspective and orientation to life that focused on meeting the future with bravery, courage, self-determination and resiliency. They did not want to be seen or act like victims, rather they were survivors: 
Being negative is not going to help me and my future... it's just going to make things bad for me... thinking about it and what I can do to make myself happy. I can choose what I want to do...I just help myself. I'm not going to let this thing stop me now. I work to keep myself busy and get somewhere at the same time as well as hurting. Making progress as well as dealing with it. $(\operatorname{Rod} 2,29 ; 36-$ $40 ; 28 ; 1-4)$

Those who struggled with their own depression and/or thoughts of suicide were challenged to see the world in a new way. Being encouraged to reassess their own lives helped create critical turning points which led these men to make positive changes, to address their own health and wellbeing. The participants could no longer ignore the grief and suffering their own deaths would cause others. It helped them move towards a greater life orientation and prompted four of them to seek help for their depression and anger:

I think this particular thing in my life it just opened up my eyes. I wanted to kill myself and then Phil did it first and then having that revelation. (Adam2, 37; 8-27)

When I saw the impact that it had on his family and his friends, I thought I can't do this to my family. ... So I felt like in a way he kind of saved me. I feel kind of bad about that. It took his life to save my life. I didn't tell anyone. I kept it to myself for so many years. ... I had to just be on top of life. ... I had to go do something about it. I didn't want to be like Phil. (Adam1, 20; 1-15)

The men experienced a change in perspective on life. They came to see the world in a new way as a place of suffering and began to value themselves, their lives, and the lives of others more highly. They men became more present and future-focused and determined to take control of their own happiness, and adopted a resilient attitude. Those who struggled with their own depression and thoughts of suicide found the experience to be life-changing and life-saving because it caused them to reassess the impact of their own suicides on others. The men also experienced a sort of inner silence or peace when they developed acceptance of their friend's suicide.

\section{Finding acceptance and inner peace.}

When the men developed acceptance of their friend's suicide they found silence and inner peace. They came to accept their loss when they acknowledged that the suicide was something they couldn't change and when they thought about their friend's being at peace: 
Can't change it so, even if that sounds like heartless like it's the truth. You can't change what he done so you've just got to respect his decision. (Harley1, 14; 6-8)

What's done is done, pretty much. But it's still raw as. Always remember, always have memories of him. Coming to terms, is definitely just realising there's nothing you can do. It's happened and move on. (Coby2, 40; 5-8)

Having time and space to think was crucial for the men to integrate their loss. They needed and made time to reflect upon the loss, and accommodated it at their own pace:

I think time does give you time to come to terms with the fact that he's dead. I don't think you ever come to terms with why he's dead, just that he is dead. (Max2, 34; 19-21)

I mean you kind of have to move on at your own pace... Some people were like "Oh the funeral's done, okay you know he's gone, that's it. That's finished. It's done". Some people will take longer you know. I really miss him, we did all these things with him, you know. I'm having trouble accepting the loss, you know, I can't believe he did this! (Adam2, 13; 20-26)

The men experienced a form of inner silence when they learnt to shift their focus away from how they died, their loss and focused on positive memories of times they shared together:

I tried remembering the good memories instead of letting the 'he's not going to be here anymore' memories take over. I kind of blocked them out. (Coby1, 47; 1-2)

Peace and quiet came when they understood or learnt to forgive their friend and let go of some of the anger:

I'm doing alright now eh. I've gotten over the fact that he's done

it... I was angry but that's not going to help me so I've gotten over

it. $(\operatorname{Rod} 2,18 ; 22-28)$

Participants learnt to accept that peace was fragile; they would never "get over it" completely, and that there would be a "new normal". Some realised they had come to accept what had happened when they were no longer constantly consumed with it mentally:

It's still there...It just has its moments eh. Sometimes it will pop up and then that's when you start thinking about it. But I reckon I'm doing alright, eh. (Rod2, 27; 31-34)

Life changes. Changes forever. But eventually you get used to the changes I guess... You never truly get over grief but from a life 
point of view you do get over it...things sort of come together to maybe a new status quo. (Luke1, 24; 6-15)

All of the men were transformed by their experience. Accepting the loss and understanding that they could not change what had happened was a part of learning to live with their loss. The men also realised that they would never "get over" the suicide and that grief and loss was something that they had to learn to adjust to. They developed inner peace when they focused on positive memories of their friends, visualised them being at peace, and started to think about the future. The last subtheme within the major theme of analytic silence is carrying on and this is described in the following section.

\section{Carrying on.}

The participants described an awareness that they had learned to carry on with life and live with the scars that the suicide and loss left them with. With time and effort their grief became more manageable, less painful, but it didn't go away completely:

You try to fill that hole with good memories. Then it gets a bit too much because you're thinking too much about it. Fuck! Like you know it just kicks in again. And then I usually just do the same thing again. I accept it, yeah, he's really gone. That mate's gone. (Rod2, $19 ; 12-16)$

Over time the need to discuss the suicide became less important and the silence around it helped re-establish a sense of normality. Silence and new demands and priorities (relationships, work, and birth of children) helped them carry on but it did not mean they had forgotten their friends:

We mostly just moved on I think. Not to say that we forgot about him but it was like once the shock wore off, except for a few occasions it just never got brought up again. We talked about it less and less over time. Personally, once I got over the shock I was mostly okay. (Luke1, 12; 5-9)

I'll never forget him, no. No way. I'll always remember him. It's just a lot easier to carry on now than when it was. I think I've had a lot more time now to come to terms with it... It's not so much forgetting about it but putting that at the back of my mind when I'm sorting all this other stuff (Coby2, 6; 17-18, 22-24).

While they understood their friend was physically gone, they described him as always being close, like a silent passenger in their car, or silently walking alongside them. The loss of their friend transformed their relationship into something more enduring, spiritual, and internal. 
Staying connected to their friend helped them find the courage and confidence to keep going and to live with their loss:

It's sort of like you could hear him. He's telling you to carry on, eh. I'd just do it. Have a few dreams about him and that. He comes and visits. He's always with me. (Fin1, 54; 27-28)

Like (pause) I can deal with it now, like I always miss him but I can carry on now, can keep going. (Coby1, 45; 18-19)

The loss of their friends was like a silent alarm, a wake-up call, a warning that life is precious and that they should try to live it well. The men changed, they changed the way they viewed life and believed they had been given an opportunity to carry on but with a different life:

At this point I feel redeemed but I don't know what's to come... I could have a short life I could have a long life, you never know. This hasn't defined me but this is probably the most important thing that's happened for me...I'm only 25 . I don't know how many years I have left or what's going to happen right up until my death but you've just got to live life as it comes and hope for the best. (Adam2, 38; 1-24)

The men described how they carried on through life despite their loss. This involved learning to manage their grief, shift their focus onto living life, but not forgetting the friend they lost or the lessons they had learned. The men were aware of how their lives had changed and how they too were different and transformed. Their ongoing connection with and loyalty to their friend helped them find the courage to keep going. In these ways, losing a close friend to suicide was a transformative learning experience.

\section{Relationship of the theme to silence.}

The men experienced changes in self, values, perspective on life, and social relationships. Through silent self-reflection and analytic silence the men became aware of the changes they experienced. They learned how the loss of their friend meant losing someone and a part of themselves that was irreplaceable. The suicide had also meant a loss of normalcy but they were determined to be survivors.

They thought about how suicide had reshaped their social relationships, shrinking their circle of close friends, making them more wary of developing new friends. They observed how their bond and connections with those friends who experienced the suicide 
bereavement alongside them strengthened. They considered how suicide had prompted them to become more sensitive and empathetic towards others who were vulnerable or experiencing grief. They pondered how they had become more caring towards themselves and others, and how reaching out, even in silence, can make a critical difference in people's lives. They experienced a change in perspective, seeing the world as a place of

suffering but also noticed how they had become more authentic in the way they now lived life - being true to themselves, valuing life and their loved ones, and more focused on appreciating life.

The silent spaces they sought out and occupied enabled them to contemplate these changes and integrate their loss. A combination of time and the realisation they could not change what had happened helped them find acceptance and inner peace which represented a form of internal quiet. Finally, they reflected on how the suicide and loss of their close friends had changed their lives but how they kept walking on with quiet determination because it was important for them and a way to honour their friend's memory.

\section{Exhaustive Description}

An exhaustive description of the men's experience was produced by integration of the findings of analysis of the data. This description captures the essence of their experience (silence) in order to convey to the reader what the phenomenon "was really like" from the participants' perspective. The following description of the lived experience of losing a close male friend to suicide is proposed:

The loss of a close male friend to suicide left the young men experiencing their loss within a context of silence. The participants were gutted, shocked and speechless. They struggled to find ways to express what they felt inside. They maintained their private silence, choosing to withdraw from others and kept quiet. They dealt internally with questions of blame, responsibility, and their own sense of powerlessness. They managed their grief by choosing to remain stoic and silent, suppressing and controlling their emotions, keeping busy. They tried to silence their grief, depression, and distress. A fear of breaking down, showing their vulnerability, and being judged as weak and/or feminine encouraged them to remain silent. 
During public rituals and funerals the men struggled to say goodbye to their friend and express what their loss meant to them. They grieved and connected silently with others. Hearing and seeing others' expressions of grief threatened to overwhelm them but helped them realise the finality of their friend's death. The men were publicly silenced by others when they were marginalised or excluded, when they or the suicide was not acknowledged, and when others shut down conversations through insensitive comments and unsupportive actions. The men broke their silence, expressing themselves and their grief when they encountered others with similar experiences, who understood grief, loss, and adversity, and with those they trusted. They broke their silence with professionals who respected their needs to focus on solving problems, develop emotional regulation, and who helped them in practical ways to maintain their wellbeing.

Analytic silence was experienced when the men found spaces for reflection, remembering, and reconnecting. Quiet spaces helped them make sense and integrate their loss. They also encountered a silence that was therapeutic and comforting when people sat alongside them in silence, cared for them, and were present for them. The analytic silence helped them develop greater awareness of self and others, and how their relationships with others and the world had changed. Their experience made them more sensitive, empathetic, and caring, and contributed to changes in perspective, new life values/priorities. They found inner silence and peace when they accepted their loss and realised that experiencing grief was part of staying connected to the memory of their friend; grief and their friend became like a silent companion. This realisation and their experience encouraged them to carry on with life as survivors. Ultimately, the men experienced silence after suicide, and that silence after suicide was ubiquitous.

\section{Chapter Summary}

This chapter has presented a description and analysis of the data extracted from the narrated lived experience of eight young men, who lost a close male friend to suicide. The major themes of their experience are presented within the context of the overarching essence - silence and an exhaustive description of what it meant to lose a close male friend to suicide is presented. In the following chapter, I examine the significance of these findings in relation to relevant theory, research, and mental health practice. The next chapter focuses on how silence and suicide bereavement is experienced by young men and the implications for promoting men's health and wellbeing. 


\section{CHAPTER SIX: DISCUSSION}

\section{Introduction}

Suicide-loss survivors are at greater risk of mental health issues (Andriessen, 2009; Cerel et al., 2009); young survivors are at greater risk of psychopathology (Brent et al., 1993c), suicidal thinking (Feigelman \& Gorman, 2008), suicide attempts (Brent et al., 1992; Ephraim, 1998) and of completing the act of suicide (Brent et al., 1989; Cerel, Roberts \& Nilson, 2005; Bell, Stanley, Mallon \& Manthorpe, 2012). This descriptive phenomenological study explored young men's experiences of losing a close friend to suicide in order to better understand their experience.

The previous chapter provided an analysis of the themes from participants' accounts of their experience. In this chapter I summarise the key findings and provide a critical discussion of these findings in relation to previous research, theoretical understanding, and knowledge and scholarship on survivorship. The key finding was that silence was at the heart of the participant's experience of losing a close friend to suicide. Participants experienced personal and private silence after the suicide of a close friend; in social contexts participants grieved in silence and were silenced by others. They chose to break their silence with and were cared for by people they trusted; occupying quiet spaces enabled the men to reconnect with the memory of their friend, make sense of their experience and reflect on personal learning and changes.

\section{Personal Silence}

When participants first learned that their friend had taken their own life they were gutted, shocked, and experienced disbelief. They struggled to find the words to describe what they were experiencing. These findings are in keeping with other studies of young men's grief following the death of a close friend (Creighton et al., 2013). Studies of survivors show they experience a range of confusing and overwhelming emotions (Bragdon, 2006; Fielden, 2003; Melhem et al., 2004). The men's orientation to their sudden and traumatic loss is similar to that outlined in the dual process model of grief (Stroebe \& Schut, 2010); where the bereaved focus on trying to manage loss-oriented stressors such as intrusive grief, pain and sadness which can mean they deny and avoid finding meaning of the death and loss. What is less emphasised in these studies and this model is the place of silence that accompanies this initial experience. 
The personal silence the men experienced prevented them from being able to describe how they were feeling. This personal silence is comparable to 'shocked detachment', a state of being shattered and disbelief (this is not happening) which survivors respond to by creating distance between themselves and the reality of the loss (Gaffney \& Hannigan, 2010, p. 530). This state of shocked detachment, numbness and disengagement has been described as 'thrownness'- an upheaval which throws people off balance and challenges their world view (Fielden, 2003, p. 79). What the current study showed was that this state of shocked detachment or thrownness, encouraged the men to withdraw from the world into silence because they did not know what to say and do.

The participants' lack of ability to describe their inner world may have also been the result of normative male alexithymia, difficulties identifying and describing feelings that come from socialised pattern of restrictive emotionality which is influenced by traditional masculine ideology (Levant et al. 2014). The participant's personal silence is also comparable to the personal silence described by Addis (2011) and stems from an inability to make sense of or understand a confusing mix of emotions and feelings. A recent study of people who have experienced traumatic bereavement (including the suicide of a family member) supports the notion of personal silence (Dyregrov, Bernsten \& Silviken, 2014). Dyregrov et al. (2014) found the "extremeness" of the experience and strong conflicting emotions hindered the ability of people to articulate their experience and need for support, creating a barrier to accessing support.

Work in the area of trauma can help shed light on this finding concerning personal silence. Finding out about the details of their friend's death by suicide and imagining their last moments may have meant the men experienced a form of secondary traumatic stress (Figley, 1995) or vicarious traumatisation (McCann \& Pearlman, 1990). People who have been exposed to trauma, witnesses or vicarious witnesses often encounter problems of representation; they struggle not only with what they have seen and heard, but also how to render to others what they have seen and heard (Weingarten, 2000). Herman (1992), a psychiatrist, argues that victims and witnesses of trauma may experience a dialectic of trauma and find it difficult to convey fully and persuasively what they have seen (or imagined in the case of vicarious trauma). 


\section{Private Silence}

A key finding of this study was that the men worked hard to be stoical and to silence the expression of emotions and grief. At times participants chose to keep quiet about their grief and vulnerability because they did not want family, friends and work colleagues to judge them as weak, vulnerable, at-risk or think of them as incapable of performing their roles. They chose to keep quiet, and controlled conversations when they felt unsafe, pressured or needed time to work out what they wanted to say.

The participants' desire to keep their inner world private fits with Addis's (2011) notion of private silence based on his work on men, masculinity and health. Addis argued that men's socialisation, beliefs about self-reliance and controlling emotions can make it difficult for men to break or resist traditional masculine norms and openly express themselves. Work in the area of masculinity and men's health supports the finding that men may be reluctant to emotionally disclose, seek or accept help because these are threats to men's sense of masculinity (Schaub \& Williams, 2007), can lead to a loss of control (Richardson \& Raibee, 2001) and be an admittance of personal failure (Addis \& Mahalik, 2003; Kimmel, 1997). Research on bereaved young men has also shown that adherence to traditional masculine norms and a fear of social displays of emotion and burdening others can reinforce men's silence (McNess, 2008).

\section{Strategies for maintaining private silence.}

The current study highlighted that participants used a number of strategies to maintain their silence and to keep their grief private including: avoiding others, emotional restraint; keeping busy, and that fear of being judged as less of a man was a motivating factor for them to remain stoical and to keep their grief private.

\section{Avoidance.}

Participants described keeping their grief private, avoiding others and distancing themselves from people and situations where they might be overwhelmed by grief, break down, and/or look vulnerable or weak. During the days following their friend's suicide, the men described withdrawing from others. They did this in order to find space to make sense of what had happened. In that silence they grappled with the whys, self-doubt, regrets, and struggled with a sense of powerlessness. This finding is congruent with 
studies that show that survivors are often left struggling to understand why the suicide happened, why they couldn't prevent it, and why they were rejected (Begley \& Quayle, 2007; Fielden, 2003; Jordan, 2008; Crow, 2013; Ford, 2016). It also is congruent with studies that show that survivors have to deal with feelings of guilt and regrets (for missing warning signs and not being able to prevent the suicide), shame, blame and stigma (Peters, Murphy \& Jackson, 2013).

The findings also parallel previous phenomenological research that shows that avoidance is a response in men who are grieving the loss of a close friend (Bragdon, 2006; Creighton et al., 2013). Creighton et al. (2013) found that young men's predominant grief responses included stoicism. They also found that the death of friend can lead young men to fear being publically seen as a less of a man. Young men fear showing vulnerability so they withdraw socially until they can regain their composure and "man up". The participants use of avoidance is also confirmed by results from quantitative research that shows young people exposed to peer suicide use avoidant coping strategies (Bartik et al., 2013).

Avoidance and maintaining private silence was used to protect others. Participants were mindful of the emotional states of others and did not want to trigger grief, or add to their worries. They chose to suffer in silence because they wanted to avoid conflict and to minimise any further stress to themselves. This finding parallels recent bereavement research which shows people may: keep feelings private in order to protect loved ones from pain and sadness (Van Humbeeck et al., 2016); avoid family and others who are over-protective (Dyregrov, 2003-2004), and avoid others because of the effects suicide can have on family systems (Rosenblatt, 1988). Weingarten (2000) argues that people may keep their grief private because people believe that no one can bear to hear their thoughts and feelings, and that silence is good and speech or sharing/imposing pain on others is selfish.

The current study shows the men chose to avoid and withdraw from others because they cared about themselves and others, and that silent suffering is a key aspect of young men's experience of grief. This finding challenges notions of young adults as selfish and uncaring (Arnett, 2007, 2014). It lends support to previous work that shows boys are emotional, empathetic and caring but try to project a confident, strong image to protect others and themselves (Pollack, 2006). This finding also supports the idea of caring being 
a part of positive masculinity (Kiselica, Englar-Carlson, Horne \& Fisher, 2008). The men genuinely cared about the wellbeing of others and wished to protect them from further pain.

\section{Emotional restraint.}

Participants used emotional restraint and suppression to keep their grief private and maintain their silence. Similar findings have been reported in recent research on bereaved adolescents (Lytje, 2017) which show that young people hide their grief from their peers because they fear looking different, do not want to upset friends, and believe that others cannot handle or cope with their grief. Stoicism and emotional restraint also had a selfprotective function for participants; they were worried that feelings, felt or expressed, could lead to a loss of composure and challenges to their masculine status. This selfprotective aspect of stoicism and emotional restraint has been found in other studies of young men who have lost close friends (Creighton et al., 2013).

The men struggled with a tension - on the one hand they wanted to connect with others and share their grief, but on the other they also wanted to avoid being judged as vulnerable, weak or feminine and avoid losing control of their emotions. This is similar to the deep conflict and emotional struggle identified in adolescent boys (Pollack, 2006). Lytje (2017) found adolescents struggled with wanting to share their grief in order to gain support but desired to maintain control over how others see them, the information others have about them, and their emotions. These types of conflicts and tensions, issues of emotional control, agency, and identity have received little attention in the research on children and young people's bereavement. Suicide bereavement and grief research has tended to focus on intrapsychic processes, responses and effect and has not utilised a gender, sociological or a youth studies perspective (McCarthy, 2007).

\section{Keeping busy.}

Participants maintained a private silence and avoided sitting around, talking and expressing their emotions and grief. They took a more active, cognitive and instrumental approach to their grief. They kept themselves busy, sought cognitive distractions and tried to maintain normal routines in order to give themselves a break from their grief and sadness. Keeping busy and working on projects alone gave the men time to sort through "un-masculine" (Creighton et al., 2013, p. 36) feelings of sadness and despair privately 
but was also a way the men could "turn down", "turn off" or "fight through" their grief (Creighton et al., 2013, p. 38) and maintain an active instrumental orientation.

Research on gender differences in cognitive emotion regulation strategies (Garnefski, Teerds, Kraaij, Legerstee \& van den Kommer, 2004) suggests that women are more likely to report using rumination and catastrophizing strategies in relation to life stress. Earlier research shows women tend to focus more on their emotional experience, acknowledge and discuss emotions more openly and ruminate more on sadness than men (Fivush \& Buckner, 2000). Men's adoption of an active, cognitive and instrumental approach to grief has been well established and is likely to be gender-influenced but not gender specific (Martin \& Doka, 2000; Doka \& Martin, 2010). The importance of establishing a sense of control, maintaining routines and re-establishing a sense of normality has been highlighted by a range of international authors and as aiding recovery (Read, 2014, Stroebe, Stroebe \& Hansson, 1988) and resiliency (Sandler, Wolchik \& Ayers, 2007).

\section{Suicidal thoughts and depression.}

Half the participants struggled with depression and suicidal thoughts. When they were alone they would often ruminate, think about their friend's pain and last moments and relate this to their own pain and situations. Previous studies of survivors support the finding that those left behind are at greater risk compared to those who are non-bereaved (Qin \& Mortensen, 2003) and those bereaved by non-suicide (Agerbo, 2005). A more recent study of 3,432 UK university staff and students (aged 18-40 years) found that people bereaved by the sudden suicide of a friend or family member were $65 \%$ more likely to attempt suicide than if the person had died by natural causes. The study found an absolute risk of suicide attempt of 1:10 (Pitman, Osborn, Rantell \& King, 2016). Men in the present study kept their suicidal ideation and self-harm hidden from others and dealt with it privately.

Participants tried to silence suicidal thoughts and feelings by engaging in risk-taking and self-harming behaviour (not taking medication, fighting, playing with knives, and causing injuries to themselves using tools at work) and substance abuse. Recent studies of bereaved young men have similarly shown that bereaved young men may maintain risktaking behaviour (living in the moment) or reign in risk practices because they recognise the fragility of life (Creighton et al., 2015). Creighton et al. (2016) also found that young 
men use alcohol to dull the pain of grief, purge sadness and bond with other men following the death of close male friends. In their study, binge and problem-drinking was a means by which young men could express emotion and connect with others. Intoxication allowed them to connect on an emotional level, helped them relax and talk to each other, to be affectionate and to connect with each other in ways that were unacceptable when they were sober.

In the present study, the men used alcohol mainly as a short-term way of coping; it was a means for suppressing emotion (whether they were alone or with others), and they kept their vulnerability to themselves. They used alcohol and self-harming behaviour to cope with emotional numbness and did not use alcohol to connect to others. Furthermore they did not engage in risk-taking behaviour which could be construed as performances of masculinity that demonstrated their fearlessness and invulnerability. Losing a close friend to suicide, in the longer-term, triggered the men to re-evaluate their lifestyles and take greater responsibility for their own wellbeing and that of family and friends, and led to reduced risky engagements and self-health practices (Creighton et al., 2013).

\section{Fear of judgment.}

Fear of being judged by others and having their masculinity questioned inhibited the expression of grief and encouraged the men to remain stoical and keep their vulnerability private. This fits with previous studies that have shown that young men who have lost close friends remain stoic and solitary in order to avoid being seen as expressing unmasculine feelings of sadness and despair and judged as less of a man (Creighton et al., 2013). Crying was seen as a feminine act, signifying weakness, a lack of control, and was unacceptable to them as men and to others (Versalle \& McDowell, 2004-2005). Participants described avoiding public displays of sensitivity, comforting and connection because these would be seen as a sign of "being gay". This finding fits with literature that contends that young men learn from an early age that these behaviours are feminine, negative and to be avoided (Vogel et al., 2011). The participants' bereavement, and expression of grief were influenced by a desire to conform to traditional masculine gender norms of anti-femininity and homophobia (Beaglaoich et al., 2013). 


\section{Social Silence}

This study showed that the young men encountered silence in a range of social contexts: during mourning rituals and events they grieved in silence, they were silenced by others, they broke their silence with certain individuals, and they experienced a therapeutic silence when joined by others who were able to support them in ways that met their gender-specific needs.

\section{Grieving in silence.}

Following the suicide of their friends some of the participants were invited to participate in social and cultural funeral rites and rituals. They were given space and opportunities to grieve alongside others. Participants struggled to speak about the importance of their friend in public but felt it was important to acknowledge their friend. They also felt it was important to be acknowledged as having a close relationship to the deceased. Being included in funerals and bearing witness to the burial of their friends was a painful but important part of the bereavement process because it helped participants realise and begin to accept their loss. Previous studies have demonstrated that there are gender differences in grief; men are less likely to share their grief experience with others (Rothaupt \& Becker, 2007) and more likely to experience active and cognitive patterns of grief (Doka \& Martin, 2010), highlighting the need for men to have opportunities to 'do' grief.

The present study adds to this work by showing that men need to be encouraged to take an active part in funeral rituals. Being asked to carry their friend's coffin, speak at funerals or have a say in how events were planned was an important way of acknowledging their "closeness" to the deceased and helped participants accept their loss. Research shows that cultural and psychotherapeutic rituals can help the bereaved manage their grief and that these can involve both intrapsychic and social processes (Romanoff, 1998).

Johnsen and Dyregrov (2016) in their recent study of the bereavement process of 13 young adults (after the loss of a close friend in a terror incident) found that the loss of a close friend had a profound effect on young people and the way they experienced grief. They found young people struggled to understand that their friend was gone forever. Those who did not get a chance to see the deceased found it difficult to understand that their friend was gone and their loss was real. The present study supports the notion that 
being involved in funerals of loved ones and close friends helps with grieving and the mourning of loss.

\section{Being silenced by others.}

Participants were publically silenced by the words and actions of others. In some social situations they were not recognised as being 'as close' as family and relatives and so were not consulted, or personally told about their friend's death. They also were frustrated and angry because they felt others failed to acknowledge the fact their friend's died by suicide. Some were treated with hostility, were excluded or made to feel unwelcome at funerals, others were silenced by people who did not know how to support them, pressured them to "move on" or "get over" their grief.

Participants described being silenced by others and this finding is supported by previous studies. Research shows that suicide-loss survivors often feel silenced and socially withdraw because: of a lack of available social support; people who fail to acknowledge their loss avoid them; insensitive responses and comments from others (Dyregrov, 20032004; Jackoby, 2014; Maple et al., 2010; Trimble, Hannigan \& Gaffney, 2012). They also feel silenced and withdraw because others are uncomfortable and unsure how to respond (Van Dongen, 1993). These types of responses discourage the bereaved from expressing their grief (Feigelman, Gorman \& Jordan., 2009; Range \& Calhoun, 1990) and added to their shame and stigma (Maple et al., 2010). Feigelman et al. (2009) found survivors reported that people avoided them and encountered a "wall of silence" where significant others avoided talking about the deceased, gave unhelpful advice, or pressured survivors to "move on"; such survivors experienced an absence of caring. Jakoby (2014) found that "Speechlessness and a lack of understanding in others can complicate the grieving process and put additional stress on bereaved" (p. 17). Many of these studies have been based on adults' and parent's experiences of suicide bereavement but the present study showed that young men also experience similar silence and social responses.

Johnsen and Dyregrov (2016) found that young adults who lost close friends to a terror act (mass shooting) experienced similar hurtful comments from friends, family and professionals. They found young adults felt others did not fully understand what they were going through, that they were expected to move on, or that their grief was minimised or marginalised because they were not afforded the same importance as kinship ties. The 192 
present study shows that young men react to these insensitive responses and "wall of silence" by withdrawing and cutting off people who they see as unsupportive, insensitive or incapable of understanding their grief.

The work of Weingarten (2000) may help shed some light on why people find it difficult to support young men and other survivors. According to Weingarten (2000) it is difficult for others to be compassionate witnesses, and to listen with open hearts and minds to the stories of others' pain for fear of being dragged into the chaos of those in such pain: "Witnesses are one layer away from chaos" (Weingarten, 2000, p. 394). She argues that people need to believe that they are not alone, and have hope that others can bear witness to their pain and suffering. When people fear and lack understanding, they discourage others from talking about it - they silence them. The men in this study struggled to find family and friends who could bear witness to their grief and loss, so they withdrew in silence. According to Weingarten (2000) when they sense a listener's apprehension, the sufferer will stop talking.

\section{Breaking the silence.}

Participants wanted people to bear witness to their pain, and to talk about their friend and their loss. However, they feared how expressing feelings and grief might affect others and how others saw them, or lead to losing emotional control. These fears and the conflict of self-disclosure has been described as common amongst boys (Pollack, 2006). As a result of these concerns the men chose to break their silence to a select few. They talked to friends, family and people in their social circles whom they trusted, who made them feel safe, would not judge them, who knew the deceased and could share stories with others who knew what it was like to lose someone close.

Weingarten (2000) claims that people will break their silence when they believe that others are also willing to assume risk in exchange for closeness (emotional, intimate connection). She proffers that people will share their pain when they learn that they can take courage together; this is when they will let others join them when they are most vulnerable. This was the case for these young men when they spoke to chick-mates and friends who had shown them they could be trusted with their vulnerability, were active non-judgemental listeners, and who wanted to "be there" for them. 
Previous studies of suicide survivors have shown that survivors' top priority is to talk to other survivors with relevant lived experience rather than to professionals (Dyregrov, 2011; McMenamy, Jordan \& Mitchell, 2008). Jakoby's (2014) study of adult survivors had a range of conversational partners including family, partner and friends as well as professional trained 'listeners' and the family of the deceased (especially when it was friends who died) and friends or colleagues of the deceased.

The present study showed that the young men were willing to talk about their grief and express themselves but needed to be provided with opportunities to do so within a safe environment; they need safety and assurance first. What they wanted was someone to talk to about their friend, loss and grief; someone who did not judge them, listened, had similar lived experience and understood, and someone who was emotionally present. Research by McNess (2008) confirms the importance of this finding. McNess found that grieving young men wanted meaningful support which involved being interpersonal interactions that encouraged their self-disclosure, that were pleasant and supportive. Menaingful support included two key elements: (i) presence support which validates the person and communicates that they matter; and (ii) disclosure support the availability, companionship, safety and containment offered that enables the bereaved to express their thoughts, feelings and grief when and where they are ready (p. 30).

Participants in the current study described breaking their silence with professionals who tried to understand their experience, were respectful of taking things slow, helped them vent or sort through their thoughts and feelings, gave them new perspectives and/or helped them learn skills for managing their grief or accessing resources. Few studies have explored young men's experiences of seeking help and support following suicide bereavement. The majority of studies have been conducted on adults and focused on barriers to seeking support (Jakoby, 2014; McMenamy et al., 2008).

Participants also experienced a number of challenges when talking to professionals; they eventually negotiated what support they needed and found ways of working constructively with them. Previous studies have shown that the majority of survivors want professional help to manage their grief (Provini et al., 2000) but less than half receive this help and less than half of those are satisfied with it (Wilson \& Marshall, 2010). These findings suggest that current forms of professional support and intervention may not be 
accessible, appropriate, or even effective in supporting the suicide bereaved and particularly young men.

When the men sought professional help it was later in their bereavement process. They sought help after their grief had taken a toll on their mental health and wellbeing and impacted their ability to perform at work. The men described feeling supported when professionals worked with them and provided guidance that matched their cognitive and instrumental grief style and traditional masculine gender norms for behaviour. The men felt supported when professionals helped them adjust and make sense of their loss, focused on cognitive processing of grief (in line with their masculine instrumental grief style), encouraged them to use appropriate coping strategies; presented them with opportunities to challenge the perception of guilt, self-blame, and other cognitive distortions; and focused on taking an active and problem-solving approach to mental health promotion. This is in alignment with research on professional interventions with survivors that show survivors benefit from assistance that help them make sense of, address guilt and manage effects of bereavement (Dyregrov \& Regel, 2012; Neimeyer, 2006; Neimeyer, Burke, Mackay \& van Dyke Stringer, 2010).

\section{Being in silence within a social context.}

Participants described quiet spaces they occupied with others who showed them they cared for and were "just there" for them. In these spaces they encountered the silent therapeutic presence of others who provided care, security and containment. Participants allowed others to sit beside them who had a connection with the deceased, who were at ease with their loss, who gave them respite, provided distractions, comfort and care and who respected their boundaries and needs for silence. The men described people who were there for them as 'silent companions'. They felt supported by people who sat alongside them, helped them, but did not try to take control or pressure them to talk about their experience.

Flickenger (1992) argues that those caring and listening can communicate much through silence. People can say things without words, their physical and psychological presence, tears, their silent connection with others can say to another - 'I am here for you, I hear you, thank you for honouring me in this way by sharing your vulnerability'. By being emotionally and physically available others show they are listening and this 
communicates to the grieving individual that they are seen and heard and no longer silent or invisible. Others have noted the social presence of others is vital to the bereaved because "Matters of life and death are too hard, to onerous, too painful to "do" alone" (Weingarten, 2000, p. 399). Weingarten (2000) argues that suffering is easier to manage and cope with when it is socially shared and when others listen, hold, hear, acknowledge, and show they understand the experience of others.

The desire for silence found in this study is supported by previous work on grief, loss and therapeutic engagement. Research has shown that people who are grieving and suffering benefit from engaging with people (supporters) who: (i) provide an emotional presence, (ii) bring reciprocity and empathy to encounters, and (iii) are responsive and assist people to make sense of their experience (Cohen-Konrad, 2009). Others have emphasised the importance of empathy, that care without empathy is less effective (Maata, 2006). Others note that genuine empathic encounters between people require mutuality, and people to connect and understand an experience from the perspective of those who are suffering (Buber, 1955/2002; 1958).

This study highlighted the importance of male survivors having access to others with lived experience who can understand their experience. Participants described finding support and care with other survivors and those with relevant lived experience; this fits with previous studies (Dyregrov, 2011; McMenamy et al., 2008). This study found that some men may struggle to connect with other survivors because the fear of being vulnerable around peers, friends and family and being judged may override their need to connect with others. The men wanted social validation of their subjective experience of suicide bereavement but also needed to control when and how they encountered others who witnessed their suffering, and who provided care and therapeutic listening.

\section{Experiences of closeness and care.}

A key finding of this study was that when the men were in social situations they sometimes wanted others to maintain their distance and at other times they wanted closeness, connection and contact with others. They experienced times when friends, family and professionals maintained their distance and this reinforced their silence, inhibited self-disclosure and led to frustration and self-withdrawal. Reported research on caring and empathy shows that this tension; between closeness and distance, exists in the 
field of health (Maata, 2006). Reviews of research have shown that caring in healthcare requires a mix of "being with" and "being there" for individuals (Fredriksson, 1999) but that people (including health professionals) may avoid closeness with those suffering. Healthcare professionals may avoid closeness because they have been warned to maintain a 'professional distance', they fear being overwhelmed (Reynolds \& Austin, 2000), 'losing themselves', or 'being swallowed up by another's feelings' or 'being broken down' (Carlsson, 2003; Rusner, 2004).

Participants described the importance of the caring presence of others and what it was like to felt connected and close to others who offered care. What this study showed was that the young men clearly preferred instrumental, cognitive and affective help (Adler, 2002) which was compatible with their masculine style of grieving and way of being in the world. They also described caring as responsive listening (Adler, 2002) or “therapeutic listening" (Flickenger, 1992) where the person attends to other's pain and truly hears and responds to what is behind the words. Participants also described being cared for by friends and family in ways that enabled them to contain their grief and adapt to their loss. They described the importance of care as emotional containment (CohenKonrad, 2009; Weingarten, 2000) and adaptive caring (McAllister \& Walsh, 2003) which includes a focus on promoting self-awareness, insight, self-refection, safe recall, expression and acceptance of memories, and resilience. What the present study shows is that despite some difficulties with finding and trusting others to see their vulnerability, the men managed to find others who were able to be with them in silence, listen to their silence, and care for them in silence.

\section{Quiet Spaces}

Participants sought out and occupied silent or quiet spaces. Quiet spaces aided reflection, remembering and reconnecting with their friend in private. In these spaces participants were vulnerable, reflected on their friend and friendship and came to terms with whom and what they had lost and how their experience had changed them. The men in this study described their lives prior to their loss, during the early days of their loss and mourning, and in the year/s since their loss. They were able to reflect and recall a time before their loss and grief and they mourned the loss of their old life as well as their friend. They recognised that there was a time of intense grief but they moved through this; they recognised that now their life was different, but that they carried the loss with them. 
Corbett (2015) has challenged people to see suffering, especially caused by grief, as being similar to van Gennep's idea of a temporary transitional or liminal space of being betwixt and between (Thomassen, 2009, p.15). It is a space between one's perceived old life (prior to the loss) and perceived new life. The findings of this study show the men experienced such a liminality as a temporal period and space (Thomassen, 2009, p. 16) and that rituals of mourning and remembrance helped them transition.

\section{Remembering and reconnecting.}

The first type of quiet spaces that the men described as important were physical locations, everyday spaces and being online. These spaces helped the men reconnect with their friend, think, reflect and remember. For some individuals, adjusting to life after the death of a loved one includes active and continuing attachments to, or bonds with, the deceased (Klass et al., 1996) and this is facilitated through rituals of remembrance and reminders of the life that was lived (Cohen-Konrad, 2009). Visiting the grave, viewing pictures and other reminders are important silent channels to remember and to initiate conversations with and about the deceased (van Humbeeck et al., 2016). Maples (1998) discusses how the process of mourning and grieving involves: learning to live a life without the deceased; confronting unsummoned thoughts, mental images and recalled memories; and this is important to help them deal with unfinished business and to "move on". The present study shows how important it was for the young men to have opportunities to access spaces of reflection, remembrance and reconnection.

\section{Analytic silence.}

A second type of silent space the men described was the analytic space in their head. They talked about needing time and space to reflect on their grief. This analytic space helped them integrate their grief, accept their loss and make sense of their experience. For all of the participants, this research was the first time they had discussed their experience of bereavement. What they had engaged in up to this point was 'private grief work' and meaning making.

Researchers have drawn attention to the importance of meaning-making for adjustment to grief and loss after suicide (Dransart, 2013; Neimeyer, 2006; Neimeyer et al., 2010; Neimeyer et al., 2014; Sands, 2009). Meaning making is important for adjustment following death (Currier et al., 2006) and has a positive influence on bereavement 198 
outcomes and mental health (Murphy, Johnson \& Lohan, 2003). The men described searching for meaning (finding an explanation), clarifying responsibility and finding a personal style of reaction and coping, and finding some personal value in the experience (Dransart, 2016). Participants engaged in both parts of the dual process proposed by Dransart (2016). They described making sense by examining and reconstructing the suicidal process, the event and what led up to it. Additionally, they preserved the deceased's memory by creating a narrative in which the suicide was only one event within the deceased's whole life. What this study shows, however, is that these processes were done predominantly alone as a solitary process. The men struggled to find others who could support them to talk about their experiences, review their accounts and reposition and reconstruct a life narrative.

Participants talked about the process of making sense of their loss, as involving taking stock, making adjustments (especially to social relationships and life priorities), developing a heightened sensitivity to life and being more caring towards others. Their experience confirms previous research that shows people change their perspectives and experience cognitive growth through critical reflection that involves exploration, taking stock, making adjustments, consolidation and stabilisation (Courtenay, Merriam \& Reeves, 1998).

In reflecting on their experience and their loss participants realised they had lost someone who was irreplaceable. They were vulnerable to future loss; this made them wary of investing in other relationships. This theme of the loss of an irreplaceable friendship, the mourning of a future relationship with the deceased, and the "hardness" of replacing friends has been found in other studies of young people who have lost close friends in terror events (Johnsen \& Dyregrov, 2016). The participants also suffered an additional loss of a sense of security and normalcy, but they remained optimistic about their ability to survive and adapt. Studies of family bereavement have shown people respond to the emptiness created by bereavement by "getting over it", "filling the emptiness" with activities and "keeping the connection" to the deceased (McClowry, Davies, May, Kulenkamp \& Martinson, 2007). The men in the current study has a similar response and desire to keep the connection. 
The men described the importance of accepting their loss and how this was easier when they began to focus on the memories of the life lived by their friend and blocked thoughts about how they died. The men developed a new internal narrative about the suicide, one which enabled them to shift their focus from a death and loss orientation to a restoration orientation (Strobe \& Schut, 1999; 2010) that led to a repositioning of the death. According to Boals and Schuettler (2011) construing the memory of a traumatic event as central to a life story so that it becomes an organising part of the individual's sense of self and view of the world, can lead to post-traumatic stress disorder symptoms. The negative event comes to colour the way they understand themselves and the world, and it becomes a key part of their identity (Boals \& Schuettler, 2011).

Reflecting on their loss and coming to an understanding that they could not have changed what happened was a key aspect of participants' experience. They rejected focusing on the event and the way their friend died as 'unhelpful' and instead turned their attention to remembering their friend. They refocused their narratives on the life (rather than the death of their friend) and the significance of their friendship. A recent study by Levi-Belz (2017) showed male survivors who gradually withdrew from the active-relational grieving process (characterised by intense longing and preoccupation with the deceased and the death circumstances), moderated their grief intensity, experienced healing and post-traumatic growth. Reworking and modifying relationship patterns with the deceased and a loosening of bonds (Levi-Belz, 2017) may have helped the participants resume authorship of their life, overcome the paralysing effects of their bereavement style and clear a path for new experiences, psychological learning and growth (Malkinson, Rubin \& Witztum, 2006).

Research indicates traumatic events such as sudden death and suicides can disrupt selfnarratives and lead to post-trauma identities that are dominated by problems (Neimeyer, Herrero \& Botella, 2006). McAdams (2006, 2008) argues that events such as suicide can disrupt the life narratives of the bereaved and contribute to narratives that contain a theme of contamination or redemption. The participants in this study used silent space to do what McAdams (1996, p. 309) calls "identity work" and "selfing" and this led to transformative learning (Tennant, 2005). Transformative learning has the following components: knowing oneself (being self-aware, looking critically at self); controlling oneself (developing self-efficacy, agency and control); caring for oneself (being self- 
aware, listening to one's needs, engaging in healing rituals); and creating oneself (discarding unwanted aspects of the self, developing new ways of being in the world) (Tennant, 2005). The suicide of their friend and the opportunity to occupy quiet and reflective spaces enabled the participants to look inward and critically at their lives, pushed them to maintain agency and self-control, care for themselves and reject selfharming behaviour.

Realising that grief and loss are not things that one ever 'recovers' from but rather learns to manage, adapt to and live with was a key aspect of the men's reflective experience. Having worked extensively with survivors and people experiencing grief I have come to realise that language is important. None of the participants described themselves as having 'recovered' or 'gotten over it' but instead talked about how they came to accept and live with the event, the emptiness in their life that the suicide created and their grief. Rosenblatt (2008) examined the phenomenology of bereavement recovery and discussed why 'recovery' is something the bereaved do not discuss or a term they use to describe their experience. He found the bereaved were more comfortable discussing 'what changes' in their life.

\section{Changes and self-awareness.}

Participants described that they had a new identity (suicide-loss survivor); their relationships with others had changed, they had become more sensitive, caring, and appreciative of life, and their values and priorities had changed. Similar themes about change are found in studies of bereaved young adults who have lost close friends (Johnsen \& Dyregrov, 2015). Previous studies have shown that bereavement can be a transformative and learning process that leads to new ways of being in the world for adults (Fielden, 2003) and adolescents (Oltjenbruns, 1991).

Oltjenbruns (1991) found that bereaved adolescents reported experiencing a deeper appreciation of life, greater caring of loved ones, strengthened emotional bonds with others and emotional strength with no significant differences between genders. The present study showed participants also experienced such positive outcomes but also a shrinking of their social circle and secondary loss of friends who withdrew or drifted away. The present study identified secondary loss as an issue for the participants. Previous research on bereavement has noted secondary loss as an issue for siblings (Hindmarch, 
1995); parentally bereaved children (Mahon, 1999); and bereaved college students (Balk et al., 2010) but has not explored it in friends.

Previous research supports the finding that bereavement and loss can lead to changes in perceptions about self and the world, a deeper sense of spiritual awareness, a more complete understanding of life and death (Douglas, 2004), transformation of self, and changes in relationships with others (Sands \& Tennant, 2010). Corbett (2015) also argues that suffering is transformative and can lead to growth of one's personality. He proffers that suffering challenges people's coping, prompts reorganisation of beliefs and rules, encourages people to be humble and acknowledge their limitations, and promotes the development of courage and meaning. The present study showed participants experienced similar changes in self, their coping was challenged, they developed courage and also became more self-aware, self-centric (Shewchuk, 2015) and self-focused; they also experienced changes in their relationships with others.

However, unlike previous studies, this study found that losing a close friend to suicide encouraged the men to become more aware of those around them who were vulnerable, more caring, empathetic and responsive to others and themselves. Shewchuk's (2015) work sheds some light on what might have been occurring for the men in regards to grief work and the integration of suffering within this private inner space. She argues that when individuals begin to explore and process their suffering and personal experience they come into contact with the wounded self, care for and have compassion for themselves and in doing so develop a more resilient self.

The men's narratives showed that they developed a new perspective on life, new values and had become more future-focused. A substantial body of work exists that shows that bereavement, and the reflection that comes with it, can lead to a change in perspective, new behaviours and greater valuing of life (Moon, 2010), an examination of core beliefs (Tedeschi, Calhoun \& Cann, 2007), learning lessons (Stein et al., 2009); greater appreciation of the brevity of life and reality of death, greater sensitivity and openness to others, feeling stronger and more mature, more emphasis on taking better physical care of self (Neimeyer, 2001), and post-traumatic growth (Tedeschi \& Calhoun, 2004). 
The work of Jungian analyst, Lionel Corbett (2015) also helps us understand that suffering can change people's worldview, values, can lead to personality growth and greater empathy and compassion and make people more appreciative of everyday life. Previous studies of people who have experienced adversity have shown that perspective change occurs over time (people become more future oriented, develop greater attention to care of self, integration of status and identity) (Courtenay, Merriam, Reeves \& Baumgartner, 2000). Schneider's transformative model of grief explains how grief, such as that experienced by the men in this study, can lead to changes as a result of growth (Ferszt, Heineman, Ferszt \& Romano, 1998). It is, however, important to acknowledge that not all adverse experiences lead to growth (Tedeschi et al., 2007).

The present study demonstrated how the young men who lost close friends to suicide adopted a more resilient attitude and approach to life and to "carrying on" while maintaining continuing bonds to the deceased (Klass et al., 1996). For Attig (2004), grieving is about both suffering and resilience, experiencing hurt and reaching through it to affirm life. Webster (2015) discusses many of the traits of resilient people which include: the ability to regulate emotion, analyse problems, be cognitively flexible, to make meaning out of one's traumatic experience and to develop a "survivor's mission" (to make a gift out of one's experience or better one's own life or others) and maintaining optimism. These cognitive characteristics of resilience may be connected to the men's masculine and cognitive pattern of grieving.

Participants revealed that they experienced a number of adjustments and adaptations in response to the loss of their friend. The adaptations they described are similar to those described by Dutton and Zisook (2005) as contributing to resiliency and included emotional and cognitive changes, coping with loss, developing a continuing relationship with the deceased, changes in social and relational domains and changes in identity. Participants described using repressive coping as an adaptive strategy, having a number of secure attachments with others, developing a more accepting attitude to life, and taking comfort from positive memories of the deceased. These strategies and factors have been linked to resiliency in the bereaved (Mancini \& Bonanno, 2009).

Findings of the present study showed that the young men experienced signs of stressrelated growth (SRG) which refers to the development of a higher level of adaptive 
functioning than was present prior to its occurrence and not merely recovery (Levi-Belz, 2015 , p. 306). Stress-related growth involves changed perceptions of self, changed relationships with others, and changed philosophy of life (Park \& Fenster, 2004; Calhoun $\&$ Tedeschi, 1998). Stress-related growth has been documented amongst survivors (LeviBelz, 2014, 2016). Levi-Belz (2016) found that low levels of self-disclosure amongst survivors was linked to low levels of SRG. The men in the present study struggled with sharing intimate information with others and with social disclosure. The findings suggest that perhaps social disclosure is less important for SRG in men who adhere to masculine norms of stoicism and silence, and perhaps related more to their use of coping strategies.

\section{Chapter Summary}

This chapter discussed the key findings in relation to relevant literature and research. The study highlighted the personal, private and social silence the men experienced and the quiet spaces that enabled them to reflect on their experience of bereavement. It was shown that the men experienced silence after suicide in different ways and contexts and that silence was an essential aspect of both their suffering, coping and adjustment to their loss. In the concluding chapter I explore the study's new contributions to knowledge and to methodology. I also offer a critique of the limitations and strengths of the study and discuss some possible implications for healthcare practice and future research. 


\section{CHAPTER SEVEN: IMPLICATIONS AND CONCLUSION}

\section{Introduction}

This descriptive phenomenological study of young's men experience of losing a close male friend to suicide has demonstrated that silence is at the heart of their experience. The findings present a new way of understanding the phenomenon of suicide bereavement, with an invisible and hard to reach vulnerable population of young male survivors. The previous chapter summarised and discussed the findings in relation to relevant literature. This chapter outlines and critically discusses the contribution of the study to knowledge, describes some implications for healthcare practice and makes recommendations for future research.

\section{Contribution to Knowledge}

This research provides insight into how eight young men experienced the loss of a close friend to suicide, an understudied group in the field of bereavement. It addresses several gaps in knowledge identified by Maple, Cerel, Jordan and McKay (2014): (i) it examines the experience of suicide bereavement in participants from a non-clinical community sample who have not been recruited from suicide-bereavement support groups or through media campaigns; (ii) it explores suicide bereavement in close friends rather than family or first-degree kinship ties (parents, children, spouse, and family); and (iii) it focuses on men's experiences. To the best of my knowledge this is the first study that has focused solely on young men's experiences of losing a close friend to suicide. This study contributes to a new understanding of suicide bereavement in survivors and highlights how traditional masculine norms influence young men's responses to suicide loss.

A strength of this study is that the bereaved young men were given the opportunity to describe their own experiences through phenomenological in-depth interviews, a method well suited to acquiring descriptions of participant's lifeworlds and their lived experience of a phenomenon. A further strength is that interview-data included descriptions of immediate grief reactions as well as longer-term responses to the loss. This enabled me to capture a description of a range of young men's bereavement experiences. Another strength was that the sample was a homogenous group. All the participants had lost a close male friend to suicide, they were all male and between the ages of 17-25 years old (in the emerging adulthood bracket). Using criterion-based sampling and having a 
homogenous sample meant saturation was reached sooner (Morse, 1995) and that the findings can be more readily and reliably transferred to similar groups (Palinkas et al., 2015).

Findings from this study reveal that silence is an important aspect of the men's experience. The participants suffered, grieved, lived through and transformed their loss experience in silence. The men experienced four main aspects of silence: personal silence, private silence, public social silence and quiet spaces. Personal silence was experienced in the immediate aftermath of the suicide when the men were "gutted" and robbed of their voice. Their immediate reactions were shock, disbelief, wanting to avoid being vulnerable around others and they struggled to put into words the confusing mix of emotions and responses.

Participants used private silence as a strategy; it was a way the men could exercise power and remain in control. Participants chose to keep quiet (not talk or express) and keep certain aspects of their grief experience private. They withheld fully experiencing their grief and loss from themselves and others. Their private silence was motivated by fear of being overwhelmed by uncontrollable and un-masculine feelings, by fear of breaking down and being judged as vulnerable, weak and feminine. The men remained stoical and restrained emotions in order to control their grief. They used strategies such as keeping busy and avoided others and situations that they saw as threatening or stressful in order to adhere to a strict code of masculinity and maintain a "mask of masculine invulnerability" (Pollack, 2006).

In public and social situations the men chose to grieve in silence around others. They broke their silence when honouring their friend and when they felt safe. They chose to talk to and express their grief with people who shared relevant lived experience and had a connection with their late friend. They felt safe expressing their grief around friends and family who were non-judgemental, caring, and respectful - around those who were able to silently witness their suffering and just "be there" for them. Participants were publically silenced by others when the suicide and their grief was not acknowledged, when the status of their relationship with their friend was marginalised, when they were disconnected or excluded by others, and when opportunities to express themselves were shut down. The men were silenced when others were insensitive, ignorant, social inept and disrespectful. 
Finally, the findings support the importance of the men having access to quiet physical and psychological spaces where they could remember and reconnect with the memory and presence of their friend and integrate their loss. In this private space they analysed, reflected, and became more aware of personal changes and transformation. In this space they realised that the silence they experienced after the suicide of a close friend was transformative - that their way of being in the world had changed.

The findings of this study highlight how masculinity influences the experience of grief, loss and suicide bereavement in young men. This study supports earlier work by Pollack (2006) that shows boys and men do experience deep despair, isolation, disconnection but that this is often invisible to others because they must adhere to traditional and rigid masculine norms (gender straightjackets). This masculine code requires them to hide their emotions and vulnerability at all costs, remain stoical, cover their pain, wear a mask and remain silent.

Based on what I found, young male survivors are emotional, vulnerable, relational/connected, caring and empathetic, experience genuine pain and struggles. They are very different from the clinical stereotypes that portray them as psychologically unaware, emotionally illiterate and unable to talk about their inner world (Pollack, 2006), grief and loss. The findings demonstrate that in order to break their silence men need to be supported in ways that take into account traditional masculine norms and gender differences. It also raises awareness of the importance of seeing and listening for the silence that comes after losing a close friend to suicide.

\section{Contribution to Phenomenological Research Methodology}

This study contributes to phenomenological methodology and methods of data collection by highlighting the influence of gender on how a phenomenon (suicide bereavement) is experienced (in young men) and researched. This study demonstrates that researchers need to be conscious of their horizon (Geniusas, 2012; Luft, 2002), their position and view of phenomenon and to see that as changing, context-dependent, participant responsive and influenced by gender and personal experience. Others have also noted that researchers engaged in qualitative research on suicide need to pay more attention to epistemic and ethical importance of feelings (of connection/disconnection, 
closeness/distance, emptiness/fullness, residues/warnings), intersubjectivity and reflexivity in research encounters (Boden, Gibson, Owen \& Benson, 2016).

Descriptive phenomenology usually requires the researcher to engage in a phenomenological attitude (remaining open) while bracketing presuppositions in order to see phenomena as they appear to individuals. It requires researchers to immerse themselves in the data and to acknowledge their subjectivity while at the same time maintain some level of objectivity in order to see patterns and structural features of a phenomenon. The concept of a horizon is also important within Husserlian descriptive phenomenology (Geniusas, 2012) as it is what delimits phenomena and allows it to manifest itself to someone. Things (objects of lived experience and lived experience itself) appear differently depending on where one is in relation to the horizon and whether one advances or retreats. Horizons are relative in regards to our positions and they limit our view and understandings. Things that come into consciousness become more meaningful when placed against a certain horizon of sense (Geniusas, 2012). Researchers need to be aware and acknowledge their horizon, as well as that of their participants, and attempt to see the world and understand phenomenon from the point of view of participants.

I adopted a phenomenological attitude in this study in order to remain open to new ways of seeing the world and the phenomenon of suicide bereavement. However, I was also aware that as a man, of working class background, who experienced the loss of multiple close friends to suicide as a young adult, I shared the same horizon as my participants. My position in relation to the phenomenon (and the horizon) was dynamic and constantly changing. At times it felt that I was close to participants and their experience of the phenomenon as it appeared to them (we shared a similar position on the horizon). At other times it felt that I had created and maintained distance so I could transcend the participant's experience of the phenomenon and see it as it was (across participants) rather than how it appeared to each individual.

My own lived experience and closeness to the horizon helped me recruit a vulnerable and hard to reach population and to navigate access to gate-keepers (the deceased's family, friends). Building trust, rapport and establishing credibility with participants prior to interviewing was important and easier because I am a man and I share a similar 208 
background, culture and interests with participants. I believe my position helped to reassure participants that I understood enough about their experience that we could have an open honest conversation about their experience. This meant interviews were more fluid, responsive, respectful, and more like a meeting of two people on a shared horizon (Finlay, 2011, pp. 200-201). At other times I responded as a researcher and practitioner to ethical and research situations and moved to a position further away on the horizon. For example, during data analysis I created distance between my own experience and interpretation, and that of the participants in order to see the phenomenon in a new way and to look at it within the context of participants' life world.

In addition to highlighting the importance of gender, the lived experience of the researcher and horizons, the study also has methodological significance (Tracy, 2010). First, I introduced the use of new methods of data collection to complement the traditional use of in depth phenomenological interviews. I used go-alongs, walk-alongs and ridealongs to collect supplementary conversational data on lived experience in action and ethnographic skills to build trust, rapport and gain entry into the lifeworlds of participants. This might encourage future phenomenological researchers to consider adding to their craft skills.

Secondly, I combined Giorgi's (1997) seven step method of data analysis often utilised with descriptive phenomenological studies with van Manen's (2014) three step process used with interpretive studies. Combining these methods enabled me to analyse the data, develop and interrogate meaning units and synthesise essential themes for individuals and across the participants. Using both methods enabled me to conduct a selective line-byline and holistic analysis of lived experience descriptions. Van Manen's work was particularly useful when it came to developing a deeper understanding of the phenomenon through engaging in the writing and practice of phenomenology. The combined steps and process meant I was able to focus on and see both the key parts as well as the phenomenon as a whole in a new way. This methodological contribution has implications for researchers wishing to utilise methods of phenomenological data analysis that have a clearly established theoretical and philosophical basis.

This study also demonstrates how phenomenological studies can have practical significance (Tracy, 2010) because it empowered participants to see the world in a new 
way and provided them with space for reflection. This was certainly the case for at least three of the participants who repaired and rekindled their friendships as a result of taking part in the study and exploring their experiences.

\section{Methodological Critique of the Study}

All research studies and designs contain inherent strengths and limitations (Anderson, 2010; Creswell, 2014; Shipman, 2014) and the following section outlines some of these as they pertain to the current study.

\section{Strengths.}

One of the strengths of this study was the choice of phenomenology as an appropriate research methodology and method to elicit specific descriptions of lived experiences of young men who lost a close friend to suicide. The study was also primarily situated within a clear philosophical framework of descriptive phenomenology. Additionally, the use of phenomenological semi-structured interviews allowed me to capture their descriptions of the experience of suicide bereavement which have been missing from the research and to identify a core aspects of the phenomenon - silence.

A further strength was the selection of male participants. The study was based on a purposive and criteria-based sample (Morse, 1995; Ritchie et al., 2003) of eight men who had lost close friends and been bereaved between six months to three years. A small sample meant I was able to build and maintain relationships with participants, immerse myself in their world and take my time with data collection and analysis. The use of rigorous phenomenological methods during data collection (the phenomenological attitude, bracketing/epoché, reduction, intuiting, and horizontalisation), substantiated methods of data analysis (Giorgi, 1997; Kvale, 1996; van Manen, 2014) and appropriate verification strategies added further strength and rigour to the study.

Researchers who act as co-participants in dialogue, co-construct narratives, and the use of reflexivity can add strength to research (Ellis, 1999, Ellis \& Bochner, 2000). I wanted this study to be about the men's experience, not mine. I used my experience to be an effective conversational partner and researcher and my experience and background in suicide was an asset. It enabled me to develop important relationships and meet participants on a common point on the experiential horizon. On many occasions, 210 
participants expressed more of an openness to share because I revealed my personal experience and said they felt that I "got it" (what they were going through) and "got them". While my experience enabled me to engage with participants I followed procedural, practical and relational ethics (Ellis, 2007). I kept clear boundaries while at the same time communicating to participants that I cared about them and what they had experienced.

\section{Limitations.}

The main limitations of this research are the sample, participant's accounts of lived experience and researcher bias. First, the sample was self-selected and relatively small. Self-selection is a common limitation of research with survivors (Moore, Maple, Mitchell \& Cerel, 2013). Individuals recruited for this study were found mostly through networks with survivors in one city and so were not representative of a distribution of people throughout geographic religions of the country. A larger and more representative sample of survivors from different communities (for example, rural and urban), as well as from different cultures and backgrounds, sexualities and those with a range of relationships with the deceased (for example, close and conflicted) may have contributed to a broader understanding of suicide bereavement in young men. It could be argued that my use of a constructivist approach supports a Western Eurocentric view negating cultural ways of understanding suicide bereavement. This trend and over-representation of Western, European or Anglo-Saxon research has been noted in reviews of published research on suicide postvention (Andriessen, 2014).

There were several reasons why I did not apply a cultural lens to understanding and exploring the experiences of the Māori and Samoan participant's experience. First, Husserl's (1976) descriptive phenomenology is atheoretical (Creswell, 1998) and encourages the researcher to remain as objectively neutral as possible in order to see phenomena in new ways (Giorgi, 2009). This meant I had to avoid applying a cultural lens to interpreting the data from participants while recognising my own cultural lens, experience and bias.

Second, an important part of descriptive phenomenology is the phenomenological attitude of openness (Creswell, 2007); bracketing prior theoretical assumptions and suspending theoretical understandings of a phenomenon (Giorgi, 1997; Giorgi, 2009); and reduction 
(the process of returning to the core essence of the experience) (Merriam, 2009). This meant I had to set aside possible cultural interpretations to see and describe the phenomenon in its essence. The purpose of this study was to find the invariant or key structure or universal essence of the lived experience (Creswell, 2007) across the men rather than highlighting individual or cultural differences which may have existed.

Third, conducting research that explores the cultural and ethnic aspects of young men's experiences of suicide bereavement, would have required the use of a different and more appropriate cultural research methodology. Researchers may wish to consider the use of cultural methodologies such as a Kaupapa Māori approach to research (Walker, Eketone \& Gibbs, 2006) and Talanoa methodology (Vaioleti, 2006). These methodologies are based on very different world views, epistemologies and include unique processes for collecting and interpreting data, constructing knowledge compared to Western approaches to research (Walker et al., 2006; Vaioleti, 2006; 2014).

A further limitation of the current study is that the interview process and recording of lived experiences may have been limited by participant's insights, their capacity to remember and articulate painful and private experiences, and social desirability. In an effort to manage limitations of recall and retrospection, participants were recruited who had been bereaved between six months to three years and were asked about recent and past experiences. Participants were provided with interview questions in advance so they could reflect on and prepare their accounts of their experience. The use of follow-up interviews also provided participants with opportunities to review transcripts, summaries of themes, and share further experiences. Participants had plenty of time to recall experiences and provide rich accounts. They were reminded that they were the experts and encouraged to tell their own story about their experience.

The subjective influence of the researcher and researcher bias is often cited as a key criticism of qualitative research (Shipman, 2014). My personal background, losing three close friends to suicide, my culture, working-class background, history and socioeconomic status could all have potentially biased aspects of the research process including: data collection, analysis and the description of the findings. Hycner (1985) notes the scientific orientation of the phenomenological researcher is very different to that of the natural scientific viewpoint and there is no way to totally eliminate subjectivity. 
The potential researcher bias was explicitly stated at the beginning of the study and to participants. Self-identification of a researcher as a suicide-bereaved person has not been shown to be coercive to participants and may in fact make the research more sensitive to survivor needs (Moore et al., 2013). Self-disclosing and "coming out" as a suicide-loss survivor to my supervisors and participants was not easy. Despite the noted limitations and the non-generalisable nature of phenomenological studies, this study does have transferability, implications for practice and raises a number of questions for health practice and research.

\section{Implications for Healthcare Practice and Support}

Phenomenological research helps uncover life processes "for qualitatively identifying intervention strategies and evaluating outcomes" (Morse, Penrod \& Hupcey, 2000, p. 125). According to van Manen (1990) the findings of phenomenological research can encourage health practitioners to be more thoughtful in regards to their responses and with 'knowing how to act' (p. 12) based on thoughtfulness. The findings of phenomenological studies cannot be generalised from, to wider or different populations. Nor do they explicitly suggest implications for health practice. However, these findings do shed light on the experience of suicide bereavement for these young men. This study highlights for health professionals, family and friends the complex nature, functions and importance of silence in young male survivors. These findings may resonate with practitioners and providers of support and prompt them to think critically and thoughtfully about how they can work effectively with young men.

\section{Initial support and postvention.}

This study showed that when the young men first found out about the suicide of their friend they were gutted and experienced personal silence. The men experienced shock, disbelief, and a range of conflicting thoughts and emotions which made it difficult for them describe to others how they felt. As a result they avoided talking to others and withdrew to try minimise their distress. First responders need to be aware that young men may experience personal silence; they need to have relevant information on common grief responses to suicide (Young et al., 2012), and information about masculine grief patterns and coping (Doka \& Martin, 2011). Providing suicide-loss survivors with early help, information about reactions and coping, and outreach support from trained personnel is 
in line with evidence-based postvention (Dyregrov, 2004b). Early support could help young men develop their understanding of grief, normalise their experience and help them develop a language they can use to describe their experience and needs to others.

Support providers need to be aware of private silence and how traditional norms of masculinity encourage boys and men to choose to keep their grief private and this makes it difficult for some young men to express their vulnerability and ask for help (Pollack, 2005). The men remained stoical, silent and in control of their grief because they feared being judged as weak, feminine or vulnerable and having their masculinity questioned. Being mindful of the pressure some men feel to maintain their silence, and emphasising the courage that it takes to seek help, could help address some of the barriers men experience in accessing support and sharing their experience. Emphasising methods that are traditionally associated with women such as talking about emotions/feelings may result in further social withdrawal of men through silence and resistance (Brooks, 2010).

Support providers also need to be mindful that they may reinforce the idea that men are ineffective grievers and need to be more like women or adopt feminine grief styles (Doka \& Martin, 2011). Those supporting young men need to challenge gender norms and stereotypes, provide safe non-judgemental environments and opportunities for men to vent their emotions (Gray, Fitch, Davis \& Phillips, 1997), express their grief and talk about their experience and focus on providing support that matches young men's instrumental or intuitive grief style (Doka \& Martin, 2011).

Results from this study showed that young men maintained their private silence by avoiding others, using emotional restraint, keeping busy, and silencing distressing thoughts and emotions. These strategies are a mix of problem-focused and productive emotion-focused coping (emotional regulation) often found in adolescent boys (Freydenberg, 2008). These strategies can be adaptive/functional in the short-term but can have negative effects if used long-term (Updegraff \& Taylor, 2000). The men used these strategies to maintain control early on and in response to the traumatic deaths. Initial support after suicide may need to be more trauma-informed (Dyregrov \& Regel, 2012) and focus on helping young men regain or retain control, manage uncontrollable emotions, and minimise the trauma while promoting the use of adaptive coping strategies in the long-term. 
Early intervention could help young men better understand their own reactions to suicide, facilitate emotional and cognitive processing and encourage the use of appropriate coping strategies in the long-term. There is tentative support for benefits for bereavement interventions, such as professionally led individual therapy, group therapy and trained volunteer counselling (Beautrais, 2004) and professionals can help survivors cope, adjust and make sense of their experience (Neimeyer, 2006; Neimeyer et al., 2010). Appropriate social and emotional support provides better outcomes for survivors decreasing distress, isolation, risk of mental illness (Dyregrov, 2011; Maple et al., 2014).

The men in this study described wanting support and genuine care that resembles that outlined in the CARE framework (McAllister \& Walsh, 2003) which could be used to educate family and other support people how to offer more effective care to survivors. The CARE framework promotes: empathic listening to understand, facilitating selfcontrol, understanding the experience of the other, caring for the individual in partnership, and helping individuals move towards health and wellbeing. The CARE framework promotes: (i) containment (providing safety, and inner calm), (ii) awareness (selfawareness, insight, self-refection, safe recall, expression and acceptance of memories), (iii) resilience (refocusing on personal strengths and abilities necessary to achieve a meaningful, connected, peaceful future), and (iv) engagement (building a trusting partnership through listening, emphasising, conveying hope and concern, facilitating a sense of meaning and manageability).

\section{Silent grieving and meaning making.}

This study suggests that men tended to grieve in silence in public and social contexts, but appreciated being consulted, included and participating in rituals. Their silence was a way for them to show respect and concentrate on their loss. Their presence (and words when they broke their silence) enabled them to demonstrate to others what their friend meant to them. It was important for participants to have these opportunities to realise their loss and feel connected to others in their grief. When they were excluded, marginalised, had their experience invalidated, or were shut down by others this reinforced their public silence.

The issues faced by friend-bereaved adolescents are well documented and a number of authors have called for psychoeducational training programmes to foster social support 
skills in family, peers and address social ineptitude around supporting the bereaved in the general public (Dyregrov, 2003-2004; Jakoby, 2014; Servaty-Seib, 2009). The men wanted to talk about their loss and their friend. They broke their silence with friends and family who were non-judgmental, validated their experience, respected their cautious approach and need to take things slowly. They also talked to those who reduced their sense of isolation and who were able to share stories and positive memories about the deceased.

\section{Working with and in silence.}

Participants described being in silence and the caring supportive presence of others. They felt supported when family and friends took an empathic approach and actively listened to and read their emotional and mental state (Maata, 2006). Participants talked about being supported when others provided a form of therapeutic listening where the person truly hears and responds to their pain and what is behind their silence or words (Flickenger, 1992). According to Flickenger, this type of listening closes the distance between people and can help people express sadness. Participants needed family and friends who could bear witness to their suffering in ways that affirmed their experience and communicated that they had been heard and understood (Cohen-Konrad, 2009). This type of support was meaningful and encouraged self-disclosure but also helped them feel less alone in their grief (McNess, 2008). Capretto (2015) recommends that professionals and those in pastoral care roles can show empathy to people who are mourning in both what they say and do. He argues that language has its limitations and that silence can be used therapeutically to establish respect, honour loss, communicate non-abandonment, attachment and address feelings of emptiness in those grieving.

Caring has been described as involving a continuum of conversation and contact, as well as closeness and distance (Fredriksson, 1999). Caregivers need to balance expressing adequate emotional reactions in the face of human suffering (De Raeve, 2002) and demonstrate emotional literacy (Steiner, 2003), while controlling unbridled emotions (Rusner, 2004). Based on the findings of this study those supporting young men may need to read the silence of young men in order to determine when they need to provide space and when they need more contact. Family, friends and health care practitioners need to listen non-judgementally and demonstrate responsive listening to help young men feel understood and supported. Supporters need to provide an environment which encourages 
men to express their grief and talk - when they are ready. This will help young men feel safe and retain autonomy and control over when they break their silence.

The men were also supported when they experienced a collaborative relationship and therapeutic alliance or engagement (Cohen-Konrad, 2009) that was characterised by person-to-person attunement (Adler, 2002). Cohen-Konrad's (2009) model for therapeutic engagement and intervention with grieving clients may be particularly relevant and useful for working with young men bereaved by suicide. This model requires supporters to be emotionally present, able to express empathy and concern regardless of how painful the experience is, and being able to contain the other's pain. Corbett (2015) also stresses the importance of others (witnesses and companions to suffering) being able to take on and hold onto the suffering of others so that they can transmute it and give it back to them in a digestible way. He argues that when health professionals (and others) force people to make sense of their suffering, rather than sitting patiently, attentive and with compassion and care, they can silence a suffering person altogether.

\section{Gender-responsive and male-friendly professional support.}

The men sought professional help when they were depressed, suicidal or struggled to cope. This was usually later on and when problems had begun to emerge. Most accessed professional support through their health providers, family doctors and work-place employee assistance schemes. This study showed that it was difficult for participants to put into words what they were experiencing and so professionals need to be mindful of personal silence after suicide. Corbett (2015) argues that there are many forms of emotional distress which are suffered silently, which cannot be put into words that do not fit neatly into the Diagnostic and Statistical Manual (American Psychiatric Association, 2013).

For Corbett (2015), suffering is an inevitable part of human life and is not the result of psychopathology or ill-health. He recommends that health professionals attend to the spiritual and emotional aspects of suffering and respond to the suffering from the subjective perspective of the one who suffers. Professionals need to pay attention to the subjective experience of suffering, provide a containing space for people to make sense of their suffering as well and help their clients see the potential for suffering to lead to personal growth and change. The current study demonstrated that the men experienced 
personal change and transformation, and came to realise this when they had time to reflect and develop self-awareness.

At times the men wanted a more behavioural and cognitive approach to support which fits with masculine grief and an instrumental grieving style (Doka \& Martin, 2011). The men found professionals more helpful when they used gender-responsive and malefriendly practice (Robertson et al., 2015). Professionals need to offer young men support to improve their mental health and wellbeing that is: activity-based, focus on assetbuilding and strengths, helps men regain control and explore the possibility for change and that utilises delivery methods shoulder-to-shoulder (men sitting next to each other) and arms-length support (online, phone-based, tele-health) which enables men to maintain distance, safety and share power (Robertson et al., 2015).

Brooks (2010) argues that traditional psychotherapy is rejected by many men when they most need it because it isn't gender-responsive. Brooks recommends that male-friendly therapy needs to be based on an eclectic orientation, therapists need to be flexible, use conscious raising (about how maladaptive strategies used to maintain a traditional male role can be harmful) and conduct therapy in out-of-office settings. Brooks argues that therapists also need to help men maintain control by negotiating therapeutic goals and tasks with male clients and focus on helping men discover meaning through developing an empathetic bond.

Participants described needing assistance with accepting and recognising their loss, thought restructuring, reframing and moving from the present pain stage to ways of preserving and finding meaning in good memories of their friend. These findings indicate that mental health practitioners need to pay attention to men's internal worlds and provide them with a voice (Pollack, 2006). Professionals should also check-in with young men about what they need and how they want to be supported rather than assuming that all men can and want to be supported in the same way (Robertson et al., 2015).

Findings from this study suggest that it is important for health professionals to carefully assess the individual's grieving style, validate their experience of grief and design interventions that build upon grieving individual's unique coping strengths and skills 
(Doka \& Martin, 2011). Doka and Martin (2011) recommend Bibliotherapy ${ }^{8}$ and the use of online resources for masculine and instrumental grievers to help them express their grief, as well as support groups that have a more cognitive and problem-solving focus. Solutions Focused Brief Therapy (Bavelas et al., 2013) has been used effectively in terms of suicide prevention (Fiske, 2002, 2008) and could be used with survivors who are also at greater risk of suicide. The men in this study sometimes struggled to find a language that enabled them to express their grief and experience. Professionals working with young men may wish to consider the use of art based therapy which can help the bereaved explore deep hurt but also creative possibilities, and help them see themselves in a new light (Rubin, 2016).

\section{Therapeutic groups and group support.}

None of the participants attended a suicide-loss support group, but one attended a weeklong therapeutic group programme with other men who had experienced trauma, adversity and loss and found it supportive. While recent research recommends that further study explore the efficacy of therapy and support group interventions for survivors (Cerel et al., 2009) there is some research that supports the finding that survivors often have the need to and can benefit from meeting with others who have experienced the same or a similar situation (Dyregrov, 2004b). The findings of the current study suggest that current suicide bereavement support groups may not be accessible, appropriate or effective in supporting the bereaved (Suicide Prevention Australia, 2008) including young men.

Men may struggle to access support groups and seek help because of traditional masculine norms (Addis \& Mahalik, 2003; Brooks, 2010). Support groups and services should consider how to make their support more male-friendly and reduce barriers for men accessing support (Dyregrov, Bernstein, \& Silviken, 2014). Englar-Carlson and Stevens (2006) discuss the importance of therapists and clinicians being aware of gender differences and tailoring their therapy to meet the needs of men. In their book they and other authors explore ways of building therapeutic connections or alliances with men and taking a relational approach to helping men cope and heal grief.

8 Bibliotherapy is an expressive therapy that involves reading specific texts (literature, philosophy, poetry, non-fiction) to promote good mental health and is often combined with writing therapy. 
The men in this study chose to maintain private silence and only broke their silence with others when they felt safe. Westwood and Ewasiw (2011) offer a model for working with individuals and groups that may be an effective way to engage with men who are reluctant to discuss their experiences of trauma, grief and loss. Their approach may also help men reconstruct their life narratives. The approach is based on Guided Autobiography (GA) and Therapeutic Enactment (TE) which enables others to witness and provide feedback on their narrative in small groups. Therapeutic Enactment has been used successfully to address issues related to personal and group trauma, grief and loss (Westwood, Keats \& Wilensky, 2003). Providing young male survivors with access to group therapy could help them engage in analytic silence but also access social support, share experience and develop new insights and awareness with others. Group-based therapeutic approaches offer additional and different types of support beyond what is available in individual clinical therapies (Westwood, McLean, Cave, Borgen \& Slakov, 2010).

\section{Implications for education and professional development.}

This study has a number of implications for education, health promotion and improving professional development around suicide postvention and aftercare support. Health educators can develop a resource for young male survivors using material from the study that validates and helps men understand their experience and supports them to make sense of cope with their loss. The findings can be used to adapt existing booklets and resources that target family, friends and work colleagues that provide advice on how people can support survivors. These could include more gender-specific information and practical advice and strategies on how to support men. The resources need to include information about how to balance encouraging men to talk about their experience while respecting their need for silence; how to interpret the different types of silence highlighted in this study; information about instrumental and intuitive grievers and how men want to be supported.

This study is an important reminder that support providers should not assume that all survivors experience loss in similar ways or have the same needs. Gender and masculinity are important influences on men's grief, practices and experiences of loss (Creighton et al., 2013) including those after suicide. Over the past decade there has been a strong emphasis on encouraging health professionals to develop culturally-responsive practice, but gender differences and the importance of gender-responsive practice needs greater 
attention (Bilsker \& White, 2011; Creighton \& Oliffe, 2010; Oliffe \& Phillips, 2008; Robertson et al., 2015). Counselling education programmes should include a curriculum review of the concept of masculinity as culture. Trainees need to more fully understand how to increase male client's motivation and engagement but also develop their culturally and gender-responsive and safe clinical practice. Practitioners need support and education to move from a position of gender awareness, to gender sensitivity and to engage in gender safe practice (Burlew \& Mosley-Howard, 2015; Nursing Council, 2011). This could be a key part of their training in cultural competency. Clinical intervention, counselling for young men, prevention and postvention strategies all need to be genderresponsive.

Since the completion of initial data collection and analysis, I have shared some of the main themes and data formally and informally at seminars for counsellors, GPs and health professionals (Bowden, 2013a, 2013b) and international conferences (Bowden, 2014; Bowden, Banister \& de Vries, 2015a, 2015b). The findings resonated with those working in the health professions and "rang true" with their experience of young men; the findings also challenged them to consider gender-responsive practice in the future. In these presentations I emphasised the importance of listening to men's accounts. Listening serves as a bridge to planning care that takes into account the resources, barriers and concerns, and the needs and health trajectory and helps practitioners offer more finely tuned support (Muller \& Thompson, 2003). I have also incorporated some findings and aspects of the research process into my undergraduate and postgraduate teaching in the hope that future professionals will understand and respond more effectively to the experiences of bereaved young men.

It is important that professionals be exposed to vivid, rich descriptions of experience so that they can understand phenomenon as they appear to others and to make their own connections to practice. Arts based methods such as Research-Based Theatre (RBT) (Beck, Belliveau, Lea \& Wagner, 2011) or Interactive Ethno-Drama (Saldana, 2008) could be used to communicate findings to a range of audiences, including family, friends and health professionals. Research-based theatre has been embraced by some health science researchers because it can be emancipatory and a powerful educational tool (Beck et al., 2011); Arts-Based Health Research (ABHR) has the power to unsettle, disturb and engage the senses in a way that provokes audiences to tap into cognitive and emotional 
parts of themselves and raise important issues that texts cannot (Cox \& Boydell, 2016; Boydell et al., 2012).

Research-Based Theatre and Ethno-Drama may help those who have little knowledge of men's suicide bereavement to engage with the phenomenon. It may help people move from roles of passive observers to active participants and interpreters in the re-presented world of the young men that is brought to life on stage. It may also be a powerful tool for validating the experiences of those who took part in the research or who have similar lived experience. This would also fit with the wishes of the participants who suggested that a public lecture timed around World Suicide Prevention Day (Sept 10) might help raise awareness and create better understanding of their experience and give them a public voice.

\section{Recommendations for Future Research}

The purpose of this study was to explore and describe the experiences of young men who have lost a close friend to suicide. Phenomenological research also helps generate and inform the development of theory and is often a precursor to the development of quantifiable hypotheses and outcome research (LoBiondo-Wood \& Habec, 1998). This study affords methodological insights that can be used to guide the efforts of future men's health research. The following recommendations are suggestions for guiding future research that stem from this study.

A growing body of research draws attention to men's health issues (Oliffe, Orgodniczuk, Bottorff, Johnson \& Hoyk, 2012; Oliffe \& Phillips, 2008). Further qualitative research is needed that focuses on capturing young men's experiences of losing a close friend to suicide using a broader sample. This could offer a broader understanding of how young men experience such a loss. Studies should also explore the essence of the phenomenon - silence after suicide. What is the function of silence? How is silence related to traditional masculine norms such as being brave, having courage, stoicism, protecting others, and maintaining autonomy? How does silence relate to cultural and gender norms in New Zealand and other countries?

Future research could explore the connection between masculinity and men's health and wellbeing in survivors. How does masculinity influence men's experiences of grief and 
loss after suicide? Are their rules and norms for male grieving and a men's code that influences the experience of suicide bereavement? In addition, research is needed that extends on early work on gender and masculine styles of grief (Martin \& Doka, 2000; Doka \& Martin, 2011). Do strategies young men use facilitate or hinder their ability to manage their grief effectively, make sense of their grief experience, integrate their loss, gain social support and experience transformative learning or stress-related growth?

More data would be useful on young men's experiences of receiving care and support after suicide. What does male-friendly suicide postvention care and support look like? We need to explore the conditions under which men break their silence with others, engage in self-disclosure, how and when they prefer presence-support and their choice of conversational partners and expert companions (McNess, 2008). A more focused approach to exploring these types of support in male survivors would help in the design of postvention care and support.

More research needs to be conducted that explores how health professionals can engage with men, and support men individually and in group contexts (Cox et al., 2014; Westwood et al., 2003). Participants in this study described the importance of having connections to others with similar lived experience, the benefit of quiet therapeutic presence of others and a solutions-focused approach to support. Future studies need to continue to investigate ways of incorporating narrative, action and silence into models of counselling and therapy and evaluate programmes and initiatives that have been designed to address trauma in men (Cox et al., 2014).

One of my goals for conducting this research was to highlight the need for a greater focus on male health issues and for male researchers to be encouraged to investigate sensitive issues such as male survivor's experiences. A significant and pervasive challenge for health researchers is a lack of emotional expression among male research participants (Affleck, Glass \& Macdonald, 2012). Some men withhold information about their emotional experiences because they fear being judged or being seen as vulnerable, while others may struggle with emotional literacy and language (Levant, Hall, Williams \& Hasan, 2009). Conducting long interviews about emotionally sensitive topics such as suicide is problematic and has led researchers to suggest methods such as photo-voice, 
photo-elicitation and visual storytelling to encourage men to share their experiences (Affleck et al., 2012; Oliffe \& Bottorf, 2012).

Future studies should consider ways of increasing male participation in health research and ABHR (Cox \& Boydell, 2016). Researchers could use digital and visual methods of data collection, such as photo-elicitation to overcome the reluctance of men to discuss sensitive health topics. These methods have been used successfully with men (Oliffe \& Bottorf, 2007) and also narrative and action-processes which encourage men to write, create art or music that re-present the meaning of their experience (Westwood et al., 2003). Such works would be powerful tools to accompany their words and accounts to help the public and health professionals better understand their experience.

More research needs to be conducted that explores the challenges and barriers to meeting ethical board requirements for conducting research on survivors (Moore et al., 2013). For example, future qualitative studies on male survivors should consider including discussion of ethical challenges (Dickson-Swift et al., 2006), the effects of emotion-work on researchers (Boden et al., 2016), the risks to researchers of researching sensitive topics (Dickson-Swift et al., 2007, 2008, 2009) and how to research hard-to-reach and vulnerable populations (Alvesson \& Deetz, 2002; Sutton et al., 2003).

Finally, results from this study found that young male survivors experienced personal change and transformation as a result of reflecting on their lived experience. Research on post-traumatic growth and stress-related growth in suicide-loss survivors is already under development (Crow, 2013; Levi-Belz, 2017) but has been based mainly on female participants. Future studies should explore these concepts, resiliency and hardiness after suicide in male populations and also look at how men integrate suicide into their life narrative (Maple, 2005).

\section{Personal Reflections}

This experience has changed me as a researcher, suicide-loss survivor and practitioner. I no longer see the world, or respond to suffering the way I used to. I believe that both the participants and I have changed as a result of this experience. I have let go of some of the rocks I have been carrying for all these years, the burden of grief, and the anger I had 
towards the world. I believe this experience has validated both the men and my own experience and validated our role in the phenomenon as men.

I have also discovered, in the reflective process of this study, new dimensions of the experience of losing a close friend to suicide. Since the deaths of my friends in highschool in the 1980s and at university in the early 1990s, I am able to step outside the frame of being a survivor and see with a fresh perspective. Prior to starting this doctorate I had positioned myself as a researcher, and praca-demic working in the field of suicide prevention and postvention. I had not acknowledged or spoken about my own experience of survivorship, given I was silenced at a young age. Throughout the research process, I was inspired by participants' bravery, their willingness to defy traditional masculine stereotypes and to genuinely connect and share their experience of suffering, loss, grief, anger and frustration, resiliency and personal growth.

I found in their stories of suicide bereavement and silence similarities to my own experience of grieving the loss of my friends. Their accounts helped me see the importance role of gender and masculinity. Their involvement and willingness to participate in this research confirmed for me that men do care, they care enough to suffer when they lose a loved one, and they care about other men who are going through the same experience. The participants wanted other young men to know that they are not alone. They have helped me realise that I am not alone. If we value the lives of our men we will continue to search for ways to include, involve and privilege their voice in health research and strive to find ways to promote their wellbeing and recovery.

\section{Conclusion}

The current study emerged from a desire to understand young men's experiences of losing a close friend to suicide and provides original insights into these experiences. Little was known about how young men experience this type of close loss or suicide bereavement. This descriptive phenomenological study was conducted to explore the essential meaning of the phenomenon. The findings of this study show that silence was at the heart of the men's experience. Silence that came after suicide was ubiquitous, complex and shaped participants' mourning, social interactions and how they adjusted to their loss. The men experienced a loss of voice when they were gutted, they tried to maintain personal and private silence to protect others and themselves, they grieved in silence, and were 
publically silenced by others. They chose to break their silence and shared and expressed their grief with people who provided them with a safe space. Participants sought silent spaces in which to remember and reconnect with their friend and appreciated the silent presence of others who supported them. Analytic silence enabled the men to understand and reflect on how they and others changed and transformed. This research revealed how traditional masculine norms (stoicism, bravery and silence) and unsupportive actions and social ineptitude of others reinforced the men's silence. Losing a close male friend to suicide meant that the men experienced, endured and transformed in silence. 


\section{REFERENCES}

Abbot, C.H., \& Zariski, A.L. (2014). Grief and attitudes toward suicide in peers affected by a cluster of suicides as adolescents. Suicide \& Life-Threatening Behavior, 44(6), 668-681. doi:10.1111/sltb.12100

Addis, M. E., \& Mahalik, J. R. (2003). Men, masculinity, and the contexts of help seeking. American Psychologist, 58(1), 5-14. doi:10.1037/0003-066X.58.1.5

Addis, M. (2011). Invisible men: Men's inner lives and the consequences of silence. New York: Times Books.

Adler, H.M. (2002). The sociophysiology of caring in the doctor-patient relationship. Journal of General Internal Medicine, 17(11), 883-890. doi:10.1046/j.15251497.2002.10640.x

Affleck, W., Glass, K.C. \& Macdonald, M.E. (2012). The limitations of language: male participants, stoicism, and the qualitative research interview. American Journal of Men's Health, 7(2) 155-162. doi:10.1177/1557988312464038

Agerbo E. (2005). Midlife suicide risk, partner's psychiatric illness, spouse and child bereavement by suicide or other modes of death: a gender specific study. Journal of Epidemiology and Community Health, 59(5), 407-12. http://dx.doi.org/10.1136/jech.2004.024950

Ahern, K. J. (1999). Pearls, pith, and provocation: ten tips for reflexive bracketing. Qualitative Health Research, 9(3), 407-11. doi:10.1177/104973239900900309

Alvesson, M. \& Deetz, S. (2002). Doing critical management research. London: Sage.

American Psychiatric Association. (2013). Diagnostic and Statistical Manual of Mental Disorders, DSM-5. (5th ed.). Washington, DC: American Psychiatric Association.

Anderson, C. (2010). Presenting and evaluating qualitative research. American Journal of Pharmaceutical Education, 74(8), 1-7.

Anderson, D.G. \& Hatton, D.C. (2000). Accessing vulnerable populations for research. Western Journal of Nursing Research, 22(2), 244-251. doi:10.1177/01939450022044386

Andriessen, K. (2006). Do we need to be cautious in evaluating suicide statistics? The European Journal of Public Health, 16(4): 445-447. https://doi.org/10.1093/eurpub/ck1056 
Andriessen K. (2009). Can postvention be prevention? Crisis, 30(1):43-47. http://dx.doi.org/10.1027/0227-5910.30.1.43

Andriessen, K. (2014). Suicide bereavement and postvention in major suicidology journals: lessons learned for the future of postvention. Crisis, 35(5), 338-348. http://dx.doi.org/10.1027/0227-5910/a000269

Andriessen, K., Draper, B., Dudley, M., \& Mitchell, P.B. (2015). Pre- and post-loss features of adolescent suicide bereavement: Findings from a systematic review of the literature. Death Studies, 40(4), 229-246.

doi:10.1080/07481187.2015.1128497

Andriessen, K. \& Krysinska, C. (2012). Essential questions on suicide bereavement and postvention. International Journal of Environmental Research and Public Health. 9(1): 24-32. doi:10.3390/ijerph9010024

Arnett, J.J. (2000). Emerging adulthood: a theory of development from the late teens though the twenties. American Psychologist, 55(5), 469-480. http://psycnet.apa.org/doi/10.1037/0003-066X.55.5.469

Arnett, J.J. (2007). Suffering, selfish, slackers? Myths and realities about emerging adults. Journal of Youth \& Adolescence, 36, 23-29. doi:10.1007/s10964-0069157-z

Arnett, J.J. (2010). Adolescence and emerging adulthood: A cultural approach. (4 ${ }^{\text {th }}$ ed.). New Jersey: Pearson.

Arnett, J.J. (2014). Adolescence and emerging adulthood. (5 ${ }^{\text {th }}$ ed.). Essex, England: Pearson Education Ltd.

Ashworth, P. (1999). "Bracketing" in Phenomenology: Renouncing assumptions in hearing about student cheating. Qualitative Studies in Education, 12(6), 707721. doi:10.1080/095183999235845

Ashworth, P. (2003a). The origins of qualitative psychology. In J. A. Smith (Ed) Qualitative Psychology: A Practical Guide to Research Methods. (pp. 4-24). London: Sage.

Ashworth, P. (2003b). An approach to phenomenological psychology: the contingencies of the lifeworld. Journal of Phenomenological Psychology, 34(6), 145-156. https://doi.org/10.1163/156916203322847119

Attig, T. (1996). How we grieve: Relearning the world. New York: Oxford University Press. 
Attig, T. (2004). Meanings of death seen through the lens of grieving. Death Studies, 28(4), 341-360. http://dx.doi.org/10.1080/07481180490432333

Ayres, L. (2007). Qualitative research proposal - part I: posing the problem. Journal of Wound, Ostomy \& Continence Nursing, 34(1), 30-32.

Barker, C., Pistrang, N. \& Elliot, R. (2002). Research methods in clinical psychology: An introduction for students and practitioners. ( $2^{\text {nd }}$ ed.). Chichester, England: John Wiley and Sons.

Balk, D.E. (1991). Death and adolescent bereavement. Journal of Adolescent Research, 6(1), 7-27. doi:10.1177/074355489161002

Balk, D.E. (1997). Death, bereavement and college students: A descriptive analysis. Mortality, 7, 207-220. http://dx.doi.org/10.1080/713685866

Balk, D.E. (2000). Adolescents, grief, and loss. In K.J. Doka (Ed.), Living with grief: Children, adolescents, and loss. (pp. 35-49). Hospice Foundation of America.

Balk, D.E. \& Corr, C.A. (Eds.). (2009). Adolescent encounters with death, bereavement, and coping. NY: Springer Publishing Company.

Balk, D.E., Walker, A.C. \& Baker, A. (2010). Prevalence and severity of college student bereavement examined in a randomly selected sample. Death Studies, 34(5), 459 468. http://dx.doi.org/10.1080/07481180903251810

Balls, P. (2009). Phenomenology in nursing research: Methodology, interviewing and transcribing. Nursing Times, 105(32-33), 30-33. Retrieved from https://www.nursingtimes.net/nursing-practice-clinicalresearch/phenomenology-in-nursing-research-methodology-interviewing-andtranscribing/5005138.article

Banister, E. M. (1999). Evolving reflexivity. Negotiating meaning of women's midlife experience. Qualitative Inquiry, 5(1), 3-23. doi:10.1177/107780049900500101

Barett, T.W. \& Scott, T.B. (1990). Suicide bereavement and recovery patterns compared with nonsuicide bereavement patterns. Suicide \& Life-Threatening Behavior, 29(3), 256-270. doi:10.1111/j.1943-278X.1990.tb00650.x

Barker, C., Pistrang, N. \& Elliot, R. (2002). Research methods in clinical psychology: An introduction for students and practitioners. ( $2^{\text {nd }}$ ed.). Chichester, England: John Wiley \& Sons. 
Barkway, P. (2001). Michael Crotty and nursing phenomenology: criticism or critique? Nursing Inquiry, 8(3), 191-195. doi:10.1046/j.1320-7881.2001.00104.x

Bartik, W., Maple, M., Edwards, H. \& Kiernan, M. (2013). Adolescent survivors after suicide: Australian young people's bereavement narratives. Crisis, 34(3), 211217. doi:10.1027/0277-5910/a000185

Bavelas, J., De Jong, P., Franklin, C., Froerer, A., Gingerisch, W., Kim, J., ...Trepper, T.S. (2013). Solutions focused therapy treatment manual for working with individuals. ( $2^{\text {nd }}$ ed.). Solutions Focused Brief Therapy Association. http://www.sfbta.org/researchdownloads.html

Beaglaoich, C.O., Sarma, K.M., \& Morrison, T.G. (2013). New directions in gender role conflict. In J. Gelfer (Ed.), Masculinities in a Global Era, International and Cultural Psychology, 4, 17-51. doi:10.1007/978-1-4614-6931-5_2

Beautrais, A. L. (2004). Suicide postvention: Support for families, whānau and significant others after a suicide. A literature review and synthesis of evidence. Retrieved from https://www.health.govt.nz/system/files/documents/publications/bereavedbysui cide-litreview.pdf

Beck, A.M., \& Konnert, C.A. (2007). Ethical issues in the study of bereavement: The opinions of bereaved adults. Death Studies, 31, 783-799. https://doi.org/10.1080/07481180701537220

Beck, C. (1992). The lived experience of postpartum depression: A phenomenological study. Nursing Research, 41(3), 705-713. doi:10.1097/00006199-19920500000008

Beck, J.L., Belliveau, G., Lea, G.W. \& Wager, A. (2011). Delineating a spectrum of research-based theatre. Qualitative Inquiry, 17(8), 687-700. doi:10.1177/1077800411411415498.

Begley, M. \& Quayle, E. (2007). The lived experience of adults bereaved by suicide: A phenomenological study. Crisis, 28(1), 26-34. http://dx.doi.org/10.1027/0227$\underline{5910.28 .1 .26}$

Bell, J., Stanley, N., Mallon, S., \& Manthorpe, J. (2012). Life will never be the same again: Examining grief in survivors bereaved by young suicide. Illness, Crisis \& Loss, 20(1), 49-68. doi:10.2190/IL.20.1.e

Benner, P. (1994). Interpretive phenomenology: Embodiment, care, and ethics in health and illness. Thousand Oaks, CA: Sage. 
Berger, J. M., Levant, R., McMillan, K. K., Kelleher, W., \& Sellers, A. (2005). Impact of gender role conflict, traditional masculinity ideology, alexithymia, and age on men's attitudes toward psychological help seeking. Psychology of Men \& Masculinity, 6(1), 73-78. doi:10.1037/1524-9220.6.1.73

Berman A.L. (2011). Estimating the population of survivors of suicide: Seeking an evidence base. Suicide \& Life-Threatening Behavior, 41(1), 110-116. doi:10.1111/j.1943-278X.2010.00009.x

Bevan, M.T. (2014). A method of phenomenological interviewing. Qualitative Health Research, 24(1), 136-144. doi:10.1177/1049732313519710

Biggerstaff, D., \& Thompson, A.R. (2008). Interpretative phenomenological analysis: A qualitative methodology of choice in healthcare research. Qualitative Research in Psychology, 5, 214-224. http://dx.doi.org/10.1080/14780880802314304

Bilsker, D. \& White, J. (2011). The silent epidemic of male suicide. British Columbia Medical Journal, 53(10), 529-534.

Bloor, M. (2001). Techniques of validation in qualitative research: A critical commentary. In R. M. Emerson (Ed.), Contemporary field research (pp. 383396). Prospect Heights, IL. Waveland Press.

Boals, A. \& Schuettler, D. (2011). A double-edged sword: Event centrality, PTSD and Posttraumatic growth. Applied Cognitive Psychology, 25(5), 817-822. doi:10.1002/acp.1753

Boden, Z., Gibson, S., Owen, G.J. \& Benson, O. (2016). Feelings and intersubjectivity in qualitative suicide research. Qualitative Health Research, 26(8), 1078-1090. doi:10.1177/1049732315576709

Bonanno, G. A. (1999). Factors associated with effective loss accommodation. In C. R. Figley (Ed.), Traumatology of grieving: Conceptual, theoretical, and treatment foundations (pp. 37-51). Philadelphia: Taylor \& Francis.

Bonanno, G.A. (2004). Loss, trauma and human resilience: Have we underestimated the human capacity to thrive after extremely adverse events? American Psychologist, 59(1), 20-28. doi:10.1037/0003-066X.59.1.20

Book, P.L. (1996). How does the family narrative influence the individual's ability to communicate about death? Omega, 33(4), 323-341. doi:10.2190/3J4E-2X29YEVE-JH14 
Boss, P., Dahl, C., \& Kaplan, L. (1996). The use of phenomenology for family therapy research: The search for meaning. In D.H. Sprenkle \& S.M. Moon (Eds.), Research methods in family therapy (pp. 83-106). NY: Guilford Press.

Bowden, C.J. (2013a). Narratives of loss: Losing a close friend to suicide. A seminar presented at the School of Health Sciences (Weltec) and the Drug and Alcohol Practitioners' Association Aotearoa New Zealand (DAPAANZ), Wellington, New Zealand, 10 October, 2013.

Bowden, C. (2013b). 'Losing a close friend to suicide: The experience of young men'A seminar presented in conjunction with the Werry Centre and Child and Adolescent Mental Health and Alcohol or Drug (CAMHS/AOD) Sector. Masterton, New Zealand. 12 November, 2013.

Bowden, C.J. (2014). Breaking the silence: Young men's experiences of losing close friends to suicide. Supporting Families in Mental Illness NZ Conference "Suicide: Is it Time for Openness?" Wellington, New Zealand, 31 October, 2014.

Bowden, C. (2015). Breaking the silence: Young men's experiences of suicide bereavement. A seminar presented at the Centre for Youth \& Society, University of Victoria, Canada, 8 October, 2015.

Bowden, C.J. Banister, E., \& de Vries, K. (2015a). Navigating silence: Understanding the grief experiences of young men bereaved by suicide. A paper presented at the $21^{\text {st }}$ Qualitative Health Research Conference, Toronto, Ontario, Canada, 21 October, 2015.

Bowden, C.J., Banister, E., \& de Vries, K. (2015b). A few good men: Recruitment, relationships and 'handling the truth' in research. A paper presented at the $21^{\text {st }}$ Qualitative Health Research Conference, Toronto, Ontario, Canada, 20 October, 2015.

Bowen, G.A. (2008). Naturalistic inquiry and the saturation concept: A research note. Qualitative Research, 8(1), 137-152. doi:10.1177/1468794107085301

Boydell, K.M., Volpe, T., Cox, S., Katz, A., Dow, R., Bunger, F., ...Wong, L. (2012). Ethical challenges in arts-based health research. The International Journal of The Creative Arts in Interdisciplinary Practice, (IJCAIP), 11 (Spring), http://www.ijcaip.com/archives/IJCAIP-11-paper1.html

Bragdon, P.K. (2006). Young male adult's experiences of the death of a peer: grief and bereavement. Retrieved from ProQuest Digital Dissertations (AAT 3206663). 
Braun, M.L. \& Berg, D.H. (1994). Meaning reconstruction in the experience of bereavement. Death Studies, 18(2) 105-129. doi:10.1080/07481189408252647

Braun, V., \& Clarke, V. (2006). Using thematic analysis in psychology. Qualitative Research in Psychology, 3, 77-101. http://dx.doi.org/10.1191/1478088706qp063oa

Brent, D.A., Kerr, M., Goldstein, C., Bozigar, J., Watella, M. \& Allan, M. (1989). An outbreak of suicide and suicidal behaviour in a high school. Journal of the American Academy of Child \& Adolescent Psychiatry, 28(6), 918-924. https://doi.org/10.1097/00004583-198911000-00017

Brent, D.A., Melhem, N., Donohoe, M.B., \& Walker, M. (2009). The incidence and course of depression in bereaved youth 21 months after the loss of a parent to suicide, accident, or sudden natural death. American Journal of Psychiatry, 166(7), 786-794. https://doi.org/10.1176/appi.ajp.2009.08081244

Brent, D.A., Moritz, G., Bridge, J., Perper, J., \& Canobbio, R. (1996a). Long-term impact of exposure to suicide: A three-year controlled follow-up. Journal of the American Academy of Child \& Adolescent Psychiatry, 35(5), 646-653. https://doi.org/10.1097/00004583-199605000-00020

Brent, D.A., Moritz, G., Bridge, J., Perper, J., \& Canobbio, R. (1996b). The impact of adolescent suicide on siblings and parents: A longitudinal follow-up. Suicide \& Life-threatening Behavior, 26, 253-259. doi:10.1111/j.1943278X.1996.tb00610.x

Brent, D.A., Perper, J.A., Moritz, G., Allman, C., Friend, A., Schweers, J., ... Harrington, K. (1992). Psychiatric effects of exposure to suicide among friends and acquaintances of adolescent suicide victims. Journal of the Academy of Child \& Adolescent Psychiatry, 31(4), 629-639. http://dx.doi.org/10.1097/00004583-199207000-00009

Brent, D.A., Perper, J.A., Moritz, G., Allman, C., Liotus, B.S., Schweers, J., ...Canobbio, R. (1993b). Bereavement or depression? The impact of the loss of a friend to suicide. Journal of the American Academy of Child \& Adolescent Psychiatry, 32(6), 1189-1197. https://doi.org/10.1097/00004583-199311000$\underline{00012}$

Brent, D.A., Perper, J.A, Moritz, G., Allman, C., Schweers, J., Roth, C. ... Liotus, L. (1993a). Psychiatric sequelae to the loss of an adolescent peer to suicide. Journal of the American Academy of Child \& Adolescent Psychiatry, 32(3), 509-517. https://doi.org/10.1097/00004583-199305000-00004 
Brent, D.A., Perper, J.A., Moritz, G., Allman, C., Liotus, B.S., Schweers, J. \& Canobbio, R. (1994). Major depression or uncomplicated bereavement? A follow-up of youth exposed to suicide. Journal of the American Academy of Child \& Adolescent Psychiatry, 33(2), 38-44. https://doi.org/10.1097/00004583-199402000-00012

Brent, D.A., Perper, J., Moritz, G., Friend, A., Schweers, J., Allman, C., ...Balach, L. (1993c). Adolescent witness to a peer suicide. Journal of the American Academy of Child \& Adolescent Psychiatry, 32(6), 1184-1188. https://doi.org/10.1097/00004583-199311000-00011

Brent, D.A., Perper, J.A., Moritz, G., Liotus, L., Richardson, D., Canobbio, R., Roth, C. (1995). Posttraumatic stress disorder in peers of adolescent suicide victims: predisposing factors and phenomenology. Journal of the American Academy of Child \& Adolescent Psychiatry, 34(2), 209-215. https://doi.org/10.1097/00004583-199502000-00016

Bridge, J.A., Day, N.L., Richardson, G.A., Birmaher, B. \& Brent, D.A. (2003). Major depressive disorder in adolescents exposed to a friend's suicide. Journal of the American Academy of Child \& Adolescent Psychiatry, 42(11), 1294-1300. doi:101097/01.chi.0000084830.67701.9

Brinkmann, S. \& Kvale, S. (2015). InterViews: Learning the craft of qualitative research interviewing ( $3^{\text {rd }}$ ed.). London: Sage.

Brod, M., Tesler, L. E., \& Christiansen, T. L. (2009). Qualitative research and content validity: Developing best practices based on science and experience. Quality of Life Research, 18(9), 1263-1278. doi:10.1007/s11136-009-9540-9

Brooks, G.R. (2010). Beyond the crisis of masculinity: A transtheoretical model for male-friendly therapy. Washington, DC: American Psychological Association.

Broussard, L. (2006). Understanding qualitative research: A school nurse perspective. The Journal of School Nursing, 22(4), 212-218.

Bruyn, S.R. (1966). The human perspective in sociology. Englewood Cliffs, NJ: Prentice-Hall.

Bryman, A. (2008). Social research methods. ( $3^{\text {rd }}$ ed.). NY: Oxford University Press.

Buber, M. (1955/2002). Between Man and Man. London: Routledge.

Buber, M. (1958). I and thou (2 ${ }^{\text {nd }}$ ed.). (R.G. Smith, Ed. Translation). NY: Charles Scribner's Sons. 
Burlew, A.K. \& Mosley-Howard, G.S. (2015). Culturally sensitive mental health services. In R.H. Witte \& G.S. Mosley-Howard (Eds.), Mental health practice in today's schools: Issues and interventions (pp. 105-124). NY: Springer Publishing Company.

Butt, T. (2006). Different readings of personal construct theory. In R. J. Butler (Ed.). On reflection: Emphasising the personal in construct. (pp. 195-208). Chichester, England: John Wiley doi:10.1002/9780470743577.ch12

Caelli, K. (2000). The changing face of phenomenological research: Traditional and American phenomenology in nursing. Qualitative Health Research, 10(3), 366377.

Calhoun, L.G., \& Tedeschi, R.G. (1998). Beyond recovery from trauma: Implications for clinical practice and research. Journal of Social Issues, 54(2), 357-371.

Capretto, P. (2015). Empathy and silence in pastoral care for traumatic grief and loss. Journal of Religion \& Health, 54(1), 339-357. doi: 10.1007/s10943-014-99045

Carlsson, G. (2003). Det våldsamma mötets fenomenologi - om hot och våld $i$ psykiatrisk context [The Phenomenology of Violent Encounters -Threats and Violence in Psychiatric Care]. Växjö University Press, Växjö.

Carpiano, R. M. (2009). Come take a walk with me: The "Go-Along" interview as a novel method for studying the implications of place for health and well-being. Health \& Place, 15(1), 263-272. https://doi.org/10.1016/j.healthplace.2008.05.003

Caserta, M., Utz, R., Lund, D., \& de Vries, B. (2010). Sampling, recruitment, and retention in a bereavement intervention study: Experiences from the Living After Loss Project. Omega Journal of Death \& Dying, 61(3), 181-203.

Center for Disease Control and Prevention (2010a). Suicide: Facts at a glance. http://www.cdc.gov/violenceprevention/pdf/Suicide_DataSheet-a.pdf

Centers for Disease Control and Prevention (2010b). Web-based Injury Statistics Query and Reporting System (WISQARS) [Online]. (2010). National Center for Injury Prevention and Control, CDC (producer). Retrieved from http://www.cdc.gov/injury/wisqars/

Cerel, J. \& Aldrich, R.S. (2011). The impact of suicide on children and adolescents. In J.R. Jordan \& J.L. McIntosh (Eds.), Grief after suicide: Understanding the consequences and caring for the survivors (pp.81-92). NY: Routledge. 
Cerel, J., \& Campbell, F. R. (2008). Suicide survivors seeking mental health services: A preliminary examination of the role of an active postvention model. Suicide \& Life Threatening Behavior, 38(1), 30-34. doi:10.1521/suli.2008.38.1.30

Cerel, J., Fristad, M., Weller, E., \& Weller, R. (1999). Suicide-bereaved children and adolescents: A controlled longitudinal examination. Journal of the American Academy of Child \& Adolescent Psychiatry, 38(6), 672-679. https://doi.org/10.1097/00004583-199906000-00013

Cerel, J., Jordan, J.R. \& Duberstein, P.R. (2008). The impact of suicide on the family. Crisis: The Journal of Crisis Intervention and Suicide Prevention, 29(1), 3844. http://dx.doi.org/10.1027/0227-5910.29.1.38

Cerel, J., Maple, M., Aldrich, R., \& van de Venne, J. (2013). Exposure to suicide and identification as survivor: Results from a random-digit dial survey. Crisis, The Journal of Crisis Intervention and Suicide Prevention, 34(6), 413-419. http://dx.doi.org/10.1027/0227-5910/a000220

Cerel, J., Padgett, J., Conwell, Y., \& Reed, G. (2009). A call for research: The need to better understand the impact of support groups for suicide survivors. Suicide \& Life-Threatening Behavior, 39(3), 269-281. doi:10.1521/suli.2009.39.3.269

Cerel, J., Roberts, T.A. \& Nilsen, W.J. (2005). Peer suicidal behavior and adolescent risk behaviour. Journal of Nervous and Mental Disease, 193(4), 237-243.

Chandra, A., Scott, M. M., Jaycox, L. H., Meredith, L. S., Tanielian, T., \& Burnam, A. (2009). Racial/ethnic differences in teen and parent perspectives toward depression treatment. Journal of Adolescent Health, 44(6), 546-553. http://dx.doi.org/10.1016/j.jadohealth.2008.10.137

Christians, C.G. (2005). Social dialogue and media ethics. Ethical Perspectives, 2(3), 182-193. doi:10.2143/EP.7.2.503805

Clark, S. (2001). Bereavement after suicide - How far have we come and where do we go from here? Crisis, 22(3), 102-108. http://dx.doi.org/10.1027//0227$\underline{5910.22 .3 .102}$

Clark, S. E. \& Goldney, R. D. (2000). The impact of suicide on relatives and friends. In K. Hawton, \& K. van Heeringen (Eds.), The international handbook of suicide and attempted suicide (pp. 467-484). Chichester, UK: Wiley. 
Cleiren, M., \& Diekstra, R. F. W. (1995). After the loss: Bereavement after suicide and other types of death. In B. L. Mishara (Ed.), The impact of suicide (pp.7-39). NY: Springer.

Cohen-Konrad, S. (2009). Loss in translation: A model for therapeutic engagement and intervention with grieving clients. Families in Society: The Journal of Contemporary Social Services, 90(4), 407-412. http://dx.doi.org/10.1606/1044-3894.3928

Colaizzi, P.F. (1973). Reflection and research in psychology: A phenomenological study of learning. Dubuque: Kendal-Hunt.

Colaizzi, P.F. (1978). Psychological research as the phenomenologist views it. In R.S. Valle \& M. King (Eds.), Existential phenomenological alternatives for psychology (pp. 48-71). NY: Plenum Press.

Coleman, D. (2015). Traditional masculinity as a risk factor for suicidal ideation: Crosssectional and prospective evidence from a study of young adults. Archives of Suicide Research, 19(3), 366-384. http://dx.doi.org/10.1080/13811118.2014.957453

Collogan, L.K., Tuma, F., Dolan-Sewell, R., Borja, S. \& Fleischman, A.R. (2004). Ethical issues pertaining to research in the aftermath of disaster. Journal of Traumatic Stress, 17(5), 363-372. doi:10.1023/B:JOTS.0000048949.43570.6a

Connell, R.W. (2002). Gender. Cambridge, UK: Polity.

Connell, R. W. (2005). Growing up masculine: Rethinking the significance of adolescence in the making of masculinities. Irish Journal of Sociology, 14(2), $11-28$.

Connell, R.W. \& Messerschmidt, J.W. (2005). Hegemonic masculinity: Rethinking the concept. Gender \& Society, 19(6), 829-859. doi:10.1177/0891243205278639

Connelly, L.M. (2010). What is phenomenology? MEDURG Nursing, 19(2), 127-128.

Connelly, L.M. (2015). Life-worlds in phenomenology. MEDSURG Nursing, 24(2), 119-20.

Cook, A.S. (1995). Ethical issues in bereavement research: An overview. Death Studies, 19(2), 103-122. http://dx.doi.org/10.1080/07481189508252719

Corbett, L. (2015). The soul in anguish: psychotherapeutic approaches to suffering. North Carolina, USA: Chiron Publications. 
Coronial Services of New Zealand (2017). Annual suicide statistics since 2011.

Ministry of Justice, New Zealand.

https://coronialservices.justice.govt.nz/suicide/annual-suicide-statistics-since$\underline{2011 /}$

Corr, C.A. (1992). A task-based approach to coping with dying. OMEGA - Journal of Death and Dying, 24(2), 81-94.

Corr, C.A. (1993). Coping with dying: Lessons we should learn and should not learn from the work of Elisabeth Kübler-Ross. Death Studies, 17(1), 69-83. http://dx.doi.org/10.1080/07481189308252605

Corr, C.A. (2000). What do we know about grieving children and adolescents? In K.J. Doka (Ed.), Living with grief: Children, adolescents, and loss. (pp. 21-34). Hospice Foundation of America.

Corr, C.A. Nabe, C.M. \& Corr, D.M. (2009). Death \& dying, life \& living (6 ${ }^{\text {th }}$ ed.). Belmont, CA: Wadsworth.

Cowles, K. (1988). Issues in qualitative research on sensitive topics. Western Journal of Nursing Research, 10(2), 163-179.

Courtenay, W.H. (2000a). Constructions of masculinity and their influence on men's well-being: a theory of gender and health. Social Science \& Medicine, 50(10), 1385-1401. https://doi.org/10.1016/S0277-9536(99)00390-1

Courtenay, W.H. (2000b). Engendering health: A social constructionist examination of men's health beliefs and behaviors. Psychology of Men \& Masculinity, 1(1), 415. http://dx.doi.org/10.1037/1524-9220.1.1.4

Courtenay, W.H., McCreary, D.R., \& Merighi, J.R. (2002). Gender and ethnic differences in health beliefs and behaviors. Journal of Health Psychology, 7(3), 219-231.

Courtenay, B.C., Merriam, S.B. \& Reeves, P.M. (1998). The centrality of meaningmaking in transformational learning: How HIV-Positive adults make sense of their lives. Adult Education Quarterly, 48(2), 65-84.

doi:10.1177/074171369804800203

Courtenay, B.C., Merriam, S., Reeves, P. \& Baumgartner, L. (2000). Perspective transformation over time: A 2-year follow-up study of HIV-Positive adults. Adult Education Quarterly, 50(2), 102-119. doi:10.1177/07417130022086937 
Cox, S.M., \& Boydell, K.M. (2016). Ethical issues in arts-based health research. In S. Clift \& P.M. Camic (Eds.), Oxford Textbook of Creative Arts, Health, and Wellbeing: International perspectives on practice, policy and research (pp. 8389). Oxford, UK: Oxford University Press.

Cox, D. W., Westwood, M. J., Hoover, S. M., Chan, E. K. H., Kivari, C. A., Dadson, M. R., \& Zumbo, B. D. (2014). The evaluation of a group intervention for veterans who experienced military-related trauma. International Journal of Group Psychotherapy, 64(3), 367-380. http://dx.doi.org/10.1521/ijgp.2014.64.3.367

Creighton, G. \& Oliffe, J.L. (2010). Theorising masculinities and men's health: A brief history with a view to practice. Health Sociology Review, 19(4), 409-418. http://dx.doi.org/10.5172/hesr.2010.19.4.409

Creighton, G., Oliffe, J.L., Butterwick, S. \& Saewyc, E. (2013). After the death of friend: Young men's grief and masculine identities. Social Science \& Medicine, 84, 35-43. https://doi.org/10.1016/j.socscimed.2013.02.022

Creighton, G., Oliffe, J., McMillan, E. \& Saewyc, E.M. (2015). Living for the moment: men situating risk taking after the death of a friend. Sociology of Health \& Illness, 37(3), 355-369. doi:10.1111/1467-9566.12194

Creighton, G., Oliffe, J., Matthews, J. \& Saewyc, E. (2016). "Dulling the edges": Young men's use of alcohol to deal with grief following the death of a male friend. Health Education \& Behavior, 43(1), 54-60. doi:10.1177/1090198115596164.

Creswell, J. (1998). Qualitative inquiry and research design: Choosing among five traditions. Thousand Oaks, CA: Sage.

Creswell, J. (2007). Qualitative inquiry and research design: Choosing among five traditions. ( $2^{\text {nd }}$ ed.). Thousand Oaks, CA: Sage.

Creswell, J. (2014). Research design: Qualitative, quantitative, and mixed methods approaches. ( ${ }^{\text {rd }}$ ed.). Thousand Oaks, CA: SAGE.

Crosby, A.E. \& Sacks, J.J. (2002). Exposure to suicide: Incidence and association with suicidal ideation and behaviour: United States, 1994. Suicide \& LifeThreatening Behavior, 32(3), 321-328. doi:10.1521/suli.32.3.321.22170

Crotty, M. (1996). Phenomenology and nursing practice. Melbourne: Churchill Livingstone. 
Crouter, A. C., Manke, B. A., \& McHale, S. M. (1995). The family context of gender intensification in early adolescence. Child Development, 66(2), 317-329. doi: $10.2307 / 1131580$

Crow, A. (2013). Survivors of suicide: What are their struggles and how do they heal? A thesis in partial fulfilment of the requirements for the degree of Master of Science in Social Work, University of Texas at Arlington https://utair.tdl.org/uta-ir/handle/10106/11906

Currier, J.M., Holland, J.M., Coleman, R., \& Neimeyer, R.A. (2007). Bereavement following violent death: an assault on life and meaning. In R. Stevenson \& G. Cox (Eds.), Perspectives on violence and violent death (pp. 177-202). Amityville, NY: Baywood.

Currier, J.M., Holland, J.M., \& Neimeyer, R.A. (2006). Sense making, grief and the experience of violent loss: toward a meditational model. Death Studies, 30(5), 403-428. http://dx.doi.org/10.1080/07481180600614351

Cutcliffe, J. (2003). Reconsidering reflexivity: introducing the case for intellectual entrepreneurship'. Qualitative Health Research, 13(1), 136-48. doi:10.1177/1049732302239416

Cutcliffe, J., Joyce, A. \& Cummins, M. (2004). Building the case for understanding the lived experiences of males who attempt suicide in Alberta, Canada. Journal of Psychiatric and Mental Health Nursing, 11(3), 305-312. doi:10.1111/j.13652850.2003.00722.x

Dahlberg, K. (2006). The essence of essences - the search for meaning structures in phenomenological analysis of lifeworld phenomena. International Journal of Qualitative Studies on Health and Well-being, 1(1), 11-19. http://dx.doi.org/10.1080/17482620500478405

Dahlberg, K., Dahlberg, H., \& Nystrom, M. (2008). Reflective Lifeworld Research (2 ${ }^{\text {nd }}$ ed.). Lund, Sweden: Studentliteratur.

De Groot, M. \& Kollen, B. (2013). Course of bereavement over 8-10 years in first degree relatives and spouses of people who committed suicide: Longitudinal community based cohort study. British Medical Journal, 347, f5519, 1-11. https://doi.org/10.1136/bmj.f5519

Denzin, N. K. (2009). The research act: A theoretical introduction to sociological methods. NY: Aldine Transaction. 
Denzin, N. K. (2012). Triangulation 2.0. Journal of Mixed Methods Research, 6(2), 8088. doi:10.1177/1558689812437186

Denzin, N.K. \& Lincoln, Y.S. (1994). Handbook of qualitative research. Thousand Oaks, CA: Sage.

Denzin, N.K. \& Lincoln, Y.S. (2008). Collecting and interpreting qualitative materials. Vol 3. London: Sage.

De Raeve L. (2002). The modification of emotional responses: a problem for trust in nurse-patient relationships? Nursing Ethics, 9(5), 465-471.

De Visser, R.O., Smith, J.A., \& McDonnell, E.J. (2009). 'That's not masculine': Masculine capital and health-related behaviour. Journal of Health Psychology, 14(7), 1047-1058.

Dickson-Swift, V., James, E.L., Kippen, S., \& Liamputtong, P. (2006). Blurring boundaries in qualitative health research on sensitive topics. Qualitative Health Research, 16(6), 853-871.

Dickson-Swift, V., James, E.L., Kippen, S., \& Liamputtong, P. (2007). Doing sensitive research: what challenges do qualitative researchers face? Qualitative Research, 7(3), 327-353. doi:10.1177/1468794107078515

Dickson-Swift, V., James, E.L., Kippen, S., \& Liamputtong, P. (2008). Risk to researchers in qualitative research on sensitive topics: Issues and strategies. Qualitative Health Research, 18(1), 133-144. doi:10.1177/1049732307309007.

Dickson-Swift, V., James, E.L., Kippen, S., \& Liamputtong, P. (2009). Researching sensitive topics: Qualitative research as emotion work. Qualitative Research, 9(1), 61-79. doi:10.1177/1468794108098031.

Doka, K.J. (Ed.), (1989). Disenfranchised grief: Recognizing hidden sorrow. Lexington, M.A: Lexington Books.

Doka, K.J. (1994). The spiritual crisis of bereavement. In K. Doka \& J. Morgan (Eds.), Death and spirituality (pp. 185-194). Amityville, NY: Baywood Press.

Doka, K. (Ed.), (2002). Disenfranchised grief: New directions, challenges, and strategies for practice. Champaign, Illinois: Research Press.

Doka, K. \& Martin, T.L. (1998). Masculine responses to loss: Clinical implications. Journal of Family Studies, 4(2), 143-158. doi:10.5172/jfs.4.2.143 
Doka, K.J. \& Martin, T.L. (2010). Grieving beyond gender: Understanding the ways men and women mourn. (revised ed.). NY: Routledge.

Doka, K. J., \& Martin, T. L. (2011). Grieving styles: Gender and grief. Grief Matters, 14(2), 42-45.

Dowling, M. (2007). From Husserl to van Manen: A review of different phenomenological approaches. International Journal of Nursing Studies, 44(1), 131-142. https://doi.org/10.1016/j.ijnurstu.2005.11.026

Douglas, D.H. (2004). The lived experience of loss: A phenomenological study. Journal of the American Psychiatric Nurses Association, 10(1), 24-32.

doi:10.1177/1078390303261942

Dransart, D.A.C. (2013). From sense-making to meaning-making: understanding and supporting survivors of suicide. British Journal of Social Work, 43(2), 317335. https://doi.org/10.1093/bjsw/bct026

Dransart, D.A.C. (2016). Reclaiming and reshaping life: Patterns of reconstruction after the suicide of a loved one. Qualitative Health Research, 27(7), 1-12, doi:10.1177/1049732316637590

Dutton, Y. \& Zisook, S. (2005). Adaptation to bereavement. Death Studies, 29, 877 903. http://dx.doi.org/10.1080/07481180500298826

Dyregrov, K. (2003-2004). Micro-sociological analysis of social support following traumatic bereavement: Unhelpful and avoidant responses from the community. OMEGA, 48(1), 23-44. doi:10.2190/T3NM-VFBK-68R0-UJ60

Dyregrov, K. (2004a). Bereaved parents' experience of research participation. Social Science and Medicine, 58(2), 391-400. https://doi.org/10.1016/S02779536(03)00205-3

Dyregrov, K. (2004b). Strategies of professional assistance after traumatic deaths: Empowerment or disempowerment? Scandinavian Journal of Psychology, 45(2), 181-189. doi:10.1111/j.1467-9450.2004.00393.x

Dyregrov, K. (2011). What do we know about needs for help after suicide in different parts of the world? A Phenomenological perspective. Crisis, 32(6), 310-318. http://dx.doi.org/10.1027/0227-5910/a000098

Dyregrov, K., Bernstein, G. \& Silviken, A. (2014). The need for and barriers to professional help - a qualitative study of the bereaved in Sámi areas. Suicidology Online, 5(1), 47-58. 
Dyregrov, K., \& Dyregrov, A. (2005). Siblings after suicide: “The forgotten bereaved". Suicide \& Life-Threatening Behavior, 35(6), 714-724. http://doi.org/10.1521/suli.2005.35.6.714

Dyregrov, K., Dieserud, G., Hjelmeland, H., Straiton, M., Rasmuusen, M., Knizek, B., \& Leenaars, A. (2011). Meaning-making through psychological autopsy interviews: The value of participating in qualitative research for those bereaved by suicide. Death Studies, 35(8), 685-710. http://dx.doi.org/10.1080/07481187.2011.553310

Dyregrov, A., Gjestad, R., Wiklander, A.M. \& Vigerust, S. (1999). Reactions following the sudden death of a classmate. Scandinavian Journal of Psychology, 40(3), 167-176. doi:10.1111/1467-9450.00114

Dyregrov, A., Kristoffersen, J.I., Mattiesen, S.B., \& Mitchell, J.T. (1994). Gender differences in adolescents' reactions to the murder of their teacher. Journal of Adolescent Research, 9(3), 363-383.

Dyregrov, A., \& Regel, S. (2012). Early interventions following exposure to traumatic events: Implications for practice from recent research. Journal of Loss and Trauma, 17(3), 271-291. http://dx.doi.org/10.1080/15325024.2011.616832

Edmonds, S., \& Hooker, K. (1992). Perceived changes in life meaning following bereavement. Omega, 25(4), 307-318. doi:10.2190/TE7Q-5G45-BETY-X1TT

Ellingson, L.L. (2008). Engaging crystallization in qualitative research. Thousand Oaks, CA: Sage.

Elliott, R., Fischer, C. T., \& Rennie, D. L. (1999). Evolving guidelines for publication of qualitative research studies in psychology and related fields. British Journal of Clinical Psychology, 38, 215-229. doi:10.1348/014466599162782

Elliot, R., \& Timulak, L. (2005). Descriptive and interpretive approaches to qualitative research. In J. Miles \& P. Gilbert (Eds.), A handbook of research methods for clinical and health psychology (pp. 147-159). NY: Oxford University Press.

Ellis, C. (1999). Heartful autoethnography. Qualitative Health Research, 9(5), 669-683 doi:10.1177/104973299129122153

Ellis, C. (2007). Telling secrets, revealing lives: Relational ethics in research with intimate others. Qualitative Inquiry, 13(1), 3-29.

doi:10.1177/1077800406294947 
Ellis, C., \& Bochner, A. P. (2000). Autoethnography, personal narrative, reflexivity: Researcher as subject. In N. K. Denzin \& Y. S. Lincoln (Eds.), The handbook of qualitative research (2nd ed.). (pp. 733-768). Newbury Park, CA: Sage.

Englar-Carlson, M. \& Stevens, M.A. (Eds.). (2006). In the room with men: A casebook of therapeutic change. Washington, DC: American Psychological Association.

Ephraim, T.A. (1998). Adolescent coping strategies after a suicide or other loss by death: A retrospective study. A dissertation submitted in Marriage and Family Therapy, in partial fulfilment of the requirements for the degree of Doctor of Philosophy, University of Texas. https://ttu-ir.tdl.org/ttu-ir/handle/2346/15416

Ephratt, M. (2008). The functions of silence. Journal of Pragmatics, 40(11), 1909-1938. https://doi.org/10.1016/j.pragma.2008.03.009

Evans, J., Frank, B., Oliffe, J.L. \& Gregory, D. (2011). Health, illness, men and masculinities (HIMM): A theoretical framework for understanding men and their health. Journal of Men's Health, 8(1), 7-15.

Evans, J. \& Jones, P. (2011). The walking interview: Methodology, mobility and place. Applied Geography, 31(2): 849-858. doi:10.1016/j.apgeog.2010.09.005

Everest, T. (2014). Resolving the qualitative-quantitative debate in healthcare research. Medical practice and Review, 5(1), 6-15. doi:10.5897/MPR.2013.0107

Feigelman, W. \& Gorman, B.S. (2008). Assessing the effects of peer suicide on youth suicide. Suicide \& Life-Threatening Behavior, 38(2), 181-194. doi:10.1521/suli.2008.38.2.181

Feigelman, W., Gorman, B.S., \& Jordan, J.R. (2009). Stigmatization and suicide bereavement. Death Studies, 33(7), 591-608. http://dx.doi.org/10.1080/07481180902979973

Feldman, R.S. (2014). Life Span Development: A Topical Approach. (PIE) (2 $2^{\text {nd }}$ ed.), Essex, England: Pearson.

Felmlee, D., Sweet, E., \& Sinclair, H.C. (2012). Gender rules: Same- and cross-gender friendships norms. Sex Roles, 66(7), 518-529. doi:10.1007/s11199-011-0109-z.

Ferszt, G.G., Heineman, L., Ferszt, E.J. \& Romano, S. (1998). Transformation through grieving: Art and the bereaved. Holistic Nursing Practice, 13(1), 68-75. 
Fielden, J.M. (2003). Grief as a transformative experience: Weaving through different lifeworlds after a loved one has completed suicide. International Journal of Mental Health Nursing, 12(1), 74-85. doi:10.1046/j.1440-0979.2003.00271.x

Figley, C.R. (1995). Compassion fatigue as secondary traumatic stress disorder: an overview. In C.R. Figley (Ed.), Compassion fatigue: coping with secondary traumatic stress disorder in those who treat the traumatized (pp. 1-19). NY: Brunner/Mazel

Finlay, L. (2003). The reflexive journey: mapping multiple routes. In L. Finlay \& B. Gough (Eds.), Reflexivity: A practical guide for researchers in health and social sciences (pp. 3-20). Oxford: Blackwell Publishing.

Finlay, L. (2008). A dance between the reduction and reflexivity: Explicating the "phenomenological psychological attitude". Journal of Phenomenological Psychology, 39(1), 1-32. https://doi.org/10.1163/156916208X311601

Finlay, L. (2009). Debating phenomenological research methods. Phenomenology \& Practice, 3(1), 6-25.

Finlay, L. (2011). Phenomenology for therapists: Researching the lived world. Oxford: Wiley-Blackwell.

Fiske, H. (2002). Applications of Solutions-focused Therapy in Suicide Prevention. In D. Deleo, A., Schmidtke, \& R. Diekstra (Eds.), Suicide Prevention: A Holistic Approach (pp. 185-198). Dordrecht, Netherlands: Kluwer.

Fiske, H. (2008). Hope in action: Solutions-focused conversations about suicide. NY: Taylor \& Francis.

Fivush, R., \& Buckner, J. P. (2000). Gender, sadness, and depression: the development of emotional focus through gendered discourse. In A. Fischer (Ed.), Gender and emotion: social psychological perspectives (pp. 232-253). Cambridge: University Press.

Flynn, L. (2009). Is suicide bereavement different? The experience of support after suicide. Grief Matters, 12(1), 18-21.

Fredriksson, L. (1999). Modes of relating in a caring conversation: a research synthesis on presence, touch and listening. Journal of Advances Nursing, 30(5), 11671176. doi:10.1046/j.1365-2648.1999.01192.x

Freydenberg, E. (2008). Adolescent coping: Advances in theory, research and practice. NY: Routledge. 
Frosh, S., Phoenix, A. \& Pattman, R. (2003). The trouble with boys. The Psychologist, 16(2), 84-87. http://eprints.bbk.ac.uk/105/1/frosh8.pdf

Fusch, P. \& Ness, L.R. (2015). Are we there yet? Data saturation in qualitative research.

The Qualitative Report, 20(9), 1408-1416.

http://www.nova.edu/ssss/QR/QR20/9/fusch1.pdf

Gadamer, H.G. (1976). Philosophical Hermeneutics. (Linge, D. Ed., Translation). Berkeley: University of California Press.

Gadamer, H.G. (1989). Truth and method. (2 ${ }^{\text {nd }}$ ed.). NY: Crossroad.

Gaffney, M., \& Hannigan, B. (2010). Suicide bereavement and coping: A descriptive and interpretive analysis of the coping process. Procedia Social and Behavioural Sciences, 5, 526-535. https://doi.org/10.1016/j.sbspro.2010.07.137

Garfield, C.F., Issacco, A., \& Rogers, T.E. (2008). A review of men's health and masculinity. American Journal of Lifestyle Medicine, 2(6), 474-487.

Garnefksi, N., Teerds, J., Kraaij, V., Legerstee, J. \& van den Kommer, T. (2004). Cognitive emotion regulation strategies and depressive symptoms: differences between males and females. Personality and Individual Differences, 36(2), 267-276. doi:10.1016/S0191-8869(03)00083-7

Gearing, R.E. (2004). Bracketing in research: A typology. Qualitative Health Research, 14(10), 1429-1452. doi:10.1177/1049732304270394

Geniusas, S. (2012). The origins of the horizon in Husserl's phenomenology. New York: Springer (ebook) doi:10.1007/978-94-007-4644-2_1

Gillies, A. (2012). Informed consent and assent: An ethical consideration when involving students in research. In P. Jones, T. Whitehurst \& J. Egerton (Eds.), Creating meaningful inquiry in inclusive classrooms: Practitioners' stories of research (pp. 53-67). NY: Routledge.

Giorgi, A. (1985). Sketch of a psychological phenomenological method. In A. Giorgi (ed.), Phenomenology and psychological research, (pp. 8-22), Pittsburgh: Duquesne University Press.

Giorgi, A. (1989). One type of analysis of descriptive data: Procedures involved in following a scientific phenomenological method. Methods: A Journal for Human Science, 1(3), 39-61. 
Giorgi, A. (1997). The theory, practice, and evaluation of the phenomenological method as a qualitative research procedure, Journal of Phenomenological Psychology, 28(2), 235-260. http://dx.doi.org/10.1163/156916297X00103

Giorgi, A. (2000). The status of Husserlian phenomenology in caring research. Scandinavian Journal of Caring Science, 14(1), 11-15. doi:10.1111/j.14716712.2000.tb00554.x

Giorgi, A. (2002). The question of validity in qualitative research. Journal of Phenomenological Psychology, 33(1), 1-18. doi:10.1163/156916202320900392

Giorgi, A. (2009). The descriptive phenomenological method in psychology. Pittsburgh, PA: Duquesne University Press.

Giorgi, A. \& Giorgi, B. (2003). Phenomenology. In J. A. Smith (Ed.) Qualitative Psychology: A practical guide to research methods (pp. 25-50). London: Sage.

Ginzburg, K., Geron, Y., \& Solomon, Z. (2002). Patterns of complicated grief among bereaved parents. Omega, 45(2), 119-132. doi:10.2190/XUW5-QGQ9-KCB8K6WW

Given, L.M. (Ed.), (2008). The Sage Encyclopaedia of Qualitative Research Methods. London: Sage Publications, 2008, Vol 1 \& 2.

Golafshani, N. (2003). Understanding reliability and validity in qualitative research. The Qualitative Report, 8(4), 597-607. Retrieved from http://nsuworks.nova.edu/tqr/vol8/iss4/6

Goodman, M., Black, H.K., \& Rubinstein, R.L. (1996). Paternal bereavement in older men. Omega, 33(4), 303-322. doi:10.2190/GGXB-1RET-4LJB-CD1Q

Grad O. (2005). An Unknown Journey from Loss to Gain-From Individual to Global Perspective. In Hawton, K., (Ed.). Prevention and Treatment of Suicidal Behaviour (pp. 352-369). Oxford, UK: Oxford University Press.

Grad, O., Clark, S., Dyregrov, K., \& Andriessen, K. (2004). What helps and what hinders the process of surviving the suicide of somebody close? Crisis, 25(3), 134-139. http://dx.doi.org/10.1027/0227-5910.25.3.134

Gray, D.E. (2014). Doing research in the real world ( $3^{\text {rd }}$ ed.). London: SAGE. 
Gray, R.E., Fitch, M., Davis, C., \& Phillips, C. (1997). Interviews with men with prostate cancer about their self-help group experience. Journal of Palliative Care, 13(1), 15-21.

Green, B.L., Krupnick, J.L., Stockton, P., Goodman, L., Corcoran, C., \& Petty, R. (2001). Psychological outcomes associated with traumatic loss in a sample of young women. American Behavioral Scientist, 44(5), 817-837.

Green, B.N., Johnson, C.D., \& Adams, A. (2006). Writing narrative literature reviews for peer-reviewed journals: Secrets of the trade. Journal of Chiropractic Medicine, 5(3), 101-116. doi: 10.1016/S0899-3467(07)60142-6.

Guba, E.G. \& Lincoln, Y.S. (1989). Fourth Generation Evaluation. Newbury Park, CA: Sage.

Guba, E.G. \& Lincoln, Y. S. (1994). Competing paradigms in qualitative research. In N.K. Denzin and Y.S. Lincoln (Eds.), Handbook of Qualitative Research (pp. 105-117). Thousand Oaks, CA: Sage.

Guest, G., Bunce, A., \& Johnson, L. (2006). How many interviews are enough?: An experiment with data saturation and variability. Field Methods, 18((1), 59-82. doi: $10.1177 / 1525822 X 05279903$

Guetterman, T.C. (2015). Descriptions of sampling practices within five approaches to qualitative research in education and the health sciences. Qualitative Social Research, 16(2), ART25. http://nbn-resolving.de/urn:nbn:de:0114-fqs1502256

Hall, C. (2014). Bereavement theory: Recent developments in our understanding of grief and bereavement. Bereavement Care, 33(1), 7-12. http://dx.doi.org/10.1080/02682621.2014.902610

Hardison, H.G., Neimeyer, R.A., \& Lichstein, K.L. (2005). Insomnia and complicated grief symptoms in bereaved college students. Behavioral Sleep Medicine, 3(2), 99-11. http://dx.doi.org/10.1207/s15402010bsm0302_4

Harms, L. (2010). Understanding human development: A multidimensional approach, $\left(2^{\text {nd }}\right.$ ed). South Melbourne, Australia: Oxford University Press.

Harvey, J.H. (1996). Embracing their memory. Needham Heights, Mass: Allyn \& Bacon.

Hazell, P. \& Lewin, T. (1993). Friends of adolescent suicide attempters and completers. Journal of the American Academy of Child \& Adolescent Psychiatry, 32(1), 7681. https://doi.org/10.1097/00004583-199301000-00011 
Heidegger, M. (1962). Being and time. (Macquarrie, J. Robinson, E. Translation). Oxford: Basil Backwell Ltd.

Henschen, K.R. \& Heil, J. (1992). A retrospective study of the effect of an athlete's sudden death on teammates. Omega, 25(3), 217-223. doi:10.2190/TUU3-Y7J9QLRG-C08G

Herman, J.L. (1992). Trauma and recovery: The aftermath of violence - from domestic abuse to political terror. NY: Basic Books.

Hesse-biber, S., \& Leavy, P. (2006). The practice of qualitative research. California: Thousand Oaks.

Higgins, R. (2017). Tangihanga - death customs. Te Ara: The Encyclopedia of New Zealand. Retrieved from http://www.TeAra.govt.nz/en/tangihanga-deathcustoms.

Hindmarch, C. (1995). Secondary losses for siblings. Child: Care, Health and Development, 21(6), 425-431. doi:10.1111/j.1365-2214.1995.tb00773.x

Ho, T.P., Leung, P.W.L., Hung, S.F., Lee, C.C., \& Tang, C.P. (2000). The mental health of the peers of suicide completers and attempters. Journal of Child Psychology and Psychiatry, 41(3), 301-308. doi:10.1111/1469-7610.00614

Hoffmann, W.A., (2004). Being an adolescent suicide survivor - A collage-facilitated phenomenological approach, DEd thesis, Department of Educational Psychology, Faculty of Education and Nursing, Rand Afrikaans University.

Hoffmann, W.A., (2007). Disorganisasiebelewenisse van vroulike laat-adolessente selfmoordagtergeblewenes [Disorganisation experiences of female late adolescent suicide survivors], Tydskrif vir Geesteswetenskappe 47(3), 431-444.

Hoffman, W.A., Myburgh, C. \& Poggenpoel, M. (2010). The lived experiences of lateadolescent female suicide survivors: 'A part of me died'. Journal of Interdisciplinary Health Sciences, 15(1), Art \#493, 9 pages. doi:10.4102/hsag.v15i1.493

Hogan, N., Morse, J.M., \& Tason, M.C. (1996). Toward an experiential theory of bereavement. Omega, 33(1), 303-322. doi:10.2190/GU3X-JWV0-AG6G-21FX 
Holland, J.M., Currier, J.M., \& Neimeyer, R.A. (2006). Meaning reconstruction in the first two years of bereavement: The role of sense-making and benefit-finding. Omega: Journal of Death and Dying, 53(3), 175-191.

Hooyman, N.R., \& Kramer, B.J. (2006). Living through loss: Interventions across the lifespan. NY: Columbia University Press.

Hunt, Q., \& Hertlein, K. (2015). Conceptualising suicide bereavement from an attachment lens. The American Journal of Family Therapy, 43(1), 16-27. http://dx.doi.org/10.1080/01926187.2014.975651

Hurwitz, C.A., Duncan, J., \& Wolfe, J. (2004). Caring for the child with cancer at the close of life: "There are people who make it, and I'm hoping I'm one of them". Journal of the American Medical Association, 292(17), 2141-2149. doi:10.1001/jama.292.17.2141

Husserl, E. (1970). The crisis of European science. (D. Carr, Translation). Chicago: Northwestern University Press.

Husserl, E. (1976). Logical investigations. (J. N. Findlay, Translation). NY: Routledge.

Hutchinson, S.A., Wilson, M.E. \& Wilson, H.S. (1994). Benefits of participating in research interviews. Journal of Nursing Scholarship, 26(2), 161-166.

Huws, J.C. \& Jones, R.S.P. (2008). Diagnosis, disclosure, and having autism: An interpretative phenomenological analysis of the perceptions of young people with autism. Journal of Intellectual \& Developmental Disability, 33(2), 99107. doi:10.1080/13668250802010394

Hycner, R.H. (1985). Some guidelines for the phenomenological analysis of interview data. Human Studies, 8(3), 279-303. doi:10.1007/BF00142995

Ihde, D. (1986). Experimental phenomenology. Albany, NY: SUNY Press.

Jakoby, N.R. (2014). Talking about grief: conversational partners sought by bereaved people. Bereavement Care, 33(1), 13-18, doi:10.1080/02682621.2014.902611

James, T., \& Platzer, H. (1999). Ethical considerations in qualitative research with vulnerable groups: Exploring lesbians' and gay men's experiences of health care - a personal perspective. Nursing Ethics, 6(1), 73-81. 
Johnsen, I. \& Dyregrov, K. (2016). "Only a friend": The bereavement process of young adults after the loss of a close friend in an extreme terror incident $-\mathrm{A}$ qualitative approach. OMEGA - Journal of Death and Dying, 74(1), 16-34. doi:10.1177/0030222815622956

Johnson, B., \& Christensen, L. (2008). Educational research: Quantitative, qualitative, and mixed approaches. LA: Sage.

Johnson, J.L. \& Repta, R. (2012). Sex and gender: Beyond binaries. In J.L. Oliffe \& L. Greaves (Eds.), Designing and conducting gender, sex \& health research (pp. 17-37). California: Sage.

Jordan, H. (2008). Mudbound. Chaphill Hill, NC: Algonquin Books.

Jordan, J.R. (2001). Is suicide bereavement different? A reassessment of the literature. Suicide \& Life-Threatening Behavior, 31(1), 91-102.

Jordan, J.R. (2008). Bereavement after suicide. Psychiatric Annals, 38(10), 679-685. doi:10.3928/00485713-20081001-05

Jordan, J.R., Feigelman, W., McMenamy, J., \& Mitchell, A.M. (2011). Research on the Needs of Survivors. In J.R Jordan \& J.L. McIntosh (Eds.), Grief after Suicide (pp. 115-131). NY: Routledge.

Jordan, J.R. \& McIntosh, J.L. (2011a). (Eds.), Grief after suicide: Understanding the consequences and caring for survivors. NY: Taylor \& Francis.

Jordan, J.R. \& McIntosh, J.L. (2011b). Suicide bereavement: Why study survivors of suicide loss? In J. R. Jordan, \& J.L. McIntosh (Eds.), (2011). Grief after suicide: Understanding the consequences and caring for survivors (pp. 3-17). NY: Taylor \& Francis.

Jordan, J.R., \& McIntosh, J.L. (2011c). A Research Agenda for Suicide Survivors. In J.R. Jordan, \& J.L. McIntosh (Eds.), Grief after Suicide: Understanding the consequences and caring for survivors (pp. 507-522). NY: Routledge.

Judd, F., Komiti, A., \& Jackson, H. (2008). How does being female assist help-seeking for mental health problems? The Australian and New Zealand Journal of Psychiatry, 42(1), 24-29.

Kail, R.V. \& Cavanaugh, J.C. (2007). The final passage: Dying and bereavement. Human development: A Life-span view (5th Ed.). (pp. 592-631). Belmont, CA: Wadsworth, Cengage Learning. 
Kaltman, S. \& Bonanno, G.A. (2003). Trauma and bereavement: examining the impact of sudden and violent deaths. Journal of Anxiety Disorders, 17(2), 131-147.

Karlsson, G. (1995). Psychological qualitative research from a phenomenological perspective, ( $2^{\text {nd }}$ ed.). Stockholm: Almqvist \& Wiksell International.

Kavanaugh, K. \& Ayres, L. (1998). "Not as bad as it could have been": Assessing and mitigating harm during research interviews on sensitive topics. Research in Nursing and Health, 21(1), 91-97. doi:10.1002/(SICI)1098240X(199802)21:1<91::AID-NUR10>3.0.CO;2-C

Keen, E. (1975). A primer in phenomenological psychology. NY: Holt, Reinhart and Winston Inc.

Keesee, N.J., Currier, J.M., \& Neimeyer, R.A. (2008). Predictors of grief following the death of one's child: the contribution of finding meaning. Journal of Clinical Psychology, 64(10), 1145-1163. doi:10.1002/jclp.20502

Kimmel, M.S. (1997). Masculinity as homophobia: Fear, shame, and silence in the construction of gender identity. In H. Brod \& M. Kaufman (Eds.), Theorizing masculinities (pp. 119-141). California: Thousand Oaks.

Kimmel, M. S. (2008). Guyland: The perilous world where boys become men. NY: Harper.

Kiselica, M.S., Englar-Carlson, M., Horne, A.M. \& Fisher, M. (2008). A positive psychology perspective on helping boys. In M.S. Kiselica, M. Englar-Carlson \& A.M. Horne (Eds.), Counseling troubled boys: A guidebook for professionals (pp. 31-48). NY: Taylor \& Francis Group.

Klapper, J., Moss, S., Moss, M., \& Rubenstein, R.L. (1994). The social context of grief among daughters who have lost a parent. Journal of Aging Studies, 8(1), 29-43. https://doi.org/10.1016/0890-4065(94)90017-5

Klass, D., Silverman, P.R., \& Nickman, S.L. (Eds.). (1996). Continuing bonds: new understandings of grief. Washington: Taylor \& Francis.

Kleiman, S. (2004). Phenomenology: To wonder and search for meaning. Nurse Researcher, 11(4), 7-19. http://dx.doi.org/10.7748/nr2004.07.11.4.7.c6211

Koch, T. (1994). Establishing rigour in qualitative research: the decision-trail. Journal of Advanced Nursing, 19, 976-986. 10.1111/j.1365-2648.2006.03681.x 
Koch, T. (1995). Interpretive approaches to nursing research: The influence of Husserl and Heidegger. Journal of Advanced Nursing, 21(5), 827-836.

doi:10.1046/j.1365-2648.1995.21050827.x

Koch, T. (1999). An interpretive research process: revisiting phenomenological and hermeneutical approaches. Nurse Researcher, 6(3), 20-34. http://dx.doi.org/10.7748/nr1999.04.6.3.20.c6085

Koch, T. (2006). Establishing rigour in qualitative research: The decision trail. Journal of Advanced Nursing, 53(1), 91-103. doi:10.1111/j.1365-2648.2006.03681.x

Kohak, E. (1978). Ideas and experience: Edmund Husserl's project of phenomenology in Ideas 1. Chicago, IL: University of Chicago Press.

Kreftling, L. (1991). Rigor in qualitative research: The assessment of trustworthiness. The American Journal of Occupational Therapy, 45(3), 214-222. doi:10.5014/ajot.45.3.214

Kruger, D. (1988). An introduction to phenomenological psychology, (2nd rev. ed.). Cape Town, South Africa: Juta.

Kübler-Ross, E. (1975). Death: The final stage of growth. NY: Prentice-Hall.

Kupers, T.A. (2005). Toxic masculinity as a barrier to mental health treatment in prison. Journal of Clinical Psychology, 61(6), 713-724. doi:10.1002/jclp.20105

Kusenbach, M. (2003). Street phenomenology: The go-along as ethnographic research tool. Ethnography, 4(3), 455-485.

Kuzel, A. (1992). Sampling in qualitative inquiry. In B. Crabtree \& W. Miller (Eds.), Doing qualitative research (pp. 31-44). Newbury Park, CA: Sage.

Kvale, S. (1994). Ten standard responses to qualitative research interviews. Journal of Phenomenological Psychology, 25(2), 147-173. doi:10.1163/156916294X00016

Kvale, S. (1996). InterViews: An introduction to qualitative research interviewing. London: Sage Publications.

Kvale, S. \& Brinkmann, S. (2009). InterViews: Learning the craft of qualitative research interviewing ( $2^{\text {nd }}$ Ed.). Thousand Oaks, CA: Sage Publications. 
Kwan, B.S.C. (2008). The nexus of reading, writing and researching in the doctoral undertaking of humanities and social sciences: Implications for literature reviewing. English for Specific Purposes, 27(1), 42-56. Doi: 10.1016/j.esp.2007.05.002.

Lane, R.C., Koetting, M.G. \& Bishop, J. (2002). Silence as communication in psychodynamic psychotherapy, Clinical Psychology Review, 22(7), 1091-1104. http://dx.doi.org/10.1016/S0272-7358(02)00144-7

Langdridge, D. (2007). Phenomenological Psychology. Harlow: Pearson Education.

Larkin, M., Watts, S., \& Clifton, E. (2008). Giving voice and making sense in interpretative phenomenological analysis. Qualitative Research in Psychology, 3(2), 102-120. doi:10.1191/1478088706qp062oa

Laverty, S.M. (2003). Hermeneutic Phenomenology and Phenomenology: A comparison of historical and methodological considerations. International Journal of Qualitative Methods, 2(3), 21-5.

Lee, R.M. (1993). Doing research on sensitive topics. London: Sage.

Leming, M.R., \& Dickinson, G.E. (1994). Understanding dying, death, and bereavement ( $3^{\text {rd }}$ ed.). New York: Holt, Rinehart \& Winston.

Levant, R.F. (1995). Towards the reconstruction of masculinity. In R.F. Levant \& W.S. Pollack (Eds.), A new psychology of men (pp. 229-251). New York, NY: Basic Books.

Levant, R.F., Allen, P.A. \& Lien, M.C. (2014). Alexithymia in men: How and when do emotional processing deficiencies occur? Psychology of Men \& Masculinity, 15(3), 324-334. doi:10.1037/a0033860

Levant, R.F., Hall, R.J., Williams, C.M. \& Hasan, N.T. (2009). Gender differences in alexithymia. Psychology of Men \& Masculinity, 10(3), 190-203. http://dx.doi.org/10.1037/a0015652

Levi-Belz, Y. (2015). Stress-related growth among suicide survivors: The role of interpersonal and cognitive factors. Archives of Suicide Research, 19(3), 305320. http://dx.doi.org/10.1080/13811118.2014.957452

Levi-Belz, Y. (2016). To share or not to share? The contribution of self-disclosure to stress-related growth among suicide survivors. Death Studies, 40(4), 405-413. http://dx.doi.org/10.1080/07481187.2016.1160164 
Levi-Belz, Y. (2017). Relationship with the deceased as facilitator of post-traumatic growth among suicide-loss survivors. Death Studies, 41(2) 1-9. http://dx.doi.org/10.1080/07481187.2017.1285372

Levin, W.C. (1988). Sociological Ideas: Concepts and Applications, Wadsworth: California.

Levy, L.H., Martinkowski, K.S., \& Derby, J.F. (1994). Differences in patterns of adaptation in conjugal bereavement: Their sources of potential significance. Omega, 29(1), 71-87. doi:10.2190/5Y05-TPHN-KETW-HLHP

Lindqvist, P., Johansson, L, \& Karlsson, U. (2008). In the aftermath of teenage suicide: A qualitative study of the psychosocial consequences for the surviving family members. BioMed Central Psychiatry, 8(26), 1-7. doi:10.1186/1471-244X-826

LoBiondo-Wood, G., \& Habec, J. (1998). Nursing research. Methods, critical appraisal, and utilization. St Louis: Mosby.

Liu, W. M. (2005). The study of men and masculinity as an important multicultural competency consideration. Journal of Clinical Psychology, 61(6), 685-697. doi:10.1002/jclp.20103

Lopez, K.A. \& Willis, D.G. (2004). Descriptive versus Interpretive Phenomenology: Their contributions to nursing knowledge. Qualitative Health Research, 14(5), 726-735.

Luft, S. (2002). Husserl's notion of the natural attitude and the shift to transcendental phenomenology. Analecta Husserliana, 80, 114-119.

Lytje, M. (2017). Towards a model of loss navigation in adolescence, Death Studies, 41(5), 291-302. http://dx.doi.org/10.1080/07481187.2016.1276488

Maata, S.M. (2006). Closeness and distance in the nurse-patient relation. The relevance of Edith Stein's concept of empathy. Nursing Philosophy, 7(1), 3-10. doi:10.1111/j.1466-769X.2006.00232.x

Maggs-Rapport, F. (2001). Best research practice: in pursuit of methodological rigour. Journal of Advanced Nursing, 35(3), 373-383. doi:10.1046/j.13652648.2001.01853.x

Magrini, J. (2012). Phenomenology for Educators: Max van Manen and "Human Science" Research. Philosophy Scholarship. Paper 32. http://dc.cod.edu/philosophypub/32 
Mahon, M.M. (1999). Secondary losses in bereaved children when both parents have died: A case study. OMEGA- Journal of Death and Dying, 39(4), 297-314.

Malkinson, R., Rubin, S. S. \& Witztum, E. (2006). Therapeutic issues and the relationship to the deceased: Working clinically with the two-track model of bereavement. Death Studies, 30(9), 797-815. http://dx.doi.org/10.1080/07481180600884723

Mallom, S., \& Stanley, N. (2015). Creation of a death by suicide: How do bereaved young adults come to understand the death of a friend as suicide? Crisis: The Journal of Crisis Intervention and Suicide Prevention, 36(2), 142-147. doi:10.1027/0227-5910/a000299 http://dx.doi.org/10.1027/0227-5910/a000299

Malteraud, K. (2001). Qualitative research: standards, challenges and guidelines. The Lancet, 358(9820), 483-489. https://doi.org/10.1016/S0140-6736(01)05627-6

Mancini, A.D. \& Bonanno, G.A. (2009). Predictors and parameters of resilience to loss: Toward an individual differences model. Journal of Personality, 77, 6, 18051831. doi:10.1111/j.1467-6494.2009.00601.x

Maple, M., Cerel, J., Jordan, J.R. \& McKay, K. (2014). Uncovering and identifying the missing voices in suicide bereavement. Suicidology Online, 5(1), 1-12.

Maple, M., Edwards, H., Plummer, D. \& Minichiello, V. (2010). Silenced voices: hearing the stories of parents bereaved through the suicide death of a young adult child. Health and Social Care in the Community, 18(3), 241-248. doi:10.1111/j.1365-2524.2009.00886.x

Maples, M.R. (1998). Mental ghosts and the process of grief. Journal of Personal \& Interpersonal Loss, 3(2), 217-231. http://dx.doi.org/10.1080/10811449808414443

Marcell, A.V., Eftim, S.E., Sonenstein, F.L., \& Pleck, J.H. (2011). Associations of family and peer experiences with masculinity attitude trajectories at the individual and group level in adolescent and young adult males. Men and Masculinities, 14(5), 565-587.

Martin, T.L. (2000). In the aftermath: children and adolescents as survivor-victims of suicide. In K.J. Doka (Ed.), Living with grief: Children, adolescents, and loss (pp. 263-273). Hospice Foundation of America.

Martin, T., \& Doka, K. (2000). Men don't cry, women do: Transcending gender stereotypes of grief. Philadelphia, PA: Taylor \& Francis. 
Mason, M. (2010). Sample size and saturation in $\mathrm{PhD}$ studies using qualitative interviews. Forum Qualitative Sozialforschung / Forum: Qualitative Social Research, 11(3), Art. 8, http://nbn-resolving.de/urn:nbn:de:0114-fqs100387

McAdams, D. (1996). Personality, modernity, and the storied self: A contemporary framework for studying persons. Psychological Inquiry, 7(4), 295-321. http://dx.doi.org/10.1207/s15327965pli0704_1

McAdams, D. (2006). The redemptive self: Generativity and the stories Americans live by. Research in Human Development, 3(2-3), 81-100. http://dx.doi.org/10.1080/15427609.2006.9683363

McAdams, D. (2008). Personal narratives and the life story. In O.P. John, R.W.Robins \& L.A. Pervin (Eds.), Handbook of personality: theory and research (pp. 242262). NY: Guilford Press.

McAllister, M. \& Walsh, K. (2003). CARE: A framework for mental health practice. Journal of Psychiatric and Mental Health Nursing, 10, 39-48. doi:10.1046/j.1365-2850.2003.00551.x

McCann, I.L. \& Pearlman, L.A. (1990). Vicarious traumatization: A framework for understanding the psychological effects of working with victims. Journal of Traumatic Stress, 3(1), 131-49. doi:10.1002/jts.2490030110

McCarthy, J.R. (2007). 'They all look as if they're coping, but I'm not': The relational power/lessness of 'Youth' in responding to experiences of bereavement. Journal of Youth Studies, 10(3), 285-303. doi:10.1080/13676260701262574

McGlothlin, J.M. (2006). Assessing perturbation and suicide in families. The Family Journal: Counseling and Therapy for Couples and Families, 14(2), 129-134.

McIntosh, J.L. \& Jordan, J.R. (2011). Going forward: A research agenda for suicide survivors. In J.R. Jordan \& J.L. McIntosh (Eds.), Grief after suicide: Understanding the consequences and caring for the survivors (pp. 507-522). NY: Routledge.

McMenamy, J.M., Jordan, J.R., \& Mitchell, A.M. (2008). What do suicide survivors tell us they need? Results of a pilot study. Suicide \& Life-Threatening Behavior, 38(4), 375-389. doi:10.1521/suli.2008.38.4.375

McNeil, J.N., Silliman, B., \& Swihart, J.J. (1991). Helping adolescents cope with the death of a peer. A high school case study. Journal of Adolescent Research, 6(1), 132-143. 
McNess, A. (2008). Happy to talk...to a point: Bereaved young men and emotional disclosure. Youth Studies Australia, 27(4), 25-34.

Melhem, N.M., Day, N., Shear, K.M., Day, R., Reynolds, C.F., \& Brent, D. (2004). Traumatic grief among adolescents exposed to a peer's suicide. American Journal of Psychiatry, 161, 1411-1415. https://doi.org/10.1176/appi.ajp.161.8.1411

Merleau-Ponty, M. (1962). The phenomenology of perception. (Translation), C. Smith. London: Routledge \& Kegan Paul Ltd.

Merriam, S.B. (2009). Qualitative research: A guide to design and implementation. Revised and expanded from Qualitative Research and Case Study Applications in Education. San Francisco: Jossey-Bass.

Meshot, C.M., \& Leitner, L.M. (1993). Adolescent mourning and parental death. Omega, 26(4), 287-299. doi:10.2190/CHE4-F4ND-QY8C-J2Y5

Milo, E.M. (1997). Maternal responses to the life and death of a child with developmental disability. Death Studies, 21(5), 443-476. http://dx.doi.org/10.1080/074811897201822

Minichiello, V., Aroni, R., Timewell, E., \& Alexander, L. (1990). In-depth interviewing: Researching people (2nd ed.). Melbourne, Australia: Longman.

Ministry of Health. (2015). Suicide Facts: Deaths and intentional self-harm hospitalisations 2012. Wellington: Ministry of Health. Retrieved from http://www.health.govt.nz/publication/suicide-facts-deaths-and-intentionalself-harm-hospitalisations-2012

Ministry of Health (2016). Suicide Facts: Deaths and intentional self-harm hospitalisations 2013. Wellington: Ministry of Health. Retrieved from http://www.health.govt.nz/publication/suicide-facts-deaths-and-intentionalself-harm-hospitalisations-2013

Ministry of Health (2017). The cost of suicide in New Zealand. Wellington: Ministry of Health. HP6587 April, 2017. Retrieved from

https://www.google.co.nz/url?sa=t\&rct=j\&q=\&esrc=s\&source=web\&cd=1\&ca $\mathrm{d}=$ rja\&uact=8\&ved=0ahUKEwi6n8eSgLrWAhUCtpQKHXz7DnEQFggoMA A\&url=https $\% 3 \mathrm{~A} \% 2 \mathrm{~F} \% 2 \mathrm{Fwww}$. health.govt.nz $\% 2 \mathrm{Fsystem} \% 2 \mathrm{Ffiles} \% 2 \mathrm{Fdocu}$ ments $\% 2$ Fpages $\% 2$ Fcost-suicide-in-nzapr17.docx\&usg=AFQjCNFTYkDbIJu9vHeu9FsASMFaFU1WZw 
Mitchell, J.T. \& Everly, G.S. (1996). Critical incident stress debriefing: An operation manual for the prevention of traumatic stress among emergency services and disaster workers. ( $2^{\text {nd }}$ Ed.). Elliot City, MD: Chevron Publishing Corporation.

Mitchell, A.M. Kim, Y., Prigerson, HG., Mortimer-Stephens, M. (2004). Complicated grief in survivors of suicide. Crisis, 25(1), 12-18. doi:10.1027/02275910.25.1.12

Mitchell, A.M., Sakraida, T.J., Kim, Y., Bullian, L., \& Chiappetta, L. (2009). Depression, anxiety and quality of life in suicide survivors: A comparison of close and distant relationships. Archives of Psychiatric Nursing, 23(1), 2-10. https://doi.org/10.1016/j.apnu.2008.02.007

Moore, M., Maple, M., Mitchell, A. M., \& Cerel, J. (2013). Challenges and opportunities for suicide bereavement research: The experience of ethical board review. Crisis, 34(5), 297-304. doi:10.1027/0227-5910/a000191

Moon, P.J. (2010). Bereaved elders: Transformative learning in late life. Adult Education Quarterly, 61(1), 1-18. doi:10.1177/074171363020

Morrow, S. (2005). Quality and trustworthiness in qualitative research in counselling psychology. Journal of Counseling Psychology, 52(2), 250-260. http://psycnet.apa.org/doi/10.1037/0022-0167.52.2.250

Morse, J.M. (1994). Designing funded qualitative research. In N. Denzin \& Y. Lincoln (Eds.), Handbook for qualitative research (pp. 220-235). Thousand Oaks, CA: Sage.

Morse, J.M. (1995). The significance of saturation. Qualitative Health Research, 5(2), 147-149. doi:10.1177/104973239500500201

Morse, J.M., Barrett, M., Mayan, M., Olson, K. \& Spiers, J. (2002). Verification strategies for establishing reliability and validity in qualitative research. International Journal of Qualitative Methods, 1(2), 1-19.

Morse, J.M. \& Niehaus, L. (2009). Mixed method design: Principles and procedures. Walnut Creek, CA: Left Coast Press.

Morse, J. M., Penrod, J., \& Hupcey, J. E. (2000). Qualitative outcome analysis: Evaluating nursing interventions for complex clinical phenomena. Journal of Nursing Scholarship, 32(2), 125-130. doi:10.1111/j.1547-5069.2000.00125.x 
Moss-Racusin, C.A., Phelan, J.E., \& Rudman, L.A. (2010). When men break the gender rules: Status incongruity and backlash against modest men. Psychology of Men \& Masculinity, 11(2), 140-151. http://psycnet.apa.org/doi/10.1037/a0018093

Moustakas, C. (1990). Heuristic research: Design, methodology, and applications. Newbury Park, CA: Sage.

Moustakas, C. (1994). Phenomenological research methods. Thousand Oaks, CA: Sage.

Muller, E.D. \& Thompson, C.L. (2003). The experience of grief and bereavement: A phenomenological study with implications for mental health counseling. Journal of Mental Health Counseling, 25(3), 183-203. http://dx.doi.org/10.17744/mehc.25.3.wu4n7dljyekuh4ef

Munhall, P.L. (1988). Ethical considerations in qualitative research. Western Journal of Nursing Research, 10(2), 150-162.

Munhall, P.L. (2007). Nursing research: A qualitative perspective (4 ${ }^{\text {th }}$ ed.). Boston: Jones \& Bartlett.

Murphy, S.A., Johnson, L.C. \& Lohan, J. (2003). Finding meaning in a child's violent death: A five-year prospective analysis of parent's personal narratives and empirical data. Death Studies, 27(5), 381-404. http://dx.doi.org/10.1080/07481180302879

Nadin, S., \& Cassell, C. (2006). The use of a research diary as a tool for reflexive practice: Some reflections from management research, Qualitative Research in Accounting \& Management, 3(3), 208-217. http://dx.doi.org/10.1108/11766090610705407

Neimeyer, R.A. (1998). Lessons of loss: A guide to coping. NY: McGraw-Hill.

Neimeyer, R.A. (2001). Reauthoring life narratives: Grief therapy as meaning reconstruction. The Israel Journal of Psychiatry and Related Sciences, 38(3-4), 171-183.

Neimeyer, R. A. (2006). Making meaning in the midst of loss. Grief Matters, 9(3), 6265.

Neimeyer, R.A. (2009). Constructions of death and loss: A personal and professional evolution. In R.J. Butler (Ed.). On reflection: Emphasising the personal in construct theory. (pp. 293-318). Chichester, UK: John Wiley \& Sons Ltd. 
Neimeyer, R. A., Burke, L. A., Mackay, M. M., \& van Dyke Stringer, J. G. (2010). Grief therapy and the reconstruction of meaning: From principles to practice. Journal of Contemporary Psychotherapy, 40(2), 73-83. doi:10.1007/s10879009-9135-3

Neimeyer, R.A., Herrero, O. \& Botella, L. (2006). Chaos to coherence: Psyhotherapeutic integration of traumatic loss. Journal of Constructivist Psychology, 19(2), 127-145. doi:10.1080/10720530500508738

Neimeyer, R.A. \& Hogan, N. (2001). Quantitative or qualitative? Measurement issues in the study of grief. In M. Stroebe, H. Shut, R. Hansson (Eds.), Handbook of bereavement research: Consequences, coping and care (pp. 89-118).

Washington, DC: American Psychological Association.

Neimeyer , R.A., Klass, D., \& Dennis, M.R. (2014). A Social Constructionist Account of Grief: Loss and the Narration of Meaning. Death Studies, 38(6-10), 485498. http://dx.doi.org/10.1080/07481187.2014.913454

Neimeyer, R.A. \& Sands, D.C. (2011). Meaning reconstruction in bereavement: from principles to practice. In R.A. Neimeyer, D.L. Harris, H.R. Winokuer, \& G.F. Thornton (Eds.), Grief and bereavement in contemporary society: bridging research and practice (pp. 9-22). NY: Routledge.

Nolen-Hoeksema, S. \& Davis, C.G. (2002). Positive responses to loss: Perceiving benefits and growth. In S. Nolen-Hoeksema, C. G Davis \& C. R. Snyder (Eds.), Handbook of positive psychology (pp. 598-606). NY: Oxford University Press.

Noppe, I.C., \& Noppe, L.D. (2004). Adolescent experiences with death: letting go of immortality. Journal of Mental Health Counseling, 26, 146-167. http://dx.doi.org/10.17744/mehc.26.2.py2tk0kmay1ukc3v

Nursing Council (2011). Guidelines for cultural safety, the Treaty of Waitangi and Maori Health in Nursing Education and Practice. Wellington, NZ: Nursing Council of New Zealand. Accessed from http://www.nursingcouncil.org.nz/Publications/Standards-and-guidelines-for$\underline{\text { nurses }}$

O'Dea, D. \& Tucker, S. (2005). The cost of suicide to suicide. Wellington, Ministry of Health. http://www.health.govt.nz/publication/cost-suicide-society

Oliffe, J.L. \& Bottorf, J.L. (2007). Further than the eye can see? Photo elicitation and research with men. Qualitative Health Research, 17(6), 850-858. 
Oliffe, J.L. \& Mróz, L. (2005). Men interviewing men about health and illness: ten lessons learned. The Journal of Men's Health \& Gender, 2(2), 257-260. https://doi.org/10.1016/j.jmhg.2005.03.007

Oliffe, J.L., Orgodniczuk, J.S., Bottorff, J.L., Johnson, J.L., \& Hoyk, K. (2012). "You feel like you can't survive anymore": Suicide from the perspective of Canadian men who experience depression. Social Science \& Medicine, 74(4), 506-514. https://doi.org/10.1016/j.socscimed.2010.03.057

Oliffe, J.L. \& Phillips, M.J. (2008). Men, depression and masculinities: A review and recommendations. Journal of Mental Health, 5(3), 194-202. https://doi.org/10.1016/j.jomh.2008.03.016

Oltjenbruns, K.A. (1991). Positive outcomes of adolescents' experience with grief. Journal of Adolescent Research, 6(1), 43-53. doi:10.1177/074355489161004

O’Neil, J.M. (2013). Gender role conflict research 30 years later: An evidence-based diagnostic schema to assess boys and men in counselling. Journal of Counseling \& Development, 91, 490-498. doi:10.1002/j.15566676.2013.00122.x

Palinkas, L.A., Horwitz, S.M., Green, C.A., Wisdom, J.P., Duan, N., \& Hoagwood, K. (2015). Purposeful sampling for qualitative data collection and analysis in mixed method implementation research. Administration and Policy in Mental Health, 42(5), 533-544. doi:10.1007/s10488-013-0528-y

Park, C.L., \& Fenster, J.R. (2004). Stress-related growth: predictors of occurrence and correlates with psychological adjustment. Journal of Social and Clinical Psychology, 23(2), 195-215. doi:10.1521/jscp.23.2.195.31019

Parker, I. (1994). Qualitative research. In P. Banister, E. Bumran, I. Parker, M. Taylor, \& C. Tindall (Eds.), Qualitative Methods in Psychology: A Research Guide (pp. 1-16). Buckingham: Open University Press.

Parkes, C.M. (1996). Bereavement: Studies of grief in adult life. ( $3^{\text {rd }}$ ed.). London: Routledge.

Parkes, C. \& Prigerson, H.G. (2010). Bereavement: Studies of grief in adult life (4 ${ }^{\text {th }}$ ed.). NY: Routledge.

Partis, M. (2003). Hope in homeless people: A phenomenological study. Primary Health Care Research and Development, 4(1), 9-19. https://doi.org/10.1191/1463423603pc118oa 
Patton, M.Q. (2002). Qualitative research and evaluation methods ( $3^{\text {rd }}$ ed.). Thousand Oaks, CA: Sage.

Payne, S. \& Field, D. (2004). Undertaking bereavement research: Sensitivities and sensibilities. Grief Matters: Australian Journal of Bereavement, 7(3), 52-56.

Peters J. (2009). Time for change? International Association for Suicide Prevention Postvention Taskforce Newsletter, Issue 3, 1-2.

Peters, K., Murphy, G., \& Jackson, D. (2013). Events prior to Completed Suicide: Perspectives of Family Survivors. Issues in Mental Health Nursing, 33, 309316. http://dx.doi.org/10.3109/01612840.2012.751639

Peters, K., Cunningham, C., Murphy, G., \& Jackson, D. (2016). Helpful and unhelpful responses after suicide: Experiences of bereaved family members. International Journal of Mental Health Nursing, 25(5), 418-425. doi:10.1111/inm.12224

Pezalla, A.E., Pettigrew, J. \& Miller-Day, M. (2012). Researching the researcher-asinstrument: an exercise in interviewer self-reflexivity. Qualitative Research, 12(2), 165-185.

Pfeffer, C.R., Jiang, H., Kakuma, T., Hwang, J., Metsch, M. (2002). Group intervention for children bereaved by the suicide of a relative. Journal of the American Academy of Child \& Adolescent Psychiatry, 41(5), 505-513. https://doi.org/10.1097/00004583-200205000-00007

Pfeffer, C.R., Martins, P., Mann, J., Sunkenberg, M., Ice, A., Damore, J.P....Jiang, H. (1997). Child survivors of suicide: Psychosocial characteristics. Journal of the American Academy of Child \& Adolescent Psychiatry, 36(1), 65-74. https://doi.org/10.1097/00004583-199701000-00019

Pfefferbaum, B., Gurwitch, R.H., McDonald, N.B, Leftwich, M.J., Sconzo, G.M., Messebaugh, A.K., \& Schultz, R.A. (2000). Posttraumatic stress among young children after the death of a friend or acquaintance in a terrorist bombing. Psychiatric Services, 51(3), 386-388. http://dx.doi.org/10.1176/appi.ps.51.3.386

Pitman, A.L., Osborn, D.P., Rantell, K. \& King, M.B. (2016). Bereavement by suicide as a risk factor for suicide attempt: a cross-sectional national UK-wide study of 3432 young bereaved adults. British Medical Journal Open, 6(1), 1-12. http://dx.doi.org/10.1136/bmjopen-2015-009948 
Podell, C. (1989). Adolescent mourning: The sudden death of a peer. Clinical Social Work Journal, 17(1), 64-78. doi:10.1007/BF00755133

Poland, S. (1989). Suicide intervention in the schools. NY: Guilford Press.

Pollack, W.S. (2006). The "War" for boys: hearing "Real Boys" voices, healing their pain. Professional Psychology, Research and Practice, 37(2), 190-195. doi:10.1037/0735-7028.37.2.190

Polkinghorne, D.E. (1989). Phenomenological research methods. In R.S. Valle \& S. Halling (Eds.), Existential-phenomenological perspectives in psychology (pp. 41-60). NY: Plenum Press.

Pompili, M., Lester, D., De Pisa, E., Del Casale, A., Tatarelli, R., \& Girardi, P. (2008). Surviving the suicides of significant others. Crisis: The Journal of Crisis Intervention and Suicide Prevention, 29(1), 45-48.

http://dx.doi.org/10.1027/0227-5910.29.1.45

Prigerson, H., \& Jacobs, S. (2001). Traumatic grief as a distinct disorder: A rationale, consensus criteria, and a preliminary empirical test. In M.S. Stroebe, R.O. Hansson, W. Stroebe, \& H. Shut (Eds.), Handbook of bereavement research: Consequences, coping and care (pp. 613-645). Washington, D.C: American Psychological Association.

Provini, C., Everett, J., \& Pfeffer, C. (2000). Adults mourning suicide: Self-reported concerns about bereavement, needs for assistance, and help-seeking behavior. Death Studies, 24(1), 1-19. http://dx.doi.org/10.1080/074811800200667

Qin, P. \& Mortensen, P.B. (2003). The impact of parental status on the risk of completed suicide. Archives of General Psychiatry, 60(8), 797-802. doi:10.1001/archpsyc.60.8.797

Randell, E. Jerdén, L., Öhman, A., Starrin, B., \& Flacking, R. (2015). Tough, sensitive and sincere: how adolescent boys manage masculinities and emotions. International Journal of Adolescence and Youth, 21(4), 486-498. http://dx.doi.org/10.1080/02673843.2015.1106414

Rando, T. (1993). Treatment of complicated mourning. Champaign, IL: Research Press.

Range, L.M. (2009). Adolescents and suicide. In D. Balk \& C.A. Corr (Eds.), Adolescent encounters with death, bereavement, and coping (pp. 81-98). NY: Springer Publishing Company. 
Range, L.M. \& Calhoun, L.G. (1990). Responses following suicide and other types of death: The perspective of the bereaved. OEMGA Journal of Death \& Dying, 21(4), 311-320. doi:10.2190/LLE5-7QNT-7M59-GURY

Rapley, T.J. (2001). The art(fullness) of open-ended interviewing: some considerations on analysing interviews. Qualitative Research, 1(3), 303-323. doi:10.1177/146879410100100303

Rapport, F. \& Wainright, P. (2006). Phenomenology as a paradigm of movement. Nursing Inquiry, 13, 3, 228-236. doi:10.1111/j.1440-1800.2006.00325.x

Read, S. (2014). Supporting people with intellectual disabilities experiencing loss and bereavement: Theory and compassionate practice. London: Jessica Kingsley Publishers.

Reynolds, S. \& Austin, W. (2000). Nursing, empathy and perception of the moral. Journal of Advanced Nursing, 32(1), 235-242. doi:10.1046/j.13652648.2000.01440.x

Rheingold, A.A., Smith, D.W., Ruggiero, K.J., Saunders, B.E., Kilpatrick, D.G. \& Resnick, H.S. (2004). Loss, trauma exposure, and mental health in a representative sample of 12-17-year-old youth: Data from the national survey of adolescents. Journal of Loss \& Trauma, 9(1), 1-19. http://dx.doi.org/10.1080/15325020490255250

Richardson, C.A. \& Raibee, F. (2001). A question of access: An exploration of the factors that influence the health of young males aged 15 to 19 living in Corby and their use of health care services. Health Education Journal, 60(1), 3-16.

Richardson, L., \& Adams St. Pierre, E. (2008). Writing: A method of inquiry. In N. K. Denzin, \& Y. S. Lincoln (Eds.), Collecting and interpreting qualitative materials ( $3^{\text {rd }}$ ed.). (pp. 473-500). Thousand Oaks, CA: Sage.

Richardson, V.E., \& Balaswamy, S. (2001). Coping with bereavement among elderly widowers. Omega, 43(2), 129-144. doi:10.2190/Y2Q6-BB75-ENM7-BBYR

Riemen, D.J. (1983). The essential structure of a caring interaction: A phenomenological study. A dissertation submitted in partial fulfilment of the requirements for the degree of Doctor of Philosophy in the Graduate School of the Texas Woman's University, College of Nursing, Texas. http://poar.twu.edu/handle/11274/4862 
Riemen, D. J. (1998). The essential structure of a caring interaction: Doing phenomenology. In John W. Creswell (Ed.), Qualitative inquiry and research design: Choosing among five traditions (pp. 272-295). Thousand Oaks, CA: Sage.

Ringler, L.L. \& Hayden, D.C. (2000). Adolescent bereavement and social support: Peer loss compared to other losses. Journal of Adolescent Research, 15(2), 209-230.

Ritchie, J., Lewis, J. \& Elam, G. (2003). Designing and selecting samples. In J. Ritchie \& J. Lewis (Eds.), Qualitative research practice: A guide for social science students and researchers (pp. 77-108). Thousand Oaks, CA: Sage.

Roberts, G. (2000). Narrative and severe mental illness: What place do stories have in an evidence-based world? Advances in Psychiatric Treatment, 6(6), 432-441. doi:10.1192/apt.6.6.432

Robertson, S., White, A., Gough, B., Robinson, M., Seims, A., Raine, G. \& Hanna, E. (2015). Promoting mental health and wellbeing with men and boys: What works? Centre for Men's Health. Leeds: Leeds Beckett University. doi:978-1907240-41-6 (ISBN) http://eprints.leedsbeckett.ac.uk/1508/

Robinson, J., Pirkis, J., Krysinska, K., Niner, S., Jorm, A., Dudley, M., ...Harrigan, S. (2008). Research priorities in suicide prevention in Australia: A comparsion of current research efforts and stakeholder-identified priorities. Crisis, 29(4), 180190. http://dx.doi.org/10.1027/0227-5910.29.4.180

Romanoff, B.D. (1998). Rituals and the grieving process. Death Studies, 22(8), 697711. http://dx.doi.org/10.1080/074811898201227

Rosenblatt, P.C. (1988). Grief: The social context of private feelings. Journal of Social Issues, 44(3), 67-78. doi:10.1111/j.1540-4560.1988.tb02077.x

Rossetto, K.R. (2014). Qualitative research interviews: Assessing the therapeutic value and challenges. Journal of Social and Personal Relationships, 31(4), 482-489. doi:10.1177/0265407514522892

Rothaupt, J., \& Becker, K. (2007). A literature review of western bereavement theory: from decathecting to continuing bonds. The Family Journal, 15(1), 6-15. doi:10.1177/1066480706294031

Rubin, J.A. (2016). Approaches to Art Therapy: Theory and technique. (3 ${ }^{\text {rd }}$ ed.). NY: Routledge. 
Rubin, S.S. (1992). Adult child loss and the two-track model of bereavement. Omega, 24(3), 183-202. doi:10.2190/2V09-H301-YMGG-M065

Runeson, B., \& Åsberg, M. (2003). Family history of suicide among suicide victims. American Journal of Psychiatry, 160(8), 1525-1526.

https://doi.org/10.1176/appi.ajp.160.8.1525

Rusner, M. (2004). Mod att sätta sitt eget välbefinnande på spel och att handla enligt sin vilja [Having the Courage to Jeopardize Your Own Well-Being and Act According to Your Own Will]. D-Uppsats, Institutionen för vårdvetenskap, Högskolan i Borås.

Saldana, J. (2008). Ethnodrama and ethnotheatre. In J.G. Knowles \& A.L. Cole (Eds.), Handbook of the Arts in Qualitative Research (pp. 195-207). Los Angeles, CA: Sage.

Saldana, J. (2011). Fundamentals of research: Understanding qualitative research. NY: Oxford University Press.

Salganik, M.J. \& Heckathorn, D.D. (2004). Sampling and estimation in hidden populations using respondent-driven sampling. Sociological Methodology, 34(1), 193-239. doi:10.1111/j.0081-1750.2004.00152.x

Sandelowksi, M. (1995). Sample size in qualitative research. Research in Nursing \& Health, 18, 179-183. doi:10.1002/nur.4770180211

Sandelowski, M. (2000). Focus on Research Methods - Whatever happened to qualitative description? Research in Nursing \& Health, 23, 334-340.

Sandelowski, M. (2010). What's in a name? Qualitative description revisited. Research in Nursing \& Health, 33, 77-84. doi:10.1002/nur.20362

Sanders, J., Munford, R., Liebenberg, L. \& Henaghan, M. (2014). Show some emotion?: Research dilemmas in undertaking research with vulnerable youth. Field Methods, 26(3), 239-251 doi:10.1177/1525822X13516842

Sandler, I.N., Wolchik, S.A. \& Ayers, T.S. (2007). Resilience rather than recovery: A contextual framework for adaptation following bereavement. Death Studies, 32(1), 59-73. http://dx.doi.org/10.1080/07481180701741343

Sands, D. (2009). A tripatriate model of suicide grief: Meaning-making and the relationship with the deceased. Grief Matters, 12(1), 10-17. 
Sands, D.A. \& Tenant, M. (2010). Transformative learning in the context of suicide bereavement. Adult Education Quarterly, 60(2) 99-121 doi:10.1177/0741713609349932

Schachter, S. (1991). Adolescent experiences with the death of a peer. Omega: Journal of Death and Dying, 24(1), 1-11.

Schaub, M., \& Williams, C. (2007). Examining the relations between masculine gender role conflict and men's expectations about counseling. Psychology of Men \& Masculinity, 8(1), 40 -52. http://psycnet.apa.org/doi/10.1037/1524-9220.8.1.40

Schwalbe, M.L. \& Wolkomir, M. (2002). Interviewing men. In J.A. Holstein, \& J.F. Gubrium (Eds.), Inside interviewing: New lenses, new concerns (pp. 55-72). Thousand Oaks, CA: Sage.

Schnider, K.R. Elhai, J.D. \& Gray, M.J. (2007). Coping style use predicts posttraumatic stress and complicated grief symptom severity among college students reporting a traumatic loss. Journal of Counseling Psychology, 54(3), 344-350. http://psycnet.apa.org/doi/10.1037/0022-0167.54.3.344

Schut, H. \& Stroebe, M. (2005). Interventions to enhance adaptation to bereavement. Journal of Palliative Medicine, 8(Suppl 1), S140-147. https://doi.org/10.1089/jpm.2005.8.s-140

Servaty-Seib, H. (2009). Death of a friend during adolescence. In D. Balk \& C.A. Corr (Eds.), Adolescent encounters with death, bereavement, and coping (pp. 217235). NY: Springer Publishing Company.

Servaty-Seib, H.L. \& Pistole, M.C. (2006). Adolescent grief: Relationship category and emotional closeness. Omega: Journal of Death and Dying, 54(2), 147-167.

Shenton, A.K. (2004). Strategies for ensuring trustworthiness in qualitative research projects. Education for Information, 22(2), 63-75. doi:10.3233/EFI-200422201

Shewchuk, D. (2015). Numinous/transformative experiences as one way to building resiliency. BC Psychologist, 4(3), 18-20.

Shipman, M. (2014). Limitations of social research (4 ${ }^{\text {th }}$ ed.). NY: Routledge.

Shneidman, E. S. (1993). Suicide as psychache: A clinical approach to self-destructive behaviour. NJ: Jason Aronson. 
Shoveller, J.A., Knight, R., Johnson, J., Oliffe, J., \& Goldenberg, S. (2010). 'Not the swab!' Young men's experiences with STI testing. Sociology of Health \& Illness, 32(1), 57-73. doi:10.1111/j.1467-9566.2009.01222.x

Silverman, H. (1987). Inscriptions: Between Phenomenology and Structuralism. NY: Routledge Kegan Paul.

Sklar, F. \& Hartley, S.F. (1990). Close friends as survivors: Bereavement patterns in a "hidden" population. Omega: Journal of Death \& Dying, 21(2), 103-112.

Smith, A., Joseph, S. \& Das Nair, R. (2011). An interpretative phenomenological analysis of posttraumatic growth in adults bereaved by suicide. Journal of Loss and Trauma, 16(5), 413-430. http://dx.doi.org/10.1080/15325024.2011.572047

Smith, J.A. (1996). Beyond the divide between cognition and discourse. Using interpretative phenomenological analysis in health psychology. Psychology and Health, 11(2), 261-271. http://dx.doi.org/10.1080/08870449608400256

Smith, J. A. (2003). Validity and qualitative psychology. In J. A. Smith (Ed.), Qualitative Psychology: A Practical Guide to Research Methods (pp. 232235). London: Sage.

Smith, J. A. (2007). Hermeneutics, human sciences and health: linking theory and practice. International Journal of Qualitative Studies in Health and Well-being, 2(3), 3-11. http://dx.doi.org/10.1080/17482620601016120

Smith, JA. (2011). Evaluating the contribution of interpretive phenomenological analysis. Health Psychology Review, 5(1), 9-27. http://dx.doi.org/10.1080/17437199.2010.510659

Smith, J.A., Braunack-Mayer, A., Wittert, G., \& Warin, M. (2008). 'It's sort of like being a detective': Understanding how Australian men self-monitor their health prior to seeking help. BC Health Services Research, 8(56), doi:10.1186/14726963-8-56

Smith, J.A. \& Osborn, M. (2008). Interpretive phenomenological analysis. In J. A. Smith (Ed.), Qualitative Psychology: A Practical Guide to Research Method (pp. 53-80). London: Sage.

Spiegelberg, H. (1975). Doing phenomenology. Dordrecht, the Netherlands; Martinus Nijhoff.

Spradley, J.P. (1979). The ethnographic interview. Longrove, Illinois: Waveland Press Inc. 
Sque, M.R. (2000). Researching the bereaved: An investigator's experience. Nursing Ethics, 7(1), 23-34.

Starks, H. and Trinidad, S. B. (2007). Choose your method: A comparison of phenomenology, discourse analysis, and grounded theory. Qualitative Health Research 17(10), 1372-80. doi:10.1177/1049732307307031

Staudacher, C. (1991). Men and grief. Oakland, CA: New Harbringer Publications.

Stein, C.H. Abraham, K.M., Bonar, E.E., McAuliffe, C.E., Fogo, W.R., Faigin, D.A. ...Potokar, D.N. (2009). Making meaning from personal loss: Religious, benefit-finding, and goal-oriented attributions. Journal of Loss and Trauma, 14(2), 83-100. http://dx.doi.org/10.1080/15325020802173819

Steiner, C.S. (2003). Emotional literacy: Intelligence with a heart. Fawnskin, California: Personhood Press.

Strauss, A. \& Corbin, J. (1998). Basics of qualitative research: techniques and procedures for developing grounded theory. ( $2^{\text {nd }}$ ed.). Newbury Park, California: Sage.

Streubert, S.H. \& Carpenter, D. (2007). Qualitative research in nursing: Advancing the humanistic perspective. (4 ${ }^{\text {th }}$ ed.). Philadelphia: Lippincott Williams \& Wilkins.

Stroebe, M.S., Hansson, R.O., Schut, H. \& Stroebe, W. (2008). Bereavement research: $21^{\text {st }}$-century prospects. In M.S. Stroebe, R.O, Hansson, H. Schut \& W. Stroebe (Eds.), Handbook of bereavement research and practice: Advances in theory and intervention (pp. 577-603). Washington DC: American Psychological Association.

Stroebe, M., Hansson, R., Stroebe, W., \& Schut, H. (2001). Future directions in bereavement research. In M. Stroebe, R. Hansson, W. Stroebe, \& H. Schut (Eds.), Handbook of bereavement research: Consequences, coping and care (pp. 741-766). Washington, DC: American Psychological Association.

Stroebe, M.S. \& Schut, H. (1999). The dual process model of coping with bereavement: rationale and description. Death Studies, 23(3), 197-224. http://dx.doi.org/10.1080/074811899201046

Stroebe, M. \& Schut, H. (2010). The dual process model of coping with bereavement: A decade on. OMEGA Journal of Death \& Dying, 61(4), 273-289 doi:10.2190/OM.61.4.b 
Stroebe, M., \& Stroebe, W. (1989). Who participates in bereavement research? A review and empirical study. Omega Journal of Death \& Dying, 20(1), 1-29.

Stroebe, M. S., Stroebe, W., \& Hansson, R. O. (1988). Bereavement research: An historical introduction. Journal of Social Issues, 44(3), 1-18. doi:10.1111/j.1540-4560.1988.tb02073.x

Stroebe, M., Stroebe, W., \& Schut, H. (2003). Bereavement research: methodological issues and ethical concerns. Palliative Medicine, 17(3), 235-240.

Suicide Prevention Australia. (2008). Position statement: Suicide prevention and capacity building in Australian Indigenous communities. Retrieved from http://suicidepreventionaust.org/Media.aspx\#section-29

Suicide Prevention Australia. (2009). Position statement: Suicide bereavement and postvention. Retrieved from http://suicidepreventionaust.org/Media.aspx\#section-29

Sutton, L.B., Erlen, J.A., Glad, J.M. \& Siminoff, L.A. (2003). Recruiting vulnerable populations for research: Revisiting the ethical issues. Journal of Professional Nursing, 19(2), 106-112. https://doi.org/10.1053/jpnu.2003.16

Sveen, C.A. \& Walby, F.A. (2008). Suicide survivors' mental health and grief reactions: A systematic review of controlled studies. Suicide \& Life-Threatening Behavior, 38(1), 13-29. doi:10.1521/suli.2008.38.1.13

Swanson-Kauffman, K.M. \& Schonwald, E. (1988). Phenomenology. In B. Sarter (Ed.), Paths to knowledge: Innovative research methods for nursing (pp. 97-105). NY: National League for Nursing.

Swihart, J., Silliman, B., \& McNeil, J. (1992). Death of a student: Implications for secondary school counselors. School Counselor, 40(1), 55-60. http://www.jstor.org/stable/23900831

Tedeschi, R.G., \& Calhoun, L.G. (2004). Posttraumatic growth: Conceptual foundations and empirical evidence. Psychological Inquiry, 15(1), 1-18. http://dx.doi.org/10.1207/s15327965pli1501_01

Tedeschi, R.G., Calhoun, L.G. \& Cann, A. (2007). Evaluating resource gain: Understanding and Misunderstanding Posttraumatic Growth. Applied Psychology: An International Review, 56(3), 396-406. doi:10.1111/j.14640597.2007.00299.x

Tedeschi, R., Park, C. \& Calhoun, L. (Eds.). (1998). Posttraumatic growth: Positive changes in the aftermath of crisis. Mahwah, NJ: Lawrence Erlbaum. 
Tennant, M. (2005). Transforming selves. Journal of Transformative Education, 3(2), 102-115. doi:10.1177/1541344604273421

Thomassen, B. (2009). The uses and meanings of liminality. International Political Anthropology, 2(1), 5-28.

Tognoli, J. (1980). Male friendship and intimacy across the lifespan. Family Relations, 29(3), 273-279. http://www.jstor.org.stable/583846

Tracy, S.J. (2010). Qualitative quality: Eight "big-tent" criteria for excellent qualitative research. Qualitative Inquiry, 16(10) 837-851. doi:10.1177/1077800410383121

Trimble, T., Hannigan, B. \& Gaffney, M. (2012). Suicide postvention, coping, support and transformation. The Irish Journal of Psychology, 33(2-3), 115-121. http://dx.doi.org/10.1080/03033910.2012.709171

Trotter, R.T. (2012). Qualitative research sample design and sample size: resolving and unresolved issues and inferential imperatives. Preventive Medicine, 55(5), 398400. https://doi.org/10.1016/j.ypmed.2012.07.003

Tufford, L. \& Newman, P. (2010). Bracketing in qualitative research. Qualitative Social Work, 11(1), 80-96. doi:10.1177/1473325010368316

Updegraff, J.A. \& Taylor, S.E. (2000). From vulnerability to growth: Positive and negative effects of stressful life events. In J.H. Harvey \& E.D. Miller (Eds.), Loss and Trauma (pp. 3-21). Sussex: Brunner-Routledge.

Urlić, I. (2010). The phenomenon of silence: A group-analytic exploration of meanings in psychotherapy and in everyday life. Group Analysis, 43(3), 337-353. doi:10.1177/0533316410376152

Urry, Y., Sanders, J., Munford, R. (2014). The 'right time' - negotiating the timing of interviews with vulnerable young people. Journal of Youth Studies, 18(3), 291304 http://dx.doi.org/10.1080/13676261.2014.944120

Vaioleti, T. (2006). Talanoa research methodology: A developing position on Pacific research. Waikato Journal of Education, 12, 21-34.

Vaioleti, T. (2014). Talanoa: differentiating the Talanoa research methodology from phenomenology, narrative, Kaupapa Maori and feminist methodologies. Te Reo, 56-57, 191-212. 
Van Baarsen, B., Van Duijin, M.A.J. Smit, J.H., Snijders, T.A.B., \& Knipscheer, K.P.M. (2002). Patterns of adjustment to partner loss in old age: The widowhood adaptation longitudinal study. Omega, 44(1), 5-36. doi:10.2190/PDUX-BE94-M4EL-0PDK

Van Dongen, C. J. (1993). Social context of postsuicide bereavement. Death Studies, 17(2), 125-141. http://dx.doi.org/10.1080/07481189308252610

Van Humbeeck, L., Dillen, L., Piers, R., Grypdonck, M., Van Den Noorgate, N. (2016). The suffering in silence of older parents whose child died of cancer: A qualitative study. Death Studies, 40(10), 607-617. http://dx.doi.org/10.1080/07481187.2016.1198942

Van Manen, M. (1990). Researching lived experience: Human science for an action sensitive pedagogy. NY: State University of New York.

Van Manen, M. (2014). Phenomenology of practice: meaning-giving methods in phenomenological research and writing. CA: Left Coast Press.

Vik, T.A. \& Bute, J.J. (2009). Utilizing crystallization in qualitative methods. The Review of Communication, 9(4), 340-343. http://dx.doi.org/10.1080/15358590903151211

Vogel, D.L., Heimerdinger-Edwards, S.R., Hammer, J.H., \& Hubbard, A. (2011). "Boys don't cry": Examination of the links between endorsement of masculine norms, self-stigma, and help-seeking attitudes for me from diverse backgrounds. Journal of Counseling Psychology, 58(3), 368-382. http://psycnet.apa.org/doi/10.1037/a0023688

Walker, A.C. (2009). Adolescent bereavement and traumatic deaths. In D. Balk \& C.A Corr (Eds.), Adolescent encounters with death, bereavement, and coping (pp. 253-270). NY: Springer Publishing Company.

Walker, S., Eketone, A. \& Gibbs, A. (2006). An exploration of kaupapa Maori research, its principles, processes and applications. International Journal of Social Research Methodology, 9(4), 331-344. doi: 10.1080/1364557060916049

Wall, C., Glenn, S., Mitchinson, S., \& Poole, H. (2004). Using reflective diary to develop bracketing skills during a phenomenological investigation. Nurse Researcher, 11(4), 20-29. http://dx.doi.org/10.7748/nr2004.07.11.4.20.c6212

Walsh, F., \& McGoldrick, M. (1991). Living beyond loss. NY: Norton. 
Walter, T. (1996). A new model of grief: Bereavement and biography. Mortality, 1(1), 7-25. http://dx.doi.org/10.1080/713685822

Way, N. (2011). Deep secrets: Boys' friendships and the crisis of connection. Cambridge, MA: Harvard University Press.

doi:10.4159/harvard.9780674061361

Way, N., Cressen, J., Bodian, S., Preston, J., Nelson, J., \& Hughes, D. (2014). "It might be nice to be a girl... Then you wouldn't have to be emotionless": Boys resistance to norms of masculinity during adolescence. Psychology of Men \& Masculinity, 15(3), 241-252. http://psycnet.apa.org/doi/10.1037/a0037262

Webster, M. (2015). You're tougher than you think you are! BC Psychologist, 4(3), 13 14.

Wellington Regional Economic Development Agency (2016). Wellington facts \& figures. http://www.wellingtonnz.com/discover/life-in-wellington/facts-andfigures/

Wendler, D.S. (2006). Assent in Paediatric Research: Theoretical and practical considerations. Journal of Medical Ethics, 32(4), 229-234.

Weingarten, K. (2000). Witnessing, wonder, and hope. Family Process, 39(4), 389-402. doi:10.1111/j.1545-5300.2000.39401.x

Weller, S. C., \& Romney, A.K. (1988). Systematic data collection. Newbury Park, CA: Sage.

Wertz, F.J. (2005). Phenomenological research methods for counseling psychology. Journal of Counseling Psychology, 52(2), 167-177. http://psycnet.apa.org/doi/10.1037/0022-0167.52.2.167

Westwood, M.J. \& Ewasiw, J.F. (2011). Integrating narrative and action processes in group counselling practice: A multimodal approach for helping clients. The Journal for Specialists in Group Work, 36(1), 78-93. http://dx.doi.org/10.1080/01933922.2010.537738

Westwood, M.J., Keats, P.A. \& Wilensky, P. (2003). Therapeutic enactment: Integrating individual and group counselling models for change. The Journal for Specialists in Group Work, 28(2), 122-138. http://dx.doi.org/10.1177/0193392203028002004 
Westwood, M.J., McLean, H., Cave, D., Borgen, W., \& Slakov, P. (2010). Coming home: A group-based approach for assisting military veterans in transition. The Journal for Specialists in Group Work, 35(1), 44-68. http://dx.doi.org/10.1080/01933920903466059

White, B. (2011). Mapping your thesis: The comprehensive manual of theory and techniques for masters and doctoral research. Victoria, Australia: ACER Press.

White, M. \& Epston, D. (1990). Narrative means to therapeutic ends. NY: Norton.

White, R. (2002). Social and political aspects of men's health. Health: An Interdisciplinary Journal for the Social Study of Health, Illness and Medicine, 6(3), 267-285.

WHO (2014). Preventing suicide: A global imperative. Geneva: WHO. http://www.who.int/mental_health/suicide-prevention/world_report_2014/en/

WHO (2015). Suicide data. Geneva: WHO http://www.who.int/mental_health/prevention/suicide/suicideprevent/en/

Williams, A.L. \& Merten, M.J. (2009). Adolescent's online social networking following the death of a peer. Journal of Adolescent Research, 24(1), 67-90.

Wilkes, L., Cummings, J., \& Haigh, C. (2014). Transcriptionist saturation: knowing too much about sensitive health and social data. Journal of Advanced Nursing, 71(2), 295-303. doi:10.1111/jan.12510

Wilson, A. \& Marshall, A. (2010). The support needs and experiences of suicidally bereaved family and friends. Death Studies, 34(7), 625-640. http://dx.doi.org/10.1080/07481181003761567

Wojnar, D. M. (2005). Miscarriage experiences of lesbian birth and social mothers. Doctoral dissertation, University of Washington, Seattle. ProQuest Digital Dissertations, AAT No. 3178122.

Wojnar, D.D., \& Swanson, K.M. (2007). Phenomenology: An exploration. Journal of Holistic Nursing, 25(3), 172-180. doi:10.1177/0898010106295172

Worden, J.W. (2003). Grief counselling and grief therapy: A handbook for the mental health practitioner, Hove, East Essex: Brunner-Routledge.

Worden, J.W. (2008). Grief counselling and grief therapy: A handbook for the mental health practitioner $\left(4^{\text {th }}\right.$ ed.). NY: Springer. 
Worthen, M.G.F. (2012). Gender differences in delinquent involvement: An exploration of the interactive effects of friend bonding and friend delinquency.

Sociological Focus, 45(2), 103-124.

http://dx.doi.org/10.1080/00380237.2012.657107

Wray, N., Markovic, M., \& Manderson, L. (2007). "Researcher saturation”: The impact of data triangulation and intensive-research practices on the researcher and qualitative research process. Qualitative Health Research, 17(10), 1392-1402. doi: $10.1177 / 1049732307308308$

Young, I. T., Igelwicz, A., Glorioso, D., Lanouette, N., Seay, K., Ilapakurti, M. \& Zisook, S. (2012). Suicide bereavement and complicated grief. Dialogues in Clinical Neuroscience, 14(2), 177-186.

Zion, D., Gillam, L. \& Loff, B. (2000). The declaration of Helsinki, CIOMS and the ethics of research on vulnerable populations. Nature America, 6(6), 615-617. 


\title{
APPENDICES
}

Appendix 1: Human Ethics Committee (VUW) approval letter

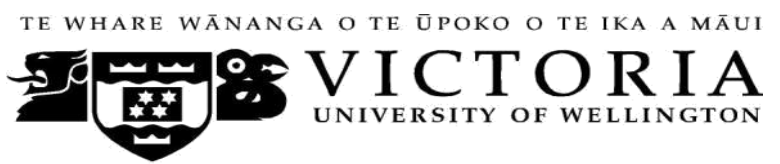

MEMORANDUM

Phone 0-4-463 5676

Fax 0-4-463 5209

Allison.kirkman@vuw.

Email ac.nz

\begin{tabular}{l|l}
\hline TO & Christopher Bowden \\
\hline COPY TO & $\begin{array}{l}\text { Elizabeth Banister } \\
\text { Kay de Vries }\end{array}$ \\
\hline FROM & Dr Allison Kirkman, Convener, Human Ethics Committee \\
\hline
\end{tabular}

\begin{tabular}{l|l}
\hline DATE & 16 October 2012 \\
\hline PAGES & 1 \\
\hline
\end{tabular}

SUBJECT Ethics Approval: 19518

Losing a close friend to suicide: A study of the experiences of young adult men

Thank you for your application for ethical approval, which has now been considered by the Standing Committee of the Human Ethics Committee.

Your application has been approved from the above date and this approval continues until 31 December 2014. If your data collection is not completed by this date you should apply to the Human Ethics Committee for an extension to this approval.

Best wishes with the research.

\author{
Allison Kirkman \\ Human Ethics Committee
}




\section{Appendix 2: Participant information sheet}

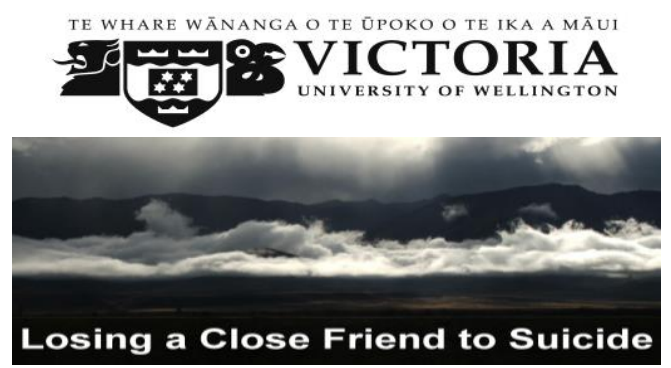

Title: Losing a close friend to suicide: A study of the experiences of young adult men.

\section{Principal Investigator: Chris Bowden}

I am a PhD student with the Graduate School of Nursing, Midwifery and Health and lecturer in the School of Education at Victoria University of Wellington. I teach courses in human development and youth issues, have worked in the area of suicide prevention and facilitate a grief education programme for adults who have been bereaved by suicide.

\section{Why is the research being done?}

New Zealand has a high rate of suicide among young people, particularly young men, aged 1524 years of age. Research shows us that suicide has a number of negative effects on the people left behind. We know very little about how young adults, in particular, young men, experience the suicide of a close friend.

- I am interested in hearing about the experiences of 17-25 year old men who have lost a close friend (male or female) to suicide in the past 6 months to 3 years. I want to know how they grieve, their experiences of support, the impact of the loss and suicide on their life, and what it means to lose a close friend to suicide.

- This research will be used to inform further research on suicide bereavement, improve support and services for men, and public health education about suicide bereavement, grief and loss in young adults.

\section{Participation (Do I have to take part?)}

- Your participation in the study is entirely voluntary (your choice). If you decide to take part you will be asked to sign a consent form to show you have agreed to take part.

- Participation in the study is confidential and no one (family/whānau, friends, counsellor, GP etc) will be told that you are being interviewed without your consent.

- You can withdraw from the study at any time prior to the interview and you can also stop and withdraw from the interview/s at any time. You can also withdraw your data from the study up to two weeks after the final interview.

- Participating in the study will not cost you any money, and you will be reimbursed the cost of any travel to and from interviews, but you will not be paid to participate in the research.

\section{The interview/s (What will I have to do?)}

- In the interview/s (which will be conversational in style) you will discuss your experiences of losing a close friend to suicide. This means that you can go at your own pace, talk about your experiences in depth and express your ideas in your own ways. The interview/s will take place on an agreed date, time and quiet place such as your home, a room at a community centre or the researcher's office. You can also bring a support person to the interview.

- You may like to bring some objects (photos of your friend or events, music, a piece of writing) to the interview to help you tell your story and share your experiences. 
- Interviews will be audio-recorded and may take 1-2 hours, but can be broken up into shorter lengths and multiple interviews if you wish.

- You will be given the option of having a follow-up interview in case there is anything else you might want to add.

- You will also have the opportunity to review the transcript of your interview and summary of key themes.

\section{Benefits and risks of being a participant (Why should I take part)?}

- Some people find it beneficial talking through their experiences of loss following suicide. You may also be able to help other young men like you because you have valuable experiences, views and ideas that can inform understanding and the development of better support for young men.

- If you become upset or distressed during the interview the interview can be stopped. You may choose to withdraw from the study, reschedule the interview, or take a short break until you feel comfortable. I will also discuss with you what supportive networks and activities are available to you, and provide you with some information about local crisis counselling and support services. I will also provide a one-off debriefing session with an experienced suicide bereavement counsellor for you (free of charge) if required.

\section{What about the privacy and confidentiality of the information I provide?}

- The only people who will have access to interview transcripts or any notes are myself and my research supervisors. Names will not be included on printed transcripts or audio recordings/files. All data will be stored securely in a locked cabinet at Victoria University for 10 years and any electronic files, recordings or data will be stored on a personal password protected computer for 10 years and then destroyed. While all steps will be taken to protect your identity a small possbility exists that someone who knows you very well may be able to identify you even from this small amount of information.

- The only time I will have to breach confidentiality is if I feel or you disclose during the interview or any other time we speak, that you (or those close to you) are at risk of harm. I will discuss my concerns with you and what information will be passed on to my supervisors and appropriate services.

\section{What will happen to this research study?}

The results of this research will be published variously in summary form, such as in professional journals, conference papers, and in seminars/professional training and education. A full copy of the study, in the form of a thesis, will be deposited in the Victoria University of Wellington Library. You may request a summary report of the overall study by filling in the appropriate details on the bottom of the Consent Form. The research study is expected to be completed by Dec 2016.

\section{Research rights}

In New Zealand all research involving human participantss must be approved by an Ethics Committee, which may be contacted if you have any concerns. Ethics approval has been granted for this study by the Victoria University of Wellington Human Ethics Committee (Reference Number 19158).

You can also contact me:

Chris Bowden: PhD Student

Graduate School of Nursing, Midwifery and

Health, Victoria University of Wellington

Mobile:

Work:

Email:
Or my supervisors:

Prof. Elizabeth Banister

Phone:

Email:

Dr. Kay de Vries

Phone:

Email: 


\section{Appendix 3: Participant consent form}

\section{Participant Consent Form}

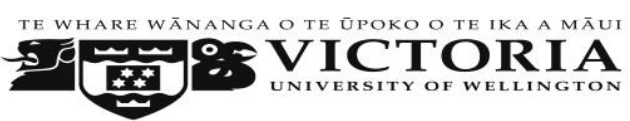

Losing a close friend to suicide: A study of the experiences of young adult men (17-25 years of age).

\section{Principal Investigator: Chris Bowden}

\begin{tabular}{|l|l|l|l|}
\hline English & I wish to have an interpreter. & Yes & No \\
\hline Maori & E hiahia ana ahau ki tetahi kaiwhakamaori/kaiwhaka pakeha korero. & $\mathrm{Ae}$ & Kao \\
\hline Cook Island & Ka inangaro au i tetai tangata uri reo. & $\mathrm{Ae}$ & Kare \\
\hline Fijian & Au gadreva me dua e vakadewa vosa vei au & Io & Sega \\
\hline Niuean & Fia manako au ke fakaaoga e taha tagata fakahokohoko kupu. & E & Nakai \\
\hline Samoan & Ou te mana'o ia i ai se fa'amatala upu. & Ioe & Leai \\
\hline Tokelauan & $\begin{array}{l}\text { Ko au e fofou ki he tino ke fakaliliu te gagana Peletania ki na gagana o na } \\
\text { motu o te Pahefika }\end{array}$ & Ioe & Leai \\
\hline Tongan & Oku ou fiema'u ha fakatonulea. & Io & Ikai \\
\hline
\end{tabular}

I have read and understood the Information Sheet dated 16/10/2012 on Losing a close friend to suicide: A

study of experiences of young adult men.

I have had the opportunity to consider the information, ask questions and discuss this study. My questions have been answered satisfactorily.

I have had the opportunity to use family or whānau support or a friend to help me ask questions and understand the study.

I understand that taking part in this study is voluntary (my choice) and know that I may withdraw from the study at any time and up to two weeks after the interview/s, but after that the interview would become part of the research data.

I understand that any information I provide will be kept confidential to the Researcher (Chris Bowden), his supervisors, Prof. Elizabeth Banister and Dr. Kay de Vries, his clinical supervisor and the person who transcribes the recordings of my interview(s). The published results will not use my name, information identifying location of events and people will be disguised or removed, and that no opinions will be attributed to me in any way that will identify me.

I understand that there is no payment for my or anyone else's participation.

I understand that the audio-recorded interview will be destroyed at the end of the project, and that the transcribed interviews will be retained in storage for 10 years, after which they will be destroyed.

I have had time to consider whether to take part.

I agree to the interview being audio-taped.

I would like a summary of the interview/s transcript

I would like a copy of the interview

I would like a summary of the overall research results

Address for interview transcript and summary
YES / NO
YES / NO
YES / NO
YES / NO
YES / NO

Signature Date

Project explained by 


\section{Appendix 4: Semi-Structured interview guide}

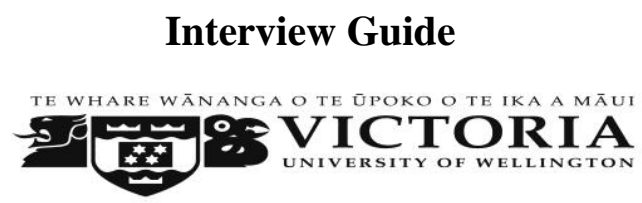

Losing a close friend to suicide: A study of the experiences of young adult men.

\section{Principal Investigator: Chris Bowden}

I want to understand your experience of losing a close friend to suicide. I am looking for a description of your experience and what losing a friend to suicide was like for you.

Experiences of the relationship

1. Can you tell me about your relationship/friendship with (name of deceased)?

Experiences of loss

2. When relationships come to an end, people can experience a sense of loss, because they no longer have access to that important person. How would you describe your loss and life without your friend?

Experiences of grief

3. People grieve for their losses in many different ways. Can you tell me about when the suicide happened and how you reacted and responded the loss of your friend? [experience of the loss event and grief]

Experience of bereavement

4. People are affected by suicide differently. How has the loss/suicide of your friend affected you, your relationships with others and your life? What has changed or stayed the same?

Wrap Up Questions

5. Is there anything else you want to tell me about your experience that we have not discussed?

6. Would you be willing for me to contact you with any follow-up questions I may have about what we have discussed?

7. If over the next two weeks you remember something you would like to add, you can contact me.

Prompts (to clarify any ambiguous, missing, confusing information)

Prompts to gain further description

- How did that happen? When did that occur?

- You mentioned......can you tell me a little more about this event/experience?

- You talked about... what was your reaction to this?

- Can you tell me more about the events that led up to this?

- Can you give me another example of that? What else?

Probes to clarify meaning

- What did that mean for you?

- What was that like?

Probes to encourage participant introspection and reflection

- What is an example of that?

- Why do you think that happened?

- What were your thoughts at the time?

- Can you tell me more about why this was so significant to you? 


\section{Appendix 5: Participant demographics}

\begin{tabular}{|c|c|c|c|c|c|c|c|c|c|c|c|c|}
\hline Participant & Age & Ethnicity & Occupation & $\begin{array}{l}\text { Education } \\
\text { Level }\end{array}$ & $\begin{array}{l}\text { Relationship } \\
\text { Status }\end{array}$ & $\begin{array}{l}\text { Religious } \\
\text { Affiliation }\end{array}$ & $\begin{array}{l}\text { Time Since } \\
\text { Bereavement/s }\end{array}$ & $\begin{array}{l}\text { Time } \\
\text { Known }\end{array}$ & Deceased & $\begin{array}{l}\text { Age of } \\
\text { deceased }\end{array}$ & $\begin{array}{l}\text { Method } \\
\text { of } \\
\text { suicide }\end{array}$ & $\begin{array}{l}\text { Support } \\
\text { Offered or } \\
\text { Accessed }\end{array}$ \\
\hline Coby & 19 & NZ/European & Manager & $\begin{array}{l}\text { NZQA } \\
\text { Level2, Nat } \\
\text { Cert Level2 }\end{array}$ & Separated & None & 1 year & $7 \mathrm{yrs}$ & Devon & $17 \mathrm{yrs}$ & Hanging & Family \\
\hline Jace & 17 & NZ/European & Student & $\begin{array}{l}\text { NCEA } \\
\text { Level2 }\end{array}$ & Defacto & None & $\begin{array}{l}1 \text { year } \\
1 \text { year }\end{array}$ & $17 \mathrm{yrs}$ & $\begin{array}{l}\text { Devon } \\
\text { Dave }\end{array}$ & $\begin{array}{l}17 \mathrm{yrs} \\
16 \mathrm{yrs}\end{array}$ & $\begin{array}{l}\text { Hanging } \\
\text { Hanging }\end{array}$ & $\begin{array}{ll}\text { Family } \quad \& \\
\text { Friends }\end{array}$ \\
\hline Fin & 17 & NZ/European & Automotive & $\begin{array}{l}\text { NCEA } \\
\text { Level2 }\end{array}$ & Single & None & $\begin{array}{l}1 \text { year } \\
1 \text { year }\end{array}$ & 12 yrs & $\begin{array}{l}\text { Devon } \\
\text { Dave }\end{array}$ & $\begin{array}{l}17 \mathrm{yrs} \\
16 \mathrm{yrs}\end{array}$ & $\begin{array}{l}\text { Hanging } \\
\text { Hanging }\end{array}$ & $\begin{array}{l}\text { Family \& } \\
\text { Friends }\end{array}$ \\
\hline Rod & 19 & Māori & Automotive & $\begin{array}{l}\text { NCEA } \\
\text { Level2 }\end{array}$ & Defacto & None & $\begin{array}{l}1 \text { year } \\
1 \text { year }\end{array}$ & $5 \mathrm{yrs}$ & $\begin{array}{l}\text { Devon } \\
\text { Dave }\end{array}$ & $\begin{array}{l}17 \mathrm{yrs} \\
16 \mathrm{yrs}\end{array}$ & $\begin{array}{l}\text { Hanging } \\
\text { Hanging }\end{array}$ & $\begin{array}{l}\text { Family \& } \\
\text { Friends }\end{array}$ \\
\hline Luke & 25 & NZ/European & $\begin{array}{l}\text { Web } \\
\text { Developer }\end{array}$ & $\begin{array}{l}\text { BSC Comp } \\
\text { Sci }\end{array}$ & Single & Agnostic & 3 years & $10 \mathrm{yrs}$ & Phil & $21 \mathrm{yrs}$ & Gunshot & None \\
\hline Adam & 25 & NZ/European & $\begin{array}{l}\text { Admin } \\
\text { Officer }\end{array}$ & $\begin{array}{l}\text { NCEA } \\
\text { Level2 }\end{array}$ & Defacto & None & 3 years & $8 \mathrm{yrs}$ & Phil & $21 \mathrm{yrs}$ & Gunshot & $\begin{array}{l}\text { EAP, } \\
\text { Family \& } \\
\text { Friends }\end{array}$ \\
\hline Max & 25 & NZ/European & IT & UE & Defacto & None & 3 years & $\begin{array}{l}3 \text { yrs } 4 \\
\text { mths }\end{array}$ & Phil & $21 \mathrm{yrs}$ & Gunshot & $\begin{array}{lr}\text { GP } \quad \& \\
\text { Counselling }\end{array}$ \\
\hline Harley & 22 & Samoan/European & Receptionist & $\begin{array}{l}\text { NZCEA } \\
\text { Level1 }\end{array}$ & Single & Mormon & 2 years $10 \mathrm{mths}$ & 4 years & Kane & $17 \mathrm{yrs}$ & Jumping & Counselling \\
\hline
\end{tabular}


Appendix 6: Datasets generated from the interviews

\begin{tabular}{|c|c|c|c|c|c|}
\hline Interview & Participant/s & Date & $\begin{array}{l}\text { Interview } \\
\text { length } \\
\text { (mins) }\end{array}$ & $\begin{array}{l}\text { Pages of } \\
\text { transcript }\end{array}$ & Field Notes \\
\hline 1 & Coby & $5-4-2013$ & 95 & 55 & $\begin{array}{l}13 \text { mins } \\
5 \text { pages }\end{array}$ \\
\hline 2 & $\begin{array}{l}\text { Rod, Fin \& } \\
\text { Jace }\end{array}$ & $27-4-2013$ & 60 & 61 & $\begin{array}{l}20 \text { mins } \\
6 \text { pages }\end{array}$ \\
\hline 3 & Adam & $17-9-2013$ & 60 & 30 & $\begin{array}{l}12 \text { mins } \\
3 \text { pages }\end{array}$ \\
\hline 4 & Luke & $19-9-2013$ & 68 & 26 & $\begin{array}{l}11 \text { mins } \\
3 \text { pages }\end{array}$ \\
\hline 5 & Max & $21-9-2013$ & 131 & 29 & $\begin{array}{l}10 \text { mins } \\
3 \text { pages }\end{array}$ \\
\hline 6 & Coby & $21-10-2013$ & 120 & 46 & $\begin{array}{l}11 \text { mins } \\
3 \text { pages }\end{array}$ \\
\hline 7 & Fin \& Jace & $27-10-2013$ & 120 & 58 & $\begin{array}{l}5 \text { mins } \\
1 \text { page }\end{array}$ \\
\hline 8 & Luke & $21-11-2013$ & 148 & 36 & $\begin{array}{l}10 \text { mins } \\
3 \text { pages }\end{array}$ \\
\hline 9 & Adam & $26-11-2013$ & 121 & 38 & $\begin{array}{l}10 \text { mins } \\
3 \text { pages }\end{array}$ \\
\hline 10 & Max & $30-11-2013$ & 131 & 36 & $\begin{array}{l}11 \text { mins } \\
3 \text { pages }\end{array}$ \\
\hline 11 & Harley & $2-12-2013$ & 65 & 33 & $\begin{array}{l}10 \text { mins } \\
3 \text { pages }\end{array}$ \\
\hline \multirow[t]{2}{*}{12} & Rod & $15-12-2013$ & 80 & 35 & $\begin{array}{l}12 \text { mins } \\
3 \text { pages }\end{array}$ \\
\hline & & & $\begin{array}{l}1,199 \\
\text { mins } \\
19.2 \mathrm{hrs}\end{array}$ & 483 pages & $\begin{array}{l}135 \text { mins } \\
39 \text { pages }\end{array}$ \\
\hline
\end{tabular}




\begin{tabular}{|c|c|c|c|c|}
\hline Theme & $\begin{array}{l}\text { Category } \\
\text { /Cluster }\end{array}$ & $\begin{array}{l}\text { Code/Meaning } \\
\text { Unit }\end{array}$ & $\begin{array}{l}\text { Transformed } \\
\text { meaning unit }\end{array}$ & $\begin{array}{l}\text { Example of meaning unit/significant } \\
\text { statement }\end{array}$ \\
\hline \multirow[t]{6}{*}{ Stoicism } & $\begin{array}{l}\text { Keeping } \\
\text { Busy }\end{array}$ & $\begin{array}{l}\text { Cognitive } \\
\text { Distraction }\end{array}$ & $\begin{array}{l}\text { Keeping busy at } \\
\text { work helps Coby } \\
\text { not think about the } \\
\text { loss of his friend. }\end{array}$ & $\begin{array}{l}\text { All that new responsibility just } \\
\text { keeps my mind busy every day. If I } \\
\text { wasn't so constantly busy, I'd start } \\
\text { thinking (Coby } 2, \text { p. } 9, \ln 35-36) \text {. }\end{array}$ \\
\hline & & & $\begin{array}{l}\text { Focusing on other } \\
\text { tasks helps Coby } \\
\text { block out his grief, } \\
\text { but the distraction is } \\
\text { only temporary and } \\
\text { the grief returns. }\end{array}$ & $\begin{array}{l}\text { I was kind of blocking it out just } \\
\text { trying to keep my head busy, keep } \\
\text { focused so that I wouldn't think } \\
\text { about it. I wanted to just block it out. } \\
\text { But it was always there (Coby1, p. } \\
10, \ln 16-18 \text { ). }\end{array}$ \\
\hline & & & $\begin{array}{l}\text { Gardening and } \\
\text { being busy helps } \\
\text { distract Max and } \\
\text { separate himself } \\
\text { from the social } \\
\text { drama and impact } \\
\text { the suicide had on } \\
\text { his social network. }\end{array}$ & $\begin{array}{l}\text { I picked up gardening and it keeps } \\
\text { me busy and my mind off } \\
\text { things...It's simple and when you're } \\
\text { surrounded by all this drama and } \\
\text { everything, it's just a good place to } \\
\text { step away to, just be inside your own } \\
\text { bubble, do your own thing for a few } \\
\text { hours... keep your mind working on } \\
\text { something else. (Max2, p. 13, ln7- } \\
\text { 24) }\end{array}$ \\
\hline & & & $\begin{array}{l}\text { Keeping busy and } \\
\text { maintaining } \\
\text { routines helps Fin } \\
\text { not think about the } \\
\text { loss of his two } \\
\text { friends. }\end{array}$ & $\begin{array}{l}\text { I just went out and did what he } \\
\text { would want us to do. Get on the piss } \\
\text { and go out ...Just try to keep busy } \\
\text { with the mates. Try and keep my } \\
\text { mind off it. (Fin } 2, \text { p. } 15, \ln 1-4 \text { ) }\end{array}$ \\
\hline & & $\begin{array}{l}\text { Emotional } \\
\text { distraction }\end{array}$ & $\begin{array}{l}\text { Keeping busy at } \\
\text { work helps Coby } \\
\text { focus on his } \\
\text { thoughts and not on } \\
\text { emotions. }\end{array}$ & $\begin{array}{l}\text { It's fine when I'm working, I've got } \\
\text { my mind on something else. When } \\
\text { I'm doing something it's helpful } \\
\text { because my brain's not rushing } \\
\text { around or anything I'm just } \\
\text { focused....just a break from hurt } \\
\text { feelings (Coby1, p. 20, ln17-22, p. } \\
25, \ln 15) \text {. }\end{array}$ \\
\hline & & $\begin{array}{l}\text { Physical } \\
\text { distraction }\end{array}$ & $\begin{array}{l}\text { Focusing on his } \\
\text { body and engaging } \\
\text { in physical activity } \\
\text { helps Adam manage } \\
\text { and express his } \\
\text { anger and feel } \\
\text { better/differently. }\end{array}$ & $\begin{array}{l}\text { Sometimes I like to go to the gym } \\
\text { when I'm angry or upset. Take it out } \\
\text { on my body instead, it makes you } \\
\text { feel so much better. You just do } \\
\text { what makes you feel the best at the } \\
\text { end of the day, go for a run or just do } \\
\text { something that's outdoors. (Adam2, } \\
\text { p. } 15, \ln 19-21 \text { ). }\end{array}$ \\
\hline
\end{tabular}

